\title{
Sensitivierung von Sarkomzellen gegenüber Doxorubizin
}

\author{
Dissertation \\ zur Erlangung des Doktorgrades \\ „Doctor rerum naturalium (Dr. rer. nat.)“ \\ im Rahmen des Programms Molekulare Medizin \\ der Georg-August-Universität Göttingen
}

vorgelegt von

Diana Marklein

aus Göttingen

Göttingen 2012 
Mitglieder des Betreuungsausschusses:

Betreuerin:

Prof. Dr. Heidi Hahn

Abteilung für Molekulare Entwicklungsgenetik

Institut für Humangenetik

Heinrich-Düker-Weg 12

37073 Göttingen

Erstes Mitglied des Betreuungsausschusses:

Prof. Dr. Jürgen Brockmöller

Abteilung Klinische Pharmakologie

Universitätsklinikum Göttingen

Robert-Koch-Straße 40

37075 Göttingen

Zweites Mitglied des Betreuungsausschusses:

Prof. Dr. Dieter Kube

Abteilung Hämatologie und Onkologie des Zentrums für innere Medizin

Universitätsklinikum Göttingen

Robert-Koch-Straße 40

37075 Göttingen

Tag der Disputation: 


\section{Eidesstattliche Erklärung}

Ich versichere, dass ich die von mir vorgelegte Dissertation selbständig und ohne unerlaubte Hilfe angefertigt, und die genutzten Quellen und Hilfmittel vollständig angegeben habe.

Göttingen, 31.01.2012

Diana Marklein 
Eidesstattliche Erklärung

Abbildungsverzeichnis

Tabellenverzeichnis.

Abkürzungsverzeichnis

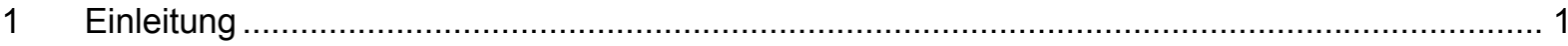

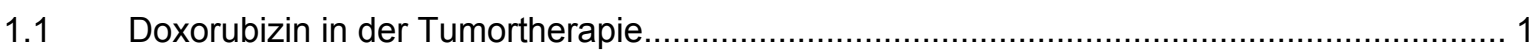

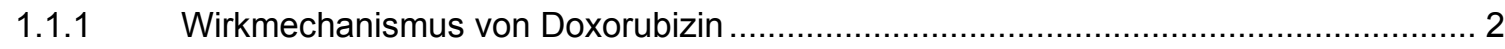

1.1.2 Unerwünschte Nebenwirkungen von Doxorubizin ...................................... 3

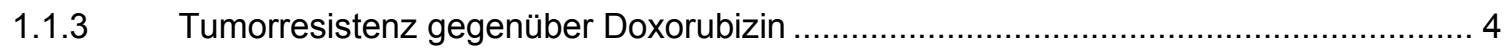

1.2 Ansätze zur Erhöhung der Wirksamkeit von Doxorubizin in der Tumortherapie .................5

1.2.1 TOP2a-Expression und die Wirksamkeit von Doxorubizin ................................. 6

1.2.2 Der PI3Kinase/AKT/mTOR-Signalweg und die Wirksamkeit von Doxorubizin ............ 8

1.2.2.1 Der PI3Kinase/AKT/mTOR-Signalweg und die Apoptose............................. 8

1.2.2.2 Inhibitoren des PI3Kinase/AKT/mTOR-Signalwegs ..................................... 11

1.2.2.3 Kooperative antitumorale Effekte von Doxorubizin und Inhibitoren des

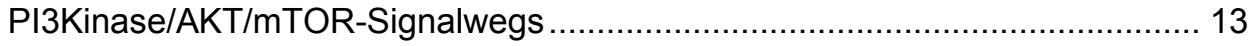

1.3 Doxorubizin in der Therapie des Rhabdomyosarkoms ............................................... 14

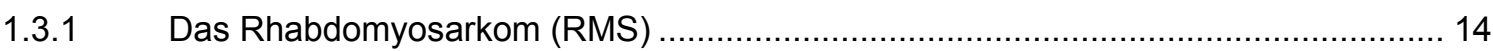

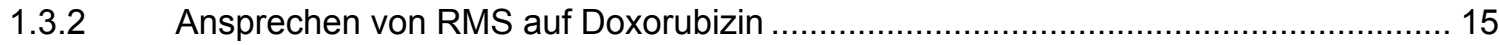

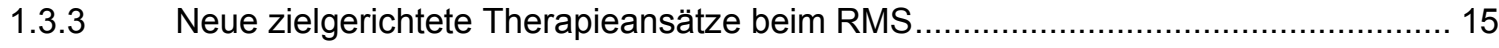

1.3.4 Die Rolle des PI3Kinase/AKT/mTOR-Signalwegs im RMS .................................... 16

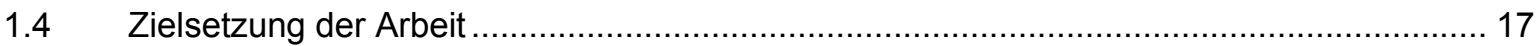

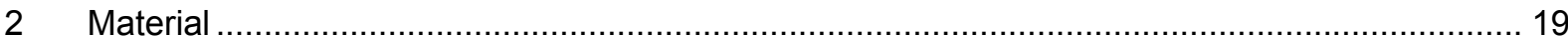

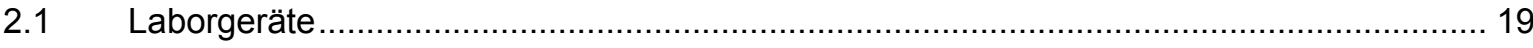

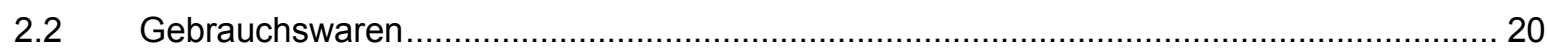

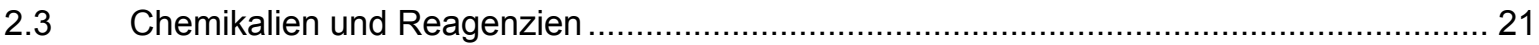

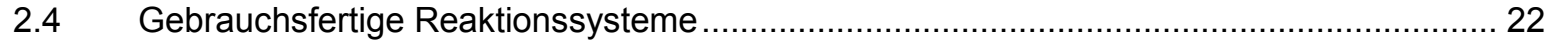

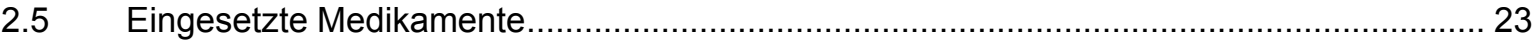

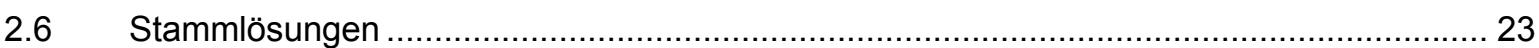

2.7 Medien und Gebrauchsmaterial für die Kultivierung eukaryotischer Zelllinien ................. 25

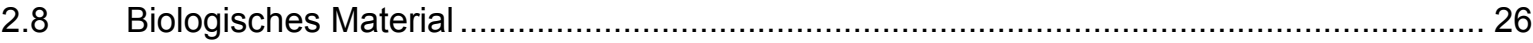

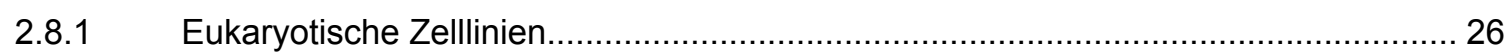

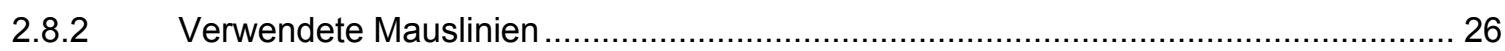

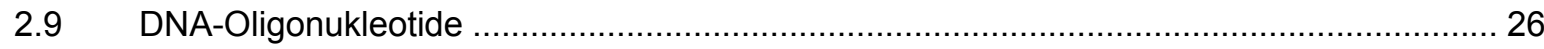

2.9.1 DNA-Oligonukleotide zur Genotypisierung von Mäusen.................................. 27

2.9.2 DNA-Oligonukleotide für die quantitative Real-Time PCR (qRT-PCR) ...................27

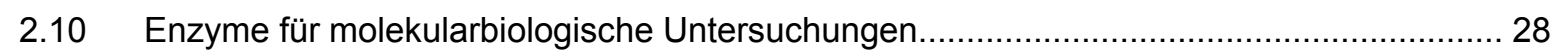

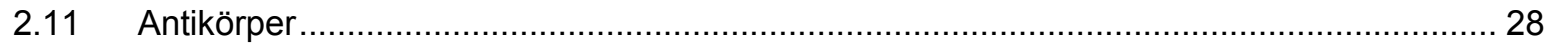

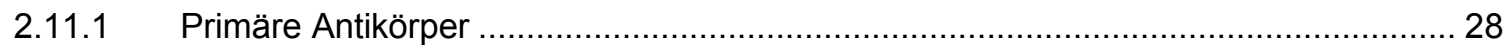




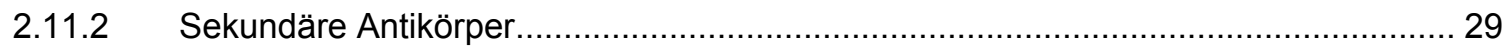

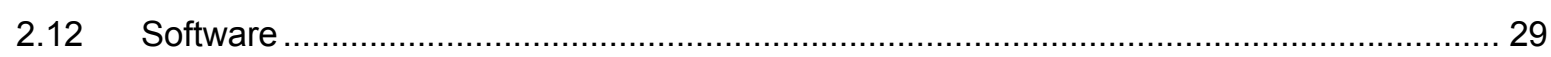

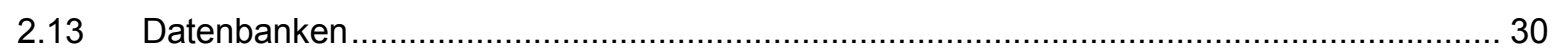

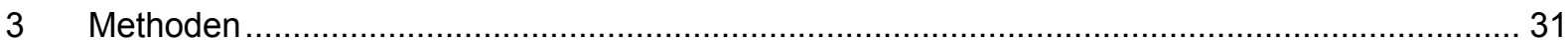

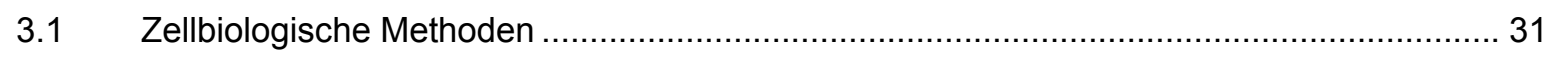

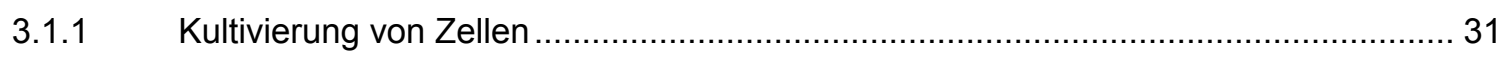

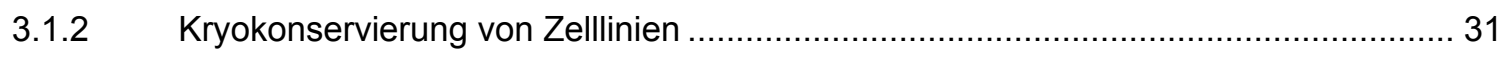

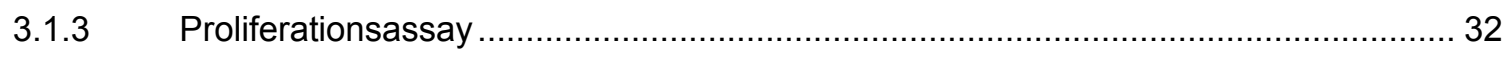

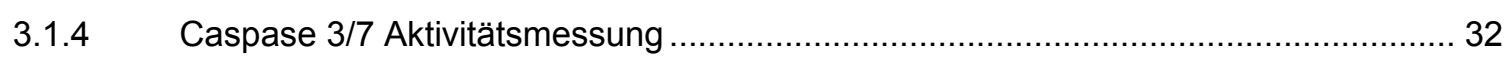

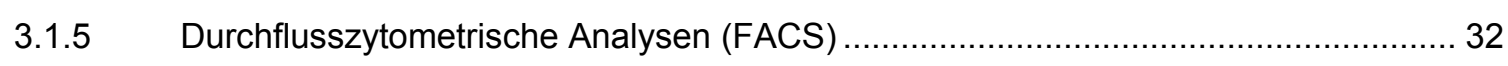

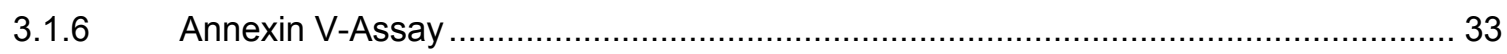

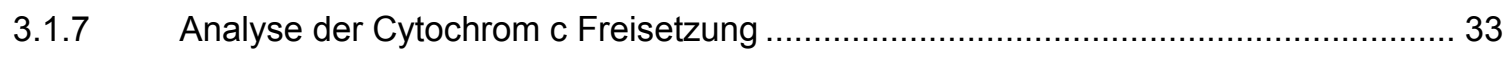

3.1.8 Messung der intrazellulären Akkumulation von Doxorubizin .................................... 34

3.1.9 Analyse der MDR1 und der MRP1 Expression ............................................ 34

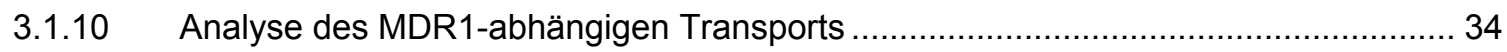

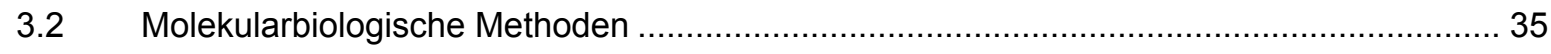

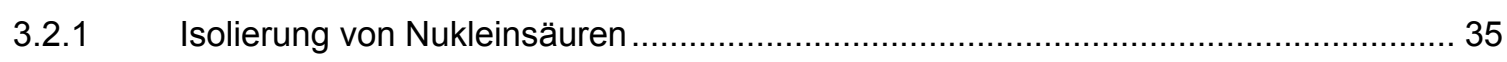

3.2.1.1 DNA-Isolierung aus murinen Geweben zur Bestimmung des Genotyps ........... 35

3.2.1.2 RNA-Isolierung aus Zellen mit Trizol ............................................... 35

3.2.2 Photometrische Konzentrationsbestimmung von Nukleinsäuren ............................. 36

3.2.3 Polymerase Kettenreaktion (polymerase chain reaktion, PCR)............................... 36

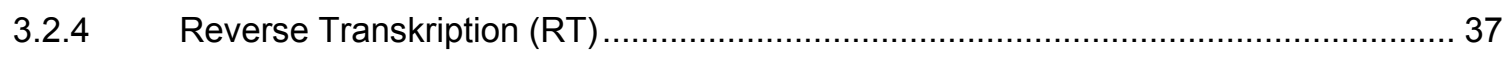

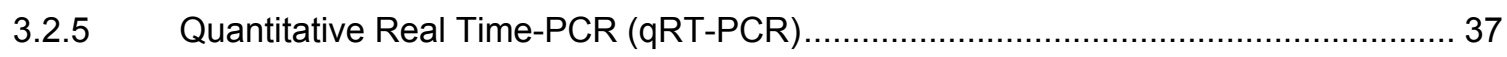

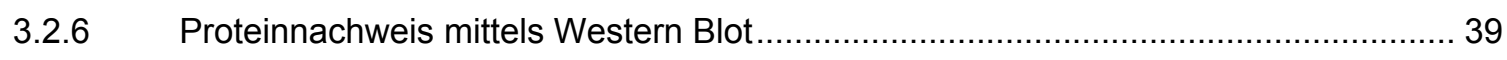

3.2.6.1 Herstellung von Proteinlysaten mit Lysepuffer ......................................... 39

3.2.6.2 Herstellung von Proteinlysaten mit RIPA-Puffer zum Nachweis von

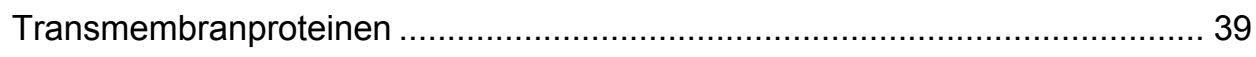

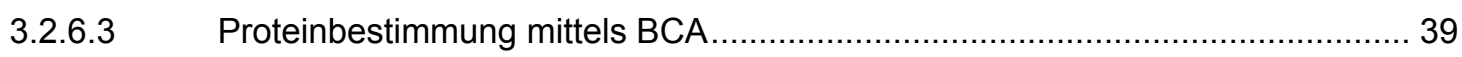

3.2.6.4 Proteinauftrennung mittels Gelelektrophorese ................................................ 39

3.2.6.5 Transfer der Proteine auf die Membran ................................................... 40

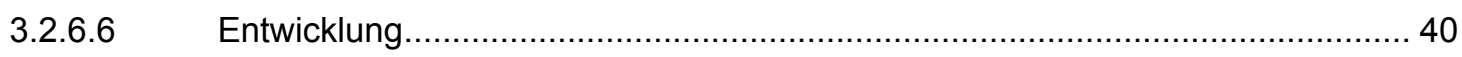

3.2.6.7 Proteinnachweis mittels Immunpräzipitation .............................................. 40

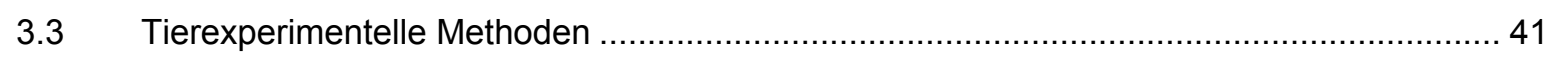

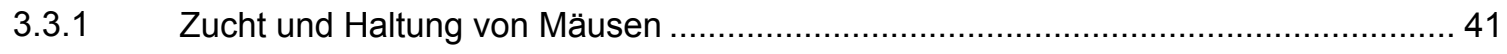

3.3.2 Schwanzbiopsie und Ohrlochmarkierung................................................... 41

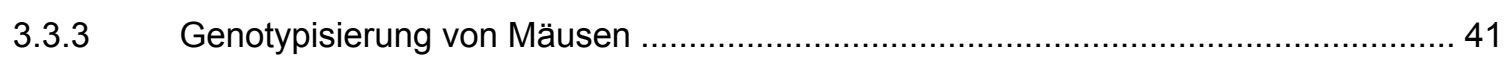

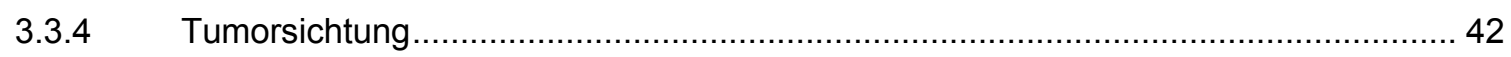

3.3.5 Transplantation von Tumorzellen in Nacktmäuse ............................................ 42

3.3.6 Systemische Applikation von GDC-0941 und/oder Doxorubizin........................... 42 
3.3.6.1 Systemische Applikation von GDC-0941 in (B6xBalbc)Ptch ${ }^{\text {neo67/+ }}$-Mäuse ......... 43

3.3.6.2 Systemische Applikation von Doxorubizin und GDC-0941 in Nacktmäuse ....... 43

3.3.7 Bestimmung der Tumorgröße mittels Volumen Computer Tomographie (VCT)........ 43

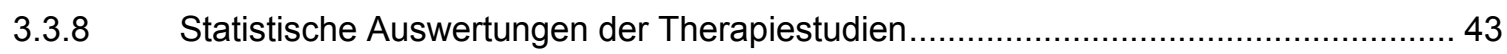

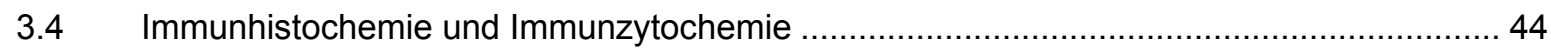

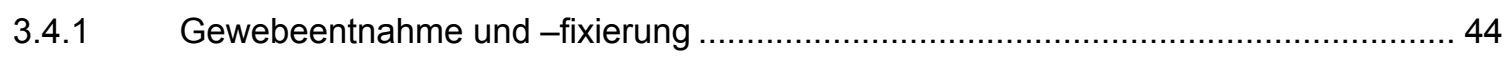

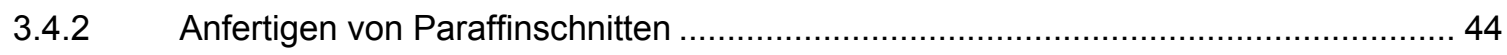

3.4.3 Entparaffinierung und Hämalaun- und Eosin-Färbungen (H\&E) von

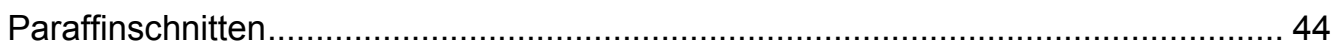

3.4.4 PAS („Periodic Acid Schiff“)-Reaktion von Paraffinschnitten ................................ 44

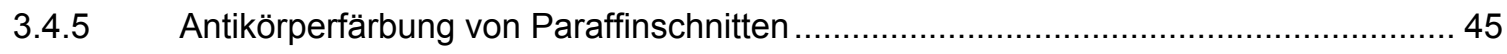

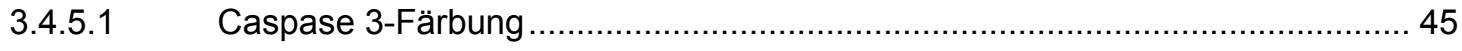

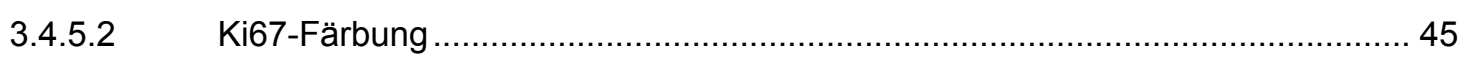

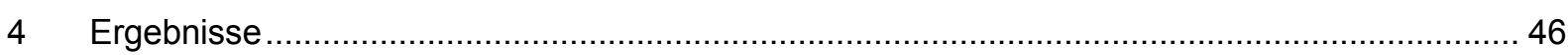

4.1 Untersuchung der antitumoralen Effekte von Doxorubizin in Kombination mit 5-Aza,

VPA, Bortezomib, Pioglitazon oder PI103 in den Zelllinien HT1080, HTETOP,

TP5014 und RD 46

4.1.1 Analyse der antitumoralen Effekte von Doxorubizin in Kombination mit 5-Aza,

VPA, Bortezomib, Pioglitazon oder PI103 in HT1080-Zellen ............................. 48

4.1.1.1 Kombination von Doxorubizin und dem Cytidinanalogon 5-Aza ....................48

4.1.1.2 Kombination von Doxorubizin und dem HDAC-Inhibitor VPA .......................... 50

4.1.1.3 Kombination von Doxorubizin und dem Proteasominhibitor Bortezomib .......... 51

4.1.1.4 Kombination von Doxorubizin und dem PPARy-Liganden Pioglitazon ............. 53

4.1.1.5 Kombination von Doxorubizin und dem dualen PI3Kinase/mTOR-Inhibitor

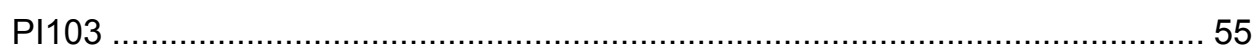

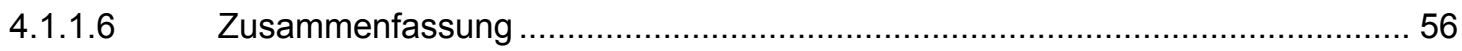

4.1.1. Wirkung von 5-Aza, VPA, Bortezomib, Pioglitazon, PI103 oder Doxorubizin

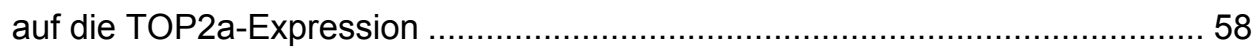

4.1.1.7.1 Etablierung des TOP2a-qRT-PCR Assays .................................................. 58

4.1.1.7.2 Effekte der Medikamente auf die TOP2a-Transkription und das

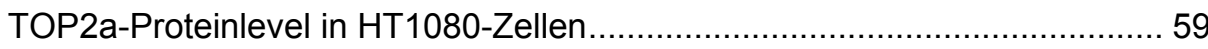

4.1.1.7.3 Analyse des antitumoralen Effekts von Doxorubizin und Pioglitazon bzw. Doxorubizin und PI103 in Abhängigkeit von der TOP2a-Expression .... 61

4.1.2 Untersuchung des kooperativen antitumoralen Effekts von Doxorubizin mit Pioglitazon oder PI103 in der RMS-Zelllinie TP5014.

4.1.2.1 Pioglitazon verstärkt den antiproliferativen, nicht aber den proapoptotischen Effekt von Doxorubizin. 64

4.1.2.2 Pl103 verstärkt sowohl den antiproliferativen als auch den proapoptotischen Effekt von Doxorubizin. 
4.1.3 Analyse der kooperativen antitumoralen Effekte in der humanen RMS-Zelllinie RD

4.1.3.1 Pl103 verstärkt den antitumoralen Effekt von Doxorubizin in der humanen

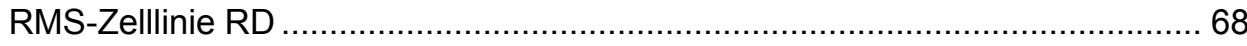

4.1.3.2 Doxorubizin und PI103 kooperieren in der Aktivierung von Caspase 3........... 70

4.2 Molekulare Analysen zum kooperativen proapoptotischen Effekt von Doxorubizin und PI103 in der RMS-Zelllinie RD

4.2.1 Kein kooperativer proapoptotischer Effekt von PI103 mit dem TOP2-Inhibitor

Etoposid

4.2.2 Alleinige mTOR-Inhibierung hat keinen Einfluss auf die kooperative Induktion der Caspase 3 Aktivität

4.2.3 Doxorubizin und PI103 kooperieren in der Aktivierung des mitochondrialen

Apoptosesignalwegs

4.2.3.1 Der kooperative proapoptotische Effekt von Doxorubizin und PI103 korreliert mit der Aktivierung von BAX. 77

4.2.3.2 Die Kombination von Doxorubizin und PI103 führt zu erhöhter Cytochrom c Freisetzung.

4.2.3.3 Die mitochondriale Aktivität von p53 scheint in den kooperativen Effekt von Doxorubizin und PI103 involviert zu sein.

4.2.4 PI103 hemmt die Expression von MDR1 und MRP1 in RD-Zellen..... 84

4.2.4.1 Die Hemmung der Expression von Effluxtransportern korreliert mit der Akkumulation von Doxorubizin in RD-Zellen

4.2.4.2 Die PI103-induzierte Doxorubizin-Akkumulation scheint nicht für den kooperativen proapoptotischen Effekt verantwortlich zu sein

4.3 Untersuchung der antitumoralen Effekte von Doxorubizin und dem PI3Kinase-Inhibitor GDC-0941 auf RMS-Zellen in vivo 93

4.3.1 Xenotransplantation von RD-Tumorzellen in Nacktmäuse . 94

4.3.2 Keine signifikante Verstärkung des antitumoralen Effekts von Doxorubizin durch GDC-0941 auf RD-Xenotransplantate

4.3.3 Vorarbeiten zur Untersuchung der antitumoralen Wirkung von Doxorubizin und GDC-0941 im (B6xBalbc)Ptch ${ }^{\text {neo67/+ }}$-Mausmodell für RMS.... 100

5 Diskussion

5.1 Allgemeine Wirkungen von Doxorubizin in den HT1080-, TP5014- und RD-Zellen 102

5.2 Keine Erhöhung der antitumoralen Wirkung von Doxorubizin durch 5-Aza oder VPA in HT1080-Zellen 103

5.3 Bortezomib sensitiviert HT1080-Zellen gegenüber Doxorubizin-induzierter Proliferationsinhibierung, nicht aber gegenüber der Apoptoseinduktion ..... 106 
5.4 Pioglitazon sensitiviert HT1080- und TP5014-Zellen gegenüber einer Doxorubizininduzierten Proliferationshemmung, jedoch nur HT1080-Zellen gegenüber Doxorubizin-induzierter Apoptose.

5.5 PI103 sensitiviert HT1080-, TP5014- und RD-Zellen gegenüber den antiproliferativen und proapoptotischen Effekten von Doxorubizin .....

5.5.1 Die TOP2a spielt keine Rolle bei der PI103-vermittelten Sensitivierung gegenüber Doxorubizin

5.5.2 Inhibierung von mTOR hat keinen Einfluss auf den kooperativen proapoptotischen Effekt von Doxorubizin und PI103 in RD-Zellen.

5.5.3 Der kooperative proapoptotische Effekt von Doxorubizin und PI103 korreliert mit der Aktivierung von BAX und der Caspase 3 Aktivierung

5.5.4 Die mitochondriale Aktivität von p53 ist vermutlich in den kooperativen proapoptotischen Effekt von Doxorubizin und PI103 involviert............................... 116

5.5.5 PI103 hemmt die Expression der Effluxtransporter MDR1 und MRP1 ................... 117

5.5.6 Hypothese über den Wirkmechanismus von Doxorubizin und PI103 in RD-Zellen.. 119

5.6 Kooperativer proapoptotischer Effekt von Doxorubizin und GDC-0941 in vivo .................. 120

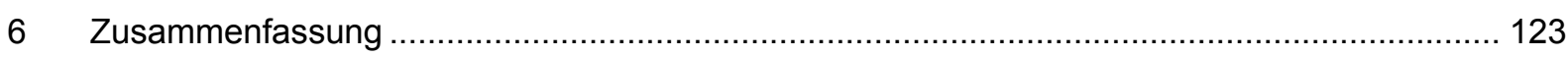

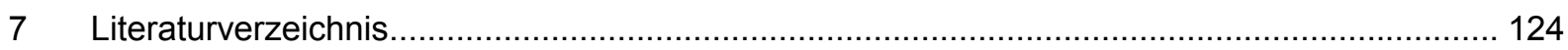

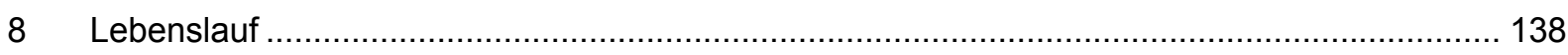

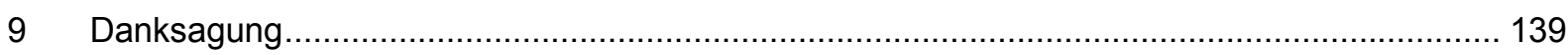




\section{Abbildungsverzeichnis}

Abbildung 1: Chemische Struktur von Doxorubizin............................................................. 1

Abbildung 2: Schematische Darstellung der PI3Kinase/AKT/mTOR-Signalkaskade................... 9

Abbildung 3: Antiproliferative und proapoptotische Wirkung von Doxorubizin in HT1080-

Zellen.

Abbildung 4: Proliferationsverhalten von HT1080-Zellen nach Behandlung mit

Doxorubizin und/oder 5-Aza.

Abbildung 5: Apoptoseinduktion in HT1080-Zellen durch Behandlung mit Doxorubizin

und/oder 5-Aza.

Abbildung 6: Proliferationsverhalten von HT1080-Zellen nach Behandlung mit

Doxorubizin und/oder VPA.

Abbildung 7: Apoptoseinduktion in HT1080-Zellen durch Behandlung mit Doxorubizin und/oder VPA.

Abbildung 8: Proliferationsverhalten von HT1080-Zellen nach Doxorubizin und/oder

Bortezomib-Behandlung.

Abbildung 9: Induktion der Apoptose in HT1080-Zellen durch Behandlung mit

Doxorubizin und/oder Bortezomib.

Abbildung 10: Proliferationsverhalten von HT1080-Zellen nach Behandlung mit

Doxorubizin und/oder Pioglitazon.

Abbildung 11: Apoptoseinduktion in HT1080-Zellen durch Behandlung mit Doxorubizin und/oder Pioglitazon.

Abbildung 12: Proliferationsverhalten der HT1080-Zellen nach Doxorubizin- und/oder PI103-Behandlung

Abbildung 13: Apoptoseinduktion in HT1080-Zellen durch Behandlung mit Doxorubizin und/oder PI103.

Abbildung 14: TOP2a-Expression in HT1080-Zellen nach Behandlung mit 5-Aza, VPA,

Bortezomib, Pioglitazon, PI103 und/oder Doxorubizin.

Abbildung 15: TOP2a-Expression nach Doxycyclin Behandlung.

Abbildung 16: TOP2a-Level in HTETOP-Zellen nach Inkubation mit Doxycyclin.

Abbildung 17: Apoptosemessungen in TOP2a-exprimierenden und TOP2a-defizienten

HTETOP-Zellen.

Abbildung 18: Proliferationsverhalten der TP5014-Zellen nach Behandlung mit

Doxorubizin und/oder Pioglitazon.

Abbildung 19: Apoptoseinduktion in TP5014-Zellen nach Behandlung mit Doxorubizin und/oder Pioglitazon.

Abbildung 20: Proliferationsverhalten von TP5014-Zellen nach Behandlung mit Doxorubizin und/oder PI103. 
Abbildung 21: Apoptoseinduktion in TP5014-Zellen nach Behandlung mit Doxorubizin und/oder PI103.

Abbildung 22: Proliferationsverhalten der RD-Zellen nach der Behandlung mit

Doxorubizin und/oder PI103.

Abbildung 23: Induktion der Apoptose nach Behandlung von RD-Zellen mit Doxorubizin und/oder PI103.

Abbildung 24: Western Blot Analyse der RD-Zellen nach Inkubation mit Doxorubizin und PI103.

Abbildung 25: Apoptoseinduktion in RD-Zellen nach Behandlung mit Etoposid und/oder PI103.

Abbildung 26: Funktionalitätstest von Everolimus in RD-Zellen.

Abbildung 27: Proliferationsverhalten der RD-Zellen nach Behandlung mit Doxorubizin und/oder Everolimus.

Abbildung 28: Apoptoseinduktion in RD-Zellen nach Behandlung mit Doxorubizin und/oder Everolimus..

Abbildung 29: Western Blot Analyse von Proteinlysaten aus RD-Zellen nach Inkubation mit Doxorubizin und Everolimus.

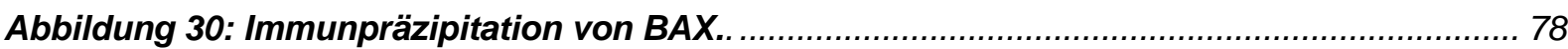

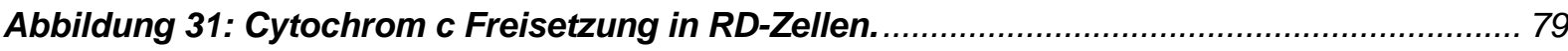

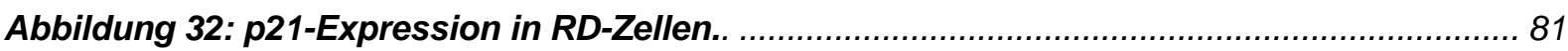

Abbildung 33: Apoptoseinduktion nach Behandlung von RD-Zellen mit Doxorubizin, PI103 und spezifischen p53 Inhibitoren.

Abbildung 34: Apoptoseinduktion nach Behandlung von RD-Zellen mit Doxorubizin, PI103 und $15 \mu M$ PFT $\mu$.

Abbildung 35: Expressionsanalyse der Transkripte von MDR1 und MRP1 in RD-Zellen.......... 85

Abbildung 36: Nachweis von MDR1 und MRP1 in RD-Zellen im Western Blot....................... 86

Abbildung 37: Einfluss von PI103 auf das Proteinlevel von MRP1 in RD-Zellen....................... 86

Abbildung 38: Nachweis von MDR1 und MRP1 mittels FACS-Analyse in A549- und RD-Zellen.

Abbildung 39: FACS Analysen der MRP1-Expression in RD-Zellen nach Inkubation mit PI103.

Abbildung 40: Analyse der MDR1- und MRP1-Aktivität in Caco-2-Zellen.

Abbildung 41: Doxorubizin-Akkumulation in RD-Zellen nach Inkubation mit Doxorubizin

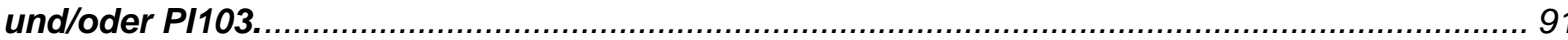

Abbildung 42: Western Blot Analyse zur Untersuchung der Effekte von 2 $\mu$ M Doxorubizin...... 92 Abbildung 43: Annexin V positive Zellen nach Behandlung mit Doxorubizin und/oder PI103.

Abbildung 44: Behandlungsschema von Nacktmäusen. 
Abbildung 45: Zunahme des Tumorvolumens von RD-Xenotransplantaten nach Therapie mit Doxorubizin, GDC-0941, der Kombination aus Doxorubizin und GDC-0941 oder den Lösungsmitteln.

Abbildung 46: Unterschiede in der Gewebestruktur der Tumoren nach der PAS-Reaktion. 98

Abbildung 47: Ki67 positive Zellen in den Tumoren der therapierten Tiere in \%. 99

Abbildung 48: Caspase 3 positive Zellen in den Tumoren der behandelten Tiere in \%. 99

Abbildung 49: Tumorwachstumskurven unter GDC-0941-Behandlung..

Abbildung 50: Schematische Darstellung der Hypothese des kooperativen Effekts von Doxorubizin und PI103 in RD-Zellen. 


\section{Tabellenverzeichnis}

Tabelle 1: Hergestellte Stockkonzentrationen der verwendeten Medikamente.......................... 23

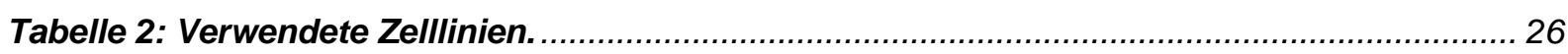

Tabelle 3: DNA-Oligonukleotide zur Genotypisierung von Mäusen. ...................................... 27

Tabelle 4: Verwendete DNA-Oligonukleotide für die qRT-PCR. ........................................... 27

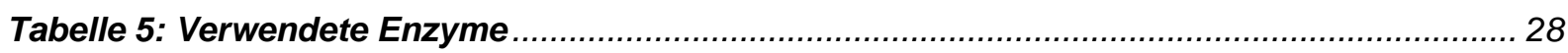

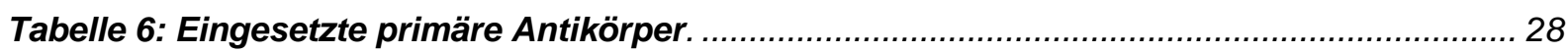

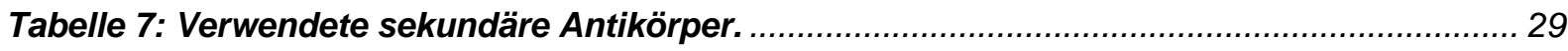

Tabelle 8: Kultivierungsmedien der verwendeten Zelllinien und Primärkulturen. ...................... 31

Tabelle 9: Herkunft der cDNA zur Erstellung von Standardkurven für die qRT-PCR. ................ 38

Tabelle 10: Zusammenfassung der antitumoralen Effekte der in den Abschnitten

4.1.1 - 4.1.1.5 beschriebenen Behandlungsschemata in HT1080-Zellen.

Tabelle 11: Vergleich der Tumorgröße nach Behandlungsbeginn (p-Werte). 


\section{Abkürzungsverzeichnis}

\begin{tabular}{|c|c|}
\hline 15d-PGJ2 & 15-Deoxy-Delta-12,14-prostaglandin J2 \\
\hline 5-Aza & 5-Aza-Deoxycytidine \\
\hline AAV & Adeno-Associated Virus \\
\hline ABC-Transporter & ATP-Binding Cassette Transporter \\
\hline AEC & 3-Amino-9-Ethyl-Carbazole \\
\hline AML & Akute myeloische Leukämie \\
\hline aRMS & Alveoläres Rhabdomyosarkom \\
\hline ATCC & American Type Culture Collection \\
\hline ATP & Adenosintriphosphat \\
\hline ATPase & Adenosinphosphatase \\
\hline $\mathrm{BCA}$ & 2,2'-Bicinchoninsäure \\
\hline Borte & Bortezomib \\
\hline bp & Basenpaare \\
\hline BrdU & 5-Bromo-2-Deoxyuridin \\
\hline BSA & Bovine Serum Albumin (Rinderserumalbum) \\
\hline C & Nukleinsäure-spezifischer Koeffizient \\
\hline cDNA & Copy DNA \\
\hline CHAPS & (3-[(3-Cholamidopropyl)-dimethylammonio]-1-propansulfonat \\
\hline Ct-Wert & Cycle Treshold (Schwellenwert) \\
\hline Cytc & Cytochrom c \\
\hline DAB & 3'3-Diaminobenzidin \\
\hline dATP & Desoxyadenosintriphosphat \\
\hline dCTP & Desoxycytidintriphosphat \\
\hline DD & Death Domain \\
\hline DEVD-Domäne & Aminosäureabfolge: Asparagin (D), Glutamin (E), Valin (V) Asparagin (D) \\
\hline dGTP & Desoxyguanosintriphosphat \\
\hline DMEM & Dublecco's Modified Eagle Medium \\
\hline DMSO & N.N.-Dimethylsulfoxid \\
\hline DNA & Desoxyribonucleic acid (Desoxyribonukleinsäure) \\
\hline DNA-PK & DNA-Dependent Proteinkinase \\
\hline dNTPs & Desoxyribonukleotidtriphosphate \\
\hline Dox & Doxorubizin \\
\hline Doxy & Doxycyclin \\
\hline DR & Direct Repeat \\
\hline DTT & Dithiothreitol \\
\hline dTTP & Desoxythymidntriphosphat \\
\hline dUTP & Desoxyuridintriphosphat \\
\hline ECL & Enhanced Chemiluminescence \\
\hline EDTA & Ethylen-Diamin-Tetraacetat \\
\hline EGFR & Epidermal Growth Factor Receptor \\
\hline EHS & Engelbreth-Holm-Swarm Tumor \\
\hline ERK & Extracellular Regulated Kinase \\
\hline eRMS & Embryonales Rhabdomyosarkom \\
\hline Eto & Etoposid \\
\hline Ever & Everolimus \\
\hline f & Verdünnungsfaktor \\
\hline Fab & Antigenbindendes Fragment \\
\hline FACS & Fluorescent Activated Cell Sorting (Durchflusszytometer) \\
\hline
\end{tabular}




\begin{tabular}{|c|c|}
\hline FADD & Fas-Associated Death-Domain \\
\hline FCS & Fetal Calf Cerum (Fötales Kälberserum) \\
\hline FITC & Fluoresceinisothiocyanat \\
\hline FOXO & Fork Head Box O \\
\hline fwd & forward \\
\hline $\mathrm{G}_{1}$ & Gap1 (Phase im Zellzyklus) \\
\hline $\mathrm{G}_{2}$ & Gap2 (Phase im Zellzyklus) \\
\hline GAPDH & Glycerinaldehyd-3-phosphatase-dehydrogenase \\
\hline GIST & Gastrointestinaler Stromatumor \\
\hline GSK3 & Glycogen Synthase Kinase 3 \\
\hline H\&E & Hämalaun- und Eosin-Färbung \\
\hline HDAC & Histon-Deacetylasen \\
\hline HEPES & 2-(4-(2-Hydroxyethyl)- 1-piperazinyl)-ethansulfonsäure \\
\hline HER-2 & Human Epidermal Growth Factor Receptor-2 \\
\hline HRP & Horseradish Peroxidase (Meerrettichperoxidase) \\
\hline IGF-1/lgf-1 & Insuline-Like Growth Factor-1 \\
\hline IGF-1R/lgf-1R & Insuline-Like Growth Factor-1 Receptor \\
\hline $\lg G$ & Immunglobulin G \\
\hline $\mathrm{IHC}$ & Immunhistochemie \\
\hline IP & Immunpräzipitation \\
\hline IRS & Intergroup Rhabdomyosarcoma Study \\
\hline IRSG & Intergroup Rhabdomyosarcoma Study Group \\
\hline $\mathrm{kDa}$ & Kilodalton \\
\hline Lsgm & Lösungsmittel \\
\hline MCT & Methylcellulose-Tween-Lösung \\
\hline MDM2 & Murine Double Minute 2 \\
\hline MDR1 & Multidrug-Resistance Protein 1 \\
\hline MEM & Minimal Essential Medium \\
\hline MET, HGFR & Hepatocyte Growth Factor Receptor \\
\hline MMP & Mitochondrial Membrane Potential Change \\
\hline M-Phase & Mitose \\
\hline mRNA & messenger RNA \\
\hline MRP1 & Multidrug-Resistance Associated Protein 1 \\
\hline mTOR & Mamalian Target of Rapamycin \\
\hline mTORC1 & mTOR Complex 1; Raptor \\
\hline mTORC2 & mTOR Complex 2; Rictor \\
\hline NF1 & Neurofibromatosis-Factor 1 \\
\hline $\mathrm{NFkB}$ & Nukleärer Faktor kappa B \\
\hline OD & optische Dichte \\
\hline PAS & Periodic acid-Schiff \\
\hline PBS & Phosphate Buffered Saline (Phosphat-gepufferte Natriumchloridlösung) \\
\hline PCR & Polymerase Chain Reaction (Polymerasekettenreaktion) \\
\hline PDGFR & Platelet-Derived Growth Factor Receptor \\
\hline PDGFRA & Platelet-Derived Growth Factor Receptor Alpha \\
\hline PDK-1 & 3’Phosphoinositide-Dependent Kinase 1 \\
\hline PFA & Paraformaldehyd-Lösung \\
\hline $\mathrm{PFT} \mu$ & Pifithin $\mu$ \\
\hline PFTa & Pifithin a \\
\hline $\mathrm{PH}$ & Pleckstrin Homology \\
\hline PI3Kinase & Phosphatidylinositol-3 Kinase \\
\hline Pio & Pioglitazon \\
\hline
\end{tabular}




\begin{tabular}{|c|c|}
\hline $\mathrm{PIP}_{2}$ & Phosphatidylinositol-4,5-bisphosphate \\
\hline $\mathrm{PIP}_{3}$ & Phosphatidylinositol-3,4,5-triphosphat \\
\hline PMSF & Phenylmethylsulfonylfluorid \\
\hline POD & Peroxidase \\
\hline PPARy & Peroxisome Proliferator-Activiated Receptor y \\
\hline PTCH/Ptch & Patched \\
\hline $\operatorname{Ptch}^{\text {neo12 }}$ & Ptch Allel mit Deletion der Exone 1 und 2 \\
\hline$P t c h^{\text {neo67 }}$ & Ptch Allel mit Deletion der Exone 6 und 7 \\
\hline PTEN & Phosphatase and Tensin Homolog \\
\hline qRT-PCR & quantitative Real-Time PCR \\
\hline rev & reverse \\
\hline Rh123 & Rhodamin 123 \\
\hline RIPA-Puffer & Radio-Immuno-Precipitation-Assay-Puffer \\
\hline RLU & Realtive Light Units (Relative Lichteinheit) \\
\hline RMS & Rhabdomyosarkom \\
\hline RNA & Ribonucleic acid (Ribonukleinsäure) \\
\hline ROS & Reactive Oxygen Species \\
\hline rpm & Rounds Per Minute (Umdrehungen pro Minute) \\
\hline RPMI & Roswell Park Memorial Institute-Medium \\
\hline rRNA & ribosomale RNA \\
\hline RTK & Rezeptortyrosinkinasen \\
\hline S473 & Serin 473 \\
\hline SCID & Severe Combined Immundeficiency (schwere kombinierte Immundefizienz) \\
\hline SDS & Natriumdodecylsulfat \\
\hline SEM & standard errror of the mean (Standardfehler des Mittelwerts) \\
\hline siRNA & Small Interfering RNA \\
\hline SiRNA & Small Interfering RNS \\
\hline SPF & spezifiziert pathogenfreien \\
\hline STE & SDS/Tris/EDTA-haltiger Puffer \\
\hline T308 & Threonin 308 \\
\hline TBE & Tris-Borsäure-EDTA-Puffer \\
\hline tBID & truncated BID \\
\hline TNF & Tumor Necrosis Factor \\
\hline TOP2 & Topoisomerase II \\
\hline TRAIL & Tumor-Necrosis Factor-Related Apoptosis-Inducing Ligand \\
\hline TSC & Tuberous Sclerosis Complex \\
\hline$U$ & Unit (Enzymaktivitätseinheit) \\
\hline UTR & Untranslatierte Region \\
\hline $\mathrm{v} / \mathrm{v}$ & Volume/Volume (Volumen/Volumen) \\
\hline VAC & Vincristin, Dactinomyzin und Cyclophosphamid \\
\hline VCT & Volumen Computer Tomographie \\
\hline VPA & Valproinsäure \\
\hline$w / v$ & Weight/Volume (Gewicht/Volumen) \\
\hline WB & Western Blot \\
\hline$x g$ & fache Erdbeschleunigung \\
\hline
\end{tabular}




\section{Einleitung}

\subsection{Doxorubizin in der Tumortherapie}

Doxorubizin wurde um 1960 aus Streptomyces peucetius isoliert und gehört zu der Gruppe der Anthrazykline [1]. Wie in Abbildung 1 zu erkennen, besteht das Molekül aus einem Tetrazyklin-Quinon, welches mit einem Daunosaminzucker glycosidisch verknüpft ist. Doxorubizin weist eine Eigenfluoreszenz auf, die bei einer Wellenlänge von $560 \mathrm{~nm}$ bis $590 \mathrm{~nm}$ detektiert werden kann [2].

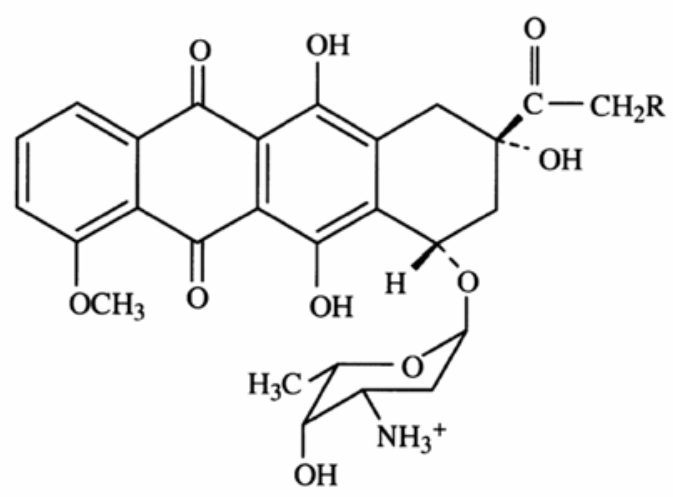

Abbildung 1: Chemische Struktur von Doxorubizin [2].

Doxorubizin ist eines der effektivsten Chemotherapeutika in der Krebstherapie und wird bei einer Vielfalt von Tumoren eingesetzt [3]. Hierzu gehören solide Sarkome, sowie Tumoren der Brust, der Galle, der Prostata, des Uterus, der Ovarien, der Speiseröhre, ebenso wie Magen- und Lebertumoren. Auch beim Kaposi-Sarkom, sowie Osteosarkomen und pädiatrischen Sarkomen wie der Wilms-Tumor und dem Rhabdomyosarkom (RMS) kommt Doxorubizin zum Einsatz. Des Weiteren wird Doxorubizin bei der akuten myeloischen und der lymphatischen Leukämie appliziert [4].

Erfolge einer Doxorubizin-Behandlung werden sowohl für Monotherapien als auch für Kombinationstherapien beschrieben. So konnte durch alleinige Gabe von Doxorubizin bei der Behandlung von 109 Patienten mit Leberzellkarzinomen bei 10\% der Patienten eine partielle Remission des Tumorwachstums und bei einem Patienten eine vollständige Remission erzielt werden. 34\% der behandelten 
Patienten überlebten nach der Therapie weitere 6 Monate, 13\% der Patienten sogar 12 Monate [5]. In einer anderen Studie konnte bei 18\% (19/94) der Patienten mit Weichteilsarkomen eine Remission der Tumoren feststellt werden. Die Patienten überlebten im Mittel 8 Monate [6]. Bei der Behandlung von Patientinnen mit metastasierendem Brustkrebs wurde sogar von einer Remissionsrate von 38\% unter Doxorubizin-Behandlung berichtet, wobei die mittlere Überlebensrate 18 Monate betrug [7].

Doxorubizin wird auch häufig in Kombination mit anderen Medikamenten eingesetzt. So konnte die Remissionsrate von mit Cyclophosphamid/Vincristin/Prednisonbehandelten Lymphomen durch Doxorubizin von ca. $51 \%$ auf $71 \%$ heraufgesetzt werden. Die mittlere Überlebensrate der Patienten betrug dabei 53 Monate [8]. Ebenso erhöhte sich die Remissionsrate bei Patienten mit progressivem multiplem Myelom von $43 \%$ auf $67 \%$, wenn diese zusätzlich zu Bortezomib und Dexamethason noch mit Doxorubizin behandelt wurden. [9].

\subsubsection{Wirkmechanismus von Doxorubizin}

Doxorubizin verursacht vorwiegend eine Störung der DNA-Replikation. Daher wirkt es insbesondere bei exponentiell wachsenden Zellen. Die Wirkung von Doxorubizin wird durch mehrere Mechanismen ausgelöst. Dies ist zum einen die Interkalation von Doxorubizin zwischen benachbarte Nukleotide der DNA [10]. Hierdurch wird die Anlagerung der Polymerasen an die DNA gestört und die Transkription blockiert [11]. Weiterhin entstehen durch die enzymatische Reduktion der Anthrazykline unter Beteiligung diverser Oxidasen, Reduktasen und Dehydrogenasen frei reaktive Sauerstoffradikale, sogenannte ROS (Reactive Oxygen Species), welche zur Antitumorwirkung beitragen [12-14]. ROS führen unter anderem zu einer Schädigung der Zellmembranen und zu DNA-Crosslinkings, wodurch die Zellen am weiteren Wachstum gehindert werden [11]. Darüber hinaus hemmt Doxorubizin die Topoisomerase II (TOP2), welches ein Schlüsselenzym der DNA-Synthese ist [15].

Die TOP2 ist für die Topologie von DNA-Molekülen verantwortlich. Somit hat diese Enzymfamilie eine wichtige Funktion bei der Chromosomenkondensation, der Replikation und der Transkription. Um superhelikale DNA zu entspiralisieren und zu entspannen, induziert sie DNA-Doppelstrangbrüche. Durch diesen Prozess wird die DNA wieder für Transkriptionsvorgänge zugänglich [16, 17]. Bevor die Replikation 
fortgesetzt wird, fügt die TOP2 die DNA-Stränge erneut zusammen [15]. Dieser Prozess läuft unter ATP-Verbrauch ab [15, 18, 19].

Zwei Isoformen der TOP2 sind bekannt: TOP2a und TOP2b. Beide Isoformen weisen ähnliche Strukturen auf, haben aber unterschiedliche biologische Funktionen. Während die TOP2a-Isoform in der $\mathrm{G}_{2} / \mathrm{M}$-Phase sehr stark exprimiert ist, unterliegt die TOP2b-Expression keiner Zellzyklusregulation [20, 21]. Dem TOP2a-Protein kommt daher vermutlich während der Mitose eine wichtige Bedeutung zu [21]. TOP2b scheint dagegen eine wichtige Funktion in der Transkription zu haben [17, 22, 23].

Der Komplex aus der DNA-Doppelhelix mit der TOP2a, bei dem die TOP2avermittelte Induktion von DNA-Doppelstrangbrüchen stattfindet, wird durch Anthrazykline wie Doxorubizin, aber auch durch Mitosehemmer wie Etoposid, stabilisiert. Da beide Medikamente das Ligieren von bereits geschnittener DNA inhibieren, entstehen gehäuft DNA-Doppelstrangbrüche. Infolge dessen kommt es zu einem Zellzyklusarrest in der $\mathrm{G}_{1}$ - und $\mathrm{G}_{2}$-Phase und schließlich zur Apoptose [3, 24]. Interessanterweise scheint die Wirkung von Doxorubizin (und Etoposid, dessen antitumoralen Effekte ausschließlich durch TOP2-Inhibierung zustande kommt [25]) auf die TOP2b für einen Großteil der Zytostatika-induzierten Nebenwirkungen und den sekundären Tumorentwicklungen verantwortlich zu sein [23, 26].

Ebenso wie andere genotoxische Agenzien kann Doxorubizin die Aktivität des Tumorsuppressorgens p53 erhöhen [27]. Dies kann durch viele Doxorubizininduzierte Vorgänge geschehen. Hierzu gehören die zuvor beschriebenen Doppelstrangbrüche der DNA, welche zur Stabilisierung von p53 führen [28]. Weiterhin können auch die unter Doxorubizin-Behandlung gebildeten ROS die Aktivität von p53 induzieren [29]. Außerdem kann Doxorubizin zur Aktivierung von ERK (Extracellular Signal-Regulated Kinase)2 führen, welche wiederum die p53vermittelte Apoptose auslöst [30].

\subsubsection{Unerwünschte Nebenwirkungen von Doxorubizin}

Zytostatika beeinflussen nicht nur Tumorzellen, sondern auch andere körpereigene Zellen. Dabei sind vor allem Gewebe mit sich schnell teilenden Zellen betroffen. Diesen Geweben zuzuordnen sind das Knochenmark, das Darmepithel und die 
Haarfollikel. Die Doxorubizin-Behandlung äußert sich daher häufig durch Nebenwirkungen wie Knochenmarksdepressionen, Übelkeit, Erbrechen, Durchfall und Haarausfall. Der dosislimitierende Effekt der Behandlung besteht jedoch in der kardiotoxischen Wirkung von Doxorubizin, welche sich in 3 Hauptgruppen gliedert. Bei der akuten Kardiotoxizität treten bereits während der Administration oder innerhalb von 24 Stunden nach Doxorubizin-Behandlung Herzrhythmusstörungen auf [31-33]. Die chronische Kardiotoxizität tritt erst bei erneuter Doxorubizin-Applikation auf, kann jedoch auch nach längeren Therapien in Erscheinung treten. Häufig werden eine Kardiomyopathie mit kontraktiler Dysfunktion und eine kongestive Herzinsuffizienz festgestellt, die sich dosisabhängig manifestieren [33]. Die Lateonset-Kardiotoxizität ist besonders bei jungen Patienten von Relevanz, da diese erst Jahre bis Jahrzehnte nach erfolgter Doxorubizin-Behandlung auftreten kann [34]. Bei der Doxorubizin-induzierten Kardiotoxizität scheinen ROS eine wichtige Rolle zu spielen [33].

Diverse Studien belegen, dass eine kumulative Dosis von $500 \mathrm{mg}$ Doxorubizin $/ \mathrm{m}^{2}$ bei 4\% der Patienten zur Herzinsuffizienz führt. Eine Erhöhung der kumulativen Dosis auf 551 bis $600 \mathrm{mg}$ Doxorubizin/m², bzw. >601 mg Doxorubizin $/ \mathrm{m}^{2}$ führt bereits bei etwa 18\% bzw. 36\% der Patienten zur Herzinsuffizienz [35]. Aufgrund der dosisabhängigen Entstehung einer Herzinsuffizienz ist die kumulative Höchstdosis heute auf $500 \mathrm{mg}$ Doxorubizin $/ \mathrm{m}^{2}$ festgelegt [3].

\subsubsection{Tumorresistenz gegenüber Doxorubizin}

Ein weiterer wichtiger Aspekt in der Tumortherapie mit Doxorubizin ist die Resistenz oder die Entwicklung von Resistenzen gegenüber Doxorubizin [36]. Für wenige Tumoren, wie beispielsweise dem Darmkrebs, wird eine generelle Resistenz gegenüber Doxorubizin beschrieben [37]. Die meisten Tumorarten wie Brustkrebs [38, 39] oder das Hepatoblastom [40] entwickeln diese Resistenzen jedoch erst unter der Doxorubizin-Behandlung.

Bei der Resistenz gegenüber Doxorubizin spielen vor allem die Multidrug Transporter MDR1 (auch p-Glycoprotein oder Multidrug-Resistance Protein 1 oder ABCB1) und MRP1 (auch Multidrug-Resistance Associated Protein 1 oder ABCC1), die der Familie der ABC-Transporter (ATP-Binding-Cassette-Transporter) zugeordnet sind, eine entscheidende Rolle. Diese beiden Effluxtransporter transportieren unter ATPVerbrauch verschiedene Moleküle aus der Zelle. Zu den Substraten von MDR1 
gehören neben Lipiden, Steroiden und Xenobiotika auch Peptide, wohingegen MRP1 eine Substratspezifität für Gluthationverbindungen und Leukotriene aufweist. Für beide Transporter ist bekannt, dass sie Zytostatika wie beispielsweise Doxorubizin aus der Zelle transportieren [36, 41, 42]. Tatsächlich konnten in Doxorubizinresistenten Zellen erhöhte Expressions-Level von MDR1 und MRP1 detektiert werden, was eine Doxorubizinresistenz erklären kann [43-46].

\subsection{Ansätze zur Erhöhung der Wirksamkeit von Doxorubizin in der Tumortherapie}

Da es sich bei Doxorubizin um ein viel verwendetes Zytostatikum handelt versucht man seit längerer Zeit, die Wirksamkeit von Doxorubizin in der Krebstherapie zu erhöhen. Dies sollte möglichst mit einer Reduktion von Nebenwirkungen bei gleichzeitiger Erhöhung des antitumoralen Effekts einhergehen. So konnten beispielsweise die kardiotoxischen Nebenwirkungen von Doxorubizin, die nach einer 15minütigen Bolusapplikation dieses Zytostatikums auftreten können, durch kontinuierliche Infusion des Medikaments über einen Zeitraum von 6 bis 96 Stunden signifikant reduziert werden $[47,48]$. Auf die Remissionsrate oder die Überlebensrate der Patienten hatte diese kontinuierliche Gabe keinen signifikanten Effekt. Allerdings verringert sich bei der langsamen Applikation von Doxorubizin die Inzidenz der Nebenwirkungen wie beispielsweise Übelkeit und Erbrechen [49].

In weiteren Arbeiten wurde Doxorubizin mit Dexrazoxan kombiniert. Dexrazoxan ist ein Eisenchelator. Da die Bildung freier Sauerstoffradikale durch Doxorubizin auch eisenabhängig ist, erhoffte man, dass eine Kombination mit Dexrazoxan die Doxorubizin vermittelten Nebenwirkungen eventuell mindern könnte. Allerdings inhibiert Dexrazoxan auch die TOP2. Dabei ist der Angriffspunkt die ATPase-Aktivität des Enzyms. Diese Inhibierung der ATPase hat die Stabilisierung von DNA/Enzymkomplexen zur Folge, welche anschließend degradiert werden [50, 51]. Tatsächlich senkte die zusätzliche Gabe von $50 \mathrm{ml}$ Dexrazoxan $/ \mathrm{m}^{2}$ zu einer Chemotherapie bestehend aus $50 \mathrm{mg}$ Doxorubizin $/ \mathrm{m}^{2}, 500 \mathrm{mg}$ Fluorouracil $/ \mathrm{m}^{2}$ und $500 \mathrm{mg}$ Cyclophosphamid $/ \mathrm{m}^{2}$ die Herztoxizität. Die Überlebensrate der Patienten wurde dagegen durch die Gabe von Dexrazoxan nicht signifikant beeinflusst [52]. Das Ansprechen der Tumoren nach Kombination mit Dexrazoxan war jedoch teilweise schlechter. Vermutet wurde, dass dies auf die Dexrazoxan-vermittelte 
Inhibierung der TOP2a zurückgeführt werden kann, infolge dessen keine DNADoppelstrangbrüche mehr durch Doxorubizin induziert werden konnten [53]. Da außerdem gezeigt wurde, dass Dexrazoxan die Inzidenz von sekundären Tumoren erhöht, wird Dexrazoxan in Kombination mit Doxorubizin bisher eher zurückhaltend in der Antitumortherapie verwendet [54].

Ein weiterer Forschungsfokus liegt auf der Sensitivierung von Tumorzellen gegenüber einer Doxorubizintherapie. So kann beispielsweise gezeigt werden, dass Tamoxifen und Megestrol die Doxorubizin-resistente Brustkrebszellinie MCF-7/ADR gegenüber einer Doxorubizin-Behandlung sensitiviert. Erklärt wurde dieser Effekt durch die Konkurrenz aller 3 Substanzen um die Bindungsstelle des Effluxtransporters MDR1 [55]. Weiterhin scheint Cysteamin HeLa-Zellen, Doxorubizinresistente MCF-7 Zellen und Melanomzellen in Zellkultur (letztere auch im Mausmodell) gegenüber einer Doxorubizin-Behandlung zu sensitivieren. Der chemosensitivierende Effekt resultiert dabei zum Teil aus der durch die Cysteamin vermittelten Induktion von Autophagie [56]. In einer weiteren Studie kann eine Sensitivierung von Sarkomzelllinien gegenüber Doxorubizin durch Infektion mit AAV (Adeno-Associated Virus) Typ 2 erreicht werden [57]. Auch können Zellen durch Hemmung der MDR1/MRP1-Funktion gegenüber einer Doxorubizin-Behandlung sensitiviert werden [46, 58].

Alle diese Arbeiten zeigen, dass sich Krebszellen prinzipiell gegenüber einer Behandlung mit Doxorubizin sensitivieren lassen. Leider hat sich noch keiner der oben genannten Ansätze zur Verbesserung der Doxorubizin-basierten Tumortherapie in der Klinik durchgesetzt.

\subsubsection{TOP2a-Expression und die Wirksamkeit von Doxorubizin}

Nun ist bekannt, dass das Ansprechen von Tumorzellen auf TOP2a-Inhibitoren wie Doxorubizin vom TOP2a-Expressionslevel abhängt. Dieses kann für Leukämiezellen gezeigt werden $[59,60]$. Ebenso sprechen Lymphomzellen in Zellkultur und nach Transplantation in Mäuse besser auf Doxorubizin an, wenn das TOP2a-Expressionslevel in den Tumorzellen erhöht ist [61]. Deshalb wird angenommen, dass zwischen der TOP2-Expression und dem Ansprechen auf TOP2a-Inhibitoren ein Zusammenhang besteht [60, 61].

Es ist daher möglich, dass Medikamente, welche die TOP2a-Expressionslevel erhöhen, Tumorzellen gegenüber Doxorubizin sensitivieren können. Da solche 
Medikamente in dieser Doktorarbeit verwendet worden sind, werden sie an dieser Stelle kurz beschrieben werden.

5-Aza-Deoxycytidin (5-Aza) ist ein Cytidinanalogon, welches durch DNA-Interkalation die Methylierung der DNA hemmt. Das Resultat ist oft die erhöhte Expression methylierter Gene [62]. Es kann gezeigt werden, dass 5-Aza auch eine verstärkte Induktion der TOP2a-Expression hervorruft [63].

Des Weiteren kann eine Induktion der TOP2-Expression nach Behandlung mit Histondeazetylase (HDAC)-Inhibitoren beobachtet werden. HDAC-Inhibitoren verhindern normalerweise die HDAC-vermittelte Deazetylierung der Histonseitenketten der DNA, die infolge dessen eine Konformationsänderung erfährt. Aus der Wirkung der HDAC-Inhibitoren resultiert die Transkriptions-Aktivierung betreffender DNA-Abschnitte und häufig eine Hemmung des Tumorwachstums [64, 65]. Eine Behandlung von Glioblastomzellen mit dem HDAC-Inhibitor Valproinsäure (VPA) resultiert in einer Sensibilisierung der Zellen auf den TOP2a-Inhibitor Etoposid. Da der TOP2a-Promotor Bindeelemente für verschiedene Regulatoren (u. a. auch für HDAC) aufweist [66] und da VPA zur Überexpression von TOP2a und TOP2b führt liegt nahe, dass diese Sensibilisierung durch eine VPA-induzierte Überexpression der TOP2a ausgelöst wurde [67].

Da auch den PPARy (Peroxisome Proliferator-Activiated Receptors y)-Rezeptoren eine regulatorische Funktion in der Transkription zugeschrieben wird, wurde untersucht, ob der PPARy-Ligand Pioglitazon eine Induktion der TOP2a-Expression in Leukämiezellen auslösen kann [68]. Tatsächlich wurde eine DR (Direct Repeat)1ähnliche Sequenz in der Promotorregion von TOP2a detektiert, durch die die TOP2aExpression mittels PPARy-Liganden induziert werden konnte [68].

Das Proteasom scheint ebenfalls ein guter Angriffspunkt für die Erhöhung der TOP2Expression in Karzinomen zu sein. So kann gezeigt werden, dass der Proteasominhibitor Bortezomib das TOP2a-Level in Myelomzellen erhöht, wodurch die Zellen verstärkt auf den TOP2-Inhibitor Ethonafide ansprechen [69].

Aufgrund dieser Fakten sind die oben genannten Medikamente in einem Versuch, Tumorzellen gegenüber Doxorubizin zu sensitivieren, in dieser Arbeit eingesetzt worden (siehe Kapitel 1.4). 


\subsubsection{Der PI3Kinase/AKT/mTOR-Signalweg und die Wirksamkeit von Doxorubizin}

Der PI3Kinase/AKT/mTOR-Signalweg ist in Tumoren häufig aktiviert und kann sogar ursächlich für die Entstehung von Tumoren sein [70]. Letzteres wird vor allem durch aktivierende Mutationen der PI3Kinase oder AKT, oder durch den Funktionsverlust von PTEN (Phosphatase and Tensin Homolog), das ein negativer Regulator dieses Signalwegs ist, ausgelöst [71]. So werden heterozygote Punktmutationen im PI3KGen gehäuft bei Brustkrebs und Kolonkarzionomen detektiert [72][73]. Diese Mutationen führen auch bei Abwesenheit von Wachstumssignalen zur konstitutiven Aktivität des PI3Kinase-Signalwegs [70]. Aktivierende Mutationen in AKT führen sowohl zur Translokation dieses Proteins an die Zellmembran als auch zur konstitutiven Phosphorylierung von S473. Die S473 Phosphorylierung von AKT ist für die Aktivierung dieses Proteins essentiell. Aktivierende AKT-Mutationen werden vor allem beim Brustkrebs, Kolonkarzinomen, Ovarialkarzinomen und beim Melanom detektiert [70]. Die häufigste Mutation im PI3Kinase-Signalweg in Tumoren ist jedoch der Funktionsverlust von PTEN, der durch Deletionen ausgelöst wird. Hemizygote aber auch homozygote Deletionen von PTEN können vor allem im Brustkrebs, Prostatakarzinom und in Hirntumoren nachgewiesen werden [71][70].

Da der PI3Kinase/AKT/mTOR-Signalweg eine wichtige Rolle in dieser Doktorarbeit spielt, wird er an dieser Stelle etwas ausführlicher beschrieben werden.

\subsubsection{Der PI3Kinase/AKT/mTOR-Signalweg und die Apoptose}

Der PI3Kinase/AKT/mTOR-Signalweg ist schematisch in Abbildung 2 dargestellt. Dieser Signalweg kann durch verschiedene Rezeptortyrosinkinasen (RTK) wie EGFR (Epidermal Growth Factor Receptor) und IGF-1R (Insuline-Like Growth Factor-1 Receptor), aber auch durch G-Protein gekoppelte Rezeptoren und durch Onkogene wie RAS, aktiviert werden [74].

Hierdurch wird wiederum die PI (Phosphatidylinositol)3Kinase aktiviert. Diese katalysiert die Phosphorylierung von Phosphatidylinositol-4,5-bisphosphat (PIP2) zu Phosphatidylinositol-3,4,5-triphosphat (PIP3). PIP3 kann an $\mathrm{PH}$ (Pleckstrin Homology)-Domänen binden, wie sie in PDK-1 (3'Phosphoinositide-Dependent Kinase 1) und in der Serin/Threonin Kinase AKT (auch als Protein-Kinase B bekannt) 
vorkommen. Über diese Bindung erfolgt die Rekrutierung beider Proteine an die Zellmembran. Dort werden PDK-1 und AKT aktiviert [74]. Die Aktivierung von AKT erfordert die Phosphorylierung an T308 sowie an S473. Die Phosphorylierung an T308 wird durch PDK-1 verursacht [75], wohingegen die Phosphorylierung an S473 entweder durch PDK-1 [76], durch die DNA-PK (DNA-Dependent Proteinkinase) [77], durch den mTOR Komplex 2 (Rictor) [74] oder durch AKT selbst [78] erfolgen kann.

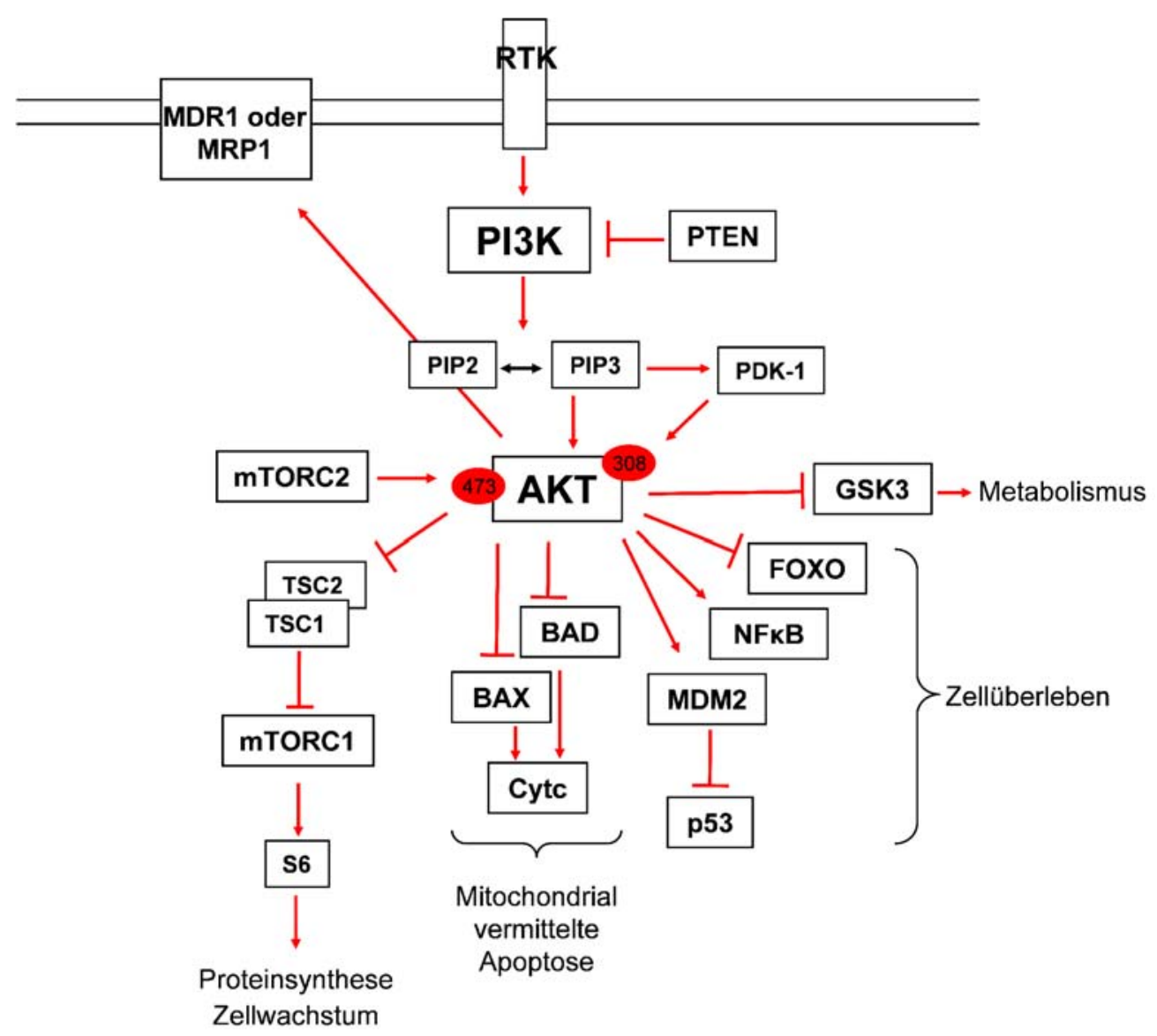

Abbildung 2: Schematische Darstellung der PI3Kinase/AKT/mTOR-Signalkaskade.

Nähere Erläuterungen siehe Text.

AKT ist in die Regulation vieler Proteine involviert. So ist gezeigt worden, dass AKT die Expression und/oder Aktivierung von MDR1 und MRP1 stimuliert. Eine Inhibierung des PI3Kinase/AKT/mTOR-Signalwegs mittels des dualen PI3Kinase/mTOR-Inhibitors LY294002 führt in MCF-7/ADR Zellen zur Hemmung der MDR1-Expression [79]. In einer anderen Studie konnte in AML (Akute myeloische Leukämie)-Zellen eine signifikante Korrelation zwischen phosphorylierter AKT und dem Expressionslevel von MRP1 detektiert werden [80]. Des Weiteren aktiviert AKT mTORC1 (mTOR Complex 1; Raptor) und stimuliert so die Proteinsynthese und das 
Wachstum der Zelle. Dabei wird die Aktivierung von mTORC1 über AKT-vermittelte Hemmung von TSC2 (Tuberous Sclerosis Complex 2), das mit TSC1 ein Dimer bildet und selbst einen hemmenden Effekt auf mTORC1 hat, verursacht. Aktiviertes mTORC1 induziert schließlich die Phosphorylierung des ribosomalen Proteins S6 $[70,81,82]$. Eine weitere Funktion von AKT ist die Phosphorylierung von MDM2 (Murine Double Minute 2), welche für die Translokation von MDM2 aus dem Zytoplasma in den Nukleus notwendig ist [83, 84]. Dort erfolgt die Bindung von MDM2 an p53. Diese Komplexbildung führt zur Inhibierung von p53 und folglich zur Hemmung von proapoptotischen Vorgängen. Auch aktiviert AKT den Transkriptionsfaktor NFKB, welcher für die Transkription antiapoptotischer Gene wie beispielsweise $\mathrm{BCl}-2$ und $\mathrm{BCl}-\mathrm{XL}$ verantwortlich ist [81]. Zudem werden die Forkhead Transkriptionsfaktoren FOXO (Fork Head Box O), die die Expression von proapoptotischen Genen wie BIM und FasL regulieren, in ihrer Funktion durch AKT blockiert [81, 85, 86]. Weiterhin inhibiert AKT die GSK3 (Glycogen Synthase Kinase 3) wodurch der Metabolismus der Zelle gefördert wird [82, 87]. Zusätzlich hemmt AKT die proapoptotischen Bcl-2 Proteine BAD und BAX [81, 88, 89]. Diesen Proteinen wird eine bedeutsame Rolle in der mitochondrialen Apoptose zugesprochen. Letztere soll an dieser Stelle kurz beschrieben werden.

Im Gegensatz zum extrinsische Apoptosesignalweg, der durch Bindung von Liganden an die Todesrezeptoren der TNF (Tumor Necrosis Factor)-Familie, wie FasR oder an TRAIL (Tumor-Necrosis Factor-Related Apoptosis-Inducing Lingand) ausgelöst und zur Aktivierung von Proteinen mit DD (Death Domain)-Domäne oder FADD (Fas-Associated Death Domain)-Domäne führt, wird die mitochondrialvermittelte Apoptose vor allem durch intrazelluläre Faktoren wie DNA-Schäden, das Ausbleiben von antiapoptotischen Signalen oder durch zytotoxische Reagenzien ausgelöst [90]. Wichtige Komponenten in der mitochondrial-vermittelten Apoptose stellen die Proteine der Bcl-2 Familie dar. Die Mitglieder dieser Familie werden in die antiapoptotischen Proteine, wie z. B. Bcl-2 und Bcl-XL, und die proapoptotischen Proteine wie beispielsweise BAX, BAK und BID unterteilt [91]. Die antiapoptotischen Bcl-2 Proteine Bcl-2 und Bcl-XL sind vorwiegend an der Mitochondrienmembran lokalisiert. Dort schützen sie das Mitochondrium vor der Induktion einer Veränderung des Membranpotentials (MMP, Mitochondrial Membrane Potential Change), indem sie wahrscheinlich an die proapoptotischen Bcl-2 Proteine BAX und BAK binden und 
diese inhibieren [92-95]. Das proapoptotische Protein BAK ist an der äußeren Mitochondrienmembran lokalisiert, wohingegen BAX zytosolisch vorliegt. Nach Induktion der Apoptose transloziert BAX an die Mitochondrienmembran und interagiert dort mit BAK oder tBID (truncated BID), welches zuvor durch Interaktion mit Caspase 8 aktiviert wurde [96]. Durch die Aktivität von BAX kommt es zu Veränderungen des MMP und zur Freisetzung von Cytochrom $\mathrm{c}$ in das Zytosol. Durch Komplexbildung von Cytochrom c mit der Caspase 9 entsteht dann das Apoptosom, welches die Effektor-Caspase 3 aktiviert [96]. Bei der Aktivierung der Caspase 3 kommt es zur Spaltung der Caspase 3-Proform, welche normalerweise inaktiv im Zytoplasma vorliegt. Durch die Spaltung der Proform entsteht ein Heterodimer mit zwei verschiedenen Untereinheiten, die eine Größe von 12 kDa bzw. 17 kDa aufweisen [97]. Die aktive Form der Caspase 3 resultiert durch Zusammenlagerung von zwei Heterodimeren zu einem Heterotetramer. Das aktive Protein besteht somit aus insgesamt vier Untereinheiten, wobei zwischen diesen Untereinheiten zwei aktive Zentren ausgebildet werden [98]. Aktive Caspase 3 bindet dann spezifisch an Proteine, die eine DEVD-Domäne (Aminosäureabfolge: Asparagin (D), Glutamin (E), Valin (V) Asparagin (D)) besitzen und spaltet diese [99].

\subsubsection{Inhibitoren des PI3Kinase/AKT/mTOR-Signalwegs}

Wie bereits erwähnt, zeigen Tumoren häufig eine konstitutive Aktivität des PI3Kinase/AKT/mTOR-Signalwegs. Die Hemmung dieses Signalwegs scheint somit ein guter Ansatz zur Behandlung von Tumorerkrankungen zu sein. Besonders die PI3Kinase, AKT und mTOR stellen dabei gute Ziele dar. Zur Hemmung dieser Proteine wurden inzwischen eine Reihe von Inhibitoren entwickelt. Spezifische AKTInhibitoren wie Perifosine, MK-2206, GSK2141795 oder GDC-0068 werden derzeit in Phase I bzw. II (Perifosine) klinischen Studien getestet [82]. Ein bekannter mTORInhibitor ist Rapamycin. Sein Derivat Everolimus wird bereits bei Nierenzellkarzinomen eingesetzt [100]. Ebenfalls in klinischen Studien getestet werden die mTOR-Inhibitioren AZD8055 und INK128 [82]. Weiterhin wurden spezifische PI3Kinase-Inhibitoren und duale PI3Kinase/mTOR-Inhibitoren entwickelt. Der spezifische PI3Kinase-Inhibitor NVP-BKM120 wird derzeit in einer klinischen Phase IStudie mit 31 Patienten, die an soliden Tumoren erkrankt sind, eingesetzt. Die vorläufigen Ergebnisse demonstrieren, dass zwei Brustkrebs-Patientinnen ein partielles Ansprechen auf die Behandlung zeigen [82]. Die ersten dualen 
PI3Kinase/mTOR-Inhibitoren waren Wortmannin und sein Derivat LY294002. In einer Reihe von in vitro-Experimenten konnte gezeigt werden, dass diese Inhibitoren die Zytotoxizität von anderen Zytostatika deutlich erhöhen. Aufgrund ihrer schlechten Löslichkeit und hohen Toxizität werden diese PI3Kinase-Inhibitoren jedoch nicht in der Klinik eingesetzt [74]. Für andere duale PI3Kinase/mTOR-Inhibitoren können jedoch inzwischen Erfolge in klinischen Studien verzeichnet werden. Dabei handelt es sich zum Beispiel um SF1126, welches momentan bei Patienten mit soliden Tumoren eingesetzt wird. Obwohl das Medikament nicht zur Tumorregression führt, konnte bei $50 \%$ der behandelten Patienten das Tumorwachstum gestoppt werden [82]. In einer anderen Studie wurden 59 Patienten mit NVP-BEZ235 behandelt. Bei zwei Patienten (eine Patientin mit Brustkrebs und ein Patient mit Lungenkarzinom) konnte ein partielles Ansprechen der Tumoren auf die Behandlung dokumentiert werden. $27 \%$ der Patienten zeigten nach der Behandlung ein stabiles Krankheitsbild für 4 Monate oder länger [82].

Ein weiterer sich in der Testphase befindlicher dualer PI3Kinase/mTOR-Inhibitor ist PI103. PI103 kann in primären Knochenmarkszellen von AML-Patienten die mitochondrial-vermittelte Apoptose induzieren. Interessanterweise erhöht Pl103 die proapoptotischen Effekte von Etoposid in diesen Zellen [101]. In der Studie von Fan und Kollegen wurde weiterhin gezeigt, dass PI103 die Proliferation von Glioblastomzellen in vitro hemmt. Diese Proliferationsinhibierung war dabei von dem PTEN- oder p53-Mutationsstatus unabhängig. Ebenfalls kann in Mäusen, denen Glioblastomzellen transplantiert wurden, nach Behandlung mit PI103 ein vermindertes Tumorvolumen festgestellt werden [102]. In einer anderen Studie ruft PI103 auch ein vermindertes Tumorwachstum von transplantierten Prostata- und Brustkrebs- sowie von Kolonkarzinom- oder Ovarialkarzinomzellen hervor [103]. Leider wird PI103 in vivo sehr schnell und extensiv metabolisiert und ist daher für eine in vivo-Applikation nicht geeignet [103]. Auf Grundlage dieser Ergebnisse wurden in den letzten Jahren PI3Kinase-Inhibitoren entwickelt, die eine bessere Pharmakokinetik und Pharmakodynamik aufweisen. Einer dieser PI3Kinase-Inhibitoren ist GDC-0941. Diese Substanz wurde von Genentech 2008 entwickelt. Im Gegensatz zu PI103 zeichnet diese Substanz neben einer erhöhten Löslichkeit und einer verlangsamten Metabolisierung auch eine verbesserte Verteilung im Gewebe aus. GDC-0941 ist jedoch im Gegensatz zu PI103 ein spezifischer PI3Kinase-Inhibitor [104]. Eine erste Phase I-Studie mit 59 Patienten zeigte ein partielles Ansprechen einer Patientin mit 
Brustkrebs, sowie aussichtsreiche Effekte in Patientinnen mit Ovarialkarzinomen [82]. In einer weiteren Studie mit 42 Patienten konnte eine partielle Remission durch GDC-0941 bei einem Melanom-Patienten, einem Patienten mit GIST und in einer Patientin mit Ovarialzellkarzinom hervorgerufen werden. Durch diese ersten Erfolge und aufgrund der guten Verträglichkeit von GDC-0941, wird eine klinische Phase II-Studie geplant [105].

\subsubsection{Kooperative antitumorale Effekte von Doxorubizin und Inhibitoren des PI3Kinase/AKT/mTOR-Signalwegs}

Für einige Inhibitoren des PI3Kinase/AKT/mTOR-Signalwegs wurden bereits Kombinationseffekte mit Doxorubizin beschrieben. Hauptsächlich scheinen PI3Kinase-Inhibitoren die Doxorubizin-vermittelten proapoptotischen Effekte zu unterstützen. So kann in Neuroblastomzellen, die mit PI103 und Doxorubizin behandelt wurden, ein Anstieg der Expression von NOXA und BIM detektiert werden. Dies korreliert mit erhöhter Konformationsänderung von BAX/BAK und dem Verlust des MMP, welches in Freisetzung von Cytochrom $\mathrm{c}$ und der Aktivierung der Caspase-abhängigen Apoptoseinduktion resultiert [106]. Ein ähnlicher kooperativer Effekt wird in Glioblastomzellen durch Kombination des dualen PI3Kinase/mTORInhibitors LY294002 mit Doxorubizin detektiert. Eine spezifische Inhibierung von mTOR mit Everolimus oder Rapamycin induziert dagegen keinen kooperativen Effekt [107]. Ebenso kann gezeigt werden, dass der duale PI3Kinase/mTOR-Inhibitor PI103 Glioblastomzellen auf die Doxorubizin-vermittelte Apoptose sensitiviert. Die Kombination beider Medikamente resultiert dabei in einer erhöhten Rate der DNADoppelstrangbrüche [108]. Kooperative proapoptotische Effekte für PI103 und Doxorubizin können ebenfalls in Chordomzellen nachgewiesen werden [109]. Interessanterweise wird postuliert, dass die Interaktion von PI103 und Doxorubizin bei der Apoptoseinduktion p53-abhängig sein könnte [110, 111].

Schließlich können auch Sarkomzellen durch Behandlung mit dem dualen PI3Kinase/mTOR-Inhibitor NVP-BEZ235 gegenüber Doxorubizin sensitiviert werden. In dieser Studie zeigt sich jedoch lediglich eine Sensitivierung hinsichtlich der Doxorubizin-vermittelten Proliferationsinhibierung, wogegen die Doxorubizin-vermittelten proapoptotischen Effekte nicht verstärkt werden [112].

Zusammengefasst zeigen diese Daten, dass PI3Kinase-Inhibitoren die antitumoralen 
Effekte von Doxorubizin verstärken können. Daher wurden PI103 bzw. GDC-0941 ebenfalls im Rahmen dieser Doktorarbeit eingesetzt.

\subsection{Doxorubizin in der Therapie des Rhabdomyosarkoms}

\subsubsection{Das Rhabdomyosarkom (RMS)}

Das Rhabdomyosarkom (RMS) gehört zu der Kategorie der klein-, blau- und rundzelligen Tumoren des Kindesalters [113] und hat Merkmale von quergestreifter Muskulatur. Neben dem Neuroblastom und dem Wilms-Tumor ist es das häufigste Weichteilsarkom bei Kindern [114]. Ungefähr 65\% der RMS-Fälle werden bei Kindern, die jünger als 6 Jahre sind, diagnostiziert, wobei die Mortalitätsrate bei $40 \%$ liegt [114]. RMS treten bevorzugt im Hals-Kopf-Bereich mit einer Häufigkeit von $\sim 40 \%$ auf. Weitere Prädilektionsstellen sind der Urogenitaltrakt und die Extremitäten mit den respektiven Häufigkeiten von $\sim 25 \%$ und 20\% [115].

Histologisch können hauptsächlich embryonale (eRMS) und alveoläre (aRMS) RMS unterschieden werden, wobei eRMS anteilig mit etwa 2/3 der Fälle überwiegen. Die beiden Hauptvarianten können lichtmikroskopisch und auf molekularer Ebene voneinander unterschieden werden [116]. ARMS bestehen typischerweise aus kleinen runden dicht gepackten Zellen und zeigen strukturelle Rearrangements in Form von Translokationen. Sehr häufig ist hierbei die Translokation $t(2 ; 13)(q 25 ; q 14)$, die zu einer Fusion von PAX3 mit FKHR (auch FOX01) führt. Weniger häufig kann die Translokation $\mathrm{t}(1 ; 13)(q 36 ; q 14)$ beobachtet werden, welche PAX7 mit FKHR fusioniert. Beide Translokationen führen zur Expression der entsprechenden chimären PAX3- bzw. PAX7-FKHR Transkriptionsfaktoren [117]. Das eRMS ist typischerweise aus spindelzellförmigen Zellen zusammengesetzt, die sehr Stromareich erscheinen. Als „Markenzeichen“ von eRMS gilt der Verlust der Heterozygotie an $11 \mathrm{p} 15$ mit gleichzeitiger Duplikation des paternalen IGF-2 Lokus, und nicht chromosomale Translokationen [117].

Die meisten Fälle von RMS entstehen sporadisch [118]. Es gibt jedoch auch vererbbare Syndrome, die für RMS prädisponieren. Hierbei handelt es sich beispielsweise um das Beckwith-Wiedemann Syndrom, das mit Imprintingstörungen im Bereich 11p15 und Überexpression von IGF-2 einhergeht. Auch das Li-FraumeniSyndrom (TP53-Mutationen), die Neurofibromatosis (NF1-Mutationen), das Costello Syndrom (HRAS-Mutationen) und das Gorlin-Goltz Syndrom (PTCH-Mutationen) 
prädisponieren für RMS [119].

\subsubsection{Ansprechen von RMS auf Doxorubizin}

Die Behandlung der RMS umfasst die Resektion, die Bestrahlung und die Chemotherapie. Liegt zum Therapiezeitpunkt keine Metastasierung vor, können etwa $70 \%$ der Patienten erfolgreich behandelt werden. Ist die Metastasierung jedoch bereits fortgeschritten, sinkt die Überlebensrate der Patienten auf etwa 25\% [120]. Für die Chemotherapie werden Kombinationen aus Vincristin, Actinomycin D, Doxorubizin, Cyclophosphamid, Ifosfamid, Etoposid, Melphalan oder Cisplatin appliziert [114]. Als limitierender Faktor der Chemotherapeutika steht die Induktion von Nebenwirkungen durch die Kombination der Medikamente an erster Stelle. Außerdem kann es zu einer Resistenz des Tumors gegenüber dem Zytostatikum kommen. Diese Resistenzen treten vor allem in Verbindung mit einer Überexpression von Multidrug-Transportern wie MDR1 oder MRP1 auf [121] (siehe auch Kapitel 1.1.3).

Obwohl Doxorubizin in der Therapie des RMS eingesetzt wird, wurde dies bisher immer kontrovers diskutiert. Erste klinische Studien zeigten Remissionsraten bei Doxorubizin-behandelten RMS von bis zu 27\% [122-124], wohingegen die Behandlung mit Doxorubizin bei Patienten, die ein hohes Risiko zu metastasierenden RMS aufwiesen, eine Remissionsrate von 65\% zeigte [125]. Das Ansprechen der Tumoren auf Doxorubizin korrelierte dabei mit der verabreichten Dosis [123]. In randomisierten Phase III-Studien der IRSG (North America Intergroup Rhabdomyosarcoma Study Group) wurde der Einfluss von Doxorubizin auf die VACChemotherapie (Vincristin, Actinomycin D und Cyclophosphamid) in RMS-Patienten getestet. Dabei konnte kein Vorteil durch zusätzliche Gabe von Doxorubizin detektiert werden [126-128]. Der Einsatz von Doxorubizin bei RMS ist deshalb weiterhin umstritten und findet nur nach gründlicher Abwägung von Nutzen und Risiken statt. Diese Ergebnisse zeigen, dass es einen extremen Bedarf an der Optimierung der Doxorubizin-basierten Therapie beim RMS gibt [120].

\subsubsection{Neue zielgerichtete Therapieansätze beim RMS}

Neue Therapien zur Behandlung von RMS richten sich üblicherweise gegen spezifische RTKs. Diese Ansätze sind jedoch noch in der Entwicklungsphase und 
zeigen oft keine Wirksamkeit. So ist beispielsweise HER-2 (Human Epidermal Growth Factor Receptor-2) häufig in RMS überexprimiert [119]. Jedoch führt eine Behandlung von RMS-Zellen mit zielgerichteten Immuntoxinen gegen HER-2 weder zur Inhibierung der Proliferation noch zur Induktion der Apoptose [129]. In der Entwicklungsphase befinden sich gegenwärtig auch Therapien, die gegen den PDGFR (Platelet-Derived Growth Factor Receptor) gerichtet sind. So ist PDGFRA häufig in humanen RMS überexprimiert [130]. Tatsächlich kann die Proliferation von RMS-Zellen durch PDGFRA-Knockdown oder durch neutralisierende Antikörper gehemmt werden [131]. Dagegen zeigt Imatinib, welches ebenfalls die Aktivität von PDGFRA blockieren kann, nur bei extrem hohen, klinisch nicht einsetzbaren Dosen eine marginale Proliferationsinhibierung [132].

Da auch IGF-1R in RMS überexprimiert ist, werden IGF-1R-Inhibitoren aktuell in dem PPTP (Pediatric Preclinical Testing Program) getestet. Für zwei dieser Inhibitoren konnte bereits gezeigt werden, dass sie das Tumorwachstum von xenotransplantierten RMS-Zelllinien verringern [133].

MET (auch HGFR, Hepatocyte Growth Factor Receptor) ist eine weitere RTK, die in RMS überexprimiert ist [134]. Die Ausschaltung von MET durch siRNA in RMSZelllinien resultiert in verminderten Wachstumsraten und in der Induktion von Apoptose [135]. Weiterhin kann MET durch SU11274 dephosphoryliert und dadurch inaktiviert werden, was in einem $\mathrm{G}_{1}$-Arrest und in der Induktion von Apoptose resultiert [136].

Die Hemmung von RTKs und natürlich auch der nachgeschalteten Signalwege scheint daher sehr aussichtsreich in der Therapie des RMS zu sein.

\subsubsection{Die Rolle des PI3Kinase/AKT/mTOR-Signalwegs im RMS}

Wie oben bereits ausführlich beschrieben, ist der PI3Kinase/AKT/mTOR-Signalweg in Tumoren häufig konstitutiv aktiv. Dies kommt dadurch zustande, dass dieser Signalweg über viele der oben genannten RTKs stimuliert werden kann.

Auch beim RMS scheint der PI3Kinase/AKT/mTOR-Signalweg, vor allem AKT, eine wichtige Rolle zu spielen. So wurde in der Children's Oncology Group Intergroup Rhabdomyosarcoma Study (IRS) gezeigt, dass Patienten mit einer erhöhten AKTExpression eine kürzere Überlebenszeit als solche ohne erhöhter AKT-Expression aufweisen [137]. Auch unsere Arbeitsgruppe kann zeigen, dass RMS von Ptch ${ }^{\text {neo67/+ }}$ - 
Mäusen eine gesteigerte Aktivität von Akt besitzen [138]. Ptch ${ }^{\text {neo67/+ }}$-Mäuse entwickeln aufgrund einer Mutation im Ptch-Gen endogene RMS. Da RMS dieser Mäuse eine hohe Expression von Igf-2 aufweisen, könnte die Aktivierung der PI3Kinase/Akt/mTOR-Signalwegkaskade in diesen Tumoren durch eine Aktivierung des Igf-2 Rezeptors Igf-1R zustande kommen [138].

Trotz dieser Datenlage sind Ansätze zur zielgerichteten Therapie des PI3Kinase/AKT/mTOR-Signalwegs beim RMS nicht häufig. Dies mag daran liegen, dass eine Inhibierung von mTOR in einer Aktivierung von AKT resultiert. Dieser Effekt konnte sowohl in vitro, als auch in Patienten die in klinischen Phase I-Studien mit Everolimus behandelt wurden, gezeigt werden [139, 140]. Es wird vermutet, dass diese AKT-Aktivierung von einem im Signalweg stromabwärts von mTOR gelegenen Protein reguliert wird, welches die Induktion von IGF-1 bewirkt. Durch diesen positiven Rückkopplungsmechanismus wird AKT weiter aktiviert [139-142]. Dennoch gibt es einige Studien, die eine Wirksamkeit von Inhibitoren der PI3Kinase/AKT/mTOR-Signalkaskade zeigen. So resultiert beispielsweise eine Behandlung von RMS-Zelllinien mit dem PDK-1 Inhibitor OSU-03012 in verminderter Aktivität von AKT, welche zum Zelltod führt [143]. In einer weiteren Arbeit kann durch den PI3Kinase-Inhibitor SF1126 die Proliferation sowie eine Metastasierung von xenotransplantierten RMS-Zellen gehemmt werden [144].

\subsection{Zielsetzung der Arbeit}

Das Ziel dieser Arbeit bestand darin, Sarkomzellen, insbesondere Rhabdomyosarkomzellen, gegenüber einer Doxorubizin-Behandlung zu sensitivieren.

Da laut Literaturangaben das TOP2a-Level beim Ansprechen von Tumoren auf die Doxorubizin-Behandlung eine wichtige Rolle zu spielen scheint, wurden zunächst Medikamente getestet, die die TOP2a-Expression erhöhen können. Hierbei handelt es sich um die Medikamente 5-Aza-Deoxycytidin (5-Aza), Valproinsäure (VPA), Bortezomib und Pioglitazon. Getestet wurde weiterhin PI103, da es die antitumorale Wirkung von Doxorubizin in Glioblastom- und Neuroblastomzellen verstärken kann.

Zur Überprüfung, ob die Medikamente Tumorzellen tatsächlich gegenüber Doxorubizin sensitivieren, wurden Proliferationsanalysen, Annexin V-Messungen und Aktivitätsmessungen der Caspasen 3 und 7 durchgeführt. Weiterhin erfolgten quantitative Analysen der TOP2a-Expression. Die Experimente wurden an der 
Sarkomzellinie HT1080 und den Rhabdomyosarkomzelllinien TP5014 (murin) und RD (human) durchgeführt. Der Einfluss der TOP2a-Expression auf die Doxorubizinvermittelte Sensitivierung wurde zudem in HTETOP Zellen untersucht.

Da PI103 alle Zelllinien eindeutig gegenüber Doxorubizin sensitivierte, wurde versucht, die molekularen Grundlagen dieses Effekts aufzuklären. Die hierzu notwendigen Untersuchungen wurden ausschließlich an der Rhabdomyosarkomzelllinie RD durchgeführt. Bei den Untersuchungen handelte es sich vorwiegend um Aktivitätsbestimmungen von Komponenten des PI3Kinase/AKT/mTOR-Signalwegs und des mitochondrialen Apoptosesignalwegs. Zudem wurden die Expression der beiden Effluxtransporter MDR1 und MRP1 und die Akkumulation von Doxorubizin in den verwendeten Tumorzelllinien untersucht.

Schließlich wurde der in vitro detektierte kooperative antitumorale Effekt von Doxorubizin und PI103 auf das Rhabdomyosarkomwachstum im Tiermodell überprüft. 


\section{Material}

\subsection{Laborgeräte}

$-80^{\circ} \mathrm{C}$ Schrank

Agarosegelelektrophorese-Kammern

Autoklav

BD FACSCalibur

Blotapparaturen

Brutschränke, Begasungsrutschränke

(6000, BBD 6220)

Digitale Fotokamera (PowerShot G10)

Einkanal-Pipetten

Entwicklermaschine (Curix 60)

Feinwaagen (Sartorius Basic plus)

Filmkassetten

Fluoreszenzmikroskop (BX60F5)

Gewebeeinbett- und entwässerungsautomat

(TP 1020)

Heizblock (Thermomixer)

Heizrührer (MR 3000/300)

Homogenisator (Miccra D-1)

Hybridisierungsofen (HB-1000 Hybridizer)

Inverses Mikroskop mit Fluoreszenzfilter

(Axiovert 25, Filter set 43, 01, 09)

Kühlplatte (EG1150C)

Kühlschrank $\left(4^{\circ} \mathrm{C}\right)$

LSR II (FACS)

Messschieber

Mikrowelle (Dimension 4)

MilliQ-Anlage

Mini-Zentrifuge

Multi-Mod Microplate Reader (Synergy Mx)

Paraffinspender, Ausgießstation

(Dispenser PAG 12)

Paraffinstreckbad

PCR-Gerät

pH-Meter I (inoLab ph Level 1)

Photometer, Thermodrucker

(Biophotometer 6131, Thermodrucker DPU-414)

Pipettierhilfe (Accu-jet)
Sanyo Electric Co., Ltd., Japan

Peqlab Biotechnologie $\mathrm{GmbH}$, Erlangen

W. Krannich GmbH \& Co. KG, Göttingen

Becton Dickinson $\mathrm{GmbH}$, Heidelberg

Bio-Rad Laboratories $\mathrm{GmbH}$, München

Heraeus Holding $\mathrm{GmbH}$, Hanau

Canon Deutschland $\mathrm{GmbH}$, Krefeld

Eppendorf, Hamburg

AGFA Deutschland Vertriebsgesellschaft $\mathrm{mbH}$

\& Co., Köln

Sartorius AG, Göttingen

Sigma-Aldrich Chemie $\mathrm{GmbH}$, Steinheim

Olympus Optical Co. Ltd., Japan

Leica Mikrosysteme Vertrieb $\mathrm{GmbH}$,

Bensheim

Eppendorf, Hamburg

Heidolph Instruments, Schwalbach

ART-moderne Labortechnik e. K., Mühlheim

UVP, Inc., Upland, USA

Carl Zeiss Jena GmbH, Jena

Leica, Nussloch

Robert Bosch $\mathrm{GmbH}$, Stuttgart

Becton Dickinson $\mathrm{GmbH}$, Heidelberg

Vogel Germany GmbH \& Co. KG, Kevelaer

Panasonic, Hamburg

Sartorius Stedim Biotech $\mathrm{GmbH}$, Göttingen

Carl Roth $\mathrm{GmbH}$, Karlsruhe

BioTek Instruments, Inc., USA

Medite Medizintechnik $\mathrm{GmbH}$, Burgdorf

Medax GmbH \& Co. KG, Rendburg

Eppendorf, Hamburg

WTW GmbH, Wien, Östereich

Eppendorf, Hamburg

Brand $\mathrm{GmbH} \&$ Co. KG, Wertheim 
Präparierbesteck

Schlittenmikrotom (HN 40)

Schüttelwasserbad (1083)

Sterilbank (Euroflow Klasse IIA)

Tank für Flüssigstickstoff

TaqMan (ABI Prism 7900HT)

Tiefkühlschränke $\left(-20^{\circ} \mathrm{C}\right)$

Trans Blot, SD Semi Dry

UV-Dokumentation (digital monochrome

Printer P91D)

Volumencomputertomograph (Volumetric CT)

Vortexer (Vortex-Genie 2)

Wipp-Taumel-Tisch (Unimax 1010)

Zählkammer nach Neubauer (Assistent)

Zentrifugen (Biofuge pico, fresco, primo,

Multifuge $3 \mathrm{~L}-\mathrm{R}$ )

\subsection{Gebrauchswaren}

1,5 ml-Reaktionsgefäße

2,0 ml-Reaktionsgefäße

$15 \mathrm{ml}$ Röhrchen

$50 \mathrm{ml}$ Röhrchen

96-Loch Platten (Tissue culture plate 96-well)

6-Loch Platten (Tissue culture plate 6-well)

Blottingpapier

Cryoröhrchen

CL-XPosure Film

Deckgläser

Dispensionspipetten (Combitips plus)

Einwegspritzen

(BD Pastik, BD Mico-Fine + Demi)

Filter

Glaswaren

Hybond ECL, 0,2 $\mu \mathrm{m}$, Nitrozellulosemembran

Kanülen (Sterican $\varnothing ~ 0,45 \times 12 \mathrm{~mm}$ )

Knopfsonde $(1,0 \times 60 \mathrm{~mm})$
Karl Hammacher $\mathrm{GmbH}$, Solingen

Leica microsysteme Vertrieb $\mathrm{GmbH}$,

Bensheim

GFL mbH, Burgwedel

Clean Air Techniek bv, Woerden, Niederlande

L'air liquide S.A., Paris Cedax, Frankreich

Applied Biosystems, Darmstadt

Liebherr Hausgeräte Ochsenhausen $\mathrm{GmbH}$,

Ochsenhausen und Robert Bosch $\mathrm{GmbH}$,

Stuttgart

Bio-Rad Laboratories $\mathrm{GmbH}$, München

Mitsubishi, Ratingen

GE Global Research, Niskayuna, USA

Scientific Industries, Inc., Bohemia, USA

Heidolph Instruments, Schwalbach

Brand $\mathrm{GmbH} \&$ Co. KG, Wertheim

Heraeus Holding $\mathrm{GmbH}$, Hanau

Ochs $\mathrm{GmbH}$, Bovenden/Lenglern

Sarstedt AG \& Co., Nürnbrecht

Greiner Bio-One $\mathrm{GmbH}$, Frickenhausen

Greiner Bio-One $\mathrm{GmbH}$, Frickenhausen

Nunc GmbH \& Co. KG, Wiesbaden

Sarstedt AG \& Co., Nürnbrecht

Inapa Tecno, Lissabon

Greiner Bio-One $\mathrm{GmbH}$, Frickenhausen

Thermo Fisher Scientific, Rockford, USA

Menzel GmbH \& Co. KG, Braunschweig

Eppendorf, Hamburg

Becton Dickinson $\mathrm{GmbH}$, Heidelberg

Sartorius Stedim Biotech GmbH, Göttingen

Schott AG, Mainz

Amersham Biosciences Europe $\mathrm{GmbH}$,

Freiburg

B. Braun Medical AG, Emmenbrücker

Unimed SA, Lausanne, Schweiz 
Küvette (UVette)

Luminometer Messplatten (96 well assay plate)

NuPAGE MES SDS Running buffer 20x

NuPAGE Novex Midi Gel

Objektträger (SuperFrost Plus, unbeschichtet)

Pasteurpipetten

PCR-Reaktionsgefäße und Deckel

(ThermoFast 96, non-skirted, natural domed cap strips, nautral, Framestar 384)

Petrischalen

Pipettenspitzen, gestopft (10 $\mu$ l)

Pipettenspitzen, gestopft

(100 $\mu \mathrm{l}, 200 \mu \mathrm{l} ; 1.000 \mu \mathrm{l})$

Pipettenspitzen; ungestopft (10 $\mu \mathrm{l}, 200 \mu \mathrm{l})$

Pipettenspitzen; ungestopft $(1.000 \mu \mathrm{l})$

Skalpellklingen (\#10, \#24)

Sterilfilter

TaqMan Platten (384-well optical

Reaction plate)

TaqMan Folien (optical adhesive covers)

Zellkulturschalen, $100 \mathrm{~mm}, 35 \mathrm{~mm}$

(Nunclon Surface)

Zellsieb $40 \mu \mathrm{m}$

\subsection{Chemikalien und Reagenzien}

$1 \mathrm{~kb}$ DNA, 50bp und 100bp DNA Ladder

Agarose

Annexin V-FITC

Annexin V Binding Buffer (10x)

Complete Mini (Protease Inhibitor Cocktail)

Desoxynukleotidtriphosphate (dNTP)

Dithiotreiol (DTT)

Ethanol $96 \%$ ig

Ethanol 99 \%ig vergällt

Ethidiumbromid

Ethylendiamintetraacetat (EDTA)

First strand buffer

Formamid 99\% DNase, RNase frei

Glycergel Mounting-Medium

Isofluran $\left(\right.$ FORENE $^{\circledR}$ )
Eppendorf, Hamburg

Costar, Corning Incorporated, Corning, USA

Invitrogen $\mathrm{GmbH}$, Karlsruhe

Invitrogen $\mathrm{GmbH}$, Karlsruhe

Menzel GmbH \& Co. KG, Braunschweig

Brand $\mathrm{GmbH} \&$ Co. KG, Wertheim

4titude ${ }^{\circledR}$ Ltd., Surrey, USA

Ochs $\mathrm{GmbH}$, Bovenden/Lenglern

Sarstedt AG \& Co. KG, Nürnbrecht

G. Kisker GbR, Steinfurt

Ochs $\mathrm{GmbH}$, Bovenden/Lenglern

Sarstedt AG \& Co. KG, Nürnbrecht

Aesculap AG \& Co. KG, Tuttlingen

Th. Geyer $\mathrm{GmbH} \&$ Co. KG, Renningen

Thermo Fisher Scientific, Rockford, USA

4titude ${ }^{\circledR}$ Ltd., Surrey, USA

Nunc GmbH \& Co. KG, Wiesbaden

Becton Dickinson $\mathrm{GmbH}$, Heidelberg

Invitrogen $\mathrm{GmbH}$, Karlsruhe

Bio-Budget Technologie GmbH, Krefeld

Becton Dickinson $\mathrm{GmbH}$, Heidelberg

Becton Dickinson $\mathrm{GmbH}$, Heidelberg

Roche Diagnostics $\mathrm{GmbH}$, Mannheim

Bio-Budget Technologie $\mathrm{GmbH}$, Krefeld

Invitrogen $\mathrm{GmbH}$, Karlsruhe

J.T.Baker, Darmstadt

Chemie-Vertrieb Hannover, Hannover

inna-TRAIN-Diagnostics. Kronberg

ICN Biochemicals Inc., Aurora, USA

Invitrogen $\mathrm{GmbH}$, Karlsruhe

Acros Organics, Geel, Belgien

Dako $\mathrm{GmbH}$, Hamburg

Abbott GmbH \& Co. KG, Wiesbaden 
Matrigel

Natriumchlorid

PBS-Tabletten

Pifithrin a, Pifithrin $\mu$

PhosSTOP (Phosphatase Inhibitor Cocktail)

Perjodsäure

Random Hexamer-Oligonukleotide

RNAse, DNAse-freies destilliertes Wasser

Salzsäure, rauchend $37 \%$

SCHIFF Reagenz

SDS (Natriumdodecylsulfat)

StreptavidinABComplex/AP

Trizol

Tween-20

To-Pro 3 iodid

Ultravist 150

Wasserstoffperoxid $30 \%$

Xylol
Becton Dickinson GmbH, Heidelberg

Merck KGaA, Darmstadt

GIBCO Invitrogen $\mathrm{GmbH}$, Karlsruhe

Merck KGaA, Darmstadt

Roche Diagnostics $\mathrm{GmbH}$, Mannheim

Merck KGaA, Darmstadt

Invitrogen $\mathrm{GmbH}$, Karlsruhe

Invitrogen $\mathrm{GmbH}$, Karlsruhe

Merck KGaA, Darmstadt

Merck KGaA, Darmstadt

ICN Biochemicals Inc., Aurora, USA

Dako $\mathrm{GmbH}$, Hamburg

Invitrogen $\mathrm{GmbH}$, Karlsruhe

Scharlau Chemie S.A., Barcelona, Spanien

Invitrogen $\mathrm{GmbH}$, Karlsruhe

Bayer AG, Leverkusen

Merck KGaA, Darmstadt

J. T. Baker B.V., Deventer, Holland

Alle weiteren nicht aufgelisteten Chemikalien wurden von der Carl Roth $\mathrm{GmbH}$, Karlsruhe, oder von der Sigma-Aldrich Chemie GmbH, Steinheim, bezogen.

\subsection{Gebrauchsfertige Reaktionssysteme}

Pierce ${ }^{\circledR}$ BCA Protein Assay Kit

Cell Proliferation ELISA, BrdU

(chemiluminescence)

Caspase-Glo 3/7 Assay

Enhanced chemoluminescence (ECL) Kit

Multidrug Resistance Direct Dye

Efflux Assay

QuantiTect SYBR Green RT-PCR

RNeasy Mini Kit

SYBR Green qPCR SuperMix-UDG
Thermo Fisher Scientific, Rockford, USA

Roche Diagnostics $\mathrm{GmbH}$, Mannheim

Promega $\mathrm{GmbH}$, Mannheim

Amersham Bioscience Europe $\mathrm{GmbH}$,

Freiburg

Millipore, Massachusetts, USA

Qiagen $\mathrm{GmbH}$, Hilden

Qiagen $\mathrm{GmbH}$, Hilden

Invitrogen $\mathrm{GmbH}$, Karlsruhe

Die Verwendung von gebrauchsfertigen Reaktionssystemen erfolgte nach Herstellerangaben, soweit im Text nicht anders erwähnt. 


\subsection{Eingesetzte Medikamente}

Die Stockkonzentrationen sowie die Lösungsmittel der einzelnen Medikamente sind in Tabelle 1 aufgelistet.

Tabelle 1: Hergestellte Stockkonzentrationen der verwendeten Medikamente. Abkürzungen: MCT, Methylcellulose-Tween-Lösung (siehe Kapitel 2.6), RT, Raumtemperatur

\begin{tabular}{l|l|l|l|l}
\hline Medikament & Lösungsmittel & Stockkonzentration & Lagerung & Hersteller \\
\hline 5-Azadeoxycytidin & PBS & $500 \mu \mathrm{M}$ & $-80^{\circ} \mathrm{C}$ & Sigma-Aldrich \\
\hline Bortezomib & $0,9 \% \mathrm{NaCl}$ & $1 \mathrm{mM}$ & $-20^{\circ} \mathrm{C}$ & Klinikumsapotheke \\
\hline Doxorubizin & $0,9 \% \mathrm{NaCl}$ & $2 \mathrm{mg} / \mathrm{ml}$ & $-20^{\circ} \mathrm{C}$ & Klinikumsapotheke \\
\hline Doxycyclin & Wasser & $2,25 \mathrm{mM}$ & $-20^{\circ} \mathrm{C}$ & Sigma-Aldrich \\
\hline Etoposid & DMSO & $8,5 \mathrm{mM}$ & $-20^{\circ} \mathrm{C}$ & Sigma-Aldrich \\
\hline Everolimus & Ethanol & $10 \mathrm{mM}$ & $-20^{\circ} \mathrm{C}$ & Sigma-Aldrich \\
\hline GDC-0941 & MCT & $37,5 \mathrm{mg} / \mathrm{ml}$ & RT & Genentech \\
\hline PI103 & DMSO & $10 \mathrm{mM}$ & $-20^{\circ} \mathrm{C}$ & Alexis \\
\hline Pioglitazon & DMSO & $2 \mathrm{mM}$ & $-20^{\circ} \mathrm{C}$ & Cayman Chemical \\
\hline Staurosporin & DMSO & $2 \mathrm{mM}$ & $-20^{\circ} \mathrm{C}$ & Sigma-Aldrich \\
\hline Valproinsäure & PBS & $200 \mathrm{mM}$ & $-80^{\circ} \mathrm{C}$ & Sigma-Aldrich \\
\hline
\end{tabular}

\subsection{Stammlösungen}

Wenn nicht anders erwähnt, wurde zum Ansetzen und Verdünnen bidestilliertes Wasser aus der MilliQ-Anlage (MembraPure GmbH, Bodenheim) verwendet.

Blocking-Puffer

Blotting-Puffer

BSA/Azid-PBST-Lösung

CHAPS-Lysepuffer
5\% Milchpulver

in PBST

$6 \%(w / v)$ Tris Base

$3 \%(w / v)$ Glycin

$0,075 \%$ SDS

$20 \%$ (v/v) Methanol

$0,02 \%$ (w/v) Natriumazid

$2 \%(w / v) B S A$

in PBST

10 mM Hepes, pH 7,4

$150 \mathrm{mM} \mathrm{NaCl}$

$1 \%$ CHAPS $\left(\mathrm{C}_{32} \mathrm{H}_{58} \mathrm{~N}_{2} \mathrm{SO}_{7}\right)$ 
Citratpuffer, pH 6

Cresol-Lösung

Deoxyribonukleotidtriphosphat-Mix

(dNTPs)

Efflux-Puffer

1\%ige Eosin-Lösung

Hämalaunlösung nach Mayer

Lysepuffer
3,6\% (v/v) 0,1 M Zitronesäure

$16,4 \%$ (v/v) 0,1 M tri-Natriumcitrat

$0,1 \%(w / v)$ Cresol

in gesättigter Sukroselösung

$10 \mathrm{mM}$ dATP

$10 \mathrm{mM}$ dCTP

$10 \mathrm{mM}$ dGTP

$10 \mathrm{mM}$ dTTP

$30 \%$ BSA

$20 \%$ RPMI

$80 \% \mathrm{ddH}_{2} \mathrm{O}$

$1 \%(w / v)$ Eosin $Y$

$70 \%$ (v/v) Ethanol

$30 \%(\mathrm{v} / \mathrm{v}) \mathrm{ddH}_{2} \mathrm{O}$

$0,1 \%(w / v)$ Hämatoxylin

$5 \%(\mathrm{w} / \mathrm{v})$ Kaliumaluminiumsulfat

0,015\% (w/v) Natriumjodat

$5 \%(\mathrm{w} / \mathrm{v})$ Trichloracethaldehydhydrat

$1 \%(w / v)$ Zitronensäure

$30 \mathrm{mM}$ Tris $\mathrm{HCl}$

$150 \mathrm{mM} \mathrm{NaCl}$

$1 \%(v / v)$ Triton X-100

$10 \%(\mathrm{v} / \mathrm{v})$ Glycerol

Protease- und Phosphatase Inhibitoren je 1 Tablette auf $50 \mathrm{ml}$ Lysispuffer frisch hinzufügen $500 \mu \mathrm{M}$ PMSF 2 mM DTT

Methylcellulose-Tween-Lösung (MCT)

$0,5 \%$ Methylcellulose

$0,2 \%$ Tween-80

4\%ige Paraformaldehyd-Lösung (PFA)

4\% (w/v) Paraformaldehyd in PBS

$8 \%(\mathrm{w} / \mathrm{v}) \mathrm{NaCl}$

$0,2 \%(w / v) \mathrm{KH}_{2} \mathrm{PO}_{4}$ 
$0,2 \%(w / v) \mathrm{KCl}$

$1,77 \%(w / v) \mathrm{Na}_{2} \mathrm{HPO}_{4} \times 2 \mathrm{H}_{2} \mathrm{O}$

PBST (Waschpuffer)

$0,1 \%(v / v)$ Tween-20

in PBS

$1 \%$ ige Perjodsäure

$1 \%$ Perjodsäure

in $70 \%$ igem Ethanol

RIPA-Puffer (modifiziert)

$50 \mathrm{mM}$ Tris $\mathrm{HCl}, \mathrm{pH} 7,4$

$150 \mathrm{mM} \mathrm{NaCl}$

$1 \mathrm{mM}$ EDTA

$1 \%(\mathrm{v} / \mathrm{v}) \mathrm{NP}-40$

$0,25 \%$ (w/v) Na-Deoxycholat

Protease- und Phosphatase Inhibitoren je 1 Tablette auf $10 \mathrm{ml}$ Lysispuffer

6 x SDS Ladepuffer

\author{
$35 \%(v / v)$ Glycerol \\ $9 \%(w / v)$ SDS \\ 8,5\% (w/v) DTT \\ 0,1\% (w/v) Bromphenolblau \\ in Upper Gel Puffer
}

STE-Puffer

$50 \mathrm{mM}$ Tris $\mathrm{HCl}, \mathrm{pH} 8,0$

$100 \mathrm{mM} \mathrm{NaCl}$

1 mM EDTA

$1 \%(w / v)$ SDS

$10 \times$ Tris-Borsäure-EDTA Puffer (TBE),

$890 \mathrm{nM}$ Tris

$\mathrm{pH} 8,0$

730 nM Borsäure

12,5 mM EDTA

Upper Gel Puffer

$6 \%(\mathrm{w} / \mathrm{v})$ Tris Base, $\mathrm{pH} 6,8$

$4 \%(v / v)$ SDS

\title{
2.7 Medien und Gebrauchsmaterial für die Kultivierung eukaryotischer Zelllinien
}

Eukaryotische Zelllinien wurden in Dulbecco's Modified Eagle Medium (DMEM), Minimal Essential Medium (MEM) oder in RPMI mit 10\% fötalem Kälberserum und Antibiotika kultiviert. Die für die verschiedenen Zelllinien verwendeten Medien, sowie die Konzentrationen der Antibiotika und anderer Zusätze sind in Kapitel 3.1.1 angegeben. 
Accutase

Dulbecco's Modified Eagle Medium (DMEM)

Fötales Kälberserum (Fetal Calf Serum, FCS)

HEPES Puffer $1 \mathrm{M}$

Minimal Essential Medium (MEM)

Nonessential Amino Acids

Penicillin (10.000 U/ml)/Streptomycin $(10 \mathrm{mg} / \mathrm{ml})$

RPMI 1640

Sodium Pyruvate

Trypsin/EDTA
PAA Laboratories $\mathrm{GmbH}$, Pasching

Gibco, Invitrogen $\mathrm{GmbH}$, Karlsruhe

Gibco, Invitrogen $\mathrm{GmbH}$, Karlsruhe

Gibco, Invitrogen $\mathrm{GmbH}$, Karlsruhe

Gibco, Invitrogen $\mathrm{GmbH}$, Karlsruhe

Gibco, Invitrogen $\mathrm{GmbH}$, Karlsruhe

PAN Biotech $\mathrm{GmbH}$, Aidenbach

Gibco, Invitrogen $\mathrm{GmbH}$, Karlsruhe

Gibco, Invitrogen $\mathrm{GmbH}$, Karlsruhe

Gibco, Invitrogen $\mathrm{GmbH}$, Karlsruhe

\subsection{Biologisches Material}

\subsubsection{Eukaryotische Zelllinien}

Die verwendeten Zelllinien sind Tabelle 2 zu entnehmen.

Tabelle 2: Verwendete Zelllinien. Abkürzungen: ATCC, American Type Culture Collection

\begin{tabular}{l|l|l}
\hline Zelllinie & Beschreibung & Referenz \\
\hline A549 & $\begin{array}{l}\text { humane } \\
\text { Lungenadenokarzinomzellen }\end{array}$ & ATCC CCL-185; [145] \\
\hline Caco-2 & humane Adenokarzinomzellen & ATCC HTB-37; [146] \\
\hline HT1080 & humane Fibrosarkomzellen & ATCC CCL-121; [147] \\
\hline HTETOP & humane Fibrosarkomzellen & {$[148]$} \\
\hline RD & $\begin{array}{l}\text { humane } \\
\text { Rhabdomyosarkomzellen }\end{array}$ & ATCC CCL-136; [149] \\
\hline TP5014 & murine Rhabdomyosarkom- & $\begin{array}{l}\text { T. Pietsch, Universität Bonn, } \\
\text { zellen aus Ptch neo12/+ -Mäusen }\end{array}$ \\
\hline
\end{tabular}

\subsubsection{Verwendete Mauslinien}

Wildtypmäuse der Inzuchtstämme Balb/c und C57BL/6N wurden von Jackson Laboratories (Bar Harbor, USA) bzw. Charles River Laboratories (Sulzfeld, Deutschland) bezogen. Ptch ${ }^{\text {neo67// }}$-Mäuse wurden durch heterozygote Deletion der Exone 6 und 7 im Ptch-Gen erschaffen [151] und durch Verpaarung von heterozygoten Ptch-Mäusen auf C57BL6/N-Hintergrund und einem entsprechenden Wildtyp-Elternteil auf Balbc/c-Hintergrund gezüchtet. Nacktmäuse (NMRI-Foxn1 ${ }^{\text {nu }}$ ) wurden von Frauke Alves (Abteilung Hämatologie und Onkologie, Universitätsklinikum Göttingen) erworben.

\subsection{DNA-Oligonukleotide}

DNA-Oligonukleotide wurden von der Eurofins MWG Operon, Ebersberg bezogen und auf eine Stammkonzentration von $100 \mu \mathrm{M}$ mit $\mathrm{ddH}_{2} \mathrm{O}$ verdünnt. Für PCR-Methoden wurden $10 \mu \mathrm{M}$ 
Stocklösungen von DNA-Oligonukleotiden verwendet.

\subsubsection{DNA-Oligonukleotide zur Genotypisierung von Mäusen}

Die Genotypisierung von Mäusen ist in Kapitel 3.2.1.1 aufgeführt. Die Genotypisierungs-PCR (Polymerase Chain Reaktion) wurde unter Verwendung der in Tabelle 3 aufgeführten DNAOligonukleotidpaare durchgeführt.

Tabelle 3: DNA-Oligonukleotide zur Genotypisierung von Mäusen. Abkürzungen: wt Amplifikatlänge des Wildtyp-Allels, ${ }^{\text {neo67 }}$ Amplifikatlänge des neo67-Allels

\begin{tabular}{l|l|l|l}
\hline Primerbezeichnung & $\begin{array}{l}\text { Primersequenz } \\
\left(\mathbf{5}^{\prime} \rightarrow \mathbf{3}^{\prime}\right)\end{array}$ & $\begin{array}{l}\text { Amplifizierte } \\
\text { Fragmentgröße }\end{array}$ & Referenz \\
\hline neo-L & AGTGCCAGCGGGGCTGCTAAA & $634 \mathrm{bp}^{\text {wt }}$ & {$[151]$} \\
mPTC11R3 & CTGCCTGTTATGTGGTTCAAACCG & $400 \mathrm{bp}^{\text {neo67 }}$ & \\
Pst4KF & GGGAGGGGATTTCAGCAGAATGTT & & \\
\hline
\end{tabular}

\subsubsection{DNA-Oligonukleotide für die quantitative Real-Time PCR (qRT-PCR)}

Für den quantitativen Nachweis der Expression von verschiedenen Genen wurden die in Tabelle 4 aufgeführten DNA-Oligonukleotide verwendet. Die Analysen erfolgten durch Inkorporation von SYBRGreen in die Amplifikate.

Tabelle 4: Verwendete DNA-Oligonukleotide für die qRT-PCR. Abkürzungen: $h$, DNAOligonukleotide binden spezifisch an die humane Sequenz, m, DNA-Oligonukleotide binden spezifisch an die murine Sequenz

\begin{tabular}{l|l|l|l}
\hline Transkript & $\begin{array}{l}\text { Primerbezeichnung } \\
\text { (Vorwärts-, } \\
\text { Rückwärtsprimer) }\end{array}$ & Primersequenz $\left.\mathbf{( 5}^{\prime} \rightarrow \mathbf{3}^{\prime}\right)$ & Referenz \\
\hline 18S rRNA & $\begin{array}{l}18 S \text { fwd } \\
18 S \text { rev2 }\end{array}$ & $\begin{array}{l}\text { CGCAAATTACCCACTCCCG } \\
\text { TTCCAATTACAGGGCCTCGAA }\end{array}$ & F. Nitzki \\
\hline hABCB1 & hABCB1-F & $\begin{array}{l}\text { GTGGTGGGAACTTTGGCTG } \\
\text { TACCTGGTCATGTCTTCCTCC }\end{array}$ & M. Schirmer \\
& hABCB1-R & ATGTCACGTGGAATACCAGC & M. Schirmer \\
\hline hABCC1 & hABCC1-F & GAAGACTGAACTCCCTTCCT & \\
\hline hp21 & hABCC1-R & ACCTCACCTGCTCTGCTGC & diese Arbeit \\
& hp21-R & TTCCTCTTGGAGAAGATCAGCC & \\
\hline hTop2a & hTop2a_4F & GAGGGGATATGATTCGGATCCT & diese Arbeit \\
& hTop2a_4R & GGTTGGTCCAGAATCTGTTACG & \\
\hline
\end{tabular}




\subsection{Enzyme für molekularbiologische Untersuchungen}

Tabelle 5: Verwendete Enzyme

\begin{tabular}{l|l|l}
\hline Enzym & Anwendung & Hersteller \\
\hline $\begin{array}{l}\text { Mo/Taq-DNA- } \\
\text { Polymerase }\end{array}$ & PCR & $\begin{array}{l}\text { Molzym GmbH \& Co. KG, } \\
\text { Bremen }\end{array}$ \\
\hline Proteinase K & DNA-Isolierung & Carl Roth, Karlsruhe \\
\hline $\begin{array}{l}\text { Reverse Transkriptase } \\
\text { SuperScript II }\end{array}$ & cDNA-Synthese & Invitrogen GmbH, Karlsruhe \\
\hline
\end{tabular}

\subsection{Antikörper}

\subsubsection{Primäre Antikörper}

Die für die immunhistochemischen Methoden und Western Blot Analysen verwendeten primären Antikörper sind in Tabelle 6 zusammengefasst. Falls nicht anderweitig angegeben, sind die eingesetzten Verdünnungen der jeweiligen Methodenbeschreibung zu entnehmen.

Tabelle 6: Eingesetzte primäre Antikörper. Abkürzungen: Cytc, Cytochrom c-Assay; FACS, Fluorescence Activated Cell Sorting; IgG, Immunglobolin; IHC, Immunhistochemie; IP, Immunpräzipitation; WB, Western Blot.

\begin{tabular}{l|l|l|l|l}
\hline Antikörper & $\begin{array}{l}\text { Ursprungspezies } \\
\text { des Antikörpers }\end{array}$ & $\begin{array}{l}\text { Verwendung } \\
\text { des } \\
\text { Antikörpers }\end{array}$ & $\begin{array}{l}\text { Verwendete } \\
\text { Antikörper- } \\
\text { verdünnung }\end{array}$ & Hersteller \\
\hline Anti-ABCB1 & Maus, monoklonal & FACS & $1: 166$ & Sigma-Aldrich \\
\hline Anti-Akt & Maus, monoklonal & WB & $1: 1.000$ & $\begin{array}{l}\text { Becton Dickinson } \\
\text { GmbH }\end{array}$ \\
\hline $\begin{array}{l}\text { Anti-pAkt } \\
\text { (Ser473) }\end{array}$ & $\begin{array}{l}\text { Kaninchen, } \\
\text { monoklonal }\end{array}$ & WB & $1: 1.000$ & Cell Signaling \\
\hline Anti-Bax 6A7 & Maus, monoklonal & IP & $1: 400$ & Sigma-Aldrich \\
\hline Anti-BaxNT & $\begin{array}{l}\text { Kaninchen, } \\
\text { polyklonal }\end{array}$ & WB & $1: 5.000$ & $\begin{array}{l}\text { Upstate } \\
\text { Biotechnology Inc }\end{array}$ \\
\hline Anti-3-Aktin & Maus, monoklonal & WB & $1: 10.000$ & Sigma-Aldrich \\
\hline Anti-Caspase 3 & $\begin{array}{l}\text { Kaninchen, } \\
\text { polyklonal }\end{array}$ & WB & $1: 1.000$ & Cell Signaling \\
\hline $\begin{array}{l}\text { Anti-aktive } \\
\text { Caspase 3 }\end{array}$ & $\begin{array}{l}\text { Kaninchen, } \\
\text { polyklonal }\end{array}$ & IHC & $1: 500$ & R\&D Systems GmbH \\
\hline $\begin{array}{l}\text { Anti-Cytochrom } \\
\text { c (IgG2b) }\end{array}$ & Maus, monoklonal & FACS & $1: 40$ & Becton Dickinson \\
\hline $\begin{array}{l}\text { Anti-P- } \\
\text { Glycoprotein } \\
\text { (MDR1) [C219] }\end{array}$ & Maus, monoklonal & WB & $1: 50$ & \\
\hline
\end{tabular}




\begin{tabular}{|c|c|c|c|c|}
\hline $\begin{array}{l}\text { Anti-yH2AX } \\
\text { (Ser139) }\end{array}$ & Maus, monoklonal & WB & $1: 500-2.000$ & Abcam \\
\hline Anti-HSC70 & Maus, monoklonal & WB & $1: 10.000$ & Santa Cruz \\
\hline $\operatorname{lgG} 1$ & Maus, monoklonal & FACS (Cytc) & $1: 40$ & Southern Biotch \\
\hline $\lg \mathrm{g} 1 \mathrm{~K}$ & Maus, monoklonal & FACS (Cytc) & $1: 10$ & Sigma-Alrich \\
\hline $\lg G 2 b$ & Maus, monoklonal & FACS & $1: 333$ & Dako \\
\hline Anti-Ki67 & Maus, monoklonal & $\mathrm{IHC}$ & $1: 50$ & $\begin{array}{l}\text { Becton Dickinson } \\
\mathrm{GmbH}\end{array}$ \\
\hline Anti-MRP1 & Maus, monoklonal & WB & $1: 500$ & Abcam \\
\hline $\begin{array}{l}\text { Anti-MRP1 } \\
\text { (QCRL.4) }\end{array}$ & Maus, monoklonal & WB, FACS & $1: 500,1: 333$ & Sigma-Aldrich \\
\hline Anti-pS6 & $\begin{array}{l}\text { Kaninchen, } \\
\text { polyklonal }\end{array}$ & WB & $1: 1.000$ & Cell Signaling \\
\hline Anti-S6 & Maus, monoklonal & WB & $1: 1.000$ & Cell Signaling \\
\hline $\begin{array}{l}\text { Anti-DNA- } \\
\text { Topoisomerase } \\
\text { lla/ß }\end{array}$ & Maus, monoklonal & WB & $1: 2.000$ & Stressgene \\
\hline Anti- $\alpha-T u b u l i n$ & Maus, monoklonal & WB & $1: 10.000$ & Dianova \\
\hline
\end{tabular}

\subsubsection{Sekundäre Antikörper}

Tabelle 7: Verwendete sekundäre Antikörper. Abkürzungen: FACS, Fluorescence Activated Cell Sorting; IHC, Immunhistochemie; WB, Western Blot.

\begin{tabular}{l|l|l|l}
\hline Antikörper & Ursprung & Verwendung & Hersteller \\
\cline { 1 - 3 } $\begin{array}{l}\text { Anti-Kaninchen IgG, HRP- } \\
\text { konjugiert }\end{array}$ & Ziege & WB & Sigma-Aldrich \\
\hline $\begin{array}{l}\text { Anti-Maus IgG, DyLight } \\
\text { konjugiert AffiniPure F }\left(\mathrm{ab}^{\mathrm{T}}\right)_{2}\end{array}$ & Ziege & FACS & Dianaova \\
\hline Anti-Maus IgG2b-FITC & Ziege & FACS & Southern Biotech \\
\hline Anti-Maus IgG, HRP-konjugiert & Schaf & WB & GE Healthcare \\
\hline Dako Envision HRP & Kaninchen & IHC & Dako \\
\hline
\end{tabular}

\subsection{Software}

ABI 3100 genetic analyzer data collection 1.0

BD FACSDiva

CellF

Exel 2000

EndNote

FlowJo

Intas GDC
Applied Biosystems, Darmstadt

Becton Dickinson $\mathrm{GmbH}$, Heidelberg

Olympus Europa Holding $\mathrm{GmbH}$, Hamburg

Microsoft Co., Redmont, USA

Thomson Reuters, New York, USA

Tree Star Inc., Ashland, USA

Intas, Göttingen 
Photoshop 7.0

Powerpoint 2000

SDS 2.1

Statistica 9

Volume Viewer Plus (Voxtool 5.5.4)

Word 2000

\subsection{Datenbanken}

MGI Mouse Genome Informatics

National Center for Biotechnology Information (NCBI)

Ensembl
Adobe Systems Incorporated, San Jose, USA

Microsoft Co., Redmont, USA

Applied Biosystems, Darmstadt

StatSoft GmbH, Hamburg

GE Healthcare, Chalfont St Giles, UK

Microsoft Co., Redmont, USA

http://www.informatics.jax.org/

http://www.ncbi.nlm.nih.gov/

http://www.ensembl.org/index.html 


\section{Methoden}

\subsection{Zellbiologische Methoden}

\subsubsection{Kultivierung von Zellen}

Die Kultivierung der Zellen erfolgte bei $37^{\circ} \mathrm{C}, 5 \%$ Kohlendioxid und $95 \%$ Luftfeuchtigkeit in einem Inkubator. Medienwechsel erfolgten alle 3 bis 4 Tage und bei Erreichen einer Konfluenz von etwa $80 \%$ wurden die Zellen passagiert. In Tabelle 8 sind die verwendeten Zelllinien sowie die entsprechenden Kultivierungsmedien angegeben.

Tabelle 8: Kultivierungsmedien der verwendeten Zelllinien und Primärkulturen.

\begin{tabular}{|c|c|c|}
\hline Zellenlinie & Medium & Zusätze \\
\hline A549 & RPMI-1640 & $\begin{array}{l}10 \% \text { FCS } \\
1 \% \text { Penicillin/Streptomycin }\end{array}$ \\
\hline Caco-2 & MEM & $\begin{array}{l}20 \% \text { FCS } \\
1 \% \text { Penicillin/Streptomycin }\end{array}$ \\
\hline HT1080 & DMEM & $\begin{array}{l}10 \% \text { FCS } \\
0,5 \% \text { Penicillin/Streptomycin } \\
20 \mathrm{mmol} / \mathrm{L} \text { HEPES } \\
10 \mathrm{mmol} / \mathrm{L} \text { Sodium Pyruvate } \\
4 \%(\mathrm{v} / \mathrm{v}) \quad \text { Nonessential Amino } \\
\text { Acids }\end{array}$ \\
\hline HTETOP & DMEM & $\begin{array}{l}10 \% \text { FCS } \\
0,5 \% \text { Penicillin/Streptomycin } \\
20 \mathrm{mmol} / \mathrm{L} \text { HEPES } \\
10 \mathrm{mmol} / \mathrm{L} \text { Sodium Pyruvate } \\
4 \%(\mathrm{v} / \mathrm{v}) \quad \text { Nonessential Amino } \\
\text { Acids }\end{array}$ \\
\hline RD & DMEM & $\begin{array}{l}10 \% \text { FCS } \\
1 \% \text { Penicillin/Streptomycin }\end{array}$ \\
\hline TP5014 & DMEM & $\begin{array}{l}10 \% \text { FCS } \\
1 \% \text { Penicillin/Streptomycin }\end{array}$ \\
\hline
\end{tabular}

\subsubsection{Kryokonservierung von Zelllinien}

Für die Langzeitkonservierung wurden 80 - 90\% konfluent gewachsene Zellen einer $10 \mathrm{~cm}$ Zellkulturschale verwendet. Nach Abnahme des Medium wurden die Zellen mit 1 x PBS gewaschen und mit $2 \mathrm{ml}$ Trypsin abgelöst. Der Ablösevorgang wurde mit gleichem Volumen FCS-haltigem Medium gestoppt und die Zellen bei $300 \mathrm{~g}$ für 5 Minuten zentrifugiert. Nach Resuspension der Zellen in $10 \mathrm{ml}$ Kulturmedium mit 10\% DMSO wurde jeweils $1 \mathrm{ml}$ der Suspension in Kryoröhrchen aliquotiert. Die 
Kryoröhrchen wurden bei $-20^{\circ} \mathrm{C}$ für 2 Stunden eingefroren und danach über Nacht bei $-80^{\circ} \mathrm{C}$ gelagert. Zur Dauerlagerung wurden die Zellen in flüssigen Stickstoff überführt.

\subsubsection{Proliferationsassay}

Zur Analyse des Proliferationsverhaltens von Zellen wurde der BrdU Chemilumineszenz ELISA verwendet. Bei diesem Assay wird während der Replikation das Pyrimidinanalogon Bromdeoxyuridin (BrdU) an Stelle von Thymidin in die DNA eingebaut. Somit ist die Menge an gebundenem BrdU proportional zur Proliferationsrate.

Zur Durchführung des Assays wurden 4.000 - 5.000 Zellen/well in eine 96-well-Platte ausgesät und mit den entsprechenden Medikamenten behandelt. 24 Stunden vor Abschluss der Inkubation wurde dem Medium $10 \mu \mathrm{M}$ BrdU (10 mM Stocklösung 1:100 in PBS verdünnt) zugesetzt. Danach wurde das Medium abgenommen und die Zellen wurden für 30 Minuten mit $200 \mu$ Fixierungspuffer, der sowohl die Zellen fixiert als auch die DNA denaturiert, inkubiert. Der mit der Peroxidase (POD) gekoppelte anti-BrdU-Antikörper wurde 1:100 im zugehörigen Puffer verdünnt und für 1 Stunde auf die Zellen gegeben. Nach 3maligem Waschen für je 5 Minuten erfolgte die Zugabe des Substrats für die Peroxidasereaktion. Dafür wurde $100 \mu \mathrm{l}$ des Substrats in jedes well gegeben. Nach einer Reaktionszeit von 100 Sekunden wurde die Lumineszenz für 20 Sekunden am Luminometer gemessen. Die gemessene relative Lichteinheit (RLU) des Lösungsmittels wurde auf $100 \%$ gesetzt, und die Proben wurden darauf normalisiert.

\subsubsection{Caspase 3/7 Aktivitätsmessung}

Die Analyse der Caspase 3/7 Aktivität erfolgte im 96-Loch-Format mit Hilfe des Caspase-Glo 3/7 Assays. Dabei wurde ein Caspase 3/7-Substrat, welches die DEVD-Sequenz enthält, die durch Caspasen erkannt und gespalten wird, zu den Zellen gegeben.

Zur Durchführung des Assays wurden 5.000 Zellen/well in einer 96-well-Platte ausgesät und für 24 Stunden mit den entsprechenden Medikamenten oder dem Lösungsmittel behandelt. Drei Stunden vor Abschluss der Inkubation wurde das Caspase 3/7 Substrat im Verhältnis 1:1 zum Kulturmedium hinzugefügt und mit dem Kulturmedium vermischt. Als Positivkontrolle für die Apoptoseinduktion diente Staurosporin in einer Konzentration von 500 nM. Ansätze ohne Caspase 3/7-Substrat dienten zur Messung von unspezifischer Hintergundlumineszenz. Alle Proben wurden in Triplikaten vermessen. Die gemessene relative Lichteinheit (RLU) des Lösungsmittels wurde auf 1 gesetzt und die Proben darauf normalisiert.

\subsubsection{Durchflusszytometrische Analysen (FACS)}

Bei der Durchflusszytometrie (Fluorescence Activated Cell Sorting, FACS) handelt sich um ein optisches Messsystem in dem vereinzelte Zellen mittels Streulicht- und Fluoreszenzsignale in einem Flüssigkeitsstrom analysiert werden können. 


\subsubsection{Annexin V-Assay}

Apoptosevorgänge in Zellen wurden mittels Annexin V-FITC bestimmt. Annexin V ist ein Protein, welches kalziumabhänging an Phosphatidylserinreste bindet. Durch Einleitung der Apoptose findet eine Translokation von Phosphatidylserin, welches sich in nicht apoptotischen Zellen an der zytoplasmatischen Seite der Membran befindet, an die extrazelluläre Seite der Membran statt. Dies ermöglicht die Annexin V-Bindung. Zur Abgrenzung von nekrotischen Zellen erfolgte eine zusätzliche Färbung mit To-Pro-3 iodid. Dieser Farbstoff wird auf Grund der permeablen Zellmembran von nekrotischen Zellen aufgenommen und in die DNA interkaliert. Das Emissionsmaximum von To-Pro-3 iodid kann bei einer Wellenlänge von $661 \mathrm{~nm}$ gemessen werden. To-Pro-3 iodid eignet sich daher für die Messungen von mit Doxorubizin-behandelten Zellen besser als das herkömmliche Propidiumiodid, das ein Emissionsmaximum bei $617 \mathrm{~nm}$ aufweist. Doxorubizin hat nämlich eine Eigenfluoreszenz, dessen Emissionsmaximum bei $585 \mathrm{~nm}$ liegt. Somit würde die Eigenfluoreszenz von Doxorubizin stark mit derjenigen von Propidiumiodid überlappen. Aus diesem Grund wurde To-Pro-3 iodid bei allen Analysen eingesetzt.

Nach Behandlung mit den jeweiligen Medikamenten wurden die Zellen mit Hilfe von $1 \mathrm{ml}$ Accutase aus der 6-well-Platte abgelöst. Nach einem Waschschritt mit 1 x PBS inkubierten die Zellen in $100 \mu \mathrm{l}$ $1 \times$ Annexin V-Binding Buffer mit je $2 \mu \mathrm{l}$ Annexin V-FITC für 10 Minuten. Anschließend folgte die Inkubation mit $10 \mathrm{nM}$ To-Pro-3 iodid für 5 Minuten bevor $300 \mu$ l Annexin V-Binding Buffer zu den Zellen gegeben wurde, und die Messung am FACS (BD FACSCalibur) erfolgte. Pro Experiment erfolgte die Analyse der Proben in Duplikaten. Die Inkubation der Zellen mit den Farbstoffen erfolgte bei Dunkelheit und bei Raumtemperatur. Analysiert wurden die Proben am FACS in Kanal FL-1 (Annexin V-FITC) und Kanal FL-4 (To-Pro-3 iodid). Die Auswertung erfolgte mit Hilfe der Software FlowJo.

\subsubsection{Analyse der Cytochrom c Freisetzung}

Die Abgabe von Cytochrom c aus den Mitochondrien in das Zytoplasma ist ein wichtiger Schritt in der Apoptoseinduktion über den mitochondrialen Apoptosesignalweg. Für die Analyse der Cytochrom c Freisetzung wurden die Zellen bei $1.800 \mathrm{rpm}$ und $4^{\circ} \mathrm{C}$ für 5 Minuten zentrifugiert und anschließend in 4\%iger PFA-Lösung für 20 Minuten bei $4^{\circ} \mathrm{C}$ fixiert. Nachfolgend wurden die Zellen mit $1 \%$ FCS in PBS gewaschen und mit 0,2\% Saponin in PBS permeabilisiert. Um unspezifische Bindungen zu blockieren wurden $5 \mu \mathrm{lgG} 1 \mathrm{~K}$ zugesetzt. Die Inkubation erfolgte für 5 Minuten bei Raumtemperatur. Schließlich wurden die Zellen mit einer 1:40 Verdünnung des Cytochrom c Antikörpers bzw. zur Detektion unspezifischer Bindungen des sekundären Antikörpers mit der Isotypkontrolle (mlgG2b) für 20 Minuten bei $4^{\circ} \mathrm{C}$ versetzt. Bevor der zweite Antikörper (1:40, IgG2b-FITC, Southern Biotech) für 20 Minuten bei $4^{\circ} \mathrm{C}$ zu den Zellen pipettiert wurde, wurden sie mit $1 \%$ iger FCS-Lösung in PBS gewaschen. Nach einem weiterem Waschschritt wurden die Zellen schließlich in 4\%iger PFA-Lösung resuspendiert und mit Hilfe des FACS (BD FACSCalibur) im FL-1 Kanal analysiert. Die Auswertung erfolgte mit Hilfe der Software FlowJo. 


\subsubsection{Messung der intrazellulären Akkumulation von Doxorubizin}

Aufgrund der Eigenfluoreszenz von Doxorubizin, die bei einer Wellenlänge von $585 \mathrm{~nm}$ detektiert werden kann, wurde die intrazelluläre Akkumulation des Medikaments alleine als auch in Kombination mit PI103 analysiert.

Für diese Analyse wurden 100.000 Zellen/well in eine 6-well-Platte gesät. Nach Abschluss der Inkubation mit den Medikamenten wurden die Zellen mit 1 x PBS gewaschen und anschließend mit $1 \mathrm{ml} /$ well Accutase abgelöst. Nach einem Waschschritt mit 1 x PBS ( $300 \mathrm{~g}, 4^{\circ} \mathrm{C}, 5$ Minuten) erfolgte die Resuspension der Zellen in 1 x Annexin V-Binding Buffer. Die Zellsuspensionen wurden bei Dunkelheit und auf Eis gehalten, bis die Messung am FACS (BD FACSCalibur) im Kanal FL-1 erfolgte. Die Auswertung wurde mit dem Programm FlowJo durchgeführt.

\subsubsection{Analyse der MDR1 und der MRP1 Expression}

Für die Analyse wurden $1 \times 10^{6}$ Zellen/10 cm Zellkulturschale ausgesät. Die Behandlung der Zellen erfolgte anschließend für 24 Stunden, bevor diese mit $1 \times$ PBS gewaschen und durch Inkubation mit $2 \mathrm{ml}$ Accutase aus dem Kulturgefäß gelöst wurden. Anschließend wurden die Zellen mit $2 \mathrm{ml} 1 \mathrm{x}$ PBS versetzt und bei $300 \mathrm{~g}$ und $4^{\circ} \mathrm{C}$ für 5 Minuten zentrifugiert. Jede Probe wurde nachfolgend auf 3 1,5 ml-Reaktionsgefäße verteilt (A, B und C). Es folgte erst die Pelletierung der Zellen bei $2.000 \mathrm{rpm}$ und $4^{\circ} \mathrm{C}$ für 5 Minuten, bevor sich die Fixierung der Zellen in $50 \mu$ leiner 0,5\%igen PFA-Lösung für 30 Minuten bei Raumtemperatur anschloss. Schließlich wurden die Zellen mit $300 \mu 1$ 1\%iger BSALösung (in PBS) bei $2.000 \mathrm{rpm}$ und $4^{\circ} \mathrm{C}$ für 5 Minuten zentrifugiert. Die Blockierung der unspezifischen Bindungen erfolgte durch Resuspension der Zellen in $50 \mu$ einer 100 mM Glycin-Lösung und Inkubation für 15 Minuten bei Raumtemperatur. Nach Zugabe von $300 \mu$ leiner 1\%igen BSALösung folgte die Pelletierung der Zellen bei $2.000 \mathrm{rpm}$ und $4^{\circ} \mathrm{C}$ für 5 Minuten. Nachfolgend wurden die Zellpellets in $50 \mu \mathrm{l}$ einer 1\%igen BSA-Lösung resuspendiert und für 15 Minuten bei Raumtemperatur inkubiert. Nach einem weiteren Zentrifugationsschritt wurden die Zellpellets von Reaktionsgefäß A in PBS (ungefärbte Kontrolle), von B mit der Isotypenkontrolle (mlgG1, $1 \mathrm{mg} / \mathrm{ml}$ in PBS) und von $C$ mit dem MDR1-Antikörper (Verdünnung: 1:166 in PBS) bzw. dem MRP1-Antikörper (Verdünnung: 1:333 in PBS) versetzt, und für 45 Minuten auf Eis gehalten. Anschließend wurden die Zellen mit $300 \mu \mathrm{l}$ einer 1\%igen BSA-Lösung und 0,1\% Triton X-100 gewaschen und mit dem sekundären Antikörper (Verdünnung 1:2.000 in 1\%iger BSA-Lösung, außer A) für 10 Minuten auf Eis inkubiert. Nach einem letzten Waschschritt folgte die Aufnahme der Zellen in $250 \mu$ leiner 0,5\%igen PFA-Lösung. Bis zur Messung am Durchflusszytometer LSRII (Becton Dickinson $\mathrm{GmbH}$ ) wurden die Zellen auf Eis gehalten. Die Auswertung der Analyse erfolgte mit Hilfe der Software FACS Diva.

\subsubsection{Analyse des MDR1-abhängigen Transports}

Die Untersuchung des MDR1-abhängigen Transports wurde mit Hilfe des Multidrug Resistance Direct Dye Efflux Assays durchgeführt. Für die Etablierung dieses Assays wurden $10 \mathrm{~cm}$-Zellkulturschalen mit etwa 70\% konfluent gewachsenen Caco-2 Zellen, die endogen P-Glycoprotein (ABCB1, MDR1) exprimieren [152] genutzt. Die Zellen wurden zunächst mit 1 x PBS gewaschen und mit $2 \mathrm{ml}$ Accutase 
aus den Kulturgefäßen gelöst. Danach wurden sie mit $2 \mathrm{ml} 1 \times$ PBS versetzt und bei $300 \mathrm{~g}$ und $4^{\circ} \mathrm{C}$ für 5 Minuten zentrifugiert. Anschließend erfolgte die Resuspension der Zellen in $10 \mathrm{ng} / \mathrm{ml}$ Rhodamin 123 in kaltem Efflux-Puffer und eine Inkubation für 30 Minuten auf Eis. Danach wurden die Zellen bei $300 \mathrm{~g}$ und $4^{\circ} \mathrm{C}$ für 5 Minuten zentrifugiert und nachfolgend in kaltem Efflux-Puffer resuspendiert. Nach erneuter Zentrifugation wurde das Zellpellet in kaltem Efflux-Puffer aufgenommen und in 3 Reaktionsgefäße A-C überführt. Nach einer weiteren Pelletierung der Zellen wurden die Zellen von A in warmem Efflux-Puffer mit DMSO (Kontrolle für Vinblastin), von B in warmem EffluxPuffer mit $22 \mu \mathrm{M}$ Vinblastin und von $C$ in kaltem Efflux-Puffer aufgenommen. Um die Aktivität des MDR1 zu analysieren, inkubierten die Zellen in Reaktionsgefäß $A$ und $B$ für 2 Stunden bei $37^{\circ} \mathrm{C}$ im Schüttelwasserbad, wobei die Zellen im Reaktionsgefäß $C$ als Kontrolle auf Eis gehalten wurden. Danach erfolgte eine Zentrifugation bei $300 \mathrm{~g}$ und $4^{\circ} \mathrm{C}$ für 5 Minuten und ein weiterer Waschschritt, bevor die Zellen im Durchflusszytometer LSRII (Becton Dickinson $\mathrm{GmbH}$ ) gemessen wurden. Für die Auswertung der Daten wurde das Programm FACS Diva verwendet.

\subsection{Molekularbiologische Methoden}

\subsubsection{Isolierung von Nukleinsäuren}

\subsubsection{DNA-Isolierung aus murinen Geweben zur Bestimmung des Genotyps}

Schwanzbiopsien wurden in einem $1,5 \mathrm{ml}$-Reaktionsgefäß mit $400 \mu \mathrm{l}$ STE-Puffer und $20 \mu \mathrm{l}$ Proteinase K (10 mg/ml Stocklösung) versetzt und über Nacht bei $55^{\circ} \mathrm{C}$ verdaut. Unverdautes Gewebe wurde durch Zentrifugation bei 13.000 rpm für 10 Minuten sedimentiert und der Überstand in ein neues $1,5 \mathrm{ml}$-Reaktionsgefäß überführt. Die Fällung der DNA fand durch Zugabe von $1 \mathrm{ml}$ 99\% Ethanol, anschließendes Schütteln und einem Zentrifugationsschritt bei $13.000 \mathrm{rpm}$ für 25 Minuten bei $4^{\circ} \mathrm{C}$ statt. Nach einem Wasch-schritt mit $70 \%$ Ethanol wurde das Pellet bei

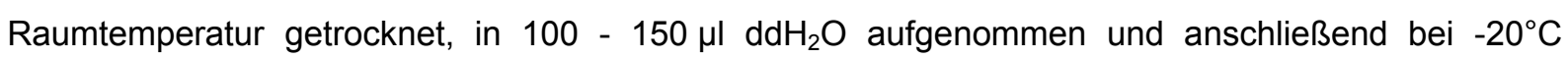
gelagert.

\subsubsection{RNA-Isolierung aus Zellen mit Trizol}

Für die Isolierung der RNA wurden die Zellen mit PBS gewaschen, anschließend in $1 \mathrm{ml}$ Trizol (pro well einer 6-Loch-Platte) aufgenommen und in ein 2 ml-Reaktionsgefäß auf Eis überführt. Für die vollständige Lyse der Zellen wurde die Suspension zunächst für 2 Minuten auf höchster Stufe auf dem Vortexer gerüttelt und anschließend bei Raumtemperatur für 5 Minuten inkubiert. Nach Zugabe von $200 \mu \mathrm{l}$ Chloroform pro $1 \mathrm{ml}$ Trizol wurden die Zellen weitere 15 Sekunden gerüttelt. Nach einer weiteren Inkubation für 3 Minuten bei Raumtemperatur wurde die Lösung zur Phasentrennung bei $10.000 \mathrm{rpm}$ bei $4^{\circ} \mathrm{C}$ für 10 Minuten zentrifugiert. Anschließend wurde die obere wässrige Phase, in der sich die RNA befindet, in ein neues 2 ml-Reaktionsgefäß überführt und mit $500 \mu \mathrm{l}$ Isopropanol versetzt. Nach mehrmaligem Invertieren wurde die RNA bei $-20^{\circ} \mathrm{C}$ über Nacht gefällt und durch Zentrifugation bei $12.000 \mathrm{rpm}$ für 20 Minuten und $4^{\circ} \mathrm{C}$ pelletiert. Es folgten 2 Waschschritte mit je $500 \mu \mathrm{l} 70 \%$ Ethanol bevor die RNA bei Raumtemperatur getrocknet und anschließend bei $56^{\circ} \mathrm{C}$ in 
$20 \mu \mathrm{l}$ RNAse freiem $\mathrm{ddH}_{2} \mathrm{O}$ für $5-10$ Minuten gelöst wurde. Die Lagerung der RNA erfolgte bei $-80^{\circ} \mathrm{C}$.

\subsubsection{Photometrische Konzentrationsbestimmung von Nukleinsäuren}

Nukleinsäuren können durch Messung der Extinktion bei $260 \mathrm{~nm}$ gegenüber einem Leerwert (üblicherweise $\mathrm{ddH}_{2} \mathrm{O}$ ) im Photometer bestimmt werden. Für die Messung wurde die RNA 1:50 und die DNA 1:100 in dd $_{2} \mathrm{O}$ verdünnt. Verunreinigungen durch Schwebstoffe werden durch die Extinktion bei $320 \mathrm{~nm}$ angegeben und sollten einen Wert gegen Null anzeigen. Die Verunreinigung mit Proteinen wird durch die Extinktion bei $280 \mathrm{~nm}$ detektiert, und der Gehalt an organischen Substanzen in der Probe wird durch die Extinktion bei $230 \mathrm{~nm}$ bestimmt. Unter Berücksichtigung des Verdünnungsfaktors und des nukleinsäurespezifischen Koeffizienten $C(0,05 \mu \mathrm{g} / \mu \mathrm{l}$ für doppelsträngige DNA, $0,04 \mu \mathrm{g} / \mu \mathrm{l}$ für RNA) kann die Nukleinsäurekonzentration $(\mu \mathrm{g} / \mu \mathrm{l})$ mit der Formel

$$
c=O D_{260} \times f \times C
$$

bei der $\mathrm{c}=$ gemessene Konzentration in $\mu \mathrm{g} / \mu \mathrm{l}, \mathrm{OD}_{260}=$ optische Dichte bei $260 \mathrm{~nm}, \mathrm{f}=$ Verdünnungsfaktor, $\mathrm{C}=$ nukleinsäurespezifischer Koeffizient

vermessen werden. Der Quotient der Extinktionen bei $260 \mathrm{~nm}$ und $280 \mathrm{~nm}$ sollte idealerweise bei in Wasser gelöster DNA zwischen 1,6 und 1,8 und bei in Wasser gelöster RNA zwischen 1,9 und 2,1 liegen. Das Verhältnis der Extinktionen bei $260 \mathrm{~nm}$ und $230 \mathrm{~nm}$ sollte nicht größer als 1,7 sein.

\subsubsection{Polymerase Kettenreaktion (polymerase chain reaktion, PCR)}

Die Amplifikation doppelsträngiger DNA-Moleküle erfolgte mittels PCR im $10 \mu$ oder $20 \mu$ l Ansatz. Die Bedingungen der PCR variierten abhängig von den verwendeten DNA-Oligonukleotiden. Der erste Schritt war die Denaturierung der DNA für $5-10$ Minuten bei $95^{\circ} \mathrm{C}$. Anschließend folgten $25-35$ Zyklen, die je aus einem Denaturierungsschritt $\left(95^{\circ} \mathrm{C}\right.$ für 30 - 60 Sekunden), einem OligonukleotidAnlagerungsschritt bei $55-65^{\circ} \mathrm{C}$ für 30 Sekunden - 2 Minuten und einem Elongationsschritt bei $72^{\circ} \mathrm{C}$ je nach Amplifikatgröße für 1 - 2 Minuten bestanden. Die PCR wurde mit einem Elongationsschritt bei $72^{\circ} \mathrm{C}$ für 10 Minuten beendet. Die Proben wurden auf 1,5 - 2\% igen Agarosegelen in TBE Puffer analysiert.

Ein typischer PCR-Ansatz enthielt folgende Komponenten:

$\begin{array}{ll}10-100 \mathrm{ng} & \text { Matritzen-DNA } \\ 0,5 \mu \mathrm{M} & \text { sequenzspezifisches Vorwärts-DNA-Oligonukleotid } \\ 0,5 \mu \mathrm{M} & \text { sequenzspezifisches Rückwärts-DNA-Oligonukleotid } \\ 0,2 \mathrm{mM} & \text { dNTP-Mix } \\ 1 \%(\mathrm{v} / \mathrm{v}) & \text { Cresollösung } \\ 1 \mathrm{x} & \text { Polymerase-Puffer } \\ 0,1 \mathrm{U} & \text { Polymerase }\end{array}$




\subsubsection{Reverse Transkription (RT)}

Für das Umschreiben der RNA in cDNA wurden $2 \mu \mathrm{g}$ RNA mit RNAse freiem dd $\mathrm{H}_{2} \mathrm{O}$ auf $7 \mu \mathrm{l}$ aufgefüllt und mit $5 \mu \mathrm{l}$ Hexameren $(50 \mathrm{ng} / \mu \mathrm{l})$ versetzt. Um die DNA zu denaturieren und die Anlagerung der Hexamere zu gewährleisten folgte eine Inkubation bei $70^{\circ} \mathrm{C}$ für 10 Minuten. Anschließend wurden $4 \mu \mathrm{l}$ $5 x$ 1st Strand Puffer, $2 \mu \mathrm{LTT}(0,1 \mathrm{M})$ und $1 \mu \mathrm{l}$ dNTPs $(10 \mathrm{mM})$ zu dem Ansatz pipettiert und für 10 Minuten bei Raumtemperatur inkubiert. Um optimale Temperaturbedingungen für die Reverse Transkriptase (SuperScript II, $40 \mathrm{U} / \mu \mathrm{l}$ ) zu schaffen, wurde der Ansatz zunächst 2 Minuten auf $42^{\circ} \mathrm{C}$ vorgewärmt, bevor die Zugabe von $1 \mu \mathrm{l}$ des Enzyms erfolgte. Die cDNA-Synthese fand für 60 Minuten bei $42^{\circ} \mathrm{C}$ statt und wurde durch Inaktivierung der Enzymaktivität bei $70^{\circ} \mathrm{C}$ für 10 Minuten gestoppt. Die cDNA wurde anschließend bei $-20^{\circ} \mathrm{C}$ gelagert.

Zur Kalkulation der cDNA-Konzentration wurde die Annahme zugrunde gelegt, dass die Effizienz der cDNA-Synthese $50 \%$ beträgt. Folglich wird bei der reversen Transkription von $2 \mu \mathrm{g}$ RNA eine Menge von $1 \mu \mathrm{g}$ cDNA synthetisiert. Bei einem Reaktionsvolumen von $20 \mu \mathrm{l}$ ergibt dies eine Endkonzentration von $50 \mathrm{ng} / \mu \mathrm{l} \mathrm{cDNA}$.

\subsubsection{Quantitative Real Time-PCR (qRT-PCR)}

Die Quantifizierung der Genexpressionslevels erfolgte an cDNA mit Hilfe des Fluoreszenzfarbstoffs SYBR-Green. Bei dieser Methode wird das Fluoreszenzsignal des in die DNA interkalierenden SYBRGreens gemessen, wobei sich das Fluoreszenzsignal proportional zu der gebildeten Amplifikatmenge verhält. Um die Primerspezifität zu überprüfen, wurden Dissoziationskurven erstellt. Dabei wurde nach erfolgter Produktamplifikation die Temperatur schrittweise auf $95^{\circ} \mathrm{C}$ erhöht und die Fluoreszenzintensität analysiert. Bei diesem Prozess denaturieren die PCR-Produkte entsprechend ihrer Größe, woraus eine Abnahme der Fluoreszenzintensität resultiert.

Zur Analyse der Probe gehörte ebenfalls die Quantifizierung der Expression eines endogenen Kontrollgens (18S rRNA). Hierdurch konnte das Expressionslevel der Zielgene normalisiert werden. Anhand von seriellen 5 fach-Verdünnungsreihen wurden zunächst die Standardkurven für jeden Assay erstellt (Tabelle 9).

Der für die Analysen verwendete SYBR-Green qPCR SuperMix-UDG (Invitrogen) und der QuantiTect SYBR-Green RT-PCR-Mix (Qiagen) bestehen hautsächlich aus folgenden Inhaltsstoffen: TaqDNA Polymerase, SYBR-Green I dye, KCL, dGTP, dATP, dCTP, dUTP, und ROX-Referenz Dye.

Die Analyse der Genexpressionsniveaus erfolgte in 384-well-Format. Dafür wurden $8 \mu \mathrm{l}$ des qRTPCR-Mix pro well vorgelegt, und anschließend $2 \mu \mathrm{l}$ cDNA hinzu pipettiert. Die Proben wurden pro Lauf in Triplikaten vermessen. 
Ein qRT-PCR Ansatz enthielt folgende Komponenten:

$\begin{array}{ll}4,0 \mu \mathrm{l} & \text { SYBR-Green-Mix } \\ 4,1 \mu \mathrm{l} & \mathrm{ddH_{2 } \mathrm { O }} \\ 0,45 \mu \mathrm{l} & \text { Vorwärts-DNA-Oligonukleotid }(10 \mu \mathrm{M}) \\ 0,45 \mu \mathrm{l} & \text { Rückwärts-DNA-Oligonukleotid }(10 \mu \mathrm{M}) \\ 2 \mu \mathrm{l} & \text { cDNA }\end{array}$

Das Programm für die qRT-PCR war abhängig von dem bezogenen SYBR-Green und schloss folgende Schritte ein:

qRT-PCR mit SYBR-Green von Qiagen

\begin{tabular}{|c|c|c|c|c|c|}
\hline $2 \min$ & $50^{\circ} \mathrm{C}$ & & $2 \min$ & $50^{\circ} \mathrm{C}$ & \\
\hline $15 \mathrm{~min}$ & $95^{\circ} \mathrm{C}$ & & $2 \min$ & $95^{\circ} \mathrm{C}$ & \\
\hline 15 sek & $95^{\circ} \mathrm{C}$ & 40 Zyklen & 15 sek & $95^{\circ} \mathrm{C}$ & 40 Zyklen \\
\hline 30 sek & $60^{\circ} \mathrm{C}$ & & $1 \mathrm{~min}$ & $60^{\circ} \mathrm{C}$ & \\
\hline
\end{tabular}

qRT-PCR mit SYBR-Green von Invitrogen

$72^{\circ} \mathrm{C}$

Tabelle 9: Herkunft der cDNA zur Erstellung von Standardkurven für die qRT-PCR. Abkürzungen: $h$, human, $m$, murin, $d$, Tag (day).

\begin{tabular}{l|l|l}
\hline Gentranskript & $\begin{array}{l}\text { Matritze für S1 } \\
\text { Verdünnungsstufe }\end{array}$ & $\begin{array}{l}\text { Eingesetzte Menge für die erste } \\
\text { Verdünnung (S1, in cDNA/ } \boldsymbol{\mu l})\end{array}$ \\
\hline 18S rRNA & Mausembryo d12,5 & $25 \mathrm{pg}$ \\
\hline hABCB1 & Hek293 & $50 \mathrm{ng}$ \\
\hline hABCC1 & PC-3 & $50 \mathrm{ng}$ \\
\hline hp21 & Mausembryo d12,5 & $50 \mathrm{ng}$ \\
\hline hTop2a & PC-3 & $25 \mathrm{ng}$ \\
\hline
\end{tabular}

Die Auswertung der qRT-PCR-Daten erfolgte mittels SDS 2.1 Software von Applied Biosystems, sowie mit Exel 2000 von Microsoft. Um die Effizienz der qRT-PCR-Reaktion zu analysieren wurden Standardkurven aus seriellen 5fach-Verdünnungen erstellt. Dabei verschob sich der Schwellenwert der Verdünnungen bei dem sich das Fluoreszenzsignal von dem Reaktionshintergrund abhebt um jeweils 2,3 Zyklen. Der Schnittpunkt der Amplifikationskurve gegen den Schwellenwert ist der Ct-Wert. Dieser wurde gegen den Logarithmus der jeweils eingesetzten cDNA-Menge aufgetragen, um eine Standartkurve zu erhalten. Dabei musste der Ct-Wert in der exponentiellen Phase des Reaktionsverlaufs liegen, damit die resultierende Standardkurve der Gleichung y $=m x+b$ folgte. Anhand dieser Gleichung wurde die Transkriptmenge jeder Probe ermittelt. Um auch Proben mit unterschiedlicher cDNA-Konzentration untereinander vergleichen zu können, erfolgte die Normalisierung jeder Probe auf die endogene Expression der 18S rRNA. Dabei wurde der Quotient aus der Produktmenge des Zielgens und der endogenen Kontrolle gebildet. Die statistische Analyse der Daten wurde mit Hilfe von Statistica 9 durchgeführt. 


\subsubsection{Proteinnachweis mittels Western Blot}

\subsubsection{Herstellung von Proteinlysaten mit Lysepuffer}

Zur Isolierung von Proteinen wurden die Zellen im Medium mit einem Zellschaber geerntet und in ein $50 \mathrm{ml}$ Falcon auf Eis überführt. Das Kultivierungsgefäß wurde mit $1 \mathrm{ml} 1 \times$ PBS abgespült um restliche Zellen zu erfassen. Anschließend wurden die Zellen bei $1.800 \mathrm{rpm}$ und $4^{\circ} \mathrm{C}$ für 5 Minuten pelletiert, mit $700 \mu \mathrm{l}$ PBS gewaschen und in ein 1,5 ml-Reaktionsgefäß überführt. Nach Zentrifugation bei $2.000 \mathrm{rpm}$ und $4^{\circ} \mathrm{C}$ für 5 Minuten wurde der Überstand abgenommen und das Zellpellet in flüssigem Stickstoff schockgefroren. Die Zellpellets wurden bis zur Weiterverarbeitung bei $-80^{\circ} \mathrm{C}$ gelagert.

Bei Bedarf wurden die Zellpellets auf Eis aufgetaut und anschließend in $50-100 \mu \mathrm{l}$ Lysepuffer, frisch versetzt mit $500 \mu \mathrm{M}$ PMSF und $2 \mathrm{mM}$ DTT, resuspendiert. Die Lyse erfolgte für 25 Minuten auf Eis. Anschließend wurden die Ansätze bei $13.000 \mathrm{rpm}$ und $4^{\circ} \mathrm{C}$ für 25 Minuten zentrifugiert und die proteinhaltigen Überstände in ein neues $1,5 \mathrm{ml}$-Reaktionsgefäß überführt. Die Proteinkonzentration wurde mit Hilfe des BCA Protein Assay Kits (siehe Kapitel 3.2.6.3) bestimmt. Proteinlysate wurden bei $-80^{\circ} \mathrm{C}$ gelagert.

\subsubsection{Herstellung von Proteinlysaten mit RIPA-Puffer zum Nachweis von Transmembranproteinen}

Für die Detektion von Transmembranproteinen wurden die Zellen zunächst mit $1 \times$ PBS gewaschen und anschließend in $500 \mu \mathrm{l}$ pro Petrischale modifiziertem RIPA-Puffer mit einem Zellschaber geerntet. Die vollständige Lyse der Zellen erfolgte in einem 1,5 ml-Reaktionsgefäß für 10 Minuten bei Raumtemperatur. Bei $10.000 \mathrm{rpm}$ und $4^{\circ} \mathrm{C}$ für 10 Minuten wurden grobe Zellbestandteile abzentrifugiert. Der proteinhaltige Überstand wurde in ein neues Reaktionsgefäß überführt und bei $-80^{\circ} \mathrm{C}$ gelagert. Die Ermittlung der Proteinkonzentration erfolgte mit Hilfe des BCA Protein Assay Kits (siehe Kapitel 3.2.6.3).

\subsubsection{Proteinbestimmung mittels BCA}

Die Bestimmung der Proteinkonzentration mit der BCA-Methode basiert auf der Reduktion von $\mathrm{Cu}^{2+}$ Ionen in einem alkalischen Millieu. Die reduzierten $\mathrm{Cu}^{+}$-Ionen bilden mit 2,2'-Bicinchoninsäure (BCA) einen violetten Komplex mit einem Absorptionsmaximum bei $562 \mathrm{~nm}$. Zur Quantifizierung der Proteinmenge wurde das BCA Protein Assay Kit von Pierce Biotechnology genutzt. Die Herstellung der Arbeitslösung erfolgte nach Herstellerangaben durch Mischen von Reagenz A mit Reagenz B im Verhältnis 1:50. Je $1 \mu \mathrm{l}$ der Proteinlösung wurde vorgelegt und mit $200 \mu \mathrm{l}$ des BCA-Gemisches versetzt. Nach einer 30 minütigen Inkubation bei $37^{\circ} \mathrm{C}$ wurden die Lösungen im Synergy MX Plate Reader bei $540 \mathrm{~nm}$ vermessen. Die Analyse der Proteinkonzentrationen erfolgte mit Hilfe einer Standardkurve mit BSA von 0 bis $2.000 \mu \mathrm{g} / \mathrm{ml}$.

\subsubsection{Proteinauftrennung mittels Gelelektrophorese}

Die Auftrennung der Proteine erfolgte mittels NuPAGE Novex Midi Gels im Gradienten von 4\% - 12\%. 
Je Probe wurden 20 - $50 \mu$ g Protein geladen. Vor dem Laden wurden die Proben mit 6 x Ladepuffer versetzt, auf ein Volumen von maximal $25 \mu$ laufgefüllt und für 5 Minuten bei $96^{\circ} \mathrm{C}$ denaturiert. Die Auftrennung der Proteine im Gel erfolgte bei einer Stromspannung von 160 Volt.

\subsubsection{Transfer der Proteine auf die Membran}

Die Übertragung der Proteine auf die Nitrozellulosemembran erfolgte unter Verwendung des BlottingPuffers mit Hilfe einer Semi-Dry Blot-Vorrichtung (Trans Blot SD Semi-Dry; Bio-Rad Laboratories $\mathrm{GmbH}$ ) bei einer Stromstärke von $120 \mathrm{~mA}$ pro Gel für etwa 1,5 Stunden. Zur Blockierung von unspezifischen Antikörperbindungen wurde die Membran anschließend für 1 Stunde bei Raumtemperatur in Blocking-Puffer (5\% Trockenmilch in PBST) geschwenkt. Nach dem Blocken erfolgten 3 Waschschritte der Membran für je 10 Minuten in PBST. Die Antikörperinkubation erfolgte in BSA/Azid-PBST-Lösung in den in Tabelle 6 angegebenen Konzentrationen über Nacht bei $4^{\circ} \mathrm{C}$. Anschließend wurde die Membran erneut 3mal für je 10 Minuten in PBST gewaschen und mit dem Sekundärantikörper in einer Verdünnung von 1:5.000 in Blocking-Puffer für 1 Stunde bei Raumtemperatur inkubiert. Nach 3 weiteren Waschschritten erfolgte die Entwicklung der Blots.

\subsubsection{Entwicklung}

Zum Sichtbarmachen der Proteinbanden wurde das ECL Plus Western Blotting Detection System (Amersham) nach Herstellerangaben gemischt und gleichmäßig auf die Membran verteilt. Nach Inkubation für 2 Minuten wurde das ECL-Gemisch entfernt und die Membran luftblasenfrei in Folie verpackt. Die Entwicklung der Blots erfolgte in Filmkassetten in der Dunkelkammer.

\subsubsection{Proteinnachweis mittels Immunpräzipitation}

Zur Analyse des mitochondrialen Apoptosesignalwegs wurde der Aktivitätszustand des mitochondrialen Proteins BAX untersucht. Hierzu wurde BAX immunpräzipiert. Für die Immunpräzipitation wurden die Zellen mit CHAPS-Lysepuffer versetzt und 25 Minuten auf Eis inkubiert. Das Lysat wurde anschließend bei 15.000 rpm für 20 Minuten zentrifugiert und die Proteinkonzentration im Überstand mittels der BCA-Methode vermessen. Für die Immunpräzipitation wurden 500 bis $1.000 \mu \mathrm{g}$ Protein verwendet. Hierzu wurde der Ansatz mit CHAPS-Lysepuffer zunächst auf $400 \mu \mathrm{l}$ aufgefüllt. Das Lysat wurde mit $2 \mu \mathrm{g}$ Anti-Bax 6A7 Antikörper (der die aktive Form von BAX detektiert [153]) und $5 \mu \mathrm{l}$ Maus-lgG-Beads (Dynabeads ${ }^{\circledR}$ Pan Maus IgG, Dako) auf einem Rotator über Nacht bei $4^{\circ} \mathrm{C}$ inkubiert. Die an die Maus-IgG-Beads gekoppelten BAX-Proteine wurden 3mal mit CHAPS-Lysepuffer gewaschen, und dann in ein magnetisches Feld gebracht (Magnetic Particle Concentrator). Nach Entfernung des Überstands wurde das Lysat in $6 \times$ Ladepuffer überführt. Die Elution der Proteine von den Beads und ihre Denaturierung erfolgten durch Erhitzen bei $96^{\circ} \mathrm{C}$. Das Proteinlysat konnte nach Abzentrifugation auf ein SDS-Gel geladen werden. Die Detektion der aktiven und der inaktiven Form von BAX erfolgte durch Einsatz des Primärantikörpers Anti-BaxNT in einer 1:5.000 Verdünnung und mit dem ECL-Plus Western Blotting Detection System (Kapitel 3.2.6.6). 


\subsection{Tierexperimentelle Methoden}

\subsubsection{Zucht und Haltung von Mäusen}

Die Mauslinien B6-Ptch ${ }^{\text {neo67/+ }}$ und B6xBalbc-Ptch ${ }^{\text {neo67/+ }}$, sowie immundefiziente Nacktmäuse wurden im institutseigenen Tierstall gehalten. B6-Ptch ${ }^{\text {neo67/+ }}$ und B6xBalbc-Ptch ${ }^{\text {neo67/+ }}$-Mäuse wurden in Makrokolonkäfigen Typ I und Typ II, bei einem 12stündigem Hell-Dunkel-Rhythmus, einer Temperatur von $20 \pm 2^{\circ} \mathrm{C}$ und einer Luftfeuchtigkeit von $50 \pm 10 \%$ gehalten. Pelletiertes Trockenfutter sowie Wasser standen den Tieren ständig zur Verfügung.

Immundefiziente Nacktmäuse wurden unter spezifiziert pathogenfreien (SPF) Bedingungen gehalten. Die Tiere wurden mit sterilisierten Trockenfutterpellets und Wasser versorgt.

\subsubsection{Schwanzbiopsie und Ohrlochmarkierung}

Die Entnahme einer Schwanzbiopsie (ca. $0,5 \mathrm{~cm}$ der Schwanzspitze) und die Durchführung der Ohrlochmarkierung zur Nummerierung der Mäuse erfolgten im Alter von 4 - 5 Wochen vom Tierstallpersonal des institutseigenen Tierstalls.

\subsubsection{Genotypisierung von Mäusen}

Die Bestimmung des Genotyps von Mäusen erfolgte mittels PCR an Gesamt-DNA, die aus Schwanzbiopsien gewonnen wurde.

Der PCR-Ansatz für die Ptch-Genotypisierung setzte sich folgendermaßen zusammen:

Matrizen-DNA

Sequenzspezifisches

Oligonukleotid

Sequenzspezifisches Rückwärts-DNA-

Oligonukleotid

dNTPs

Cresol

Polymerasepuffer

Mo/Tag DNA Polymerase

$\mathrm{ddH}_{2} \mathrm{O}$

$\begin{array}{rr}10-100 \mathrm{ng} & 1 \mu \mathrm{l} \\ 10 \mu \mathrm{M} & 0,5 \mu \mathrm{l} \\ 10 \mu \mathrm{M} & 0,5 \mu \mathrm{l} \\ & \\ 10 \mathrm{mM} & 0,2 \mu \mathrm{l} \\ 0,1 \%(\mathrm{w} / \mathrm{v}) & 1 \mu \mathrm{l} \\ 10 \mathrm{fach} & 1 \mu \mathrm{l} \\ 5 \mathrm{U} / \mu \mathrm{l} & 0,2 \mu \mathrm{l} \\ & \text { ad } 10 \mu \mathrm{l}\end{array}$


Das PCR-Programm für die Genotypisierung durchlief folgende Schritte:

$\left.\begin{array}{ll}5 \mathrm{~min} & 94^{\circ} \mathrm{C} \\ 30 \mathrm{~s} & 94^{\circ} \mathrm{C} \\ 1 \mathrm{~min} & 60^{\circ} \mathrm{C} \\ 1,5 \mathrm{~min} & 72^{\circ} \mathrm{C}\end{array}\right] 35$ Zyklen

\subsubsection{Tumorsichtung}

Zur Erfassung von RMS wurden die $P_{t c h}^{\text {neo67/+ }}$ Mäuse 1- bis 2 mal die Woche manuell untersucht. RMS manifestieren sich meistens an den Extremitäten, weshalb die Sichtung und Ertastung relativ einfach war.

\subsubsection{Transplantation von Tumorzellen in Nacktmäuse}

Nacktmäuse besitzen eine homozygote Mutation im Foxn1-Gen [154]. Dies resultiert in Haarlosigkeit und fehlendem Thymus [155]. Aufgrund des Fehlens des Thymus weist die Nacktmaus keine reifen T-Zellen auf. Daher gibt es bei der Nacktmaus keine vom Immunsystem induzierten Abstossungsreaktionen. Dies macht die Nacktmaus zu einem idealen Transplantationsmodell.

Die zu transplantierenden RD-Zellen wurden mit 1 x PBS gewaschen und mit 2 ml Trypsin aus den Kulturgefäßen gelöst. Anschließend wurden die Zellen mit $2 \mathrm{ml}$ FCS-haltigem Medium versetzt und bei $300 \mathrm{~g}$ und $4^{\circ} \mathrm{C}$ für 5 Minuten zentrifugiert. Der Überstand wurde vorsichtig abgesaugt, die Zellen in $5 \mathrm{ml} 1 \times$ PBS resuspendiert und bei $300 \mathrm{~g}$ und $4^{\circ} \mathrm{C}$ für 5 Minuten pelletiert. Die Zellen wurden anschließend in $500-1.000 \mu \mathrm{l} 1 \times$ PBS aufgenommen, und auf Eis gehalten. Zur Zellzahlbestimmung wurden $5 \mu \mathrm{l}$ der Zellsuspension mit $45 \mu \mathrm{l} 1$ x PBS verdünnt (1:10 Verdünnung). Aus dieser Verdünnung wurden $5 \mu \mathrm{l}$ mit $45 \mu \mathrm{l}$ einer Trypanblau-Lösung Vermischt. Trypanblau ist ein Farbstoff, der sich in tote, nicht aber in lebendige Zellen einlagert. Die Zellzahlbestimmung wurde mittels Zählkammer durchgeführt. Die Zellsuspension wurde anschließend auf eine Lebendzellzahl von $2 \times 10^{7}$ Zellen/ml eingestellt. $100 \mu \mathrm{l}$ der Zellsuspension wurden mit $100 \mu \mathrm{l}$ Matrigel auf Eis gemischt. Diese Suspension wurde den Mäusen links und rechts subkutan in die laterale Bauchwand implantiert. Das Wachstum der Tumoren wurde mit dem Messschieber analysiert.

\subsubsection{Systemische Applikation von GDC-0941 und/oder Doxorubizin}

Die Stocklösung von $2 \mathrm{mg} / \mathrm{ml}$ Doxorubizin in einer 0,9\% Kochsalzlösung wurde über die Klinikumsapotheke Göttingen bezogen, aliquotiert und maximal für 4 Wochen bei $-20^{\circ} \mathrm{C}$ gelagert. GDC-0941 wurde von der Firma Genentech zur Verfügung gestellt. Dieses Medikament wurde für die Applikation alle 3 Tage frisch in Methylcellulose-Tween-Lösung gelöst und für diesen Zeitraum bei Raumtemperatur gelagert. Das Lösungsmittel wurde bei $4^{\circ} \mathrm{C}$ aufbewahrt und konnte so über einen Zeitraum von 4 Wochen genutzt werden. 


\subsubsection{Systemische Applikation von GDC-0941 in (B6xBalbc)Ptch ${ }^{\text {neo67/+}}$-Mäuse}

Tumortragende (B6xBalbc)Ptch ${ }^{\text {neo67/+ }}$-Mäuse wurden täglich mit GDC-0941 in einer Konzentration von $75 \mathrm{mg} / \mathrm{kg}$ per Knopfschlundsonde über einen Zeitraum von 5 Wochen behandelt. Kontrolltiere erhielten dasselbe Volumen des Lösungsmittels (Methylcellulose-Tween-Lösung). Die Tiere wurden bei Verlust von $20 \%$ des Körpergewichts, einem schlechten Allgemeinzustand oder bei Überschreiten einer Tumorgröße von $1,5 \mathrm{~cm}$ abgetötet. Das Tumorvolumen wurde vor und nach dem Behandlungszeitraum, sowie 3 Wochen nach Abschluss der Therapie mittels VCT (Kapitel 3.3.7) erfasst.

\subsubsection{Systemische Applikation von Doxorubizin und GDC-0941 in Nacktmäuse}

Nach der Transplantation von RD-Tumorzellen und bei Erreichen einer Tumorgröße von $30-60 \mathrm{~mm}^{3}$ wurden die Mäuse entweder mit 1,2 mg/kg Doxorubizin am Tag 1, 4, 7, 10, 13, 16, 19 und 22 i. p. behandelt. Das Dosierungsschema hemmt die Proliferation von RD-Zellen und wird von SCID-Mäusen gut vertragen [156]. Kontrolltiere erhielten jeweils $100 \mu \mathrm{l}$ Kochsalzlösung. GDC-0941 wurde den tumortragenden Mäusen täglich in einer Dosis von $75 \mathrm{mg} / \mathrm{kg}$ per Knopfschlundsonde verabreicht. Kontrolliere erhielten das Lösungsmittel. Bei der Kombinationstherapie wurden beide Medikamente zu den oben genannten Zeitpunkten appliziert. Das Tumorvolumen wurde mittels Messschieber bestimmt. Abbruchkriterien waren ein Verlust von mehr als $20 \%$ des Körpergewichts, ein schlechter Allgemeinzustand oder eine Tumorgröße von mehr als $1,5 \mathrm{~cm}$.

\subsubsection{Bestimmung der Tumorgröße mittels Volumen Computer Tomographie (VCT)}

Das VCT ist eine nichtinvasive Methode zur Bestimmung von Tumorvolumina in vivo. Mit einer Auflösung von $200 \mu \mathrm{m}$ kann eine exakte räumliche Darstellung des Tumors erreicht werden [157]. Die Betäubung der Mäuse erfolgte über Inhalationsnarkose mit Isoflouran. Zur Erhaltung der Narkose wurde die Mundöffnung der Maus in eine Maske eingeführt, deren Zulauf an die Isofluoran-Vorrichtung angeschlossen war. So wurde die Betäubung der Maus auch während des Scan-Vorgangs sichergestellt. Narkotisierten Tieren wurden $150 \mu \mathrm{l}$ des Kontrastmittels Ultravist intrabulbär injiziert. Zur Visualisierung der Weichteilsarkome erfolgte ein Scan mit 125 Bildern/s [158]. Für die Bestimmung der Tumorwachstumsrate erfolgte die Aufnahme der Tumore vor Beginn, am Ende und 3 Wochen nach Beendigung der Therapie. Die Auswertung der Tumorvolumina erfolgte mittels Volume Viewer Plus (Voxtool 5.5.4) Software.

\subsubsection{Statistische Auswertungen der Therapiestudien}

Zur Ermittlung der Wirkung der applizierten Substanzen auf das Tumorvolumen wurden die Messdaten mit Hilfe von gemischten linearen Modellen adjustiert um eine Funktion zu erhalten, die diese Daten abbildet. Der Vergleich der Behandlungen untereinander erfolgte über die $p$-Werte nach 
der Methode von Turkey (all-pair comparison). Der Vergleich der erwarteten Tumorgrößen an Tag 1, 7, 14 und 21 erfolgte unter Nutzung des Q.-Q Plots und des Residuals-Predicted-Plots. Das Signifikanzniveau wurde auf $5 \%$ festgelegt. Die statistische Analyse erfolgte durch Herrn Rosenberger, Genetische Epidemiologie der Universität Göttingen mit dem Programm SAS 9.2.

\subsection{Immunhistochemie und Immunzytochemie}

\subsubsection{Gewebeentnahme und -fixierung}

Für die Paraffineinbettung wurden die Gewebe sofort nach der Entnahme für mindestens 24 Stunden in 4\%iger PFA-Lösung fixiert. Die Paraffineinbettung erfolgte maschinell in der Pathologie des Universitätsklinikums Göttingen. Das Gewebe wurde anschließend luftblasenfrei in eine Einbettungsform überführt und mit Hilfe einer erhitzen Pipette ausgerichtet. Zum Auffüllen der Einbettungsform wurde Paraplast Plus genutzt. Nach Erkalten des Paraplasts wurden die Blöcke aus den Einbettungsformen gelöst und bei Raumtemperatur gelagert.

\subsubsection{Anfertigen von Paraffinschnitten}

Für die Herstellung von Paraffinschnitten wurden die Paraffinblöcke auf einer Kühlplatte auf $4^{\circ} \mathrm{C}$ gekühlt. Dann wurden ca. $4 \mu \mathrm{m}$ dicke Schnitte am Schlittenmikrotom erstellt. Nach dem Strecken der Schnitte in einem $50^{\circ} \mathrm{C}$ heißen Wasserbad wurden sie auf Objektträger gezogen und über Nacht bei $37^{\circ} \mathrm{C}$ getrocknet.

\subsubsection{Entparaffinierung und Hämalaun- und Eosin-Färbungen (H\&E) von Paraffinschnitten}

Die Entparaffinierung der Paraffinschnitte erfolgte in Xylol für 2mal 10 Minuten. Mit Hilfe einer absteigenden Ethanolreihe (je 2 Minuten in 100\% (2 x), 96\% (2x) und 70\% Ethanol) wurden die Schnitte rehydriert. Nach 2minütiger Inkubation in $\mathrm{ddH}_{2} \mathrm{O}$ wurden die Schnitte für 10 Minuten in Hämalaun nach Meyer gefärbt, wobei die Farbentwicklung unter fließendem, lauwarmen Leitungswasser für mindestens 5 Minuten stattfand. Dann wurden die Schnitte für 15 Sekunden in $1 \%$ iger Eosin-Lösung mit Eisessig (0,5\% v/v) getaucht. Anschließend wurden die Schnitte mit $\mathrm{ddH}_{2} \mathrm{O}$ gewaschen und über eine aufsteigende Ethanolreihe (je eine Minute 70\%, 96\% (2 x) und 100\% (2x) Ethanol) entwässert. Zur vollständigen Dehydrierung wurden die Objektträger vor dem Eindeckeln mit Pertex kurz in Xylol getaucht.

\subsubsection{PAS („Periodic Acid Schiff“)-Reaktion von Paraffinschnitten}

Die Paraffinschnitte wurden wie unter Kapitel 3.4.3 beschrieben entparaffiniert und rehydriert. Dann erfolgte eine Inkubation mit $1 \%$ Perjodsäure für 5 Minuten. Nachdem die Schnitte 5 Minuten mit Leitungswasser gespült worden waren, wurden sie für 20 Minuten in $40^{\circ} \mathrm{C}$ warmem SCHIFF-Reagenz inkubiert. Nachfolgend wurden die Schnitte erneut für 5 Minuten mit Leitungswasser gespült. Eine 
Gegenfärbung erfolgte mittels Inkubation in Mayer's Hämalaunlösung für 2 Minuten und einem anschließendem Spülschritt mit Leitungswasser. Bevor die Schnitte eingedeckelt wurden, wurden sie zunächst mit Hilfe der aufsteigenden Ethanolreihe und Xylol dehydriert. Die Färbungen wurden von Mitarbeitern der AG Dr. Schulz-Schaeffer durchgeführt.

\subsubsection{Antikörperfärbung von Paraffinschnitten}

\subsubsection{Caspase 3-Färbung}

Nach Entparaffinierung und Rehydrierung wurden die Paraffinschnitte mit Citratpuffer $(\mathrm{pH} 6) \mathrm{im}$ Dampfgarer für 16 Minuten vorbehandelt. Nach einem Waschschritt in TBS mit 0,1\% Triton X-100 wurden die Schnitte mit 3\% $\mathrm{H}_{2} \mathrm{O}_{2}$ in TBS zur Inhibierung von endogenen Peroxidasen für 20 Minuten auf dem Schüttler inkubiert. Nachfolgend wurden die Schnitte für 5 Minuten mit $\mathrm{ddH}_{2} \mathrm{O}$ gespült, in TBS mit 0,1\% Triton X-100 überführt, und dann für 20 Minuten mit 10\% Casein in TBS geblockt. Die Inkubation mit dem Primärantikörper (1:500 in 10\% Casein in TBS) erfolgte für 90 Minuten bei Raumtemperatur oder bei $4^{\circ} \mathrm{C}$ über Nacht. Als sekundärer Antikörper wurde der rabbit/mouse HRP aus dem Envision System von Dako für 30 Minuten bei Raumtemperatur eingesetzt. Nach einem Waschschritt in TBS mit 0,1\% Triton X-100 folgte die Inkubation der Schnitte mit 1:15 verdünnter AECFärbelösung für 30 Minuten in Dunkelheit. Nach Spülen in $\mathrm{ddH}_{2} \mathrm{O}$ wurde kurz mit Hämaunlösung gegen gefärbt, bevor die Schnitte schließlich mit Glycergel eingedeckelt wurden. Die Färbungen wurden von Dr. F. Nitzki und A. Frommhold durchgeführt. Je Tumor wurden 1.000 Caspase 3-positive Zellen mit Hilfe der CellF-Software ausgezählt.

\subsubsection{Ki67-Färbung}

Die Entparaffinierung, Entwässerung und die Demaskierung der Oberflächenantigene erfolgte wie bei der Caspase 3 Färbung. Anschließend kühlten die Schnitte für 20 Minuten auf dem Schüttler ab und wurden dann 2mal für je 2 Minuten in TBS gespült. Zur Hemmung der Aktivität der endogenen Peroxidasen wurden die Schnitte für 20 Minuten in 3\% $\mathrm{H}_{2} \mathrm{O}_{2}$ in TBS behandelt. Anschließend wurden sie für 5 Minuten mit $\mathrm{ddH}_{2} \mathrm{O}$ und für 1 Minute in TBS gespült. Unspezifische Bindungen wurden für 20 Minuten in 5\% FCS/ 10\% BSA in PBS blockiert. Die Inkubation mit dem primären Antikörper (1:50) erfolgte für 1 Stunde bei Raumtemperatur in Dunkelheit. Zur Visualisierung des Signals wurde das Envision Polyclonal rabbit/mouse HRP von Dako verwendet, wobei die Schnitte für 30 Minuten mit dem Sekundärantikörper inkubierten und anschließend 2mal für je 2 Minuten mit TBS gewaschen wurden. Im Anschluss erfolgte die Inkubation mit 1:50 verdünntem DAB-Chromogen (3'3Diaminobenzidin) für 10 Minuten. Zur besseren Übersicht wurden die Schnitte schließlich für 15 Sekunden mit Hämalaunlösung gegen gefärbt und mit Glycergel eingedeckelt. Die Färbungen wurden von Dr. F. Nitzki und A. Frommhold durchgeführt. Je Tumor wurden 1.000 Ki67-positive Zellen mit Hilfe der CellF-Software ausgezählt. 


\section{Ergebnisse}

\subsection{Untersuchung der antitumoralen Effekte von Doxorubizin in Kombination mit 5-Aza, VPA, Bortezomib, Pioglitazon oder PI103 in den Zelllinien HT1080, HTETOP, TP5014 und RD}

Zur Untersuchung der Verbesserung der antitumoralen Wirksamkeit von Doxorubizin wurde Doxorubizin mit 5-Aza, VPA, Bortezomib, Pioglitazon oder PI103 kombiniert. Die Eignung der Medikamente, den antitumoralen Effekt von Doxorubizin zu erhöhen wurde mittels Proliferationsassay, anhand von Apoptosemessungen mittels Annexin V-Assay, sowie durch Analyse der Caspase 3 und 7 Aktivität im CaspaseGlo 3/7 Assay bestimmt (siehe Kapitel 3.1.4 und 3.1.6).

Erste Untersuchungen wurden in der Fibrosarkomzelllinie HT1080 durchgeführt. Diese Zelllinie wird häufig bei Analysen mit Doxorubizin eingesetzt. Zudem ist sie die Parentalzellinie für die HTETOP-Zellen [148]. Die Besonderheit der HTETOP-Zellen ist eine Substitution der endogenen TOP2a durch ein TOP2a-Transgen, dessen Expression durch Doxycyclin reprimierbar ist. Aufgrund dieser Eigenschaften können Experimente durchgeführt werden, bei denen es um die Fragestellung zu TOP2aabhängigen Prozessen geht.

Nach der Überprüfung der Medikamente in HT1080-Zellen erfolgte die Analyse des Kombinationseffekts in der murinen RMS-Zelllinie TP5014 und in der humanen RMSZelllinie RD.

Für alle Analysen wurde Doxorubizin in einer Konzentration von $1 \mu \mathrm{M}$ eingesetzt. Diese Konzentration entspricht der therapeutisch relevanten Plasmakonzentration beim Menschen und wird häufig für in vitro-Experimente verwendet [159, 160]. Um potentielle sensitivierende Effekte der zusätzlich eingesetzten Medikamente nicht zu übersehen, wurden für die Proliferationsanalysen auch 10 nM Doxorubizin genutzt.

Wie in Abbildung 3A zu sehen ist, führt die Behandlung der HT1080-Zellen mit 10 nM Doxorubizin zu einer signifikanten Proliferationsinhibierung von etwa $20 \%$, wohingegen $1 \mu \mathrm{M}$ Doxorubizin in einer Wachstumshemmung von ungefähr $80 \%$ resultiert. Auch die Doxorubizin-vermittelte Apoptoseinduktion im Annexin V-Assay ist mit 30\% signifikant (Abbildung 3B). Die Aktivierung der Caspasen 3 und 7 wird mit Doxorubizin im Vergleich zur Lösungsmittelkontrolle verdoppelt (Abbildung 3C). 
A

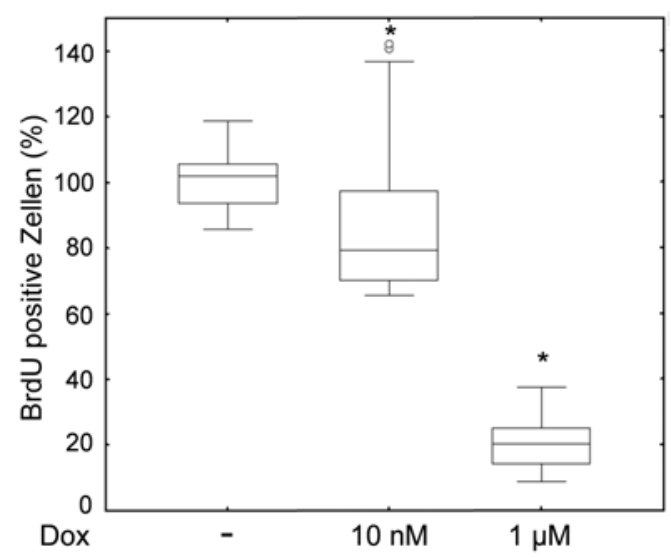

B

C
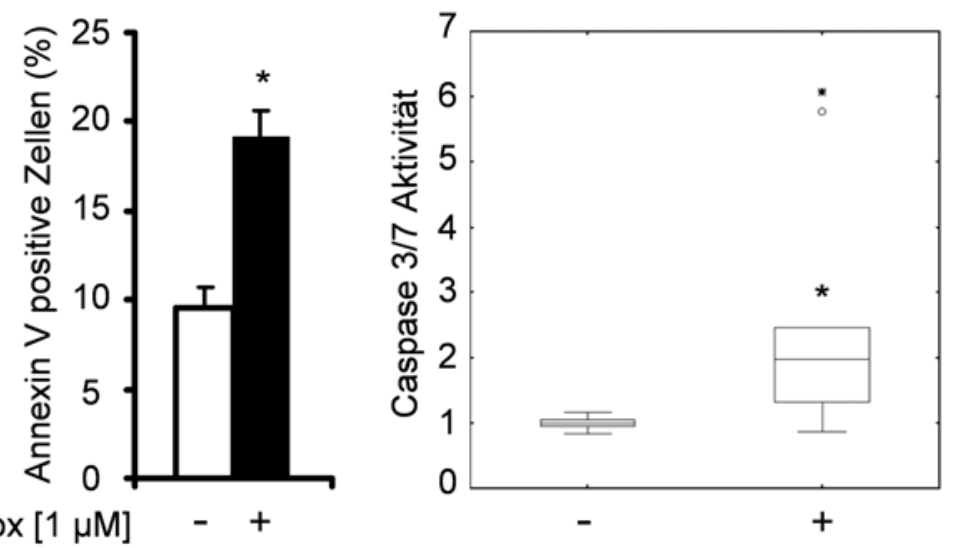

Abbildung 3: Antiproliferative und proapoptotische Wirkung von Doxorubizin in HT1080-Zellen. A Die Zellen wurden für 24 Stunden mit 10 nM Doxorubizin (Dox, $n=21)$ bzw. $1 \mu$ M Dox $(n=21)$ oder dem Lösungsmittel $(n=28$ ) inkubiert. Der Effekt auf die Proliferation der Zellen wurde auf die Lösungsmittelkontrolle (100\%) normalisiert und als Box-Whisker-Plot dargestellt. B HT1080-Zellen wurden für 24 Stunden mit $1 \mu \mathrm{M}$ Dox oder dem Lösungsmittel (jeweils $n=6$ ) behandelt. Der Mittelwert (+/- SEM) der Annexin V positiven Zellen ist in \% im Säulendiagramm dargestellt. Daten: T. Yan. C HT1080-Zellen wurden für 24 Stunden mit $1 \mu$ Dox $(n=10)$ oder dem Lösungsmittel $(n=12)$ inkubiert. Die Aktivität der Caspasen 3 und 7 wurde in Relation zum Lösungsmittel (Mittelwert des Lösungsmittels wurde 1 gesetzt) in Form eines Box-Whisker-Plots dargestellt. *signifikant $(p<0,05)$ im Vergleich zur Lösungsmittelkontrolle. $\square, 25 \%$ - 75 \%; I, Bereich ohne Ausreißer; -, Median; ${ }^{\circ}$, Ausreißer; $\mathbf{~}$, Extremwert.

Dann wurde untersucht, ob 5-Aza, VPA, Bortezomib, Pioglitazon oder PI103 die Tumorzellen gegenüber Doxorubizin sensitivieren können. Die entsprechenden Konzentrationen der Medikamente wurden der Literatur entnommen. So werden in Zellkulturexperimenten 5-Aza in einer Konzentration von $5 \mu \mathrm{M}$ [161, 162], VPA in einer Konzentration von $2 \mathrm{mM}[67,163]$ und Pioglitazon in einer Konzentration von $10 \mu \mathrm{M}$ [164] eingesetzt. Da die Literaturangaben zu Bortezomib bei Zellkulturexperimenten unterschiedlich waren [165, 166], wurde der antiproliferative Effekt von Bortezomib zunächst in Konzentrationen zwischen $10 \mathrm{nM}$ und $50 \mathrm{nM}$ in HT1080- 
Zellen ausgetestet. Da schon $10 \mathrm{nM}$ Bortezomib eine Proliferationsinhibierung hervorruft (Daten nicht gezeigt), wurde diese Konzentration in allen weiteren Untersuchungen eingesetzt. PI103 kann in Zellkulturexperimenten laut Literatur in Konzentrationen von $10 \mathrm{nM}$ bis $100 \mu \mathrm{M}$ verwendet werden [167]. Häufig wird jedoch $1 \mu \mathrm{M}$ PI103 eingesetzt [101]. Die Experimente wurden daher mit $1 \mu \mathrm{M}$, aber auch mit einer höheren Konzentration von $3 \mu \mathrm{M}$ PI103 durchgeführt.

\subsubsection{Analyse der antitumoralen Effekte von Doxorubizin in Kombination mit 5-Aza, VPA, Bortezomib, Pioglitazon oder PI103 in HT1080- Zellen}

\subsubsection{Kombination von Doxorubizin und dem Cytidinanalogon 5-Aza}

Für die Proliferationsanalysen wurde Doxorubizin in einer Konzentration von $10 \mathrm{nM}$ und $1 \mu \mathrm{M}$ eingesetzt. Wie schon in Abbildung $3 \mathrm{~A}$ gezeigt wurde, wird die Proliferation von HT1080-Zellen durch sowohl $10 \mathrm{nM}$ als auch durch $1 \mu \mathrm{M}$ Doxorubizin signifikant gehemmt (Abbildung 4).

Unerwarteterweise scheint eine Inkubation der Zellen mit $5 \mu \mathrm{M}$ 5-Aza einen signifikanten proliferationsstimulierenden Effekt zu haben. Eine Kombination von Doxorubizin und 5-Aza führt dagegen wieder zur Proliferationsinhibierung. Diese ist jedoch nicht so stark ausgeprägt, wie diejenige, die durch alleinige Inkubation mit Doxorubizin hervorgerufen wird (Abbildung 4).

Für den Annexin V-Assay und den Caspase-Glo 3/7 Assay wurde $1 \mu \mathrm{M}$ Doxorubizin in Kombination mit $5 \mu \mathrm{M}$ 5-Aza eingesetzt.

Wie schon in Abbildung 3B gezeigt wurde, führt eine alleinige Behandlung mit Doxorubizin zu einem signifikanten Anstieg von Annexin $V$ positiven Zellen (Abbildung 5A). Dagegen hat eine Behandlung mit 5-Aza keinen Effekt. Auch die Kombination beider Medikamente zeigt im Vergleich zur Doxorubizin-Behandlung keine Erhöhung der Anzahl der Annexin $V$ positiven Zellen.

Im Caspase-Glo 3/7 Assay kann dagegen sowohl mit Doxorubizin als auch mit 5-Aza eine signifikante Steigerung der Aktivität der Caspasen nachgewiesen werden. Diese kann jedoch durch Behandlung der Zellen mit beiden Medikamenten nicht weiter gesteigert werden (Abbildung 5B). 
A

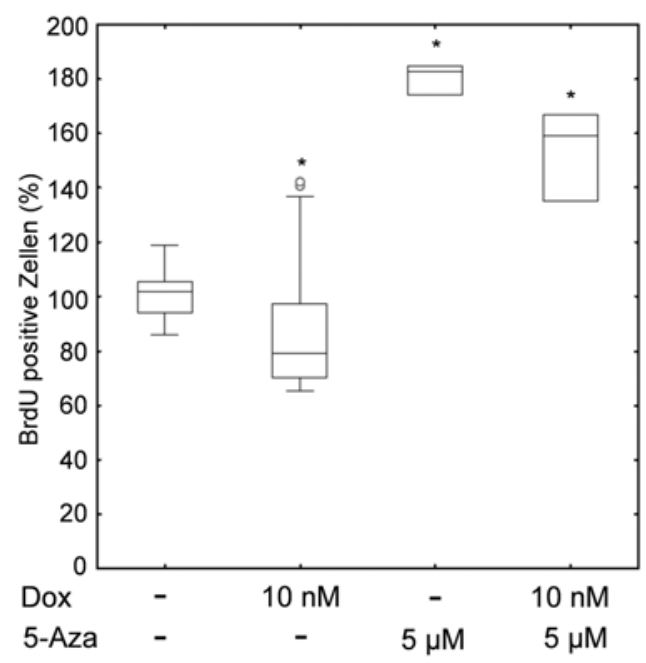

B

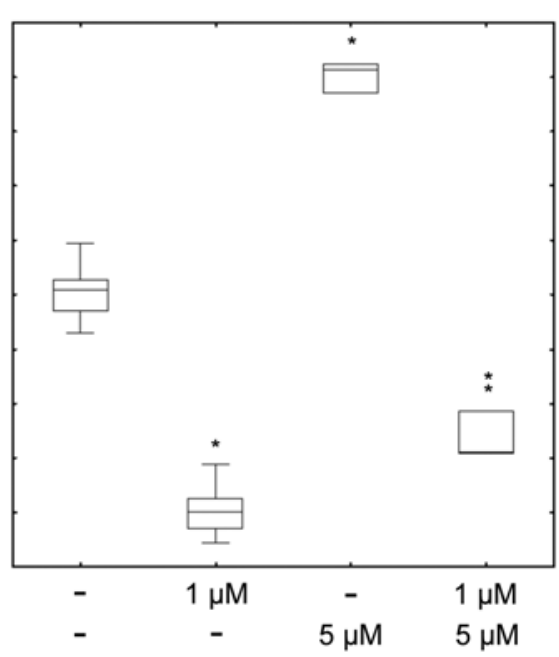

Abbildung 4: Proliferationsverhalten von HT1080-Zellen nach Behandlung mit Doxorubizin und/oder 5-Aza. HT1080-Zellen wurden für 24 Stunden mit $\mathbf{A} 10 \mathrm{nM}$ Doxorubizin (Dox, $\mathrm{n}=21$ ), $5 \mu \mathrm{M}$ 5-Aza $(n=3)$ oder der Kombination beider Medikamente $(n=3)$ bzw. B $1 \mu M$ Dox $(n=21), 5 \mu M$ 5-Aza $(n=3)$ oder der Kombination beider Medikamente $(n=3)$ behandelt. Die Inkubation mit dem Lösungsmittel $(n=28)$ diente als Kontrolle. Der Effekt auf die Proliferation der Zellen wurde auf die Lösungsmittelkontrolle (100\%) normalisiert und als Box-Whisker-Plot dargestellt. * signifikant $(p<0,05)$ im Vergleich zur Lösungsmittelkontrolle, ${ }^{* *}$ signifikant im Vergleich zur Behandlung mit sowohl dem Lösungsmittel, Doxorubizin als auch 5-Aza. $\square, 25 \%$ - $75 \%$; I, Bereich ohne Ausreißer; -, Median; ${ }^{\circ}$, Ausreißer.

A

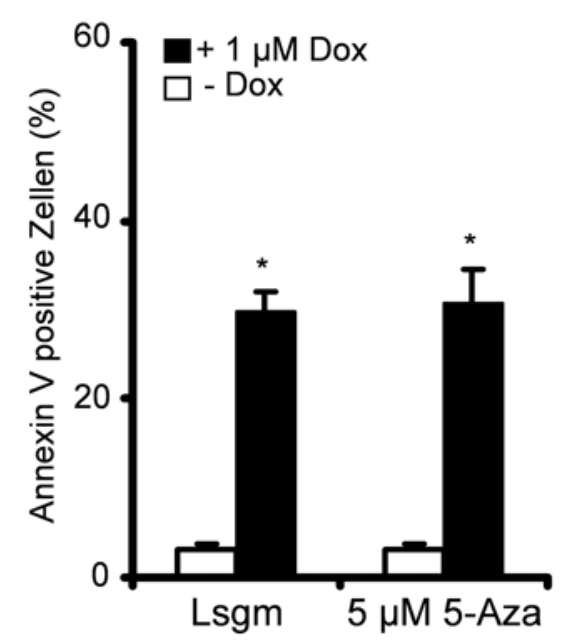

B

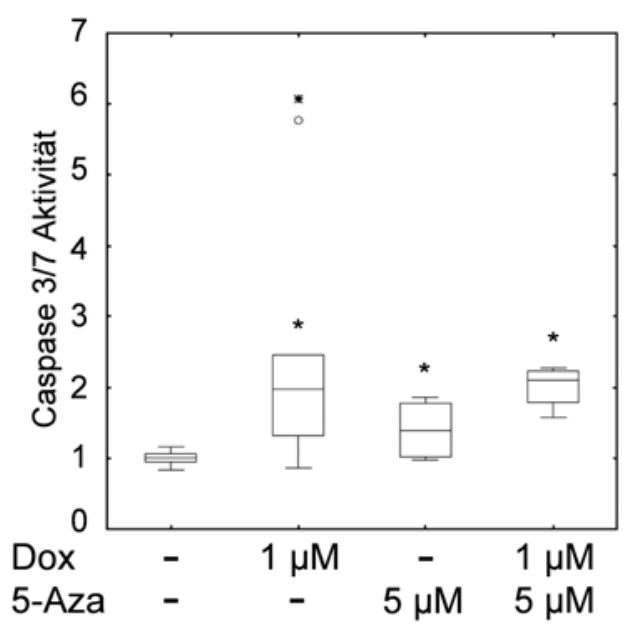

Abbildung 5: Apoptoseinduktion in HT1080-Zellen durch Behandlung mit Doxorubizin und/oder 5-Aza. A HT1080-Zellen wurden für 24 Stunden mit $1 \mu \mathrm{M}$ Doxorubizin (Dox, $\mathrm{n}=6$ ), $5 \mu \mathrm{M}$ 5-Aza $(n=4)$ oder beiden Medikamenten zusammen $(n=4)$ behandelt. Die Inkubation mit dem Lösungsmittel $(n=6)$ diente als Kontrolle. Der Mittelwert (+/- SEM) Annexin V positiver Zellen ist als Säulendiagramm dargestellt. Daten: T. Yan. B Die Zellen wurden für 24 Stunden mit $1 \mu \mathrm{M}$ Dox $(n=10), 5 \mu M$ 5-Aza $(n=4)$ oder der Kombination beider Medikamente $(n=4)$ behandelt. Eine Inkubation mit dem Lösungsmittel $(n=12)$ diente als Kontrolle. Die Aktivität der Caspasen 3 und 7 wurde in Relation zum Lösungsmittel (Mittelwert des Lösungsmittels wurde 1 gesetzt) in Form eines Box-Whisker-Plots dargestellt. * signifikant $(p<0,05)$ im Vergleich zur Lösungsmittelkontrolle. $25 \%$ - $75 \%$; I, Bereich ohne Ausreißer; -, Median ; ${ }^{\circ}$, Ausreißer. 
Zusammenfassend führt 5-Aza zu keiner Steigerung der antiproliferativen Effekte von Doxorubizin. Die proapoptotische Wirkung von Doxorubizin wird ebenfalls nicht eindeutig verstärkt.

\subsubsection{Kombination von Doxorubizin und dem HDAC-Inhibitor VPA}

Der Einfluss der Behandlung mit Doxorubizin und dem HDAC-Inhibitor VPA auf die Proliferationsrate der HT1080-Zellen ist in Abbildung 6 dargestellt.

Nach Inkubation der Zellen mit 2 mM VPA wird, wie auch nach 5-Aza-Behandlung (siehe Abbildung 4), eine signifikante Proliferationsstimulierung detektiert. Die Kombination mit $10 \mathrm{nM}$ Doxorubizin kann diesen Effekt zwar etwas mindern, resultiert jedoch in einer immer noch signifikant erhöhten Proliferationsrate (Abbildung 6A). Durch Kombination mit $1 \mu \mathrm{M}$ Doxorubizin kann der proliferationsinduzierende Effekt von VPA hingegen deutlich reduziert werden, führt jedoch zu keiner signifikanten Proliferationsinhibierung gegenüber der alleinigen DoxorubizinBehandlung (Abbildung 6B).

A

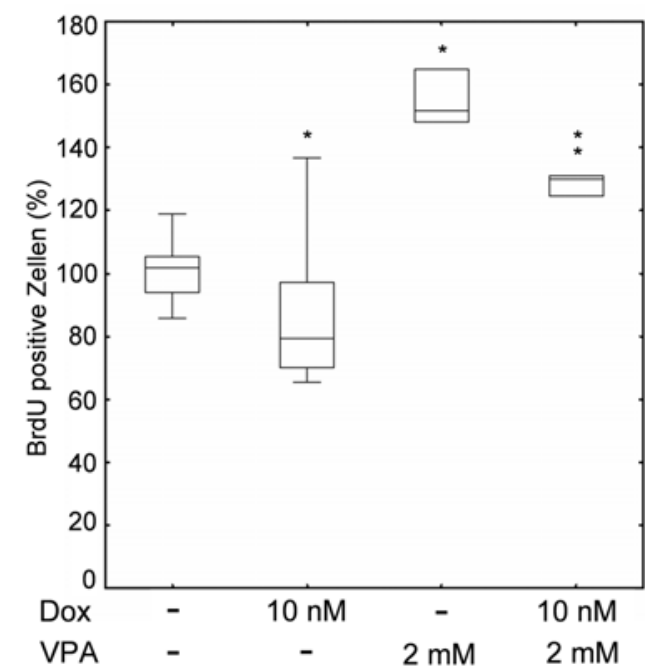

B

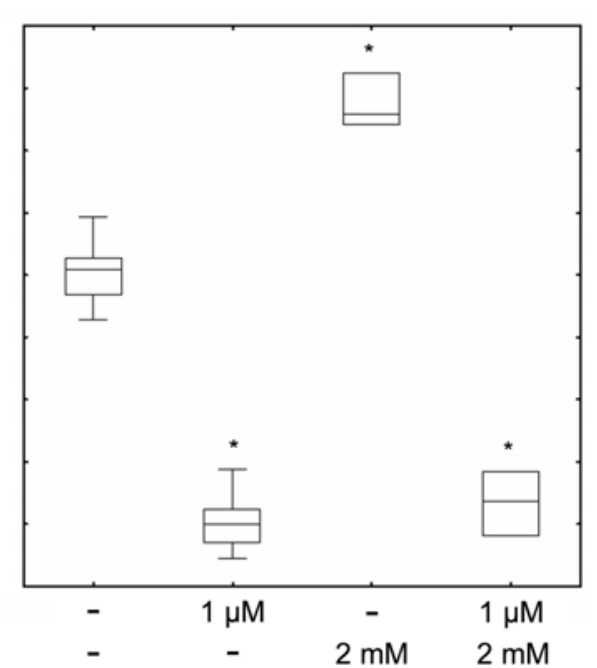

Abbildung 6: Proliferationsverhalten von HT1080-Zellen nach Behandlung mit Doxorubizin und/oder VPA. Die Zellen wurden für 24 Stunden mit $\mathbf{A} 10 \mathrm{nM}$ Doxorubizin (Dox, $\mathrm{n}=21$ ), $2 \mathrm{mM}$ VPA $(n=3)$ oder der Kombination beider Medikamente $(n=3)$ bzw. mit B $1 \mu M$ Dox $(n=21), 2$ mM VPA $(n=3)$ oder der Kombination beider Medikamente $(n=3)$ behandelt. Die Inkubation mit dem Lösungsmittel $(n=21)$ diente als Kontrolle. Der Effekt auf die Proliferation der Zellen wurde auf die Lösungsmittelkontrolle $(100 \%)$ normalisiert und als Box-Whisker-Plot dargestellt. * signifikant $(p<0,05)$ im Vergleich zur Lösungsmittelkontrolle, ${ }^{* *}$ signifikant im Vergleich zur Behandlung mit sowohl dem Lösungsmittel, Doxorubizin als auch VPA. $\square, 25 \%$ - 75 \%; I, Bereich ohne Ausreißer; - , Median.

Obwohl die Inkubation der Zellen mit VPA in keiner signifikanten Erhöhung der 
Annexin $\vee$ positiven Zellen resultiert (Abbildung 7A), wird die Aktivität der Caspasen 3 und 7 durch Behandlung mit VPA signifikant verstärkt (Abbildung 7B). Durch Kombination der Medikamente kann der Doxorubizin-vermittelte Effekt in beiden Assays jedoch nicht signifikant gesteigert werden.

A

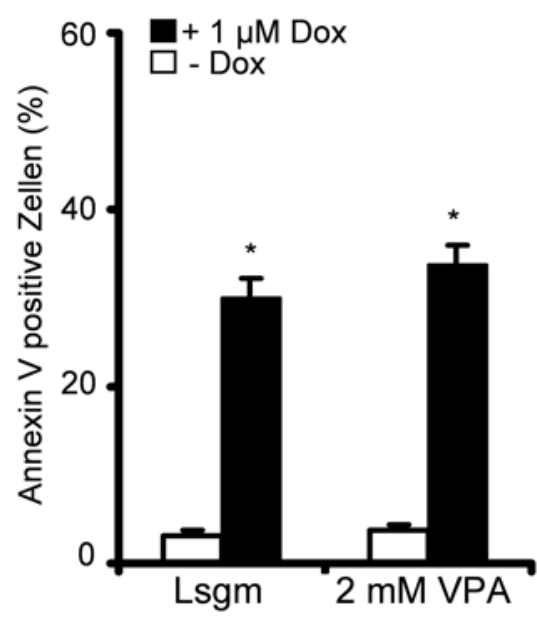

B

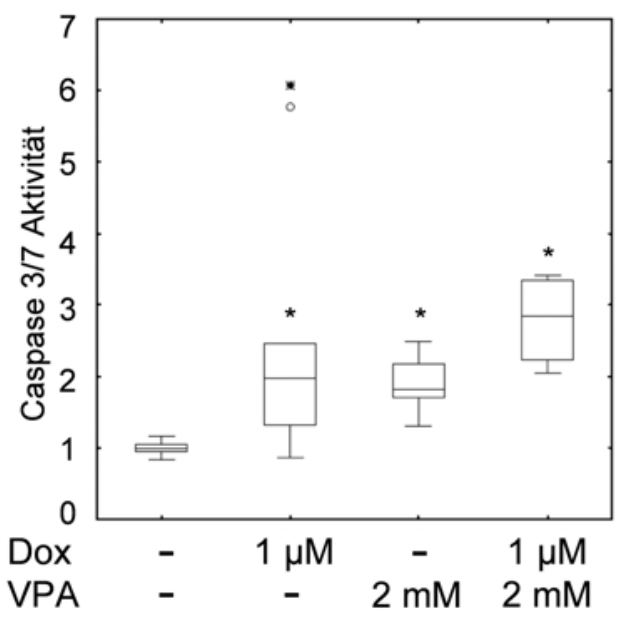

Abbildung 7: Apoptoseinduktion in HT1080-Zellen durch Behandlung mit Doxorubizin und/oder VPA. A Die Zellen wurden für 24 Stunden mit $1 \mu \mathrm{M}$ Doxorubizin (Dox, $n=6), 2 \mathrm{mM}$ VPA $(n=4)$, sowie der Kombination der Medikamente $(n=4)$ inkubiert. Als Kontrolle wurden Zellen mit dem Lösungsmittel behandelt $(n=6)$. Der Mittelwert $(+/-$ SEM) Annexin $V$ positiver Zellen ist als Säulendiagramm dargestellt. Daten: T. Yan. B HT1080-Zellen wurden für 24 Stunden mit $1 \mu \mathrm{M}$ Dox $(n=10), 2$ mM VPA $(n=8)$ oder der Kombination beider Medikamente $(n=4)$ behandelt. Eine Behandlung mit dem Lösungsmittel $(n=12)$ diente als Kontrolle. Die Aktivität der Caspasen 3 und 7 wurde in Relation zum Lösungsmittel (Mittelwert des Lösungsmittels wurde 1 gesetzt) in Form eines Box-Whisker-Plots dargestellt. * signifikant $(p<0,05)$ im Vergleich zur Lösungsmittelkontrolle. $25 \%$ - $75 \%$; I, Bereich ohne Ausreißer; -, Median; ${ }^{\circ}$, Ausreißer; $\mathbf{~ . , ~ E x t r e m w e r t . ~}$

Zusammenfassend lässt sich festhalten, dass weder die antiproliferativen noch die proapoptotischen Effekte von Doxorubizin in HT1080-Zellen durch VPA verstärkt werden können.

\subsubsection{Kombination von Doxorubizin und dem Proteasominhibitor Bortezomib} Die Wirkung von Doxorubizin in Kombination mit Bortezomib auf das Proliferationsverhalten der HT1080-Zellen ist in Abbildung 8 dargestellt.

Dabei wird gezeigt, dass die Behandlung der HT1080-Zellen mit 10 nM Bortezomib in einer Proliferationsinhibierung resultiert, die stärker ist, als diejenige, welche durch $10 \mathrm{nM}$ Doxorubizin induziert wird (Abbildung 8A). Eine Kombination beider Medikamente hat jedoch keine weitere signifikante Proliferationsinhibierung zur Folge. 
Dagegen kann der antiproliferative Effekt, der durch $1 \mu \mathrm{M}$ Doxorubizin erzielt wird, signifikant durch Bortezomib gesteigert werden (Abbildung 8B).

A

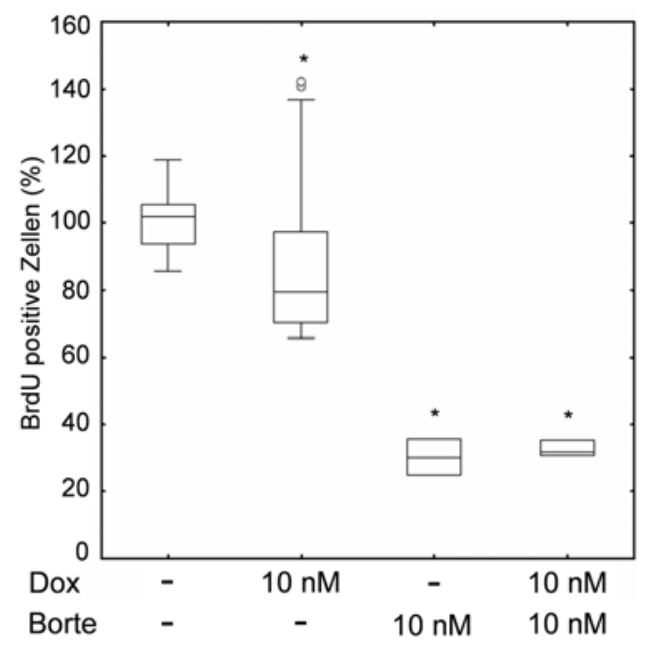

B

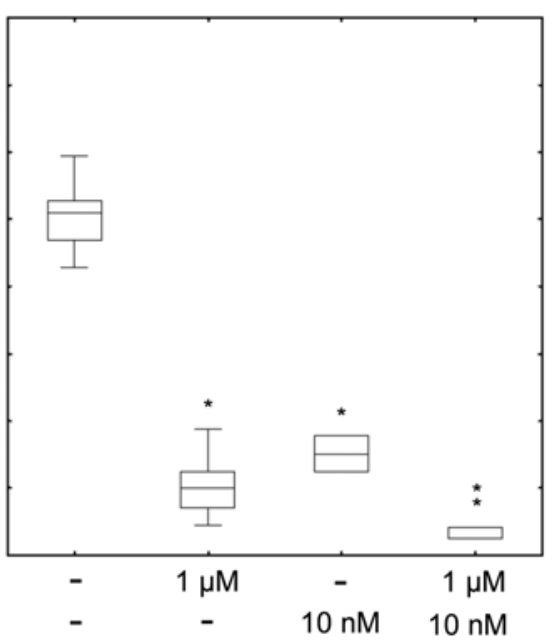

Abbildung 8: Proliferationsverhalten von HT1080-Zellen nach Doxorubizin und/oder Bortezomib-Behandlung. Die Zellen wurden für 24 Stunden mit A $10 \mathrm{nM}$ Doxorubizin (Dox, $\mathrm{n}=21$ ), $10 \mathrm{nM}$ Bortezomib (Borte, $\mathrm{n}=2$ ), sowie der Kombination beider Medikamente $(\mathrm{n}=3)$ bzw. mit B $1 \mu \mathrm{M}$ Dox $(n=21), 10 n M$ Borte $(n=2)$, oder der Kombination aus beiden Medikamenten $(n=3)$ behandelt. Die Inkubation mit dem Lösungsmittel $(n=28)$ diente als Kontrolle. Der Effekt auf die Proliferation der Zellen wurde auf die Lösungsmittelkontrolle (100\%) normalisiert und als Box-Whisker-Plot dargestellt. * signifikant $(p<0,05)$ im Vergleich zur Lösungsmittelkontrolle, ** signifikant im Vergleich zur Behandlung mit sowohl dem Lösungsmittel, Doxorubizin als auch Bortezomib. $\square, 25 \%$ - 75 \%; $工$, Bereich ohne Ausreißer; -, Median; ${ }^{\circ}$, Ausreißer.

Abbildung $9 \mathrm{~A}$ ist zu entnehmen, dass $10 \mathrm{nM}$ Bortezomib eine, wenn auch nicht signifikante, Erhöhung der Annexin V positiven Zellen induziert. Obwohl die Prozentzahl Annexin $\mathrm{V}$ positiver Zellen durch Kombination beider Medikamente gesteigert werden kann, ist dieser Effekt nicht signifikant gegenüber der alleinigen DoxorubizinBehandlung. Die durch Bortezomib ausgelöste Caspase 3 und 7 Aktivität schwankt stark und kann die durch Doxorubizin-induzierte Aktivierung der Caspasen ebenfalls nicht weiter verstärken (Abbildung 9).

Es lässt sich festhalten, dass Bortezomib zur signifikanten Steigerung der antiproliferativen Effekte von Doxorubizin führt. Die kooperativen Effekte beider Medikamente auf die Apoptose sind dagegen nicht signifikant. 
A

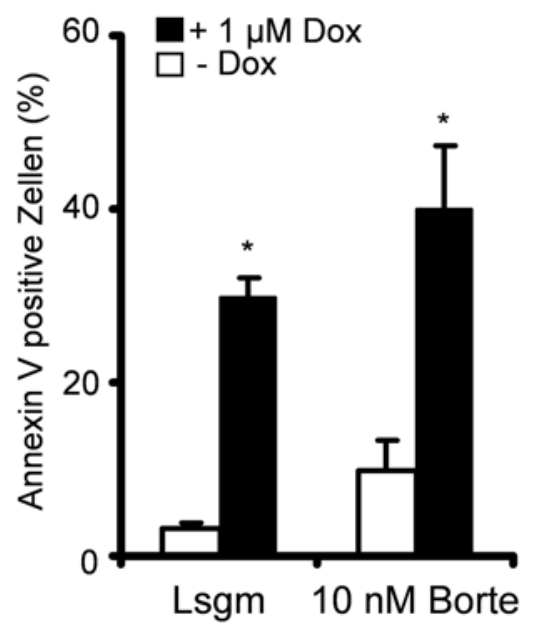

B

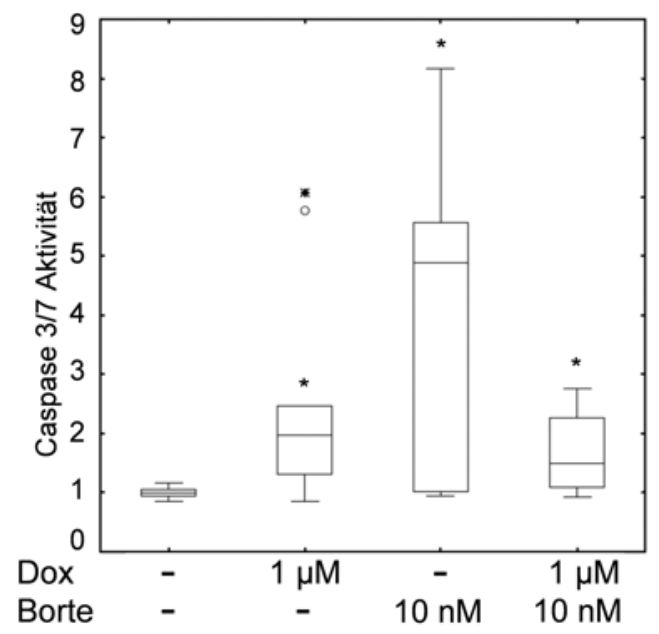

Abbildung 9: Induktion der Apoptose in HT1080-Zellen durch Behandlung mit Doxorubizin und/oder Bortezomib. A HT1080-Zellen wurden für 24 Stunden mit $1 \mu \mathrm{M}$ Doxorubizin (Dox, $\mathrm{n}=6$ ), $10 \mathrm{nM}$ Bortezomib (Borte, $\mathrm{n}=4$ ) oder beiden Medikamenten zusammen $(\mathrm{n}=4)$ behandelt. Als Kontrolle wurden Zellen mit dem Lösungsmittel $(n=6)$ behandelt. Der Mittelwert (+/- SEM) Annexin V positiver Zellen ist als Säulendiagramm dargestellt. Daten: T. Yan. B Die Zellen wurden für 24 Stunden mit $1 \mu \mathrm{M}$ Dox $(n=10), 10 \mathrm{nM}$ Borte $(n=10)$ oder der Kombination beider Medikamente $(n=4)$ behandelt. Die Inkubation mit dem Lösungsmittel $(n=12)$ diente als Kontrolle. Die Aktivität der Caspasen 3 und 7 wurde in Relation zum Lösungsmittel (Mittelwert des Lösungsmittels wurde 1 gesetzt) in Form eines Box-Whisker-Plots dargestellt. * signifikant $(p<0,05)$ im Vergleich zur Lösungsmittelkontrolle. $\square, 25 \%$ - 75 \%; I, Bereich ohne Ausreißer; -, Median; ' , Ausreißer; $\mathbf{~}$, Extremwert.

\subsubsection{Kombination von Doxorubizin und dem PPARy-Liganden Pioglitazon}

Der Einsatz von $10 \mu \mathrm{M}$ Pioglitazon scheint keine signifikante Auswirkung auf das Proliferationsverhalten der HT1080-Zellen zu haben. Die Kombination mit 10 nM Doxorubizin führt hingegen zu einem signifikanten kooperativen antiproliferativen Effekt (Abbildung 10A). Dieser signifikante kooperative Effekt wird auch bei Kombination mit der höheren Doxorubizin-Konzentration detektiert (Abbildung 10B).

Wie in Abbildung 11A und B zu erkennen ist, führt die Behandlung der HT1080Zellen mit Pioglitazon nicht zur Apoptoseinduktion. So wird weder die Zahl der Annexin V positiven Zellen, noch die Caspase 3/7 Aktivität durch Pioglitazon erhöht. Durch Kombination mit Doxorubizin kann dagegen der Doxorubizin-vermittelte proapoptotische Effekt im Annexin V Assay signifikant gesteigert werden (Abbildung 11A). Dagegen war dieser kooperative Effekt bei Messung der Aktivität der Caspasen 3 und 7 nicht zu detektieren (Abbildung 11B). 
A

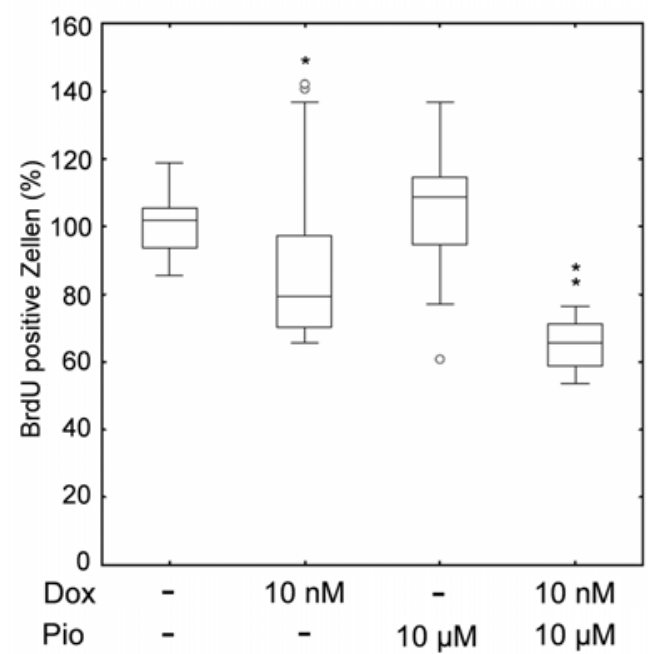

B

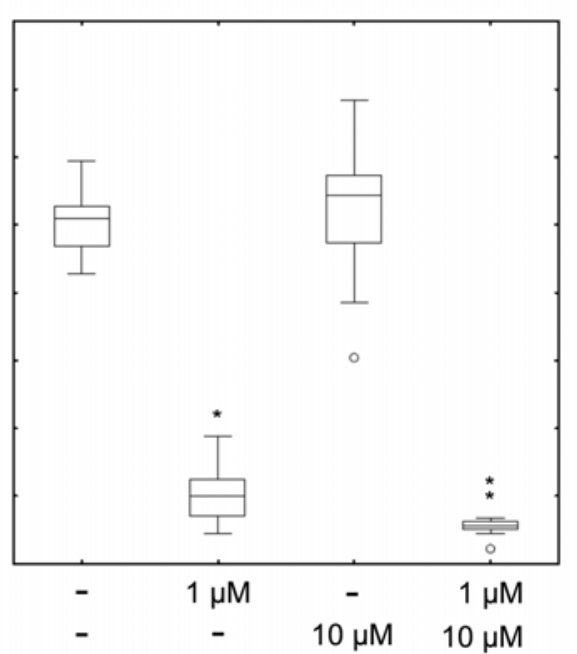

Abbildung 10: Proliferationsverhalten von HT1080-Zellen nach Behandlung mit Doxorubizin und/oder Pioglitazon. Die Zellen wurden für 24 Stunden mit $\mathbf{A} 10 \mathrm{nM}$ Doxorubizin (Dox, $\mathrm{n}=21$ ), $10 \mu \mathrm{M}$ Pioglitazon (Pio, $\mathrm{n}=12$ ) oder mit beiden Medikamenten zusammen $(\mathrm{n}=12)$ bzw. mit B $1 \mu \mathrm{M}$ Dox $(n=21), 10 \mu$ M Pio $(n=12)$ oder der Kombination beider Medikamente $(n=12)$ inkubiert. Die Behandlung mit dem Lösungsmittel $(n=28)$ diente als Kontrolle. Der Effekt auf die Proliferation der Zellen wurde auf die Lösungsmittelkontrolle $(100 \%)$ normalisiert und als Box-Whisker-Plot dargestellt. * signifikant $(p<0,05)$ im Vergleich zur Lösungsmittelkontrolle, ${ }^{* *}$ signifikant im Vergleich zur Behandlung mit sowohl dem Lösungsmittel, Doxorubizin als auch Pioglitazon. $\square, 25 \%-75$ \%; 工, Bereich ohne Ausreißer; -, Median; ${ }^{\circ}$, Ausreißer.

A

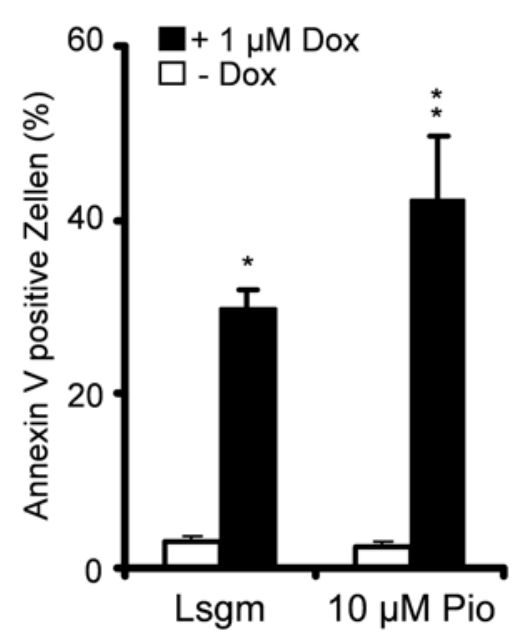

B

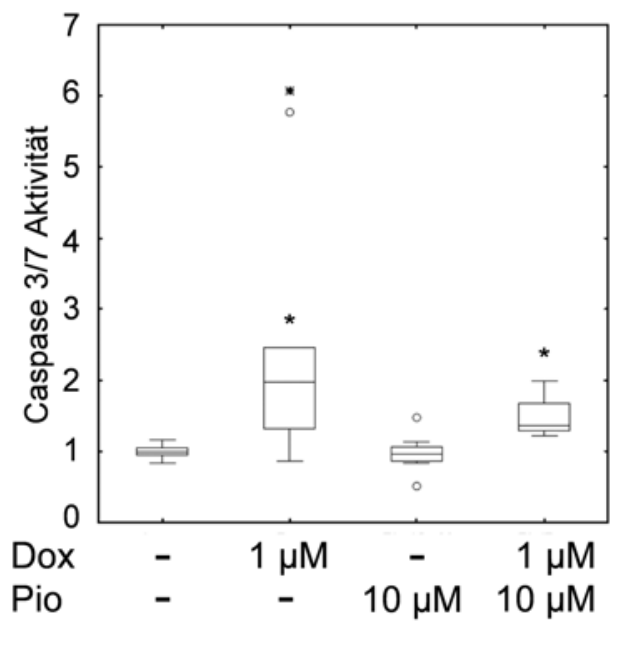

Abbildung 11: Apoptoseinduktion in HT1080-Zellen durch Behandlung mit Doxorubizin und/oder Pioglitazon. A Die Zellen wurden für 24 Stunden mit $1 \mu \mathrm{M}$ Doxorubizin (Dox, $\mathrm{n}=6$ ), $10 \mu \mathrm{M}$ Pioglitazon (Pio, $n=4)$ oder der Kombination beider Medikamente $(n=4)$ behandelt. Die Behandlung mit dem Lösungsmittel $(n=6)$ diente als Kontrolle. Der Mittelwert (+/- SEM) Annexin V positiver Zellen ist als Säulendiagramm dargestellt. Daten: T. Yan. B Die Zellen wurden für 24 Stunden mit $1 \mu \mathrm{M}$ Dox $(n=10), 10 \mu \mathrm{M}$ Pio $(n=8)$ oder der Kombination beider Medikamente $(n=4)$ behandelt. Die Behandlung mit dem Lösungsmittel $(n=12)$ diente als Kontrolle. Die Aktivität der Caspasen 3 und 7 wurde in Relation zum Lösungsmittel (Mittelwert des Lösungsmittels wurde 1 gesetzt) in Form eines Box-Whisker-Plots dargestellt. * signifikant $(p<0,05)$ im Vergleich zur Lösungsmittelkontrolle, ** signifikant im Vergleich zur Behandlung mit sowohl dem Lösungsmittel, Doxorubizin als auch

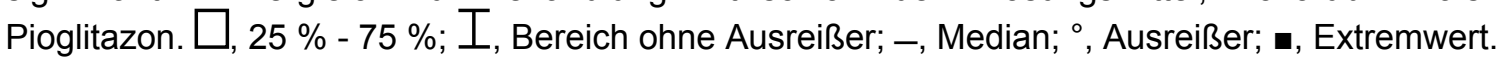


Zusammenfassend lässt sich festhalten, dass Pioglitazon sowohl zur Verstärkung der antiproliferativen, als auch der proapoptotischen Wirkung von Doxorubizin führt, wobei bei letzterem Effekt die Aktivität der Caspasen 3 und 7 wahrscheinlich keine Rolle spielen.

\subsubsection{Kombination von Doxorubizin und dem dualen PI3Kinase/mTOR- Inhibitor PI103}

Die alleinige Behandlung der Zellen mit PI103 resultiert in einer geringen, aber signifikanten Proliferationsinhibierung (Abbildung 12). Eine Kombination von PI103 mit $10 \mathrm{nM}$ Doxorubizin führt zu keiner signifikanten Steigerung der Doxorubizin vermittelten Proliferationshemmung (Abbildung 12A). Durch Kombination mit $1 \mu \mathrm{M}$ Doxorubizin kann der antiproliferative Effekt von Doxorubizin dagegen signifikant gesteigert werden (Abbildung 12B).

A

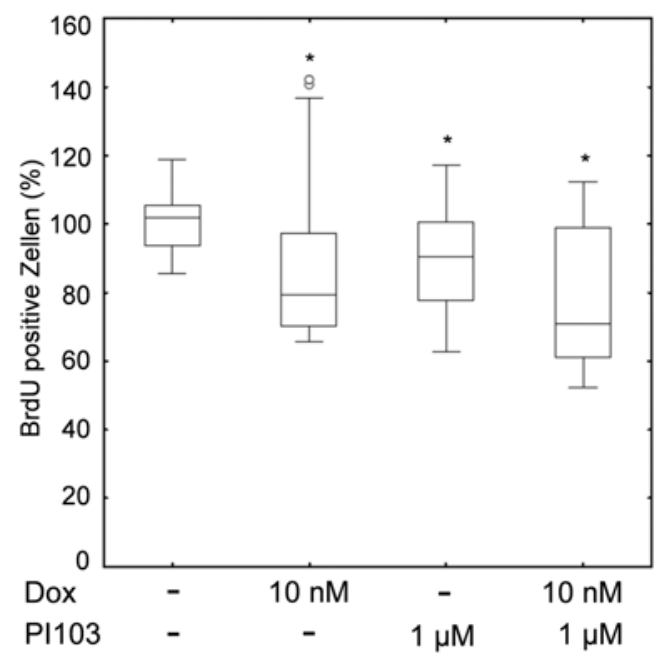

B

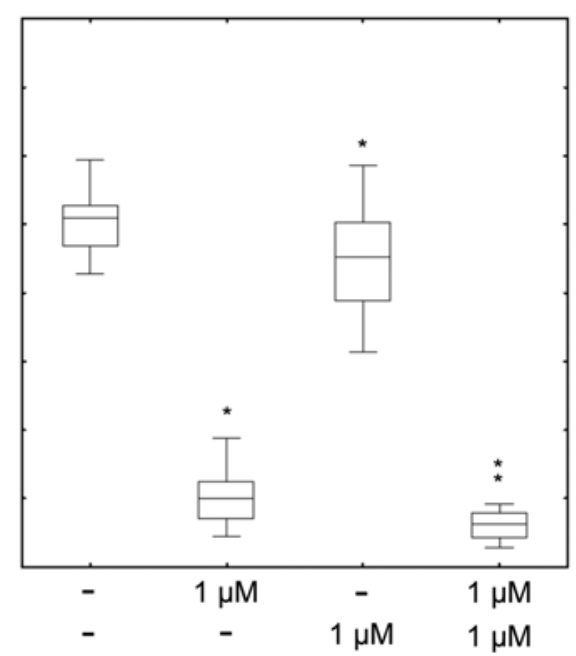

Abbildung 12: Proliferationsverhalten der HT1080-Zellen nach Doxorubizin- und/oder PI103Behandlung. HT1080-Zellen wurden für 24 Stunden mit $\mathbf{A} 10 \mathrm{nM}$ Doxorubizin (Dox, $\mathrm{n}=21$ ), $1 \mu \mathrm{M}$ PI103 $(n=12)$ oder der Kombination beider Medikamente $(n=9)$ bzw. B $1 \mu M$ Dox $(n=21), 1 \mu M$ PI103 $(n=12)$ oder mit der Kombination beider Medikamente $(n=9)$ behandelt. Eine Behandlung mit dem Lösungsmittel $(n=28)$ diente als Kontrolle. Der Effekt auf die Proliferation der Zellen wurde auf die Lösungsmittelkontrolle (100\%) normalisiert und als Box-Whisker-Plot dargestellt. * signifikant $(p<0,05)$ im Vergleich zur Lösungsmittelkontrolle, ${ }^{* *}$ signifikant im Vergleich zur Behandlung mit sowohl dem Lösungsmittel, Doxorubizin als auch PI103. $\square, 25 \%$ - $75 \%$; I, Bereich ohne Ausreißer; -, Median; ${ }^{\circ}$, Ausreißer.

Kooperative Effekte von PI103 und Doxorubizin zeigen sich auch hinsichtlich der Apoptoseinduktion.

Obwohl eine alleinige Applikation von PI103 die Zahl Annexin V positiver Zellen 
(Abbildung 13A) nicht erhöht und zudem die Aktivität der Caspasen 3 und 7 eher hemmt als induziert, wurde der antiapoptotische Effekt von Doxorubizin durch Kombination mit PI103 signifikant verstärkt. Dies wird nicht nur im Annexin V-Assay deutlich (Abbildung 13), sondern auch im Caspase 3/7 Assay (Abbildung 13B).

A

B
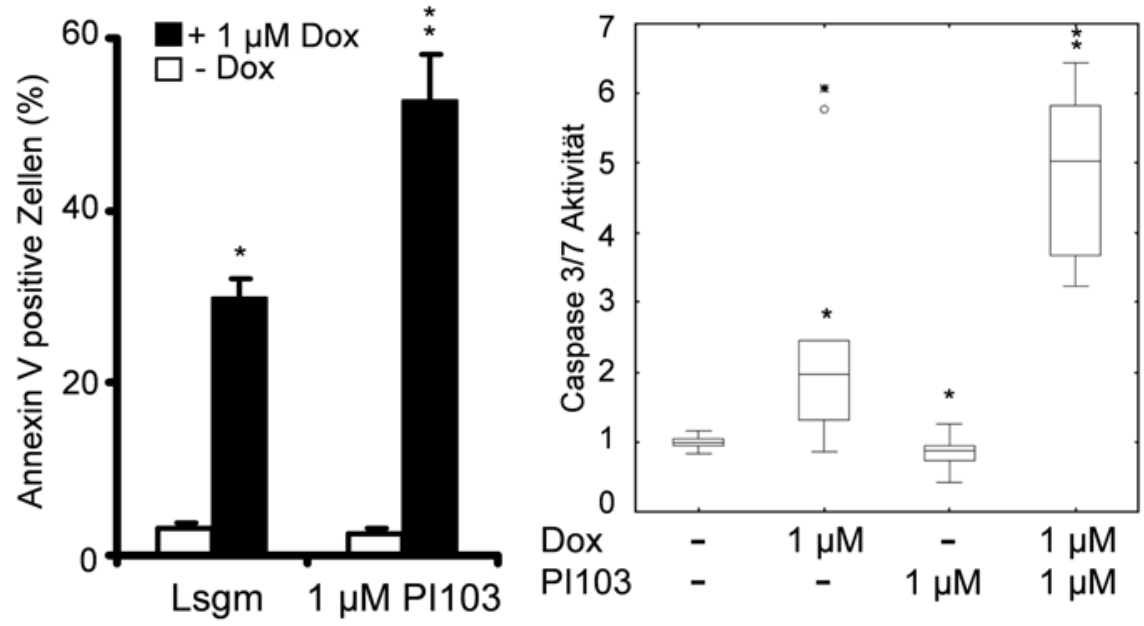

Abbildung 13: Apoptoseinduktion in HT1080-Zellen durch Behandlung mit Doxorubizin und/oder PI103. A HT1080-Zellen wurden für 24 Stunden mit $1 \mu \mathrm{M}$ Doxorubizin (Dox, $n=6$ ), $1 \mu \mathrm{M}$ PI103 $(n=4)$ oder beiden Medikamenten zusammen $(n=4)$ behandelt. Als Kontrolle diente die Behandlung mit dem Lösungsmittel $(n=6)$. Der Mittelwert (+/- SEM) Annexin V positiver Zellen ist als Säulendiagramm dargestellt. Daten: T. Yan. B Die Zellen wurden für 24 Stunden mit $1 \mu \mathrm{M}$ Dox $(n=10), 1 \mu$ M PI103 $(n=20)$ oder der Kombination beider Medikamente $(n=10)$ behandelt. Eine Inkubation mit dem Lösungsmittel $(n=12)$ diente als Kontrolle. Die Aktivität der Caspasen 3 und 7 wurde in Relation zum Lösungsmittel (Mittelwert des Lösungsmittels wurde 1 gesetzt) in Form eines Box-Whisker-Plots dargestellt. * signifikant $(p<0,05)$ im Vergleich zur Lösungsmittelkontrolle, ** signifikant im Vergleich zur Behandlung mit sowohl dem Lösungsmittel, Doxorubizin als auch PI103.

$\square, 25 \%$ - 75 \%; I, Bereich ohne Ausreißer; -, Median; ${ }^{\circ}$, Ausreißer; - , Extremwert.

Zusammenfassend führt PI103 zur signifikanten Verstärkung der antiproliferativen als auch der proapoptotischen Wirkung von Doxorubizin.

\subsubsection{Zusammenfassung}

Um einen besseren Überblick über die in den Abschnitten 4.1.1 - 4.1.1.5 beschriebenen Ergebnisse zu geben, sind die antitumoralen Effekte der Einzelmedikamente als auch der Kombinationen mit Doxorubizin in Tabelle 10 zusammengefasst.

In rot sind kooperative Effekte gekennzeichnet, durch die die Doxorubizin-vermittelte Proliferationshemmung oder Apoptoseinduktion in HT1080-Zellen signifikant verstärkt wurde. 
Tabelle 10: Zusammenfassung der antitumoralen Effekte der in den Abschnitten 4.1.1 - 4.1.1.5 beschriebenen Behandlungsschemata in HT1080-Zellen. *signifikant $(p<0,05)$ im Vergleich zur Lösungsmittelkontrolle, ${ }^{* *}$ signifikant im Vergleich zur Behandlung mit sowohl dem Lösungsmittel, Doxorubizin als auch 5-Aza, VPA, Bortezomib, Pioglitazon oder PI103. n. d., nicht durchgeführt. Rot: signifikante kooperative Effekte mit Doxorubizin hinsichtlich Proliferationshemmung oder Apoptoseinduktion in HT1080-Zellen.

\begin{tabular}{|c|c|c|c|c|}
\hline \multicolumn{2}{|c|}{ Medikamente } & \multirow{2}{*}{$\begin{array}{l}\text { BrdU- } \\
\text { Inkooperation } \\
\text { in \% über dem } \\
\text { Lösungsmittel }\end{array}$} & \multirow{2}{*}{$\begin{array}{c}\text { Annexin V } \\
\text { positive } \\
\text { Zellen in \% }\end{array}$} & \multirow[b]{2}{*}{$\begin{array}{c}\text { Anstieg } \\
\text { Caspase 3/7 } \\
\text { Aktivität über } \\
\text { dem } \\
\text { Lösungsmitte }\end{array}$} \\
\hline Doxorubizin & $\begin{array}{c}\text { andere } \\
\text { Medikamente }\end{array}$ & & & \\
\hline $10 \mathrm{nM}$ & - & $-20 \%{ }^{*}$ & n. d. & n. d. \\
\hline $1 \mu \mathrm{M}$ & - & $-80 \% *$ & $30 \% *$ & 2 fach* $^{*}$ \\
\hline- & $5 \mu \mathrm{M}$ 5-Aza & $+80 \%{ }^{*}$ & $3 \%$ & 1,4 fach $^{*}$ \\
\hline $10 \mathrm{nM}$ & $5 \mu \mathrm{M}$ 5-Aza & $+60 \%{ }^{*}$ & n. d. & n. d. \\
\hline $1 \mu \mathrm{M}$ & $5 \mu \mathrm{M}$ 5-Aza & $-60 \%{ }^{* *}$ & $31 \% *$ & 2,1 fach $^{*}$ \\
\hline- & 2 mM VPA & $+50 \%$ * & $3,6 \%$ & $1,8 f a c h *$ \\
\hline $10 \mathrm{nM}$ & $2 \mathrm{mM}$ VPA & $+30 \%$ ** & n. d. & n. d. \\
\hline $1 \mu \mathrm{M}$ & $2 \mathrm{mM}$ VPA & $-70 \% *$ & $33,7 \%$ * & 2,8 fach $^{*}$ \\
\hline- & $\begin{array}{c}10 \mathrm{nM} \\
\text { Bortezomib }\end{array}$ & $-70 \% *$ & $10 \%$ & 4,9fach* \\
\hline $10 \mathrm{nM}$ & $\begin{array}{c}10 \mathrm{nM} \\
\text { Bortezomib }\end{array}$ & $-70 \% *$ & n. d. & n. d. \\
\hline $1 \mu \mathrm{M}$ & $\begin{array}{c}10 \mathrm{nM} \\
\text { Bortezomib }\end{array}$ & $-90 \%$ ** & $40 \% *$ & $1,5 f^{\prime}{ }^{*}$ \\
\hline- & $\begin{array}{c}10 \mu \mathrm{M} \\
\text { Pioglitazon }\end{array}$ & $+10 \%$ & $2,4 \%$ & 0,96 fach \\
\hline $10 \mathrm{nM}$ & $\begin{array}{c}10 \mu \mathrm{M} \\
\text { Pioglitazon }\end{array}$ & $-40 \%$ ** & n. d. & n. d. \\
\hline $1 \mu \mathrm{M}$ & $\begin{array}{c}10 \mu \mathrm{M} \\
\text { Pioglitazon }\end{array}$ & $-95 \%$ ** & $42,5 \%$ ** & 1,35 fach $^{*}$ \\
\hline- & $1 \mu \mathrm{M}$ PI103 & $-10 \% *$ & $2,5 \%$ & 0,9 fach* \\
\hline $10 \mathrm{nM}$ & $1 \mu \mathrm{M}$ PI103 & $-30 \% *$ & n. d. & n. d. \\
\hline $1 \mu \mathrm{M}$ & $1 \mu \mathrm{M}$ PI103 & $-90 \%$ ** & $53 \%$ ** & $5,02 f a c h^{* *}$ \\
\hline
\end{tabular}

Zusammenfassend zeigen die Daten, dass Bortezomib den antiproliferativen Effekt von Doxorubizin verstärkt. Die proapoptotischen Effekte von Doxorubizin werden 
durch dieses Medikament dagegen nicht signifikant beeinflusst. Pioglitazon verstärkt dagegen sowohl die antiproliferative Wirkung als auch die proapoptotische Wirkung von Doxorubizin signifikant, wobei die Caspasen 3 und 7 nicht involviert zu sein scheinen. PI103 kooperiert mit Doxorubizin sowohl hinsichtlich der Proliferationsinhibierung als auch der Apoptoseinduktion, wobei hierbei auch ein kooperativer Effekt auf die Aktivierung der Caspasen 3 und 7 stattfindet.

\subsubsection{Wirkung von 5-Aza, VPA, Bortezomib, Pioglitazon, PI103 oder Doxorubizin auf die TOP2a-Expression}

Wie in Kapitel 1.2.1 beschrieben, ist es möglich dass 5-Aza, VPA, Bortezomib und Pioglitazon einen Einfluss auf die Expression der TOP2a haben, wodurch die sensitivierende Wirkung gegenüber einer Behandlung mit Doxorubizin erklärt werden könnte. Um den Einfluss der oben genannten Medikamente auf die TOP2aExpression zu untersuchen, wurde zunächst ein TOP2a-spezifischer qRT-PCR Assay etabliert.

\subsection{Etablierung des TOP2a-qRT-PCR Assays}

Zum Zeitpunkt der Etablierung des Assays waren 3 Spleißvarianten des humanen TOP2a-Gens in der Ensemble-Datenbank bekannt. Diese 3 Sequenzen können unter den Nummern ENST0000026957, ENST00000348049 und ENST00000357601 in der Datenbank eingesehen werden. Da alle Spleißvarianten die Exone 1 bis 14 betreffen, wurden die Primerpaare in den Bereich von Exon 15 bis Exon 31 gelegt. Die Primerpaare waren hierbei intronübergreifend. Eine Überprüfung der Oligonukleotidpaare erfolgte zunächst mittels semiquantitativer PCR an cDNAs aus verschiedenen humanen Zelllinien. Um zu analysieren, ob die Primerpaare spezifisch für die humane TOP2a-cDNA sind, wurden sie auch an cDNA von murinen Embryonen (Tag 12,5) getestet (Daten nicht gezeigt). Das Primerpaar hTop2a_4F x hTop2a_4R wurde schließlich für die Analysen eingesetzt, da es spezifisch für die humane cDNA ist. Dieses Primerpaar umfasst die Exone 26 und 27 der humanen TOP2a und amplifiziert ein PCR-Produkt mit der Größe von 135 bp. 


\subsection{Effekte der Medikamente auf die TOP2a-Transkription und das TOP2a- Proteinlevel in HT1080-Zellen}

Die Auswirkungen auf die TOP2a-Transkription in HT1080-Zellen wurden nach einer 24stündigen Behandlung mit 5-Aza, VPA, Bortezomib, Pioglitazon oder PI103 analysiert. Die Ergebnisse sind in Abbildung 14A dargestellt. Für die Untersuchungen der TOP2a-Proteinlevel wurden die Zellen zusätzlich mit Doxorubizin inkubiert. Die Western Blot Analysen dieser Versuchsreihe wurden von Dr. med. Tiandong Yan (Klinische Pharmakologie und Pharmakogenetik, Universität Mainz) durchgeführt und für diese Arbeit zur Verfügung gestellt. Western Blot Analysen von vier unabhängigen Experimenten wurden densitometrisch ausgewertet. Die Mittelwerte mit den jeweiligen SEM-Werten sind in Abbildung 14B dargestellt.

Auf transkriptioneller Ebene zeigt sich, dass Pioglitazon zu einer 3fachen Steigerung der TOP2a-Expression gegenüber der Lösungsmittelkontrolle führt (Abbildung 14A). Die Behandlung mit 5-Aza, VPA und Bortezomib hat hingegen eine signifikante Reduktion der TOP2a-Expression zur Folge. Eine Behandlung der Zellen mit PI103 führt im Vergleich zur Lösungsmittelkontrolle zu keiner signifikanten Veränderung der TOP2a-Expression.

Auf Proteinebene kann man zunächst sehen, dass die Inkubation mit Doxorubizin zu einer, wenn auch nicht signifikanten, Erhöhung des TOP2a-Proteinlevels führt (Abbildung 14B). Eine Inkubation der HT1080-Zellen mit 5-Aza, VPA oder Pioglitazon hat dagegen keinen Einfluss auf das TOP2a-Proteinlevel. Die Inkubation der Zellen mit dem Proteasominhibitor Bortezomib führt hingegen zu einem signifikant erhöhten TOP2a-Level, wohingegen die Inkubation der Zellen mit dem dualen PI3Kinase/mTOR-Inhibitor PI103 eine signifikante Reduktion des TOP2a-Proteinlevels zur Folge hat. Eine Ko-Inkubation mit Doxorubizin führt dagegen zur Reversion dieser Effekte. 

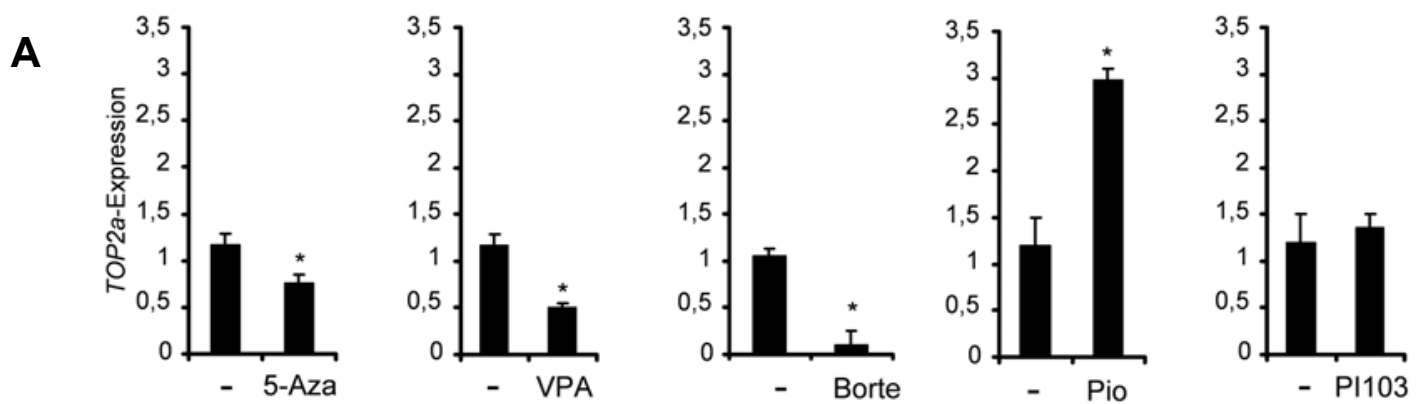

B
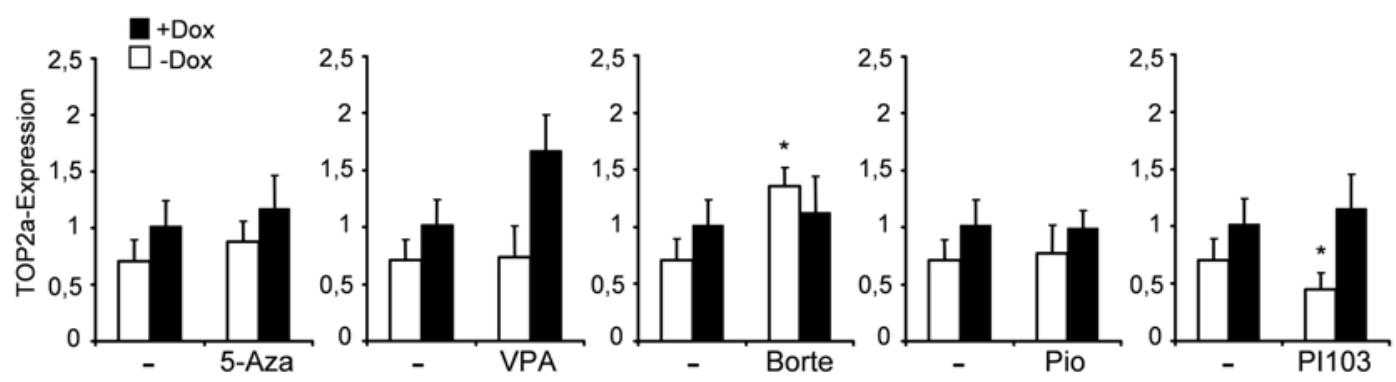

Abbildung 14: TOP2a-Expression in HT1080-Zellen nach Behandlung mit 5-Aza, VPA, Bortezomib, Pioglitazon, PI103 und/oder Doxorubizin. A HT1080-Zellen wurden für 24 Stunden mit $5 \mu$ M 5-Aza ( $n=12), 2$ mM VPA $(n=12), 10 \mathrm{nM}$ Bortezomib (Borte, $n=6), 10 \mu$ M Pioglitazon (Pio, $n=12)$ oder $1 \mu$ M PI103 $(n=16)$ behandelt. Als Kontrolle wurde das entsprechende Lösungsmittel (für 5-Aza und VPA: PBS $n=12$; für Pio und PI103: DMSO $n=25$; für Borte: $\mathrm{NaCl} n=34$ ) eingesetzt. Die TOP2a-Transkription wurde mittels qRT-PCR analysiert und auf die 18S rRNA normalisiert. Gezeigt sind die Mittelwerte +/- SEM. B Die Zellen wurden wie in A behandelt, zusätzlich jedoch noch in Kombination mit $1 \mu \mathrm{M}$ Doxorubizin. Die TOP2a-Proteinexpression wurde mittels Western Blot Analyse untersucht und densitometrisch ausgewertet. Gezeigt sind die Mittelwerte +/- SEM. Die Analyse beruht auf Western Blot Analysen von 4 unabhängigen Experimenten. * signifikant gegenüber dem Lösungsmittelwert $(p<0,05)$.

Zusammenfassend zeigen die Daten, dass die TOP2a-Expression durch die Medikamente prinzipiell moduliert werden kann. Die Interpretation der Daten wird jedoch dadurch erschwert, dass mRNA- und Proteinlevel der TOP2a in dem hier beschriebenen Versuchsaufbau durch alle Medikamente gegensätzlich reguliert zu sein scheinen. So reprimiert beispielsweise Bortezomib die TOP2a-mRNA-Expression, das TOP2a-Proteinlevel wird dagegen jedoch hochreguliert.

Für Pioglitazon und PI103, welche die antiproliferativen als auch proapoptotischen Effekte von Doxorubizin teilweise signifikant verstärkt haben (siehe Tabelle 10), wurde ein potentieller Einfluss der TOP2a-Expression auf diesen Kombinationseffekt dennoch in HTETOP-Zellen überprüft. 


\subsection{Analyse des antitumoralen Effekts von Doxorubizin und Pioglitazon} bzw. Doxorubizin und PI103 in Abhängigkeit von der TOP2aExpression

Bei HTETOP-Zellen handelt es sich um HT1080-Zellen, in denen das endogene TOP2a-Gen durch ein TOP2a-Transgen ersetzt wurde, dessen Expression durch Doxycyclin-Behandlung reprimiert werden kann.

Zunächst wurde geprüft, ob sich die TOP2a-Expression in dieser Zelllinie tatsächlich durch Doxycyclin supprimieren lässt. Hierzu wurden die Zellen für 24 oder 48 Stunden mit $1 \mu \mathrm{g} / \mathrm{ml}$ Doxycyclin behandelt und die TOP2a-Expression mit Hilfe der qRT-PCR bestimmt. Wie man in Abbildung 15 sieht, wurde die TOP2aExpression durch Doxycyclin eindeutig gehemmt. Der Verlust der TOP2a-Expression in HTETOP-Zellen ist schon nach 24stündiger Inkubation mit Doxycyclin sichtbar und erfährt keine Veränderung wenn die Zellen für einen längeren Zeitraum mit dem Medikament versetzt werden.

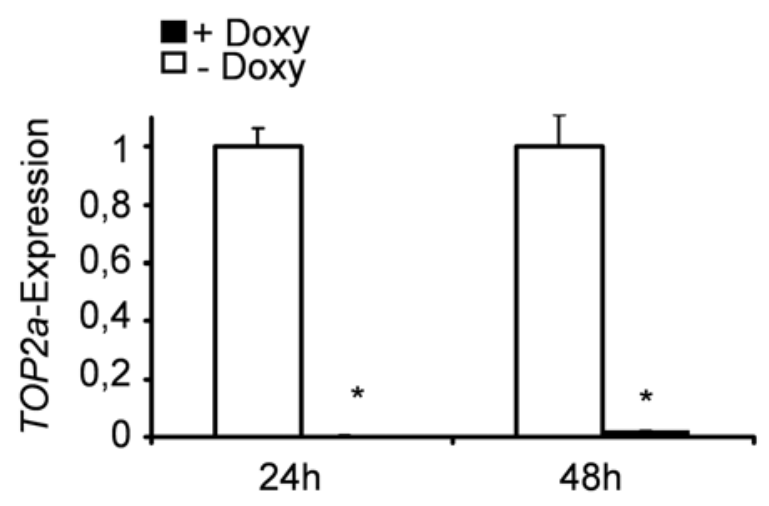

Abbildung 15: TOP2a-Expression nach Doxycyclin Behandlung. HTETOP-Zellen wurden für 24 Stunden mit $1 \mu \mathrm{g} / \mathrm{ml}$ Doxycyclin (Doxy, $n=6$ ) oder dem Lösungsmittel $(n=5)$ bzw. für 48 Stunden mit $1 \mu \mathrm{g} / \mathrm{ml}$ Doxy $(n=6)$ oder dem Lösungsmittel $(n=6)$ behandelt. Die TOP2a-Expression in den Zellen wurde anschließend mittels qRT-PCR vermessen und auf die 18S rRNA-Expression jeder Probe normalisiert. Die Expressionswerte ohne Doxy wurden $=1$ gesetzt. Gezeigt sind die Mittelwerte + - SEM. * signifikant gegenüber dem Lösungsmittelwert $(p<0,05)$.

Zusätzlich zur Reduktion der TOP2a-Expression auf RNA-Ebene konnte die Reduktion auch auf Proteinebene mittels Western Blot Analyse in HTETOP-Zellen nachgewiesen werden (Abbildung 16).

Diese Ergebnisse zeigen, dass sich die TOP2a-Expression in HTETOP-Zellen sehr effizient reduzieren lässt. 


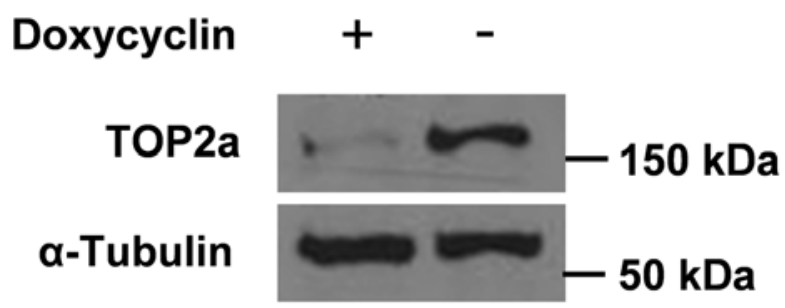

Abbildung 16: TOP2a-Level in HTETOP-Zellen nach Inkubation mit Doxycyclin. HTETOP-Zellen wurden mit $1 \mu \mathrm{g} / \mathrm{ml}$ Doxycyclin für 24 Stunden behandelt. Die TOP2a-Expression wurde auf Proteinebene mittels Western Blot Analysen überprüft. Als Ladungskontrolle diente die Detektion von a-Tubulin.

Um nun den Einfluss der TOP2a auf die ermittelten antitumoralen Effekte einer Kombinationsbehandlung von Doxorubizin mit Pioglitazon oder Pl103 zu untersuchen, wurden Apoptosemessungen mit Hilfe des Annexin V-Assays vorgenommen. Bei den Analysen, die von Dr. med. Tiandong Yan durchgeführt wurden, wurde die TOP2a-Expression in HTETOP-Zellen dabei durch Doxycyclin moduliert. Zunächst ist der Abbildung $17 \mathrm{zu}$ entnehmen, dass Pioglitazon und PI103 in HTETOP-Zellen keine Apoptose induzieren. Weiterhin wird deutlich, dass weder PI103 noch Pioglitazon einen kooperativen proapoptotischen Effekt mit Doxorubizin in HTETOP-Zellen zeigen. Dies steht ganz im Gegensatz zu den Ergebnissen an HT1080-Zellen.

Ferner zeigen die Daten, dass der durch Doxorubizin hervorgerufene proapoptotische Effekt in den HTETOP-Zellen durch Abschalten der TOP2a supprimiert wird. Letzterer Effekt ist im Gegensatz zu Literaturangaben nicht signifikant. Auch kann dieser Effekt durch eine gleichzeitige Inkubation mit Pioglitazon oder PI103 nicht eindeutig moduliert werden.

Obwohl diese Ergebnisse vermuten lassen, dass der kooperative antitumorale Effekt von Doxorubizin und Pioglitazon, oder von Doxorubizin und PI103 TOP2a-unabhängig ist, sind sie auf Grund mangelnder Signifikanz nicht aussagekräftig. 
A

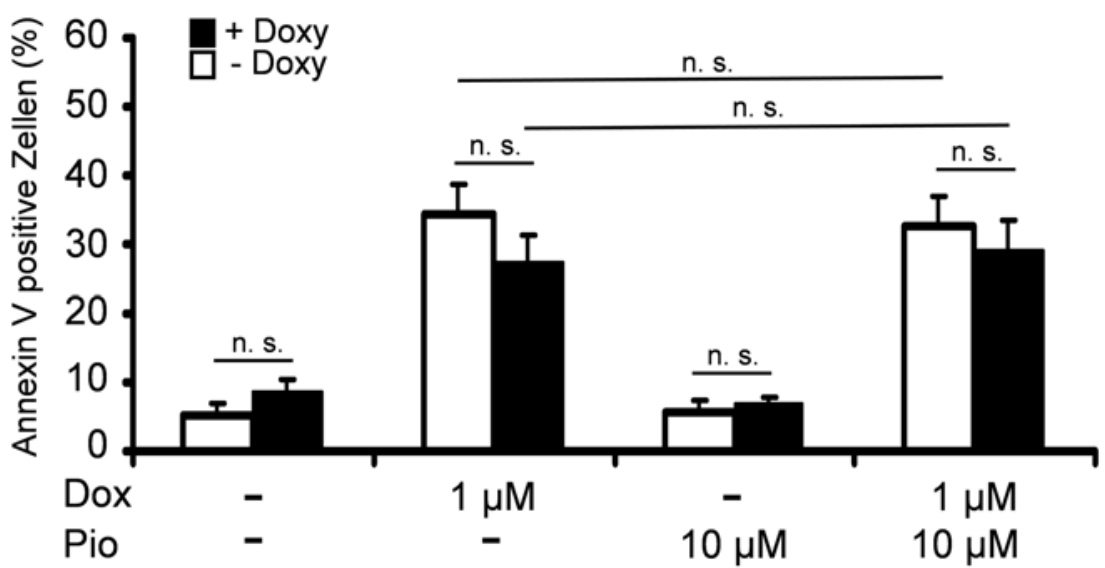

B

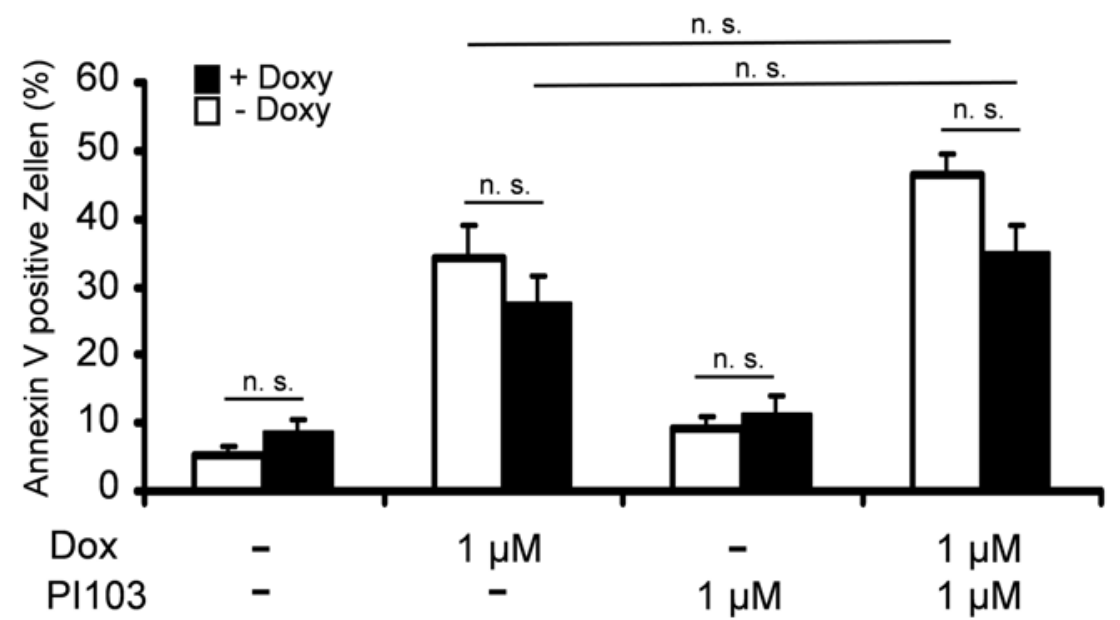

Abbildung 17: Apoptosemessungen in TOP2a-exprimierenden und TOP2a-defizienten HTETOPZellen. Die Messung der Annexin V positiven Zellen nach einer 24stündigen Inkubation der Zellen mit Doxorubizin (Dox) und/oder A Pioglitazon (Pio) bzw. B PI103 wurde in TOP2a-exprimierenden (-Doxy) und in TOP2a-defizienten (+Doxy) HTETOP-Zellen durchgeführt. Die Reprimierung des TOP2a-Transgens erfolgte durch gleichzeitige Zugabe von $1 \mu \mathrm{g} / \mathrm{ml}$ Doxycyclin (Doxy). Gezeigt sind die Mittelwerte +/- SEM von insgesamt 4 unabhängigen Experimenten. n. S., nicht signifikant.

\subsubsection{Untersuchung des kooperativen antitumoralen Effekts von Doxorubizin mit Pioglitazon oder PI103 in der RMS-Zellinie TP5014}

Die Analysen an HT1080-Zellen zeigen, dass Pioglitazon als auch PI103 sowohl die antiproliferativen als auch proapoptotischen antitumoralen Effekte von Doxorubizin steigern können. Nun sollte untersucht werden, ob dies auch für Rhabdomyosarkomzelllinien zutrifft. Dafür wurde zunächst die murine RMS-Zelllinie TP5014 verwendet. Diese Zellen wurden aus RMS einer Ptch ${ }^{\text {neo12/+}}$-Maus generiert [150]. 


\subsubsection{Pioglitazon verstärkt den antiproliferativen, nicht aber den proapoptotischen Effekt von Doxorubizin}

Die Proliferationsanalysen in TP5014-Zellen wurden mit 100 nM und 500 nM Doxorubizin durchgeführt. Dabei zeigt 100 nM Doxorubizin keinen signifikanten antiproliferativen Effekt, wogegen 500 nM Doxorubizin die Proliferation signifikant gegenüber der Lösungsmittelkontrolle hemmt (Abbildung 18). Obwohl eine alleinige Inkubation mit $10 \mu \mathrm{M}$ Pioglitazon keinen Effekt auf die Proliferation hat, kann ein signifikanter sensitivierender Effekt auf mit 500 nM Doxorubizin behandelte Zellen festgestellt werden.

A

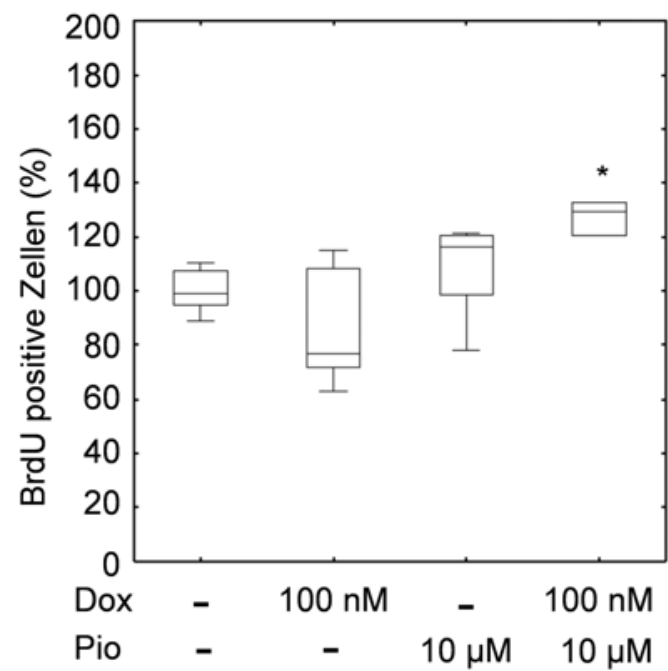

B

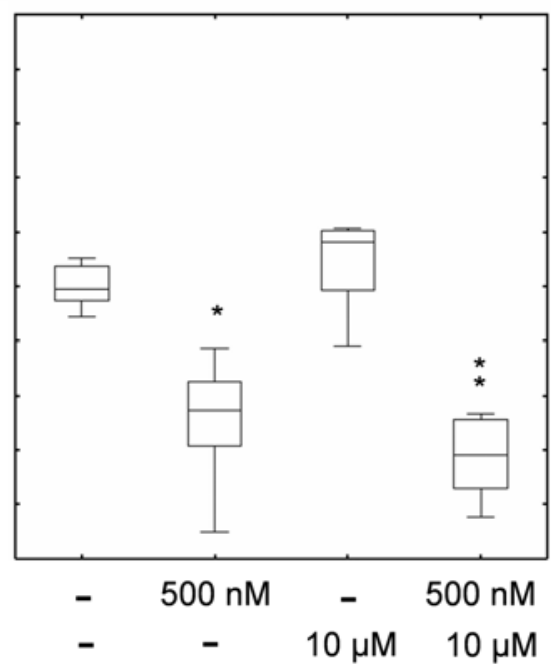

Abbildung 18: Proliferationsverhalten der TP5014-Zellen nach Behandlung mit Doxorubizin und/oder Pioglitazon. TP5014-Zellen wurden für 24 Stunden mit A 100 nM Doxorubizin (Dox, $n=12$ ), $10 \mu M$ Pioglitazon (Pio, $n=6$ ), sowie der Kombination beider Medikamente $(n=3)$, bzw. mit B $1 \mu$ M Dox $(n=18), 10 \mu$ M Pio $(n=6)$ oder der Kombination beider Medikamente $(n=6)$ behandelt. Die Inkubation mit dem Lösungsmittel $(n=18)$ diente als Kontrolle. Der Effekt auf die Proliferation der Zellen wurde auf die Lösungsmittelkontrolle (100\%) normalisiert und als Box-Whisker-Plot dargestellt. * signifikant $(p<0,05)$ im Vergleich zur Lösungsmittelkontrolle, ${ }^{* *}$ signifikant im Vergleich zur Behandlung mit sowohl dem Lösungsmittel, Doxorubizin als auch Pioglitazon. $\square$, $25 \%-75 \%$; Bereich ohne Ausreißer; -, Median; ${ }^{\circ}$, Ausreißer.

Bei Durchführung der Annexin V-Messungen ist zunächst ein hohes basales Apoptoselevel in den mit Lösungsmittel-behandelten Zellen beobachtet worden (Abbildung 19A). Doxorubizin führt in einer Konzentration von $1 \mu \mathrm{M}$ zur signifikanten Erhöhung Annexin V positiver Zellen. Dagegen war der Effekt durch alleinige Gabe von $10 \mu \mathrm{M}$ Pioglitazon nicht signifikant. Auch konnte kein kooperativer Effekt der beiden Medikamente festgestellt werden. Im Gegensatz hierzu führt eine alleinige Pioglitazon-Behandlung zur signifikanten Induktion der Aktivität der Caspasen 3 
und 7 (Abbildung 19B). Obwohl Pioglitazon die Doxorubizin-vermittelte Caspase 3/7 Aktivität steigert, war dieser Effekt jedoch nicht signifikant.

A

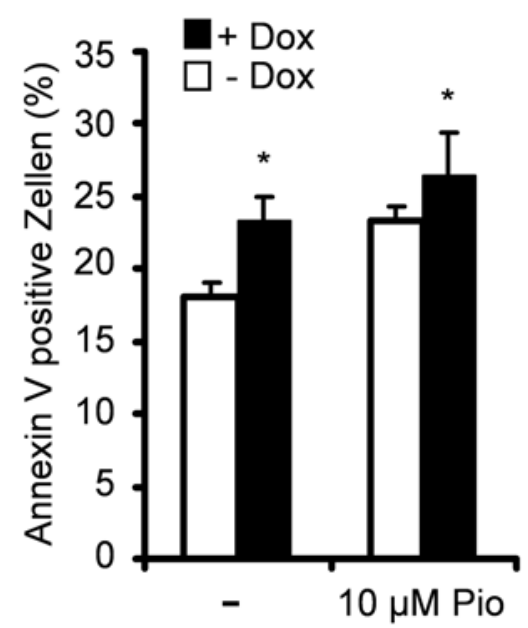

B

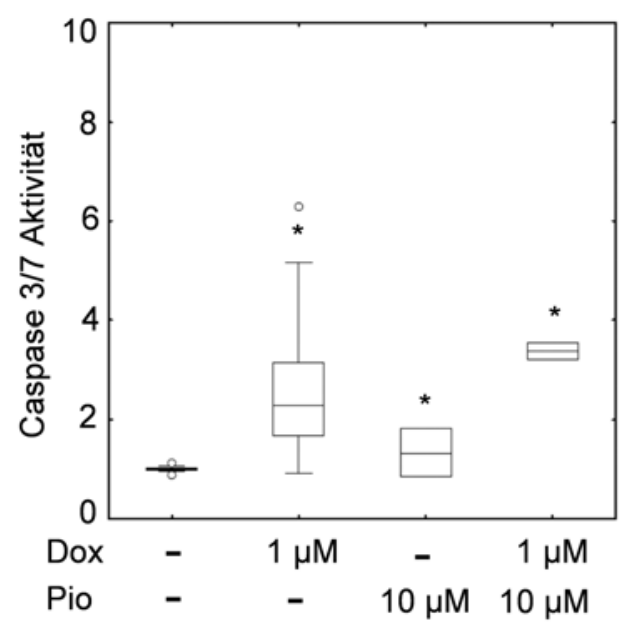

Abbildung 19: Apoptoseinduktion in TP5014-Zellen nach Behandlung mit Doxorubizin und/oder Pioglitazon. A TP5014-Zellen wurden für 24 Stunden mit $1 \mu \mathrm{M}$ Doxorubizin (Dox, $\mathrm{n}=12$ ), $10 \mu \mathrm{M}$ Pioglitazon (Pio, $n=2)$, oder der Kombination beider Medikamente $(n=2)$ behandelt. Als Kontrolle wurden Zellen mit dem Lösungsmittel $(n=12)$ behandelt. Der Mittelwert (+/- SEM) Annexin V positiver Zellen ist als Säulendiagramm dargestellt. B Die Zellen wurden für 24 Stunden mit $1 \mu M$ Dox $(n=14)$, $10 \mu \mathrm{M}$ Pio $(n=2)$ oder der Kombination beider Medikamente $(n=2)$ behandelt. Die Behandlung mit dem Lösungsmittel $(n=14)$ diente als Kontrolle. Die Aktivität der Caspasen 3 und 7 wurde in Relation zum Lösungsmittel (Mittelwert des Lösungsmittels wurde 1 gesetzt) in Form eines Box-Whisker-Plots dargestellt. *signifikant $(p<0,05)$ im Vergleich zur Lösungsmittelkontrolle. $\square, 25 \%$ - 75 \%; I, Bereich ohne Ausreißer; -, Median; ’ , Ausreißer.

Zusammengefasst zeigen diese Daten, dass Pioglitazon in TP5014-Zellen den proliferationshemmenden, nicht aber den proapoptotischen Effekt von Doxorubizin signifikant steigern kann.

\subsubsection{PI103 verstärkt sowohl den antiproliferativen als auch den proapoptotischen Effekt von Doxorubizin}

Abbildung 20 zeigt das Ergebnis zur Proliferationsanalyse in TP5014-Zellen, die mit 100 nM bzw. 500 nM Doxorubizin in Kombination mit $1 \mu \mathrm{M}$ PI103 bzw. 3 MM PI103 behandelt worden sind. Der proliferationsinhibierende Effekt von Doxorubizin in TP5014-Zellen wurde bereits in Abschnitt 4.1.2.1 beschrieben.

Sowohl $1 \mu \mathrm{M}$ als auch $3 \mu \mathrm{M}$ Pl103 führen zu einer Hemmung der Proliferation von TP5014-Zellen (Abbildung 20). Die Hemmung des Wachstums liegt dabei im Mittel bei $30 \%$ bzw. $50 \%$. Der antiproliferative Effekt von $100 \mathrm{nM}$ Doxorubizin wird durch beide PI103-Konzentrationen (Abbildung 20A), derjenige von $500 \mathrm{nM}$ Doxorubizin 
nur in Kombination mit $3 \mu \mathrm{M}$ PI103 signifikant gesteigert (Abbildung 20B).

A

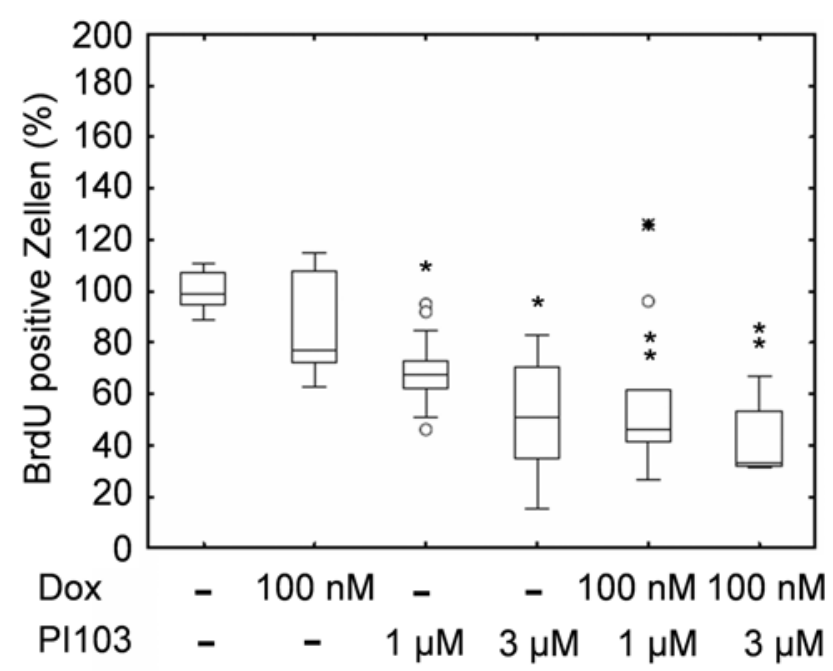

B

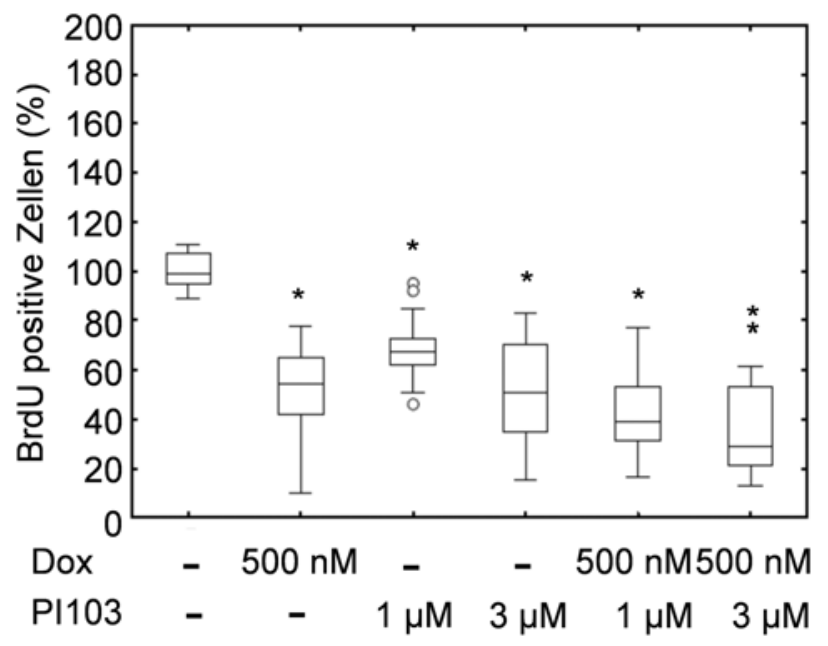

Abbildung 20: Proliferationsverhalten von TP5014-Zellen nach Behandlung mit Doxorubizin und/oder PI103. Die Zellen wurden für 24 Stunden mit A 100 nM Doxorubizin (Dox, $n=12$ ), $1 \mu \mathrm{M}$ PI103 $(n=17), 3 \mu M$ PI103 $(n=14)$ oder der Kombination aus Dox und $1 \mu$ M PI103 $(n=12)$ oder $3 \mu \mathrm{M}$ PI103 ( $n=9)$, bzw. mit B $1 \mu \mathrm{M}$ Dox $(\mathrm{n}=18), 1 \mu \mathrm{M}$ PI103 $(\mathrm{n}=17), 3 \mu \mathrm{M}$ PI103 $(\mathrm{n}=14)$ oder der Kombination von Dox und $1 \mu \mathrm{M}$ PI103 $(\mathrm{n}=15)$ oder $3 \mu \mathrm{M}$ PI103 $(\mathrm{n}=15)$ inkubiert. Die Behandlung mit dem Lösungsmittel $(n=18)$ diente als Kontrolle. Der Effekt auf die Proliferation der Zellen wurde auf die Lösungsmittelkontrolle (100\%) normalisiert und als Box-Whisker-Plot dargestellt. * signifikant $(p<0,05)$ im Vergleich zur Lösungsmittelkontrolle, ${ }^{* *}$ signifikant im Vergleich zur Behandlung mit sowohl dem Lösungsmittel, Doxorubizin als auch PI103. $\square, 25 \%$ - 75 \%; I, Bereich ohne Ausreißer; -, Median; ’ , Ausreißer, $\mathbf{a}$, Extremwert.

Wie im Abschnitt 4.1.2.1 bereits beschrieben wurde, führt die alleinige Inkubation mit $1 \mu \mathrm{M}$ Doxorubizin zum signifikanten Anstieg Annexin V positiver TP5014-Zellen. Dagegen kann die Zahl Annexin $\mathrm{V}$ positiver Zellen durch alleinige Behandlung mit $1 \mu \mathrm{M}$ PI103 oder $3 \mu \mathrm{M}$ PI103 nicht signifikant erhöht werden (Abbildung 21A). Die 
Kombination von Doxorubizin mit $3 \mu \mathrm{M}$, nicht aber mit $1 \mu \mathrm{M}$ PI103, hat dagegen einen signifikanten kooperativen Effekt auf die Apoptoseinduktion. Die Aktivität der Caspasen 3 und 7 wird sowohl durch Doxorubizin, als auch durch $1 \mu \mathrm{M}$ und $3 \mu \mathrm{M}$ Pl103 signifikant induziert (Abbildung 21B). Auch hier wird eine signifikante Steigerung des Doxorubizin vermittelten Effekts in Kombination mit $3 \mu \mathrm{M}$ PI103 erzielt.

A

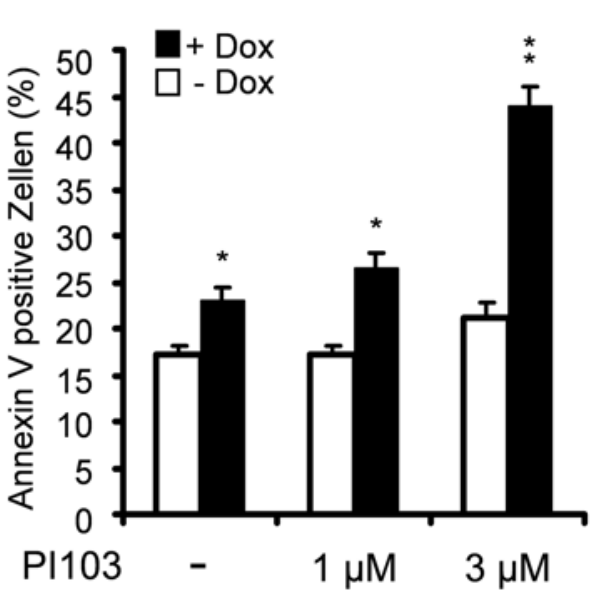

B

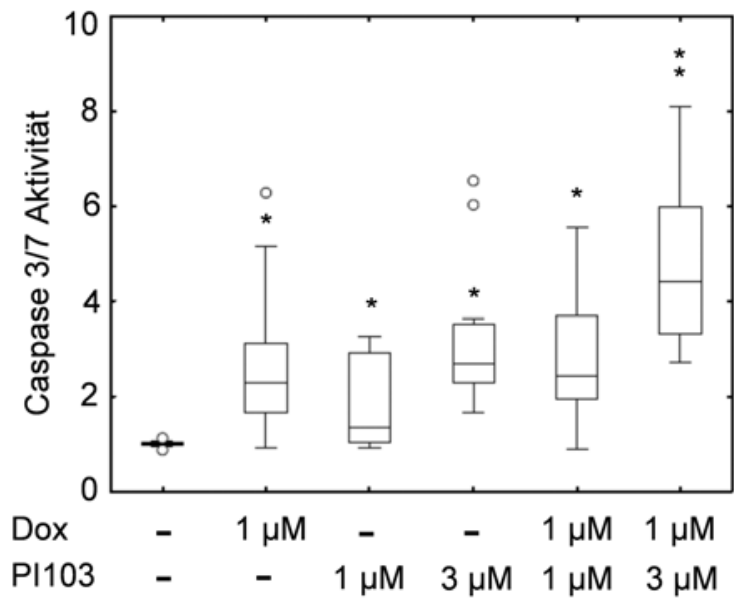

Abbildung 21: Apoptoseinduktion in TP5014-Zellen nach Behandlung mit Doxorubizin und/oder PI103. A TP5014-Zellen wurden für 24 Stunden mit $1 \mu \mathrm{M}$ Doxorubizin (Dox, $n=14$ ), $1 \mu \mathrm{M}$ PI103 $(n=12), 3 \mu \mathrm{M}$ PI103 $(n=14)$ oder der Kombination von Dox und $1 \mu \mathrm{M}$ PI103 $(n=12)$, bzw. $3 \mu \mathrm{M}$ PI103 $(n=14)$ behandelt. Als Kontrolle diente die Inkubation mit dem Lösungsmittel $(n=14)$. Der Mittelwert (+/- SEM) der Annexin V positiven Zellen ist als Säulendiagramm dargestellt. B Die Zellen wurden für 24 Stunden mit $1 \mu \mathrm{M}$ Dox, $1 \mu \mathrm{M}$ PI103, $3 \mu \mathrm{M}$ PI103 oder der Kombination von Dox und $1 \mu \mathrm{M}$ PI103, bzw. 3 MM PI103 behandelt. Die Inkubation mit dem Lösungsmittel diente als Kontrolle (je Behandlung: $n=14$ ). Die Aktivität der Caspasen 3 und 7 wurde in Relation zum Lösungsmittel (Mittelwert des Lösungsmittels wurde 1 gesetzt) in Form eines Box-Whisker-Plots dargestellt. * signifikant $(p<0,05)$ im Vergleich zur Lösungsmittelkontrolle, ** signifikant im Vergleich zur Behandlung mit sowohl dem Lösungsmittel, Doxorubizin als auch PI103. $\square, 25 \%$ - $75 \%$; I, Bereich ohne Ausreißer; -, Median; ${ }^{\circ}$, Ausreißer.

Zusammenfassend kann festgehalten werden, dass eine Kombinationsbehandlung der Zellen mit Doxorubizin und 3 MM PI103 signifikante kooperative Effekte, sowohl hinsichtlich der Proliferationshemmung als auch hinsichtlich der Apoptoseinduktion, bewirkt.

\subsubsection{Analyse der kooperativen antitumoralen Effekte in der humanen RMS-Zelllinie RD}

Die bisherigen Daten zeigen, dass die antiproliferativen und die proapoptotischen Effekte von Doxorubizin (Erhöhung Annexin V positiver Zellen; Induktion der 
Caspase 3/7 Aktivität) nur durch den PI3Kinase/mTOR-Inhibitor PI103 in den bisher untersuchten Zelllinien HT1080 und TP5014 gesteigert werden können. Aus diesem Grund habe ich mich ab diesem Zeitpunkt auf die Analyse der kooperativen antitumoralen Effekte von Doxorubizin und PI103 konzentriert. Als nächstes sollte untersucht werden, ob die Kombination von Doxorubizin und PI103 auch in der humanen Rhabdomyosarkomzellinie RD einen kooperativen antitumoralen Effekt zeigt.

\subsubsection{PI103 verstärkt den antitumoralen Effekt von Doxorubizin in der humanen RMS-Zelllinie RD}

Die antitumoralen Effekte von Doxorubizin und PI103 wurden an RD-Zellen mittels Proliferationsanalysen, Annexin V-Messungen und der Bestimmung der Aktivität der Caspasen 3 und 7 ausgetestet. Auch in diesem Versuch wurden $100 \mathrm{nM}$ oder $500 \mathrm{nM}$ Doxorubizin für die Proliferationsanalysen bzw. $1 \mu \mathrm{M}$ Doxorubizin in den Apoptoseassays eingesetzt. PI103 wurde, wie auch zuvor, in Konzentrationen von $1 \mu \mathrm{M}$ und $3 \mu \mathrm{M}$ verwendet.

Wie Abbildung 22 zu entnehmen ist, führt $100 \mathrm{nM}$ bzw. $500 \mathrm{nM}$ Doxorubizin in RDZellen zu einer signifikanten Proliferationsinhibierung von etwa 25\% bzw. 55\%. Auch die alleinige Inkubation der Zellen mit $1 \mu \mathrm{M}$ oder $3 \mu \mathrm{M}$ PI103 führt zur signifikanten Hemmung der Proliferation (Abbildung 22). Die Hemmung des Wachstums liegt dabei im Mittel bei 19\% bzw. 43\%. Der antiproliferative Effekt von 100 nM Doxorubizin kann durch beide PI103 Konzentrationen nicht signifikant gesteigert werden (Abbildung 22A). Dagegen wurde derjenige von $500 \mathrm{nM}$ Doxorubizin in Kombination mit 1 MM PI103 signifikant erhöht (Abbildung 22B). 
A

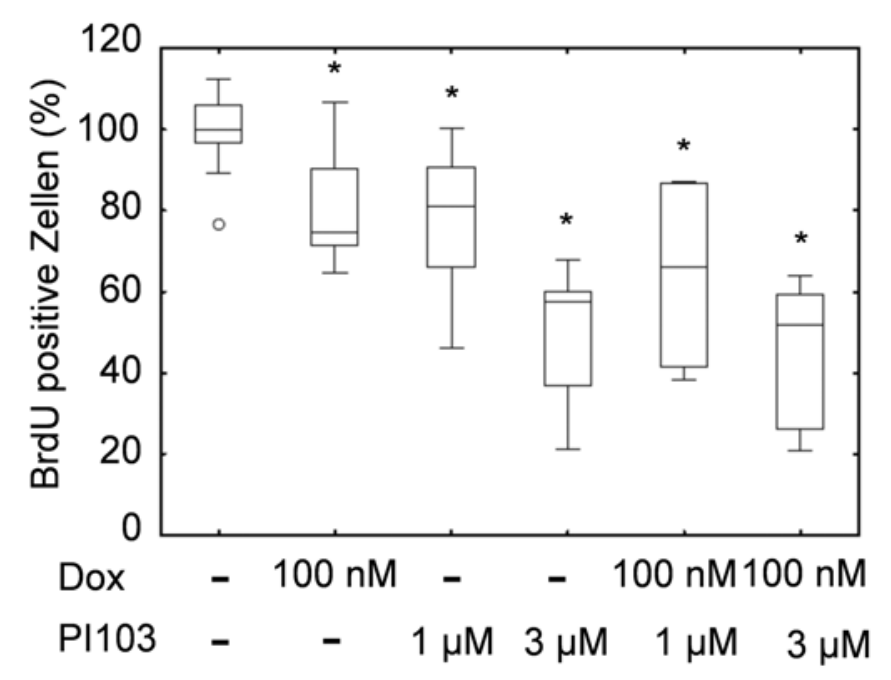

B

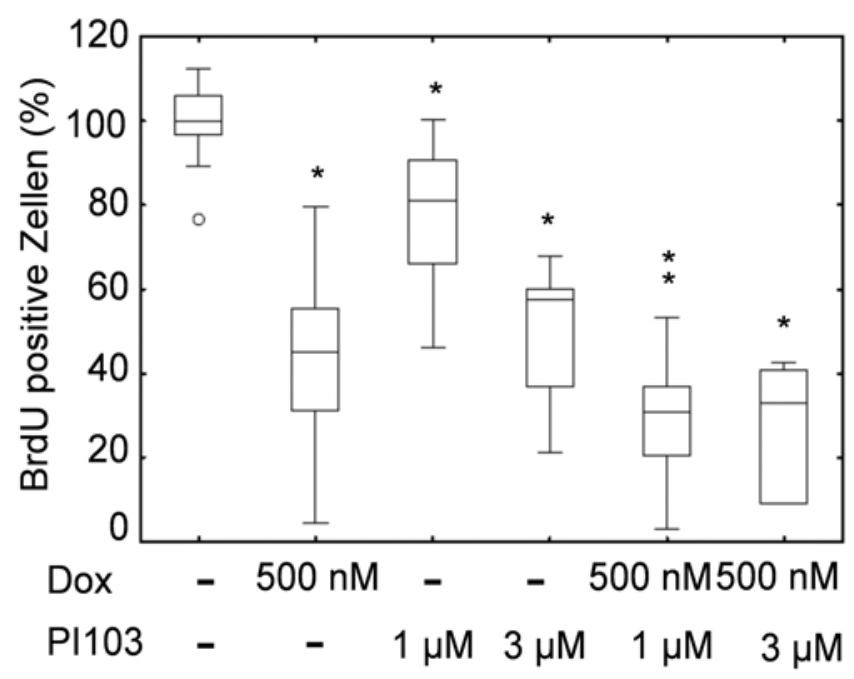

Abbildung 22: Proliferationsverhalten der RD-Zellen nach der Behandlung mit Doxorubizin und/oder PI103. RD-Zellen wurden für 24 Stunden mit $\mathbf{A} 100 \mathrm{nM}$ Doxorubizin (Dox, $\mathrm{n}=9$ ), $1 \mu \mathrm{M}$ PI103 $(n=16), 3 \mu$ M PI103 $(n=9)$ oder der Kombination aus Dox und $1 \mu$ M PI103 $(n=6)$ oder $3 \mu$ M PI103 $(n=9)$ bzw. mit B $500 \mathrm{nM}$ Dox $(n=16), 1 \mu \mathrm{M}$ PI103 $(n=16), 3 \mu \mathrm{M}$ PI103 $(n=9)$ oder der Kombination von Dox und $1 \mu$ M PI103 $(n=16)$ bzw. $3 \mu$ M PI103 $(n=6)$ behandelt. Die Behandlung mit dem Lösungsmittel $(n=14)$ diente als Kontrolle. Der Effekt auf die Proliferation der Zellen wurde auf die Lösungsmittelkontrolle (100\%) normalisiert und als Box-Whisker-Plot dargestellt. * signifikant $(p<0,05)$ im Vergleich zur Lösungsmittelkontrolle, ${ }^{* *}$ signifikant im Vergleich zur Behandlung mit sowohl dem Lösungsmittel, Doxorubizin als auch PI103. $\square, 25 \%$ - $75 \%$; I, Bereich ohne Ausreißer; -, Median; ${ }^{\circ}$, Ausreißer.

Auch die Apoptoserate kann in RD-Zellen durch $1 \mu \mathrm{M}$ Doxorubizin signifikant gesteigert werden. Dies wurde sowohl im Annexin V-Assay als auch bei der Messung der Aktivität der Caspasen 3 und 7 sichtbar (Abbildung 23). Eine alleinige Behandlung mit $1 \mu \mathrm{M}$ PI103 zeigt im Annexin V-Assay keine Induktion der Apoptose, wohingegen $3 \mu \mathrm{M}$ Pl103 zur signifikanten Apoptoseinduktion im Vergleich zu der Lösungsmittelkontrolle führt (Abbildung 23A). In Kombination mit Doxorubizin kann 
bei beiden Konzentrationen von PI103 eine signifikante Steigerung der Doxorubizinvermittelten Apoptoserate detektiert werden, wobei die Steigerung mit der PI103Dosis korreliert. Im Caspase 3/7 Assay können sowohl durch $1 \mu \mathrm{M}$ PI103 als auch durch $3 \mu \mathrm{M}$ PI103 eine signifikante Erhöhung der Aktivität der Caspasen detektiert werden (Abbildung 23B). In Kombination mit Doxorubizin zeigt sich ein signifikanter kooperativer Effekt, der mit $3 \mu \mathrm{M}$ PI103 höher ist, als mit $1 \mu \mathrm{M}$ PI103.

A

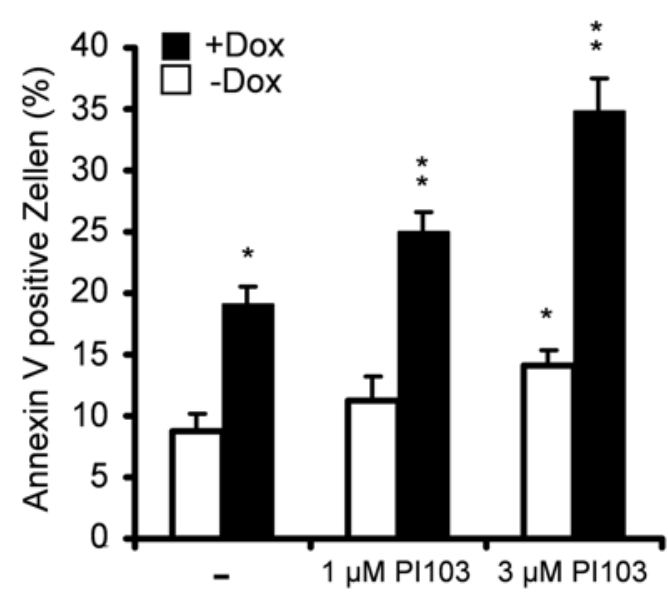

B

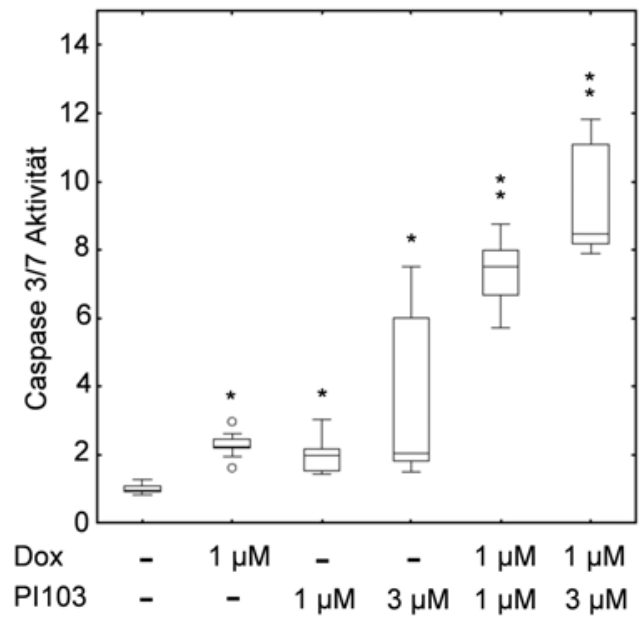

Abbildung 23: Induktion der Apoptose nach Behandlung von RD-Zellen mit Doxorubizin und/oder PI103. A RD-Zellen wurden für 24 Stunden mit $1 \mu \mathrm{M}$ Doxorubizin (Dox, $\mathrm{n}=13$ ), $1 \mu \mathrm{M}$ PI103 $(n=14), 3 \mu \mathrm{M} \mathrm{PI} 103(n=17)$ oder der Kombination von Dox und $1 \mu \mathrm{M}$ PI103 $(n=8)$, bzw. $3 \mu \mathrm{M}$ PI103 $(n=13)$ behandelt. Als Kontrolle diente die Inkubation mit dem Lösungsmittel $(n=19)$. Der Mittelwert (+/- SEM) der Annexin V positiven Zellen ist als Säulendiagramm dargestellt. B Die Zellen wurden für 24 Stunden mit $1 \mu \mathrm{M}$ Dox $(n=11), 1 \mu \mathrm{M}$ PI103 $(n=18), 3 \mu \mathrm{M}$ PI103 $(n=16)$ oder der Kombination aus Dox und $1 \mu \mathrm{M}$ PI103 $(n=9)$, bzw. $3 \mu \mathrm{M}$ PI103 $(n=7)$ behandelt. Die Inkubation mit dem Lösungsmittel $(n=20)$ diente als Kontrolle. Die Aktivität der Caspasen 3 und 7 wurde in Relation zum Lösungsmittel (Mittelwert des Lösungsmittels wurde 1 gesetzt) in Form eines Box-Whisker-Plots dargestellt. * signifikant $(p<0,05)$ im Vergleich zur Lösungsmittelkontrolle, ${ }^{* *}$ signifikant im Vergleich zur Behandlung mit sowohl dem Lösungsmittel, Doxorubizin als auch PI103. $\square, 25 \%$ - 75 \%; I, Bereich ohne Ausreißer; -, Median; ${ }^{\circ}$, Ausreißer.

Zusammengefasst zeigen diese Daten, dass die Inkubation der RD-Zellen mit Doxorubizin und PI103, genauso wie in TP5014- und HT1080-Zellen, einen signifikanten kooperativen Effekt hinsichtlich der Proliferationsinhibierung als auch auf die Apoptoseinduktion hat.

\subsubsection{Doxorubizin und PI103 kooperieren in der Aktivierung von Caspase 3}

PI103 ist ein dualer PI3Kinase und mTOR-Inhibitor. Wie in Kapitel 1.2.2.3 bereits erläutert, ist 2010 eine Studie publiziert worden, die den kooperativen antiproliferativen Effekt von PI103 und Doxorubizin in RD-Zellen näher untersucht hat 
[112]. Da die Autoren keinen kooperativen Effekt hinsichtlich Apoptoseinduktion und Aktivierung der Caspase 3 beschrieben haben, habe ich diesen Effekt nun im Detail untersucht.

Wie bereits in der Einleitung beschrieben wurde, inaktiviert PI103 die PI3Kinase und hemmt dadurch die Aktivität bzw. die Phosphorylierung von AKT. Zudem inhibiert PI103 auch mTOR (siehe 1.2.2.1).

Der Phosphorylierungszustand von AKT kann anhand eines Anti-pAkt Antikörpers, der die Phosphorylierung an Serin 473 von AKT detektiert, im Western Blot untersucht werden. Um eine Aussage über den Phosphorylierungszustand von AKT zu treffen, muss in den Proben auch die Gesamtexpression von unphosphoryliertem AKT nachgewiesen werden, was mit Hilfe eines Anti-Akt Antikörper geschieht. Der Aktivierungszustand von mTOR kann über die Phosphorylierung von dem im Signalweg stromabwärts von mTOR gelegenen ribosomalen Protein S6 mit Hilfe der AntipS6 und Anti-S6 Antikörper untersucht werden. Für den Nachweis der aktiven Caspase 3 wurde ein Anti-Caspase 3 Antikörper eingesetzt, der die Caspase 3Proform, welche eine Größe von $32 \mathrm{kDa}$ aufweist, als auch die Cleavage-Produkte von $17 \mathrm{kDa}$ und $12 \mathrm{kDa}$, die bei Aktivität der Caspase 3 auftreten, detektiert.

Für die Analyse wurden die RD-Zellen für 24 Stunden mit $1 \mu \mathrm{M}$ Doxorubizin, $3 \mu \mathrm{M}$ PI103, der Kombination beider Medikamente oder dem Lösungsmittel behandelt.

Wie man in Abbildung 24 sieht, führt eine alleinige Pl103-Behandlung zur Abnahme der AKT-Phosphorylierung. Durch die Kombinationsbehandlung wird AKT dann vollständig dephosphoryliert (Abbildung 24). Auch die Aktivität von mTOR wird durch Pl103 sehr gut gehemmt, was durch eine komplette Dephosphorylierung von S6 sichtbar wird. Dies zeigt die Funktionalität von PI103. Eine Untersuchung der Caspase 3 zeigte, dass eine alleinige Behandlung mit Doxorubizin oder mit Pl103 zum Auftreten des $12 \mathrm{kDa}$ Cleavage-Produktes führt, dessen Auftreten durch eine kombinierte Behandlung dramatisch gesteigert wird. Unter Kombinationsbehandlung kann gleichzeitig eine Abnahme der $32 \mathrm{kDa}$ Caspase 3-Proform beobachtet werden. 


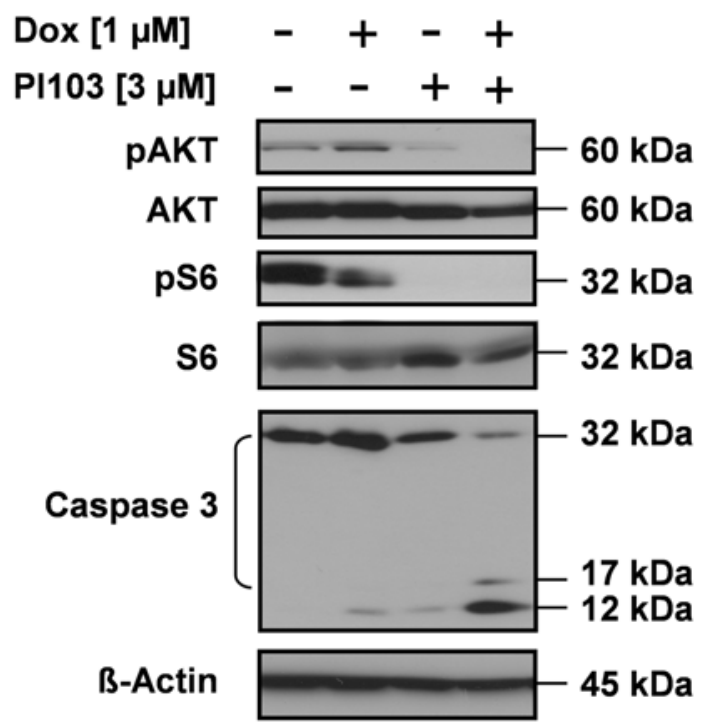

Abbildung 24: Western Blot Analyse der RD-Zellen nach Inkubation mit Doxorubizin und PI103. Der Aktivierungsstatus von AKT, S6 und der Caspase 3 wurde nach einer Inkubation der Zellen mit $1 \mu \mathrm{M}$ Doxorubizin (Dox), $3 \mu \mathrm{M}$ PI103 oder der Kombination beider Medikamente von 24 Stunden analysiert. Die Abbildung zeigt repräsentativ eines von 4 unabhängigen Experimenten. Zur Normalisierung der Proteinbanden wurde das Proteinlevel von ß-Actin bestimmt.

Zusammenfassend bestätigen diese Daten, dass eine Kombination von Doxorubizin und PI103 zu einer enormen Steigerung der Caspase 3 Aktivität führt, welche auch auf Proteinebene sehr gut sichtbar gemacht werden kann.

\subsection{Molekulare Analysen zum kooperativen proapoptotischen Effekt von Doxorubizin und PI103 in der RMS-Zelllinie RD}

Im Rahmen dieser Arbeit wurde nun der zugrunde liegende Mechanismus des kooperativen proapoptotischen Effekts von Doxorubizin und PI103 analysiert.

\subsubsection{Kein kooperativer proapoptotischer Effekt von PI103 mit dem TOP2-Inhibitor Etoposid}

Zunächst stellte sich die Frage, ob PI103 Tumorzellen auch gegenüber anderen TOP2-Inhibitoren sensitivieren kann, oder ob der Effekt von Pl103 für eine Kombination mit Doxorubizin spezifisch ist. Für diese Untersuchungen wurden daher Apoptosemessungen mit Etoposid durchgeführt. Bei Etoposid handelt es sich um ein Zytostatikum, welches den TOP2-Hemmern zugeordnet ist. Es wird vermutet, dass Etoposid die Funktion der TOP2 hemmt, ohne dabei in die DNA zu interkalieren [168, 169].

Wie auch Doxorubizin, induziert Etoposid die Apoptose (Abbildung 25). Wird PI103 in 
Kombination mit Etoposid verabreicht, erhöht sich zwar die Anzahl der Annexin V positiven Zellen, jedoch zeigt sich kein signifikanter kooperativer proapoptotischer Effekt. Die Induktion der Caspase 3/7 Aktivität durch Behandlung der Zellen mit Etoposid unterliegt großen Schwankungen (Abbildung 25). Ein kooperativer Effekt von Etoposid und PI103 kann jedoch auch in diesem Assay nicht detektiert werden.

A

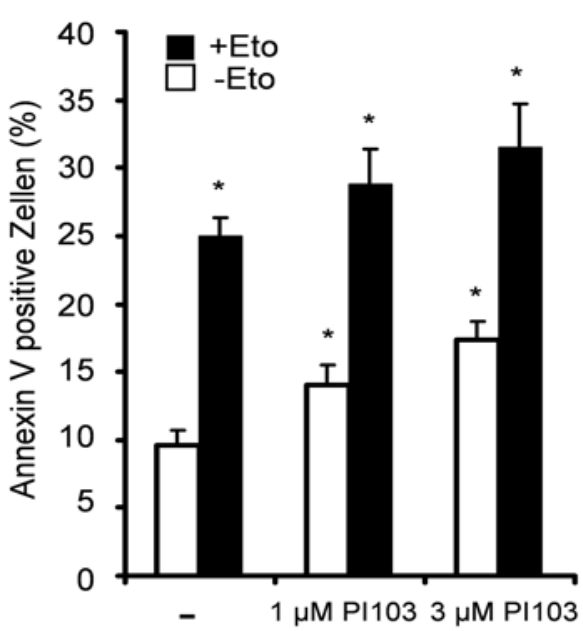

B

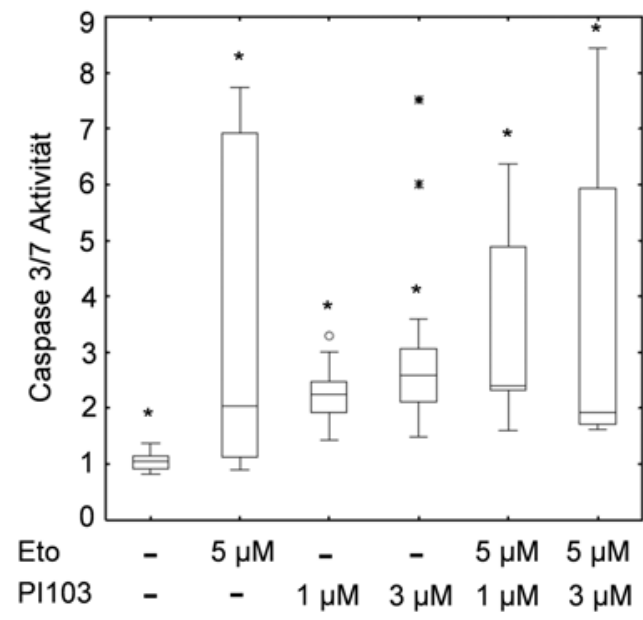

Abbildung 25: Apoptoseinduktion in RD-Zellen nach Behandlung mit Etoposid und/oder PI103. A RD-Zellen wurden für 24 Stunden mit $5 \mu \mathrm{M}$ Etoposid (Eto, $n=6), 1 \mu \mathrm{M}$ PI103 $(n=14), 3 \mu \mathrm{M}$ PI103 $(n=15)$ oder der Kombination aus Eto und $1 \mu$ M PI103 $(n=6)$ oder $3 \mu$ M PI103 $(n=6)$ behandelt. Als Kontrolle diente die Inkubation mit dem Lösungsmittel $(n=19)$. Der Mittelwert $(+/-$ SEM) Annexin $V$ positiver Zellen ist als Säulendiagramm dargestellt. B Die Zellen wurden für 24 Stunden mit $5 \mu \mathrm{M}$ Eto $(n=9), 1 \mu \mathrm{M}$ PI103 $(n=18), 3 \mu \mathrm{M}$ PI103 $(n=16)$ oder der Kombination aus Eto und $1 \mu \mathrm{M}$ PI103 $(n=9)$ bzw. $3 \mu$ M PI103 $(n=8)$ behandelt. Die Inkubation mit dem Lösungsmittel $(n=20)$ diente als Kontrolle. Die Aktivität der Caspasen 3 und 7 wurde in Relation zum Lösungsmittel (Mittelwert des Lösungsmittels wurde 1 gesetzt) in Form eines Box-Whisker-Plots dargestellt. * signifikant $(p<0,05)$ im Vergleich zur Lösungsmittelkontrolle. $\square, 25 \%$ - 75 \%; I, Bereich ohne Ausreißer; -, Median; ’ Ausreißer, घ, Extremwert.

Zusammenfassend zeigen diese Daten, dass PI103 den proapoptotischen Effekt des spezifischen TOP2-Hemmers Etoposid nicht signifikant erhöhen kann. Dies bedeutet weiterhin, dass die TOP2 bei der PI103-vermittelten Sensitivierung der Zellen gegenüber einer Doxorubizin-Behandlung eher keine Rolle spielt.

\subsubsection{Alleinige mTOR-Inhibierung hat keinen Einfluss auf die kooperative Induktion der Caspase 3 Aktivität}

PI103 ist ein dualer Inhibitor, der sowohl die PI3Kinase als auch mTOR hemmt. Um zu untersuchen, ob der kooperative proapoptotische Effekt von Doxorubizin und PI103 ausschließlich durch mTOR vermittelt wird, wurde anstatt PI103 Everolimus 
eingesetzt. Everolimus ist ein reiner mTOR-Inhibitor und wird als Immunsuppressivum oder als Antitumoragens in der Onkologie (z. B. beim Nierenzellkarzinom) verwendet [170]. Everolimus wird in Zellkultur häufig in einer Konzentration von $1 \mu \mathrm{M}$ eingesetzt [171]. Daher wurde diese Konzentration auch in den hier beschriebenen Versuchen genutzt.

Um die Funktionalität von Everolimus in RD-Zellen zu testen, wurden zunächst Western Blot Analysen durchgeführt. Dafür wurden die Zellen für 4 und 24 Stunden mit dem Medikament inkubiert. Die Wirksamkeit von Everolimus wird durch Dephosphorylierung des Zielproteins von mTOR, dem ribosomalen Protein S6, nachgewiesen.

Wie in Abbildung 26 dargestellt ist, führt die Inkubation der Zellen mit Everolimus zur effizienten Dephosphorylierung von S6. Überraschenderweise wurde jedoch auch eine verstärkte AKT-Phosphorylierung nach Behandlung mit Everolimus festgestellt (siehe pAKT in Abbildung 26), obwohl das AKT-Gesamtprotein vermindert exprimiert zu sein scheint (siehe AKT in Abbildung 26).

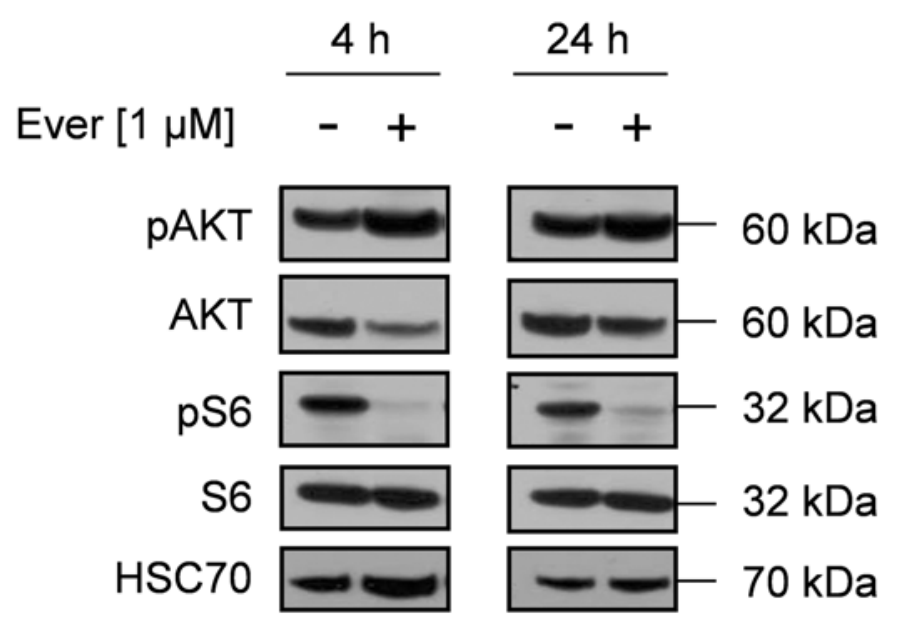

Abbildung 26: Funktionalitätstest von Everolimus in RD-Zellen. RD-Zellen wurden für 4 und für 24 Stunden mit $1 \mu \mathrm{M}$ Everolimus (Ever) inkubiert. Nachfolgend wurden Proteinlysate hergestellt, und der Phosphorylierungsstaus von S6 und AKT in Western Blot Analysen überprüft.

Anschließend wurde das Proliferationsverhalten von RD-Zellen nach Behandlung mit Doxorubizin und Everolimus überprüft. Wie in Abbildung 27 gezeigt ist, hemmt eine alleinige Inkubation mit Everolimus die Zellproliferation. Dieser Effekt ist signifikant. Dagegen kann der antiproliferative Effekt von Doxorubizin durch Kombination mit Everolimus nicht signifikant verstärkt werden (Abbildung 27). 


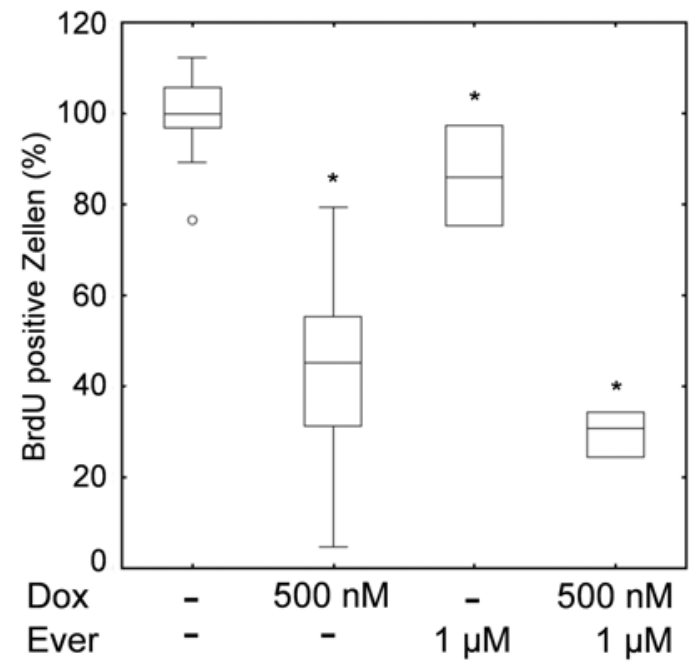

Abbildung 27: Proliferationsverhalten der RD-Zellen nach Behandlung mit Doxorubizin und/oder Everolimus. RD-Zellen wurden für 24 Stunden mit $500 \mathrm{nM}$ Doxorubizin (Dox, $\mathrm{n}=19$ ), $1 \mu \mathrm{M}$ Everolimus (Ever, $n=3$ ), oder der Kombination beider Medikamente $(n=3)$ inkubiert. Die Behandlung mit dem Lösungsmittel $(n=17)$ diente als Kontrolle. Der Effekt auf die Proliferation der Zellen wurde auf die Lösungsmittelkontrolle (100\%) normalisiert und als Box-Whisker-Plot dargestellt. * signifikant $(p<0,05)$ im Vergleich zur Lösungsmittelkontrolle. $\square, 25 \%$ - $75 \%$; I, Bereich ohne Ausreißer; -, Median.

A

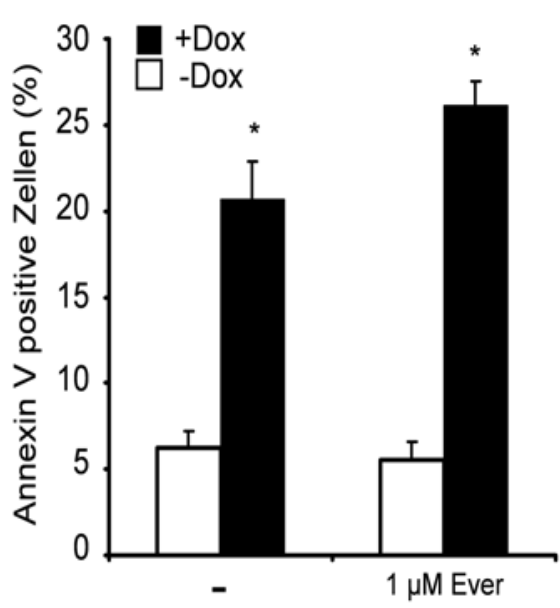

B

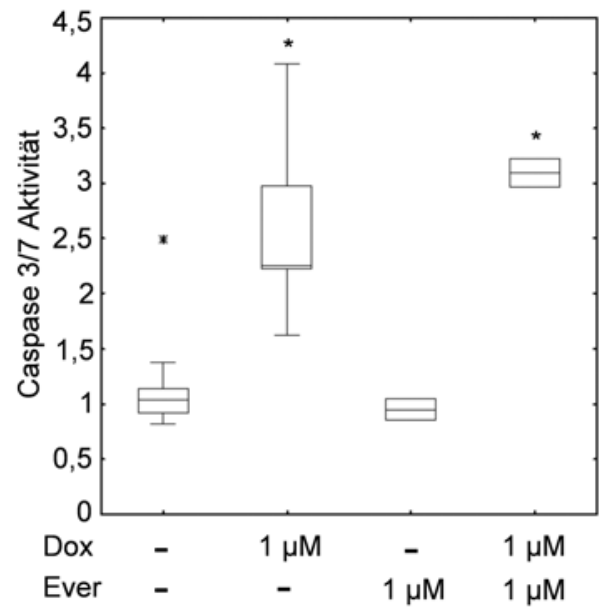

Abbildung 28: Apoptoseinduktion in RD-Zellen nach Behandlung mit Doxorubizin und/oder Everolimus. A Die Zellen wurden für 24 Stunden mit $1 \mu \mathrm{M}$ Doxorubizin (Dox, $n=4$ ), $1 \mu \mathrm{M}$ Everolimus (Ever, $n=4)$, sowie der Kombination beider Medikamente $(n=4)$ inkubiert. Als Kontrolle diente die Inkubation mit dem Lösungsmittel $(n=4)$. Der Mittelwert $(+/-$ SEM) von Annexin $V$ positiven Zellen ist als Säulendiagramm dargestellt. B RD-Zellen wurden für 24 Stunden mit $1 \mu \mathrm{M}$ Dox $(n=11), 1 \mu \mathrm{M}$ Ever $(n=2)$ oder der Kombination beider Medikamente $(n=2)$ behandelt. Eine Behandlung mit dem Lösungsmittel $(n=20)$ diente als Kontrolle. Die Aktivität der Caspasen 3 und 7 wurde in Relation zum Lösungsmittel (Mittelwert des Lösungsmittels wurde 1 gesetzt) in Form eines Box-Whisker-Plots dargestellt. * signifikant $(p<0,05)$ im Vergleich zur Lösungsmittelkontrolle. $\square, 25 \%-75 \%$; 工, Bereich ohne Ausreißer; -, Median.

Im Annexin V-Assay führt eine alleinige Behandlung mit Everolimus zu keiner Induktion der Apoptose (Abbildung 28). Die Doxorubizin-vermittelte Apoptoseinduktion 
kann durch Kombination mit Everolimus zwar erhöht, aber nicht signifikant verstärkt werden. Das gleiche Ergebnis zeigt sich auch im Caspase 3/7 Aktivitätstest (Abbildung 28).

Auch in Western Blot Analysen kann kein kooperativer Effekt von Doxorubizin und Everolimus in Bezug auf die Aktivierung der Caspase 3 nachgewiesen werden (Abbildung 29). Es wird jedoch wiederholt eine verstärkte Phosphorylierung von AKT nach Inkubation mit Everolimus detektiert, die durch eine Kombination mit Doxorubizin möglicherweise noch gesteigert wird.

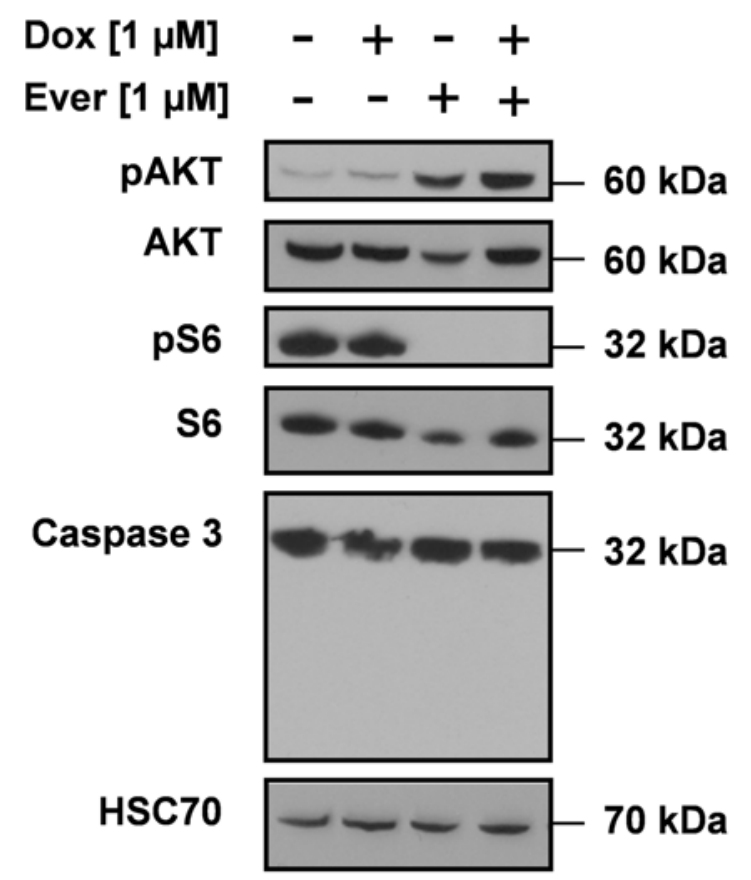

Abbildung 29: Western Blot Analyse von Proteinlysaten aus RD-Zellen nach Inkubation mit Doxorubizin und Everolimus. Die Zellen wurden für 24 Stunden mit $1 \mu \mathrm{M}$ Doxorubizin (Dox), $1 \mu \mathrm{M}$ Everolimus (Ever), der Kombination beider Medikamente, sowie dem Lösungsmittel inkubiert. Anschließend erfolgte die Detektion von pAKT/AKT, pS6/S6 und Caspase 3. Für die Normalisierung der Proben wurde zusätzlich HSC70 detektiert.

Zusammengefasst zeigen diese Daten, dass der reine mTOR-Inhibitor Everolimus keine signifikante Steigerung der antiproliferativen und der proapoptotischen Effekte von Doxorubizin bewirkt. Vielmehr verstärkt Everolimus die Expression und Aktivität von AKT. 


\subsubsection{Doxorubizin und PI103 kooperieren in der Aktivierung des mitochondrialen Apoptosesignalwegs}

Wie bereits in Kapitel 1.2.2.1 erwähnt, ist das antiapoptotische Protein AKT in viele Signaltransduktionswege involviert. Einer dieser Signalwege ist der mitochondrialvermittelte Apoptosesignalweg. AKT hemmt hierbei das proapoptotische Protein BAX [88]. Eine Aktivierung von BAX führt dagegen zur Induktion des mitochondrialen Apoptosesignalwegs und zur Cytochrom c Freisetzung aus den Mitochondrien, was wiederum in der Aktivierung der Caspase 3 resultiert [96].

Die Auslösung der mitochondrialen Apoptose kann neben der Inhibierung von AKT auch über den Tumorsuppressor p53 erfolgen [93, 172]. Dieser wird z. B. in Folge von DNA-Doppelstrangbrüchen, die unter anderem durch Behandlung mit Doxorubizin ausgelöst werden, aktiviert [28].

Aufgrund dieser Tatsachen habe ich nun die Aktivierung von BAX und die Cyctochrom c Freisetzung in RD-Zellen nach Kombinationsbehandlung mit Doxorubizin und PI103 untersucht. Weiterhin habe ich versucht, einen kleinen Einblick in die Rolle von p53 bei den kooperativen proapoptotischen Vorgängen zu gewinnen. Hierzu habe ich die Expression von p21, welches über die transkriptionelle Aktivität von p53 reguliert werden kann, nach Kombinationsbehandlung mit Doxorubizin und PI103 analysiert. Zusätzlich habe ich zwei p53-Inhibitoren genutzt. Dabei inhibiert Pifithin a (PFTa) die transkriptionelle Aktivität von p53, wohingegen Pifithrin $\mu$ (PFT $\mu)$ die mitochondriale Aktivität von p53 inhibieren soll $[173,174]$. Die Apoptoseinduktion in RD-Zellen wurde dementsprechend nach Behandlung mit der Kombination aus Doxorubizin und PI103, sowie mit jeweils einem der beiden p53-Inhibitoren analysiert.

\subsubsection{Der kooperative proapoptotische Effekt von Doxorubizin und PI103 korreliert mit der Aktivierung von BAX}

Für die Analyse der mitochondrial-vermittelten Apoptose wurde zunächst der Aktivierungsstatus des proapoptotischen Proteins BAX untersucht. Um die Aktivierung von BAX nach Behandlung der Zellen mit Doxorubizin, PI103 oder der Kombination aus beiden Medikamenten zu analysieren, wurde aktives BAX mit dem Anti-Bax 6A7 Antikörper immunpräzipiert. Parallel erfolgte die Herstellung von Proteinlysaten, in denen das basale Proteinlevel von BAX nachgewiesen werden 
sollte. BAX wurde dann sowohl im Immunpräzipitat als auch im Gesamtproteinlysat mit Hilfe des Antikörpers Anti-BaxNT in Western Blot Analysen detektiert (zur genauen Vorgehensweise siehe Kapitel 3.2.6.7).

Wie in Abbildung $30 \mathrm{zu}$ sehen ist, resultiert eine alleinige Doxorubizin-Behandlung nicht in der Aktivierung von BAX. PI103 hingegen führt zur moderaten Aktivierung des proapoptotischen Proteins. Durch die Kombination beider Medikamente wird dagegen eine deutliche Aktivierung des Proteins hervorgerufen.

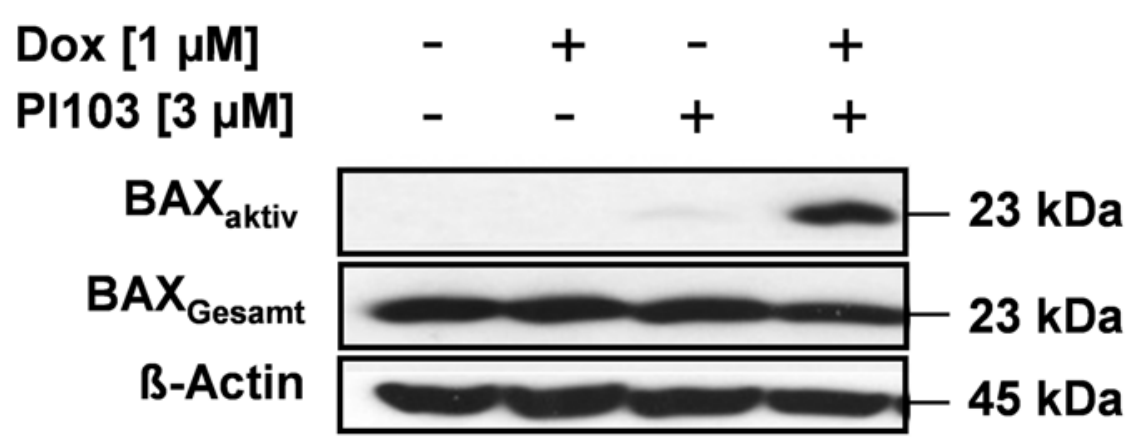

Abbildung 30: Immunpräzipitation von BAX. RD-Zellen wurden für 24 Stunden mit $1 \mu \mathrm{M}$ Doxorubizin (Dox), 3 MM PI103, der Kombination aus beiden Medikamenten, sowie dem Lösungsmittel behandelt. Aktives BAX wurde mit dem Antikörper Anti-Bax 6A7, sowie unter Verwendung von MausIgG-Beads immunpräzipitiert. Das gesamte BAX wurde anhand von Proteinlysaten, die sowohl inaktives, als auch aktives BAX enthielten, analysiert. Beide Formen von BAX wurden mit dem Antikörper Anti-BaxNT nachgewiesen. Der Nachweis von B-Actin diente als Ladungskontrolle.

\subsubsection{Die Kombination von Doxorubizin und PI103 führt zu erhöhter Cytochrom c Freisetzung}

Die BAX-Aktivierung kann die Freisetzung von Cytochrom c aus den Mitochondrien zur Folge haben. Dieses Ereignis leitet die Apoptose über den mitochondrialen Signalweg in der Zelle ein [94].

Für die Untersuchungen der Cytochrom c Freisetzung wurden RD-Zellen mit Doxorubizin, PI103 oder der Kombination beider Medikamente, sowie den jeweiligen Lösungsmitteln inkubiert. Die Zellen wurden anschließend fixiert und permeabilisiert. Die Cytochrom c-Detektion erfolgte mit dem Anti-Cytochrom c (7H8.2C12) Antikörper, der spezifisch an membrangebundenes Cytochrom $\mathrm{c}$ bindet. Cytochrom $\mathrm{c}$, welches durch Freisetzung aus den Mitochondrien eine Konformationsänderung erfährt, kann durch diesen Antikörper nicht detektiert werden [175]. Nach Zugabe eines sekundären Antikörpers erfolgte die Analyse mittels FACS.

In Abbildung 31 ist zunächst zu sehen, dass die Behandlung der Zellen mit 
Doxorubizin zu einer im Vergleich zur Lösungsmittelkontrolle erhöhten Fluoreszenzintensität führt. Die Erhöhung der Fluoreszenzintensität resultiert dabei höchstwahrscheinlich aus der Eigenfluoreszenz von Doxorubizin, dessen Emissionsmaximum im FL1-H-Kanal detektiert wird (siehe auch Kapitel 3.1.8). Werden die Zellen nun mit PI103 inkubiert, kann die Freisetzung von Cytochrom $\mathrm{c}$ aus den Mitochondrien anhand der Abnahme des Fluoreszenzsignals festgestellt werden. Diese Abnahme kommt dadurch zustande, dass weniger membrangebundenes Cytochrom c vorhanden ist, welches durch den Cytochrom c Antikörper detektiert wird. Wie man eindeutig sieht, wird die Abnahme durch die Kombination von Doxorubizin und $\mathrm{PI} 103$ verstärkt.

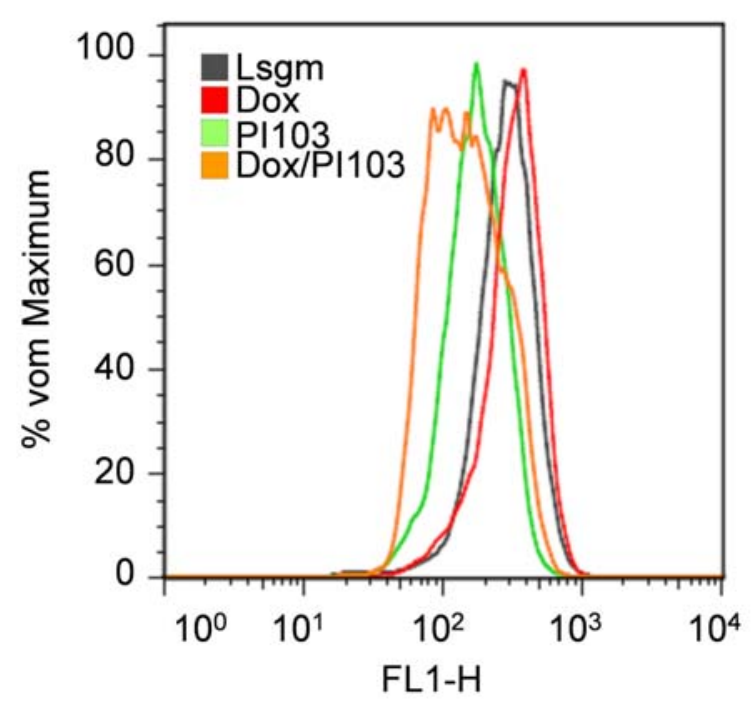

Abbildung 31: Cytochrom c Freisetzung in RD-Zellen. Nach der Behandlung der Zellen mit $1 \mu \mathrm{M}$ Doxorubizin (Dox), $3 \mu \mathrm{M}$ Pl103 oder der Kombination aus beiden (Dox/PI103), sowie dem Lösungsmittel erfolgte die Analyse der Cytochrom c Freisetzung mit einem Antikörper, der spezifisch membrangebundenes Cytochrom c bindet. Die Freisetzung von Cytochrom c aus den Mitochondrien resultierte folglich in einer Verringerung der detektierten Fluoreszenzintensität in den Zellen.

Zusammenfassend kann man festhalten, dass die Kombinationsbehandlung mit Doxorubizin und PI103 eine starke Aktivierung von BAX induziert. Ebenfalls zeigt die Kombination beider Medikamente einen kooperativen Effekt auf die Induktion der Cytochrom c Freisetzung. Somit korreliert der kooperative proapoptotische Effekt von Doxorubizin und PI103 mit der mitochondrial-vermittelten Apoptose.

\subsubsection{Die mitochondriale Aktivität von p53 scheint in den kooperativen Effekt von Doxorubizin und PI103 involviert zu sein}

Wie zuvor bereits erwähnt, kann die Aktivierung von BAX nicht nur durch die 
Inhibierung von AKT induziert werden, sondern auch über Aktivierung durch p53.

Für p53 ist bekannt, dass es sowohl eine transkriptionelle, als auch eine mitochondriale Aktivität besitzt $[83,176]$. Diese Aktivitäten sollen an dieser Stelle kurz erläutert werden.

Die transkriptionelle Aktivität von p53 führt zur verstärkten Expression von p21. p21 wiederum ist ein potenter Inhibitor von Cyclin-abhängigen Kinasen und hemmt den Zellzyklus in der $\mathrm{G}_{1}$-Phase [177]. Da Doxorubizin p53 aktivieren kann, ist es möglich, dass die Sensitivität von Tumorzellen gegenüber Doxorubizin mit einem Anstieg von p21 vergesellschaftet ist. Dies ist tatsächlich der Fall, wie Ravizza und Kollegen demonstrieren konnten. Sie detektierten in Doxorubizin-sensitiven Kolonkarzinomzellen nach Exposition mit dem Zytostatikum erhöhte p21-Proteinlevel [178].

Aktives p53 transloziert auch an die Mitochondrienmembran (mitochondriale Aktivität). Hier interagiert es mit den proapoptotischen Bcl-2-Proteinen BAX oder BAK. Durch diese Interaktion kommt es zur Aktivierung von BAX oder BAK, was dann zur Auslösung der mitochondrial-vermittelten Apoptose führt (siehe Kapitel 1.2.2.1) $[93,179,180]$.

Um eine Rolle der transkriptionellen p53 Aktivität bei den kooperativen antitumoralen Effekten von Doxorubizin und PI103 zu überprüfen, wurde die Expression von p21 vermessen. Hierzu wurde Doxorubizin in der Konzentration von $1 \mu \mathrm{M}$ eingesetzt, und mit $1 \mu \mathrm{M}$ bzw. $3 \mu \mathrm{M}$ PI103 kombiniert. Sollte die transkriptionelle Aktivität von p53 tatsächlich bei der Sensitivierung der RD-Zellen eine Rolle spielen, müsste die Expression von p21 unter einer Kombinationsbehandlung von Doxorubizin und PI103 ansteigen.

Die Ergebnisse in Abbildung 32 zeigen, dass $1 \mu \mathrm{M}$ Doxorubizin nach 6 Stunden zu einer signifikanten Steigerung der p21-Expression führt. Die Verlängerung der Inkubationszeit resultiert hingegen in einer drastischen, signifikanten Reprimierung des p21-Expressionslevels. $1 \mu \mathrm{M}$ und $3 \mu \mathrm{M}$ PI103 haben nach 6stündiger Inkubation nur geringe Auswirkungen auf das Expressionslevel von p21, reduzieren die p21Expression nach Verlängerung der Inkubationszeit jedoch deutlich. Dieser Effekt ist für beide Konzentrationen nach einer 12- bzw. 24stündigen Inkubation signifikant. Wird Doxorubizin nun mit PI103 kombiniert, kann nach 6stündiger Inkubation kein signifikanter kooperativer Effekt auf die p21-Expression detektiert werden. Nach 12stündiger als auch nach 24stündiger Kombinationsbehandlung kommt es jedoch 
zu einer drastischen Reprimierung der p21-Expression. Diese ist nach 24stündiger Inkubation für die Kombination von $1 \mu \mathrm{M}$ Doxorubizin mit $1 \mu \mathrm{M}$ PI103 als auch für die Kombination von $1 \mu \mathrm{M}$ Doxorubizin mit $3 \mu \mathrm{M}$ Pl103 signifikant gegenüber dem Lösungsmittel und der Inkubation mit den Einzelsubstanzen.
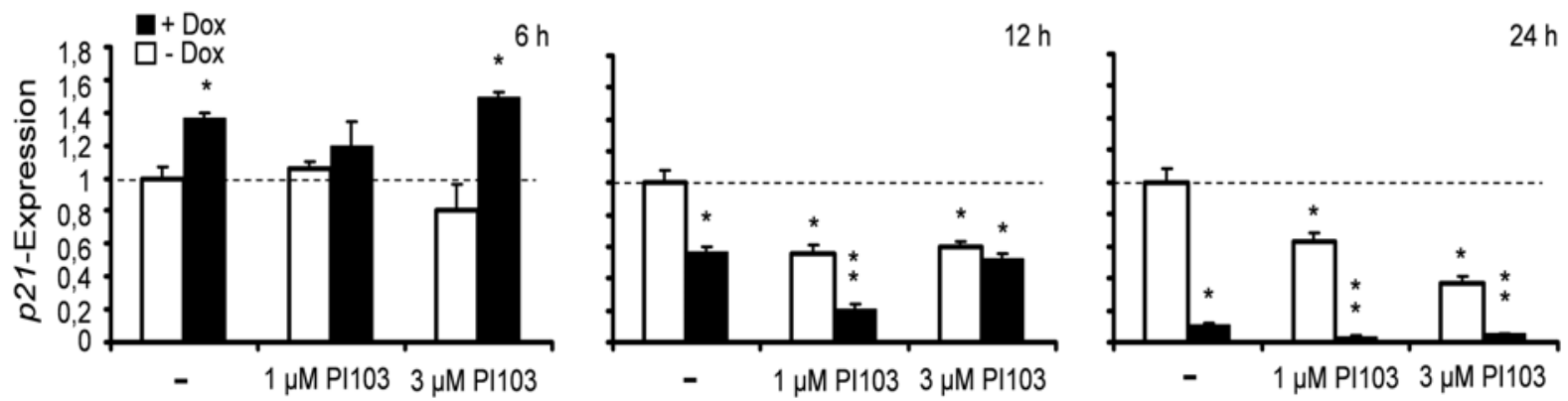

Abbildung 32: p21-Expression in RD-Zellen. Die Zellen wurden für 6 bis 24 Stunden (6h, 12h, 24h) mit $1 \mu \mathrm{M}$ Doxorubizin (Dox), $1 \mu \mathrm{M}$ PI103, $3 \mu \mathrm{M}$ PI103, der Kombination von Dox mit $1 \mu \mathrm{M}$ PI 103 bzw. $3 \mu \mathrm{M}$ PI103, sowie dem Lösungsmittel inkubiert (jeweils $n=6$ ). Die Expression von p21 wurde auf die 18S rRNA-Expression normalisiert. Gezeigt sind die Mittelwerte +/- SEM. * signifikant $(p<0,05)$ im Vergleich zur Lösungsmittelkontrolle. ${ }^{* *}$ signifikant im Vergleich zur Behandlung mit sowohl Lösungsmittel, Doxorubizin als auch PI103.

Die Ergebnisse lassen vermuten, dass die transkriptionelle Aktivität von p53 möglicherweise keine Rolle bei dem kooperativen proapoptotischen Effekt von Doxorubizin und PI103 spielt.

Die transkriptionelle Aktivität von p53 kann auch mit Hilfe von Pifithrin a (PFTa) untersucht werden. Diese Substanz hemmt die transkriptionelle Aktivität von p53 indem es vermutlich den nukleären Transports des Proteins verhindert [173, 181]. PFT $\mu$ dagegen blockt die mitochondriale Aktivität dieses Tumorsuppressors [174]. Laut Literatur werden beide Inhibitoren in Konzentrationen von $30 \mu \mathrm{M}$ eingesetzt [182, 183]. Diese Konzentrationen wurden daher auch in den unten aufgeführten Experimenten verwendet.

Die Wirkung der beiden Inhibitoren auf den kooperativen proapoptotischen Effekt von Doxorubizin und PI103 wurde mittels Annexin V-Assay untersucht. Die Daten sind in Abbildung 33 gezeigt, wobei in Abbildung 33A die absoluten Werte, und in Abbildung 33B die Werte in Relation zu den Lösungsmittelwerten dargestellt sind.

Die Analysen zeigen, dass eine Inhibierung der transkriptionellen Aktivität von p53 mittels PFTa den kooperativen Effekt von Doxorubizin und PI103 nicht beeinflusst 
(Abbildung 33). Diese Daten sprechen somit - genauso wie die qRT-PCR der p21Expressionsanalysen - gegen eine Involvierung der transkriptionellen Aktivität von p53 in den kooperativen proapoptotischen Effekt von Doxorubizin und PI103.

A
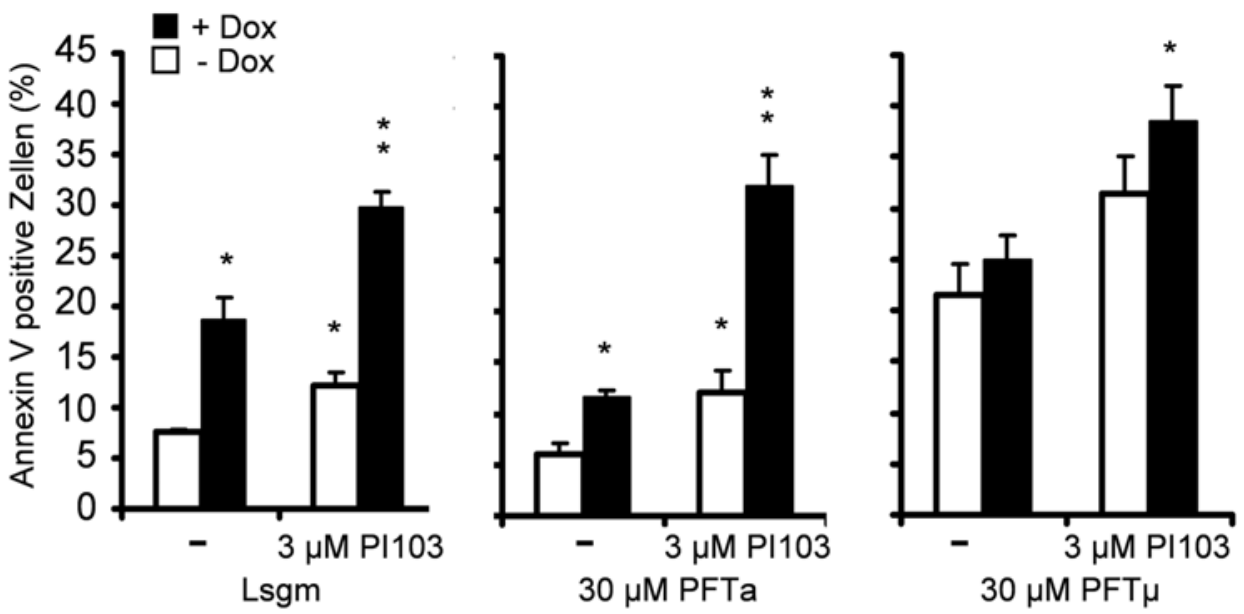

B
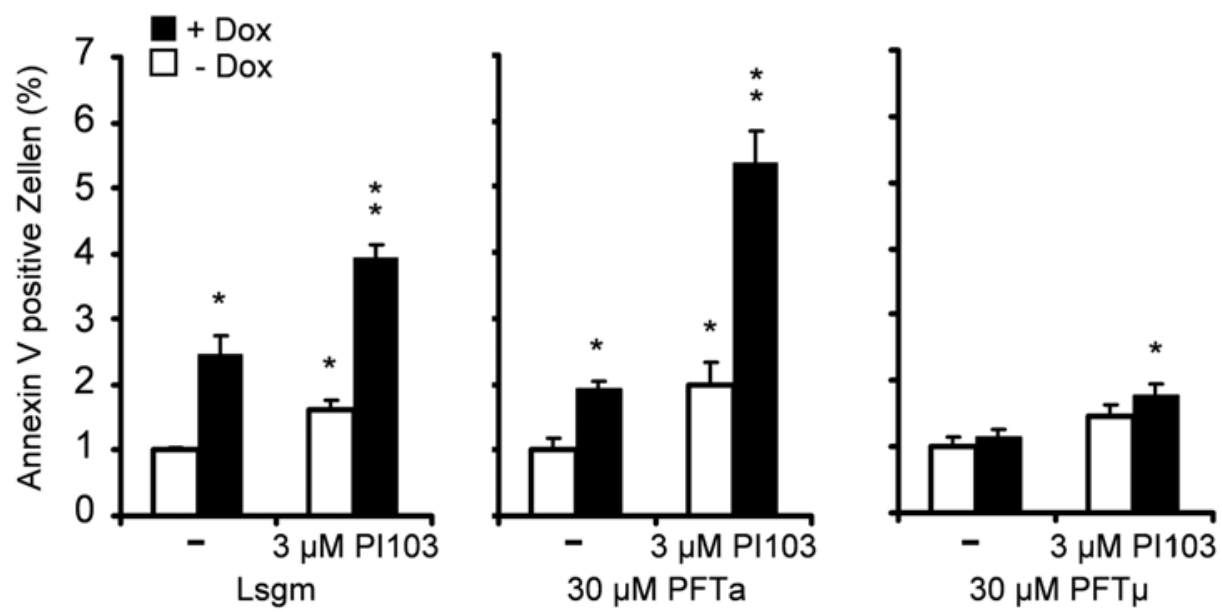

Abbildung 33: Apoptoseinduktion nach Behandlung von RD-Zellen mit Doxorubizin, PI103 und spezifischen p53 Inhibitoren. RD-Zellen wurden für 24 Stunden mit $1 \mu \mathrm{M}$ Doxorubizin (Dox, $\mathrm{n}=6$ ), $3 \mu \mathrm{M}$ PI103 $(n=6), 30 \mu \mathrm{M}$ PFTa $(n=4), 30 \mu \mathrm{M}$ PFT $\mu(n=4)$, oder den jeweiligen Lösungsmitteln $(n=6)$ wie dargestellt behandelt. A zeigt die absoluten prozentualen Werte; $\mathbf{B}$ zeigt die Werte in Relation zur Lösungsmittelkontrolle, welche $=1$ gesetzt wurde. Die Mittelwerte (+/- SEM) der induzierten Apoptoserate wurde als Säulendiagramm dargestellt. * signifikant $(p<0,05)$ gegenüber dem Lösungsmittelwert; ${ }^{* *}$ signifikant gegenüber Doxorubizin als auch PI103.

Bei Behandlung der Zellen mit PFT $\mu$ (welches als Inhibitor der mitochondrialen Aktivität von p53 gilt) fiel zunächst auf, dass dieser Inhibitor selbst Apoptose induziert. So ist der Anteil Annexin V positiver Zellen nach Behandlung mit PTF $\mu$ um $14 \%$ höher als nach einer Behandlung mit dem Lösungsmittel. Dies wird vor allem in Abbildung 33A deutlich, in der im Gegensatz zur Abbildung 33B die Werte nicht auf die Lösungsmittelkontrolle normalisiert wurden. Obwohl dieses basale Apoptoselevel 
die Interpretation der Ergebnisse erschwert, zeigen die Daten, dass weder $1 \mu \mathrm{M}$ Doxorubizin noch $3 \mu \mathrm{M}$ PI103 die Zahl Annexin V positiver Zellen nach PFT $\mu$ Behandlung signifikant erhöht. Zudem wird der kooperative Effekt von Doxorubizin und PI103 durch Einsatz von PFT $\mu$ gehemmt (Abbildung 33B).

Aufgrund der hohen basalen Apoptoselevel bei $30 \mu \mathrm{M}$ PFT $\mu$ wurde das Experiment mit einer niedrigeren Konzentration $(15 \mu \mathrm{M})$ wiederholt. Die Ergebnisse waren jedoch die gleichen (Abbildung 34).

A
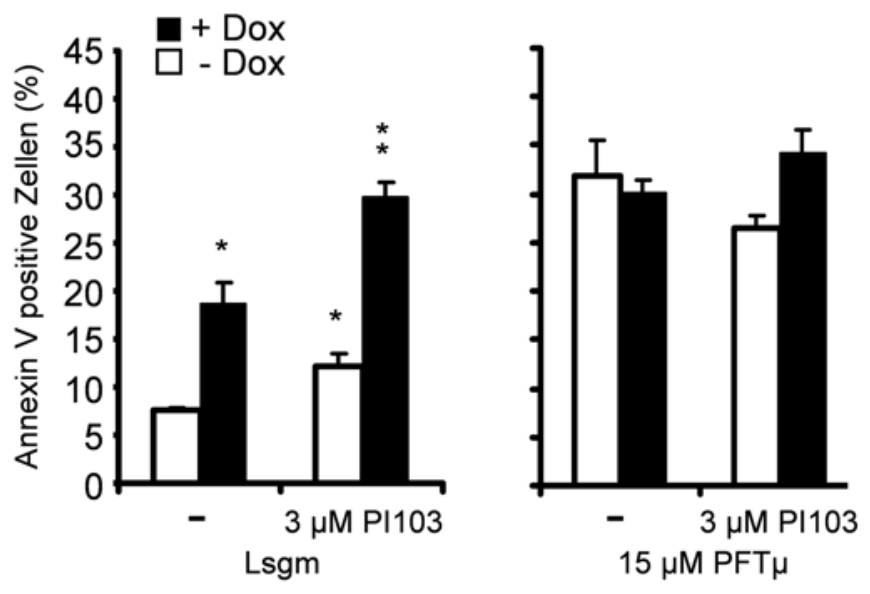

B
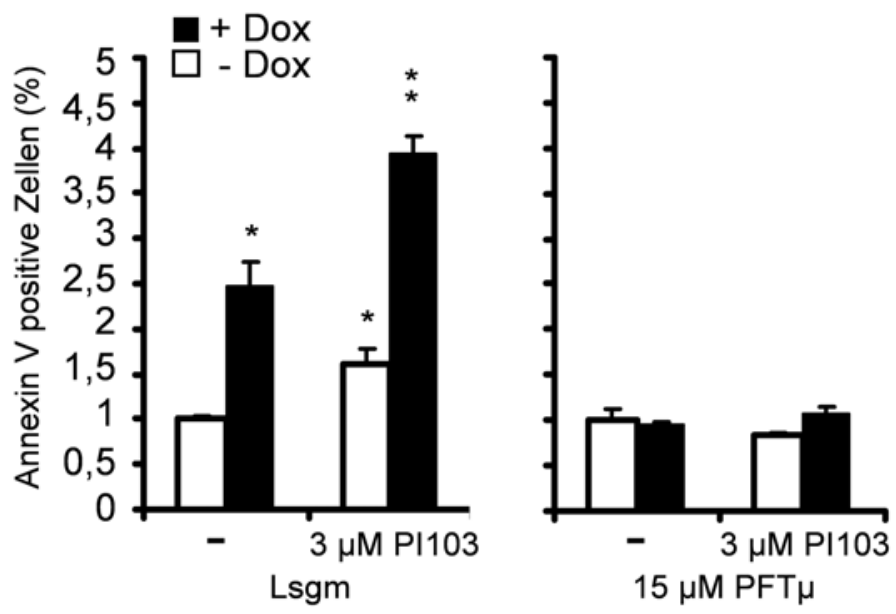

Abbildung 34: Apoptoseinduktion nach Behandlung von RD-Zellen mit Doxorubizin, PI103 und $15 \mu \mathrm{M}$ PFT $\mu$. RD-Zellen wurden für 24 Stunden mit $1 \mu \mathrm{M}$ Doxorubizin (Dox, $\mathrm{n}=6$ ), $3 \mu \mathrm{M}$ PI103 $(n=6), 15 \mu$ M PFT $\mu(n=2)$, sowie den jeweiligen Lösungsmitteln $(n=6)$ wie dargestellt behandelt. A zeigt die absoluten prozentualen Werte; B zeigt die Werte in Relation zur Lösungsmittelkontrolle, welche = 1 gesetzt wurde. Die Mittelwerte (+/- SEM) der induzierten Apoptoserate wurde als Säulendiagramm dargestellt. * signifikant $(p<0,05)$ gegenüber dem Lösungsmittelwert; ${ }^{* *}$ signifikant gegenüber Doxorubizin als auch PI103. 
Diese Daten zeigen, dass PFT $\mu$ wahrscheinlich die proapoptotischen Effekte der Einzelsubstanzen als auch diejenigen der Kombination beider Medikamente hemmt.

Zusammenfassend lässt sich somit festhalten, dass die transkriptionelle Aktivität von p53 vermutlich nicht in den kooperativen proapoptotischen Effekt von Doxorubizin und PI103 involviert ist. Dagegen könnte die mitochondriale Aktivität von p53 bei dieser Kooperation eine Rolle spielen.

\subsubsection{PI103 hemmt die Expression von MDR1 und MRP1 in RD-Zellen}

In dem nächsten Schritt sollte untersucht werden, ob die beiden Effluxtransporter MDR1 und MRP1 in den kooperativen proapoptotischen Effekt von Doxorubizin und PI103 involviert sind.

In der Literatur ist beschrieben, dass AKT die Expression oder die Aktivität von dem Multidrug Resistance Protein p-Glycoprotein (MDR1) und Multidrug Resistanceassociated Protein (MRP1) positiv regulieren kann [79, 80]; siehe 1.1.3). Beide Proteine gehören zur Familie der ABC-Transporter und sind für den Efflux verschiedener Zytostatika aus der Zelle verantwortlich. Es ist bekannt, dass Doxorubizin ein Substrat von MDR1 und MRP1 ist, und folglich durch diese Transporter aus der Zelle transportiert wird [36]. Daher sollte überprüft werden, ob PI103 (über die Inhibierung der AKT) zu einer Hemmung dieser Effluxtransporter führt. Falls das so wäre, könnte dies wiederum zu einer Akkumulation von Doxorubizin in der Zelle führen und den kooperativen antitumoralen Effekt von Doxorubizin und Pl103 erklären.

Um die Expression der Transporter zu analysieren, wurden RD-Zellen für 12 oder 24 Stunden mit PI103 oder dem Lösungsmittel inkubiert. Die Untersuchung der Expressionslevel erfolgte zunächst mit Hilfe einer qRT-PCR Analyse. Wie Abbildung 35 zeigt, hemmt PI103 tatsächlich die Transkription von MDR1 und MRP1. Dieser Effekt war schon nach einer 12stündigen Inkubation mit PI103 zu sehen. Dabei muss erwähnt werden, dass die basale Expression von MDR1 in RD Zellen im Vergleich zu MRP1 um den Faktor 100 geringer war. 
A
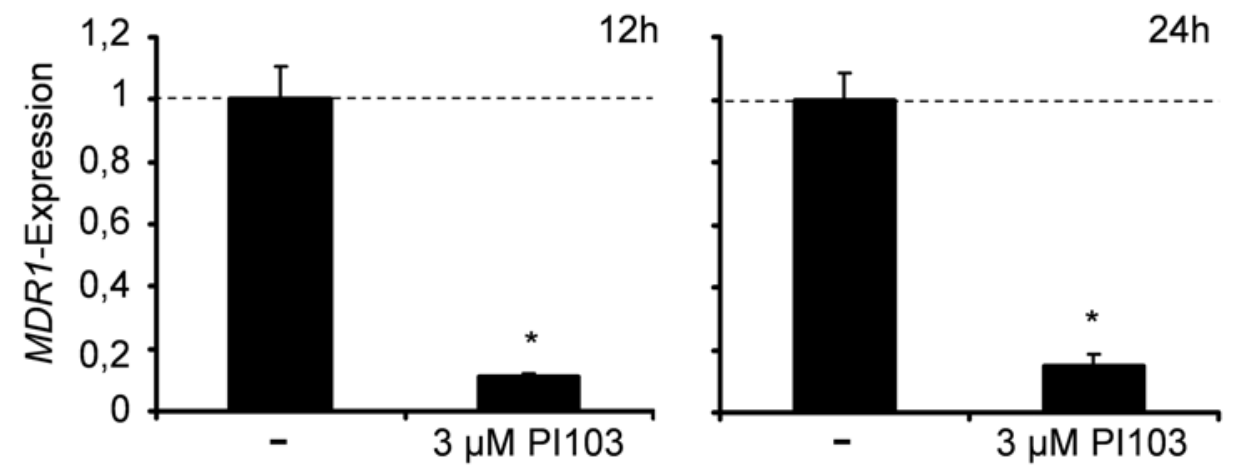

B
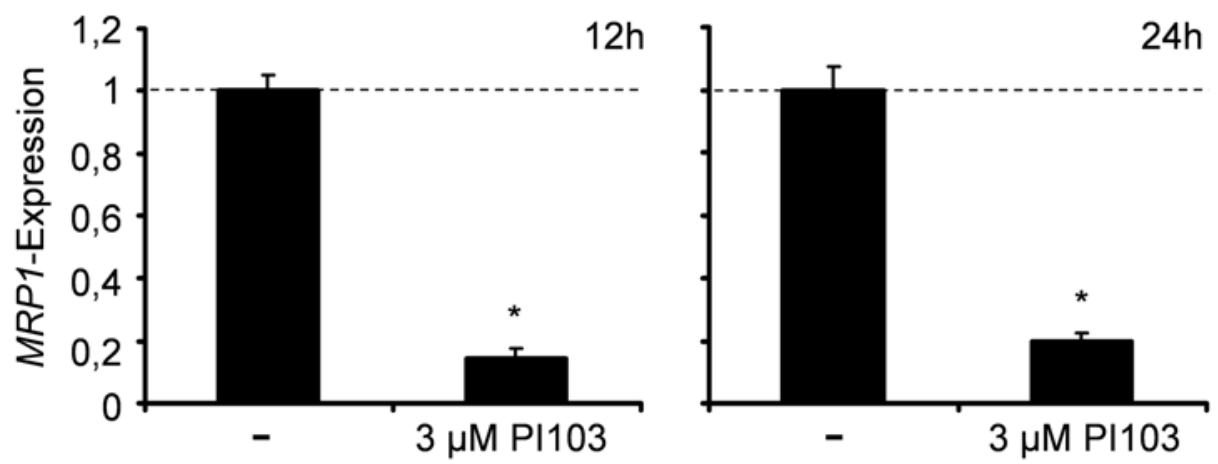

Abbildung 35: Expressionsanalyse der Transkripte von MDR1 und MRP1 in RD-Zellen. Für die Analyse der MDR1-Expression (A) bzw. der MRP1-Expression (B) wurden die Zellen für 12 Stunden mit $3 \mu$ M PI103 $(n=6)$ oder dem Lösungsmittel $(n=5)$, bzw. für 24 Stunden mit $3 \mu$ M PI103 $(n=6)$ oder dem Lösungsmittel $(n=6)$ inkubiert. Die Expression von MDR1 bzw. MRP1 wurde auf die 18S rRNA-Expression normalisiert. Gezeigt sind die Mittelwerte +/- SEM. * signifikant $(p<0,05)$ im Vergleich zur Lösungsmittelkontrolle.

Diese Hemmung sollte nun auch auf Proteinebene überprüft werden. Die Analyse der Proteinlevel von MDR1 und MRP1 musste zunächst etabliert werden. Zur Etablierung wurden die Proteine in zwei verschiedenen Puffern aufgenommen. Hierbei handelt es sich um den "modifizierten RIPA-Puffer" und den sogenannten "Lysepuffer" (siehe Kapitel 3.2.6.1 und 3.2.6.2).

In den RD-Zellen wurde über die Western Blot Analyse nur MRP1, nicht aber MDR1 detektiert (Abbildung 36). Sowohl RIPA-Puffer als auch der Lysepuffer schienen für die Herstellung der Proteinlysate geeignet zu sein. Für weitere Analysen wurden die Proteine jedoch in modifiziertem RIPA-Puffer aufgenommen. 


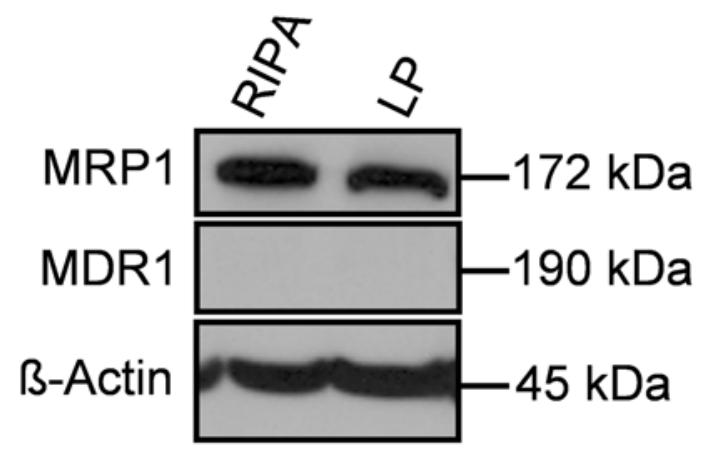

Abbildung 36: Nachweis von MDR1 und MRP1 in RD-Zellen im Western Blot. Die Herstellung der Proteinlysate erfolgte mit „modifiziertem RIPA-Puffer“ (RIPA) oder „Lysepuffer“ (LP). Die Proteine wurden mit den Antikörpern Anti-P-Glycoprotein [C219] (MDR1; Abcam) und Anti-MRP1 (Sigma) nachgewiesen. ß-Actin wurde als Ladekontrolle eingesetzt.

Da in RD-Zellen nur MRP1 nachgewiesen werden konnte, wurde nun der Einfluss von PI103 auf dieses Protein untersucht. Hierfür wurden die Zellen für 48 Stunden mit $3 \mu \mathrm{M}$ PI103 inkubiert. Anschließend erfolgten die Herstellung von Proteinlysaten und die Analyse mittels Western Blot.

In Abbildung 37 ist erkennbar, dass PI103 tatsächlich auch auf Proteinebene zu einer Abnahme des Proteinlevels von MRP1 führt.

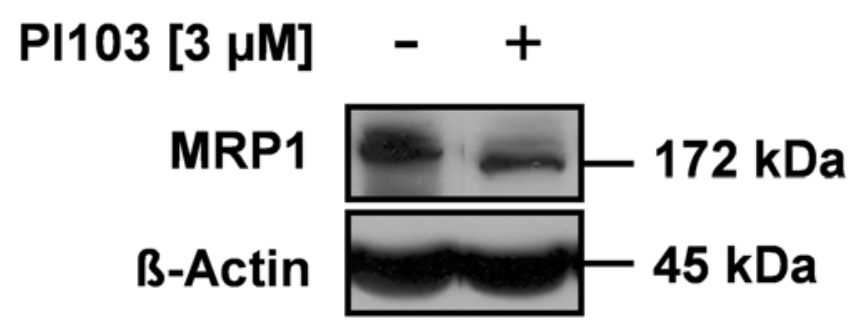

Abbildung 37: Einfluss von PI103 auf das Proteinlevel von MRP1 in RD-Zellen. RD-Zellen wurden für 48 Stunden mit $3 \mu \mathrm{M}$ PI103 behandelt. Die Isolierung der Proteine erfolgte mit modifiziertem RIPA-Puffer. MRP1 wurde mit dem Antikörper Anti-MRP1 (Sigma) mittels Western Blot Analyse detektiert. Der Nachweis von ß-Actin erfolgte als Ladungskontrolle.

Neben den Western Blot Analysen wurde zusätzlich versucht, MDR1 oder MRP1 per FACS-Analyse nachzuweisen. Da die Antikörper, die für die Western Blot Analysen verwendet wurden, in dem FACS-Assay nicht funktionierten (Daten nicht gezeigt), wurden zwei neue Antikörper von Sigma-Aldrich genutzt: Für die Detektion von MDR1 wurde der Antikörper Anti-ABCB1, und für den Nachweis von MRP1 wurde der Anti-MRP1 (QCRL.4) in RD-Zellen getestet. Als Positivkontrolle für die FACSAnalysen diente die MDR1- und MRP1-exprimierende Lungenadenokarzinomzellinie A549 [184, 185]. Für die Analysen wurden die Zellen mit den primären Antikörpern 
behandelt, bevor der sekundäre Antikörper hinzu gegeben wurde. Als Kontrolle wurde nur der sekundäre Antikörper eingesetzt. Die Analysen erfolgten am FACS BDCalibur im Kanal FL4-H. Abbildung 38A stellt das Ergebnis der Messung in A549Zellen dar, Abbildung 38B zeigt das Ergebnis für die RD-Zellen.

Es ist zu erkennen, dass der MRP1-Antikörper in beiden Zellinien ein stärkeres Fluoreszenzsignal hervorruft als die Kontrolle. Man kann daher von einem spezifischen Signal des MRP1-Antikörpers ausgehen. Leider kann dies für den MDR1-Antikörper in beiden Zelllinien nicht gezeigt werden.

A

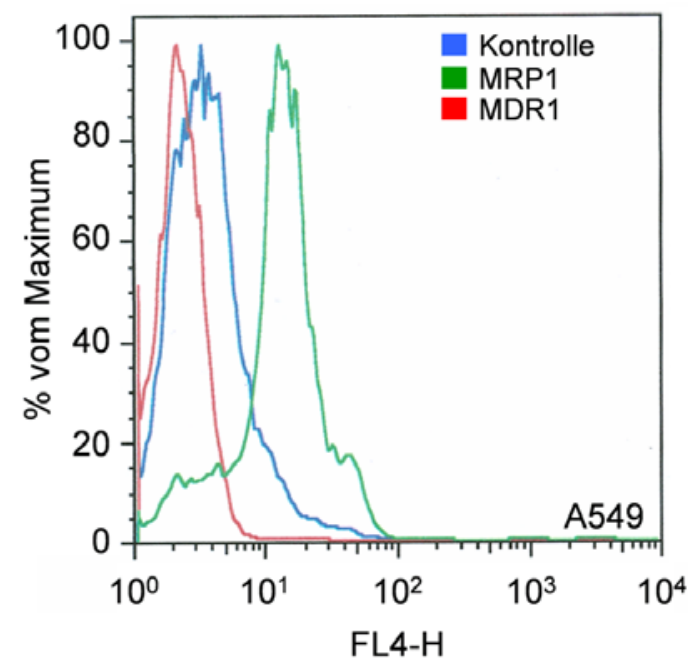

B

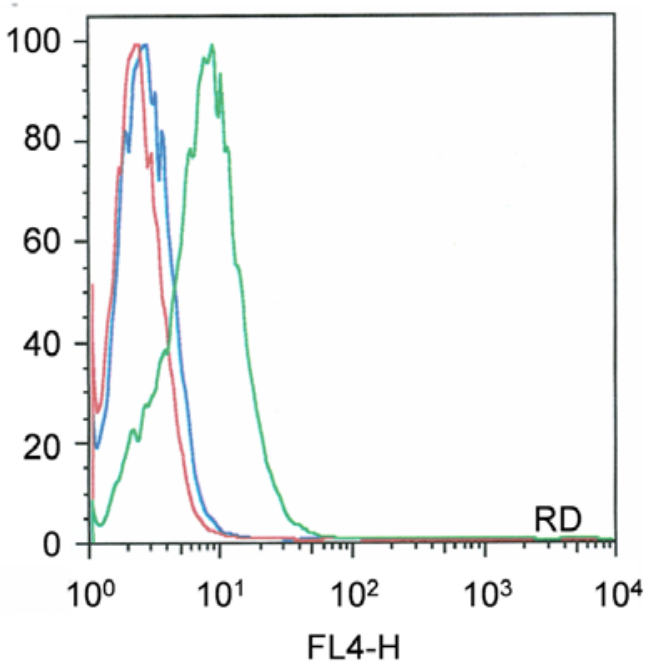

Abbildung 38: Nachweis von MDR1 und MRP1 mittels FACS-Analyse in A549- und RD-Zellen. Die Zellen wurden mit den primären Antikörpern (MDR1: Anti-ABCB1; MRP1: Anti-MRP1 (QCRL.4)) inkubiert, bevor sie mit dem sekundären Antikörper (Anti-Maus IgG, DyLight ${ }^{\mathrm{TM}} 649$ ) versetzt wurden. Als Kontrolle für die Detektion von unspezifischen Bindungen des sekundären Antikörpers wurden Zellen nur mit diesem Antikörper inkubiert (Kontrolle). In A ist das Ergebnis für die A549-Zellen, in B ist das Ergebnis für die RD-Zellen gezeigt. Die Abbildung stellt jeweils einen von zwei Messwerten dar.

Für die Analysen von MRP1 in mit PI103-behandelten RD-Zellen wurde dann das LSRII FACS genutzt, da es sensitiver als das BDCalibur Gerät ist. Die Eigenfluoreszenz der Zellen wurde außerdem durch Analyse von ungefärbten Zellen, und die Analyse der unspezifischen Bindungen des sekundären Antikörpers durch Verwendung einer Isotypkontrolle kontrolliert. Eine Isotypkontrolle ist ein unspezifisch bindender Antikörper, der den gleichen Isotyp wie der eingesetzte Proteinspezifische Primärantikörper hat und somit unspezifische Bindungen des sekundären Antikörpers aufdeckt. 
Wie Abbildung 39 zeigt, wird durch die Isotypkontrolle eine zu den ungefärbten Zellen erhöhte Fluoreszenz detektiert. Dies zeigt die unspezifische Bindung des sekundären Antikörpers. Allerdings kann auch ein Unterschied zwischen Zellen, die mit der Isotypkontrolle und denen die mit dem MRP1-Antikörper behandelt wurden, detektiert werden. Wie die Abbildung weiterhin zeigt, ist jedoch kein eindeutiger Unterschied der MRP1-Expression zwischen Lösungsmittel-behandelten und PI103behandelten RD Zellen zu erkennen.

A
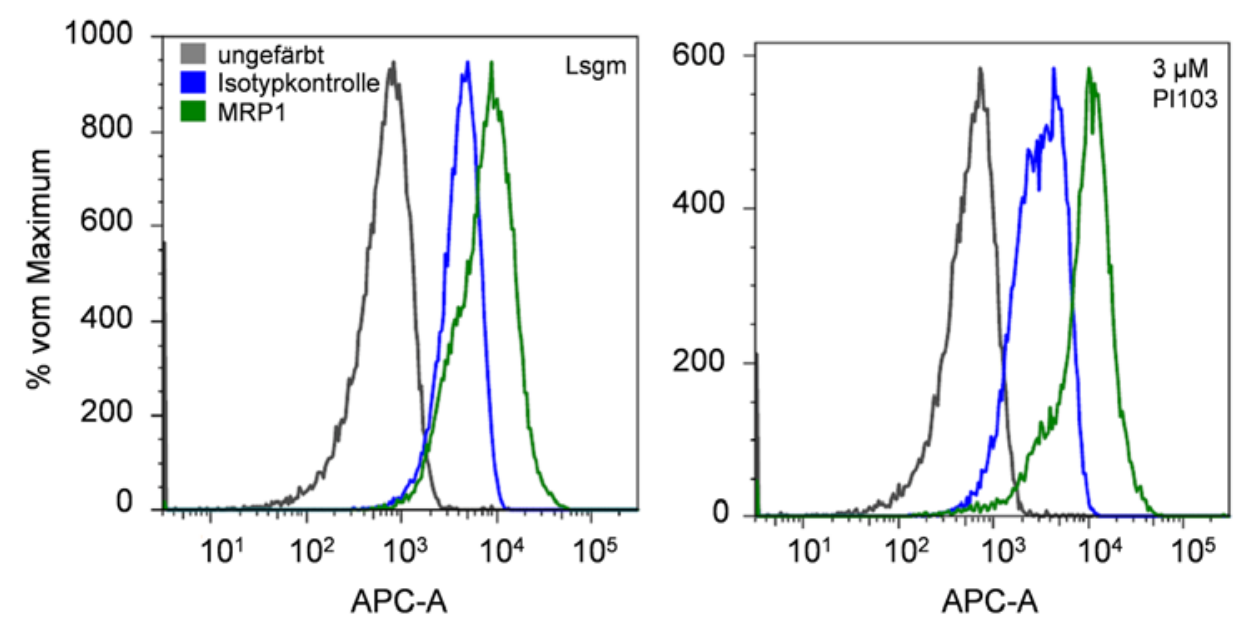

B
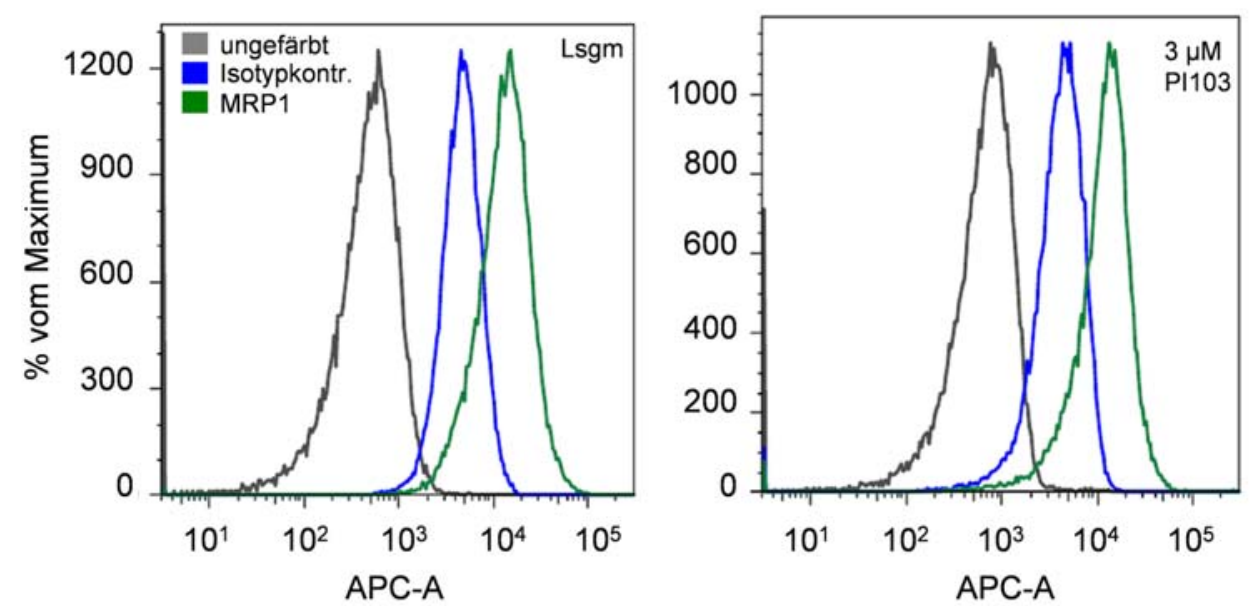

Abbildung 39: FACS Analysen der MRP1-Expression in RD-Zellen nach Inkubation mit PI103. RD-Zellen wurden für 18 Stunden (A) bzw. für 24 Stunden (B) mit $3 \mu \mathrm{M}$ PI103 oder dem Lösungsmittel, behandelt. Nach Ablauf der Behandlungszeit erfolgte die Inkubation der Zellen mit PBS (ungefärbt, grau), der Isotypkontrolle (IgG1, blau) oder dem MRP1-Antikörper (grün). Zellen, die mit den Antikörpern inkubierten, wurden schließlich mit dem sekundären Antikörper Anti-Maus IgG, DyLight ${ }^{\mathrm{TM}} 649$ versetzt. Die Analyse der MRP1-Expression erfolgte am LSRII im APC-A Kanal. Die Abbildung stellt jeweils einen von zwei Messwerten dar.

Die Etablierung des Nachweises von MPR1 (und auch MDR1) über FACS-Analyse 
ist jedoch noch nicht abgeschlossen und kann sicherlich verbessert werden. So soll in der Zukunft ein anderer sekundärer Antikörper eingesetzt werden, der eine höhere Affinität zu seiner Bindungsstelle aufweist. Auch sollte das Methodenprotokoll verbessert werden.

Neben den oben genannten quantitativen Analysen sollte in einem weiteren Experiment untersucht werden, ob PI103 die Funktion der MDR1- und MRP1Transporter hemmen kann. Ich habe hierzu begonnen, einen solchen Assay zu etablieren. In diesem Assay werden Zellen mit Rhodamin 123 (Rh123) inkubiert, welches per Diffusion in die Zelle gelangt und sich dort in den Mitochondrien einlagert. Nach Beladung der Zellen mit Rh123 werden die Zellen gewaschen und mit Rh123 freiem Medium versetzt. Da Rh123 von Effluxtransportern aus der Zelle transportiert wird, ist die Abnahme der Rh123-Floureszenzintensität in den Zellen ein Maß für die Funktion dieser Transporter.

Für die Etablierung dieses Assay (ist noch nicht abgeschlossen) wurde der "Multidrug Resistance Direct Dye Efflux Assay“ eigesetzt und Caco-2-Zellen genutzt. Diese exprimieren endogen MDR1 und MRP1 [152]. Für den Versuch wurden die Zellen zunächst mit Rh123 beladen. Ein Teil der Zellen wurde anschließend bei $37^{\circ} \mathrm{C}$ im Wasserbad inkubiert, um den Efflux des Rh123 durch die Aktivität von MDR1 und MRP1 zu aktivieren. Kontrollzellen wurden stattdessen bei $4^{\circ} \mathrm{C}$ gehalten, um die Transporteraktivität zu hemmen. Das genaue methodische Vorgehen ist im Methoden-Teil in Kapitel 3.1.10 beschrieben. Als Kontrolle wurden die Zellen mit Vinblastin, einem Inhibitor von MDR1 [186] und MRP1 [187], behandelt. Die Analyse der Fluoreszenzabnahme von Rh123 in den Zellen erfolgte am FACS (LSRII) im FITC-A Kanal.

Abbildung 40 zeigt, dass die Zellen nach Inkubation mit Vinblastin eine annähernd hohe Rh123-Konzentration aufweisen wie Zellen in denen die MDR1- und MRP1Transporter durch Inkubation bei $4^{\circ} \mathrm{C}$ gehemmt wurden. Wurden die Zellen mit dem Lösungsmittel DMSO inkubiert, war die Fluoreszenzintensität dagegen geringer. Dieses lässt auf einen Efflux von Rh123 und damit auf eine Aktivität der Transporter schließen.

Die Etablierung des Assays an RD-Zellen steht noch aus. 


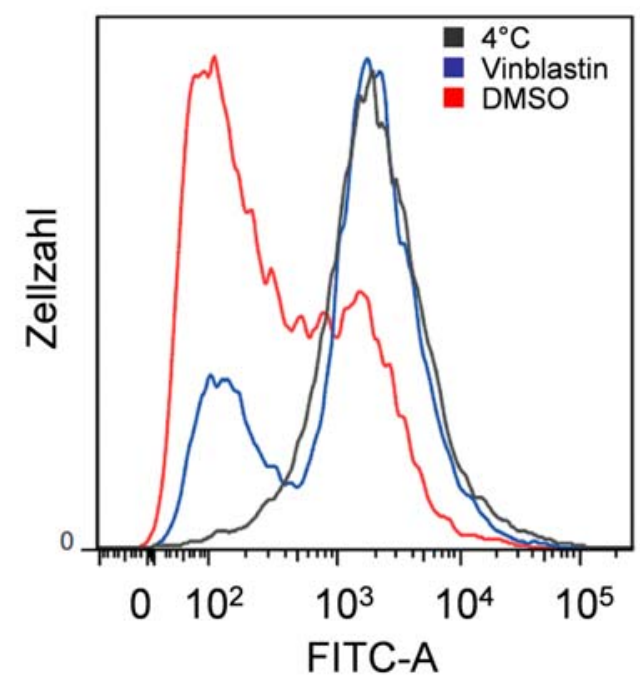

Abbildung 40: Analyse der MDR1- und MRP1-Aktivität in Caco-2-Zellen. Caco-2-Zellen wurden in Suspension genommen und zur Inaktivierung der MDR1- und MRP1-Aktivität bei $4^{\circ} \mathrm{C}$ gehalten oder mit Vinblastin (bei $37^{\circ} \mathrm{C}$ ) behandelt. Um den Efflux von Rh123 zu gewährleisten, wurden Zellen mit dem Lösungsmittel von Vinblastin, DMSO, bei $37^{\circ} \mathrm{C}$ inkubiert. Die Fluoreszenzintensität von Rh123 in den Zellen wurde mittels FACS analysiert. Die Abbildung stellt jeweils einen von zwei Messwerten dar.

Zusammenfassend kann man zu diesem Kapitel festhalten, dass eine Behandlung von RD-Zellen mit PI103 zur Hemmung der Transkription von MDR1 und MRP1 führt. Auf Proteinebene kann dies bisher nur für MRP1 im Western Blot bestätigt werden. Ein Assay zur funktionellen Analyse der Reporter wird momentan etabliert.

\subsubsection{Die Hemmung der Expression von Effluxtransportern korreliert mit der Akkumulation von Doxorubizin in RD-Zellen}

Wie bereits beschrieben, hemmt PI103 die Expression von MDR1 und MRP1 in RDZellen. Daher wurde nun untersucht, ob diese Hemmung möglicherweise zu einer Akkumulation von Doxorubizin in der Zelle führt, welche den kooperativen antitumoralen Effekt von Doxorubizin und PI103 erklären könnte.

Da Doxorubizin eine Eigenfluoreszenz hat, die bei $585 \mathrm{~nm}$ gemessen werden kann, konnte die Doxorubizin-Beladung der Zellen mittels FACS-Analyse gemessen werden. Hierfür wurden die Zellen mit Doxorubizin, mit PI103, mit einer Kombination beider Substanzen oder dem Lösungsmittel inkubiert.

Wie in Abbildung 41 zu erkennen ist, führt die Behandlung der Zellen mit PI103 tatsächlich zu einer Doxorubizin-Akkumulation. So kann die Fluoreszenzintensität, die nach Behandlung mit $1 \mu \mathrm{M}$ Doxorubizin in den Zellen gemessen wird, durch Kombination mit $3 \mu \mathrm{M}$ PI103 deutlich gesteigert werden (PI103 selbst hat keine 
Eigenfluoreszenz und ist somit zum Kontrollwert identisch). Die durch Kombination von Doxorubizin und $3 \mu \mathrm{M}$ PI103 hervorgerufene Erhöhung der Doxorubizinassoziierten Fluoreszenz ist äquivalent zu derjenigen, die durch eine Inkubation der Zellen mit $2 \mu \mathrm{M}$ Doxorubizin hervorgerufen wird (Abbildung 41).

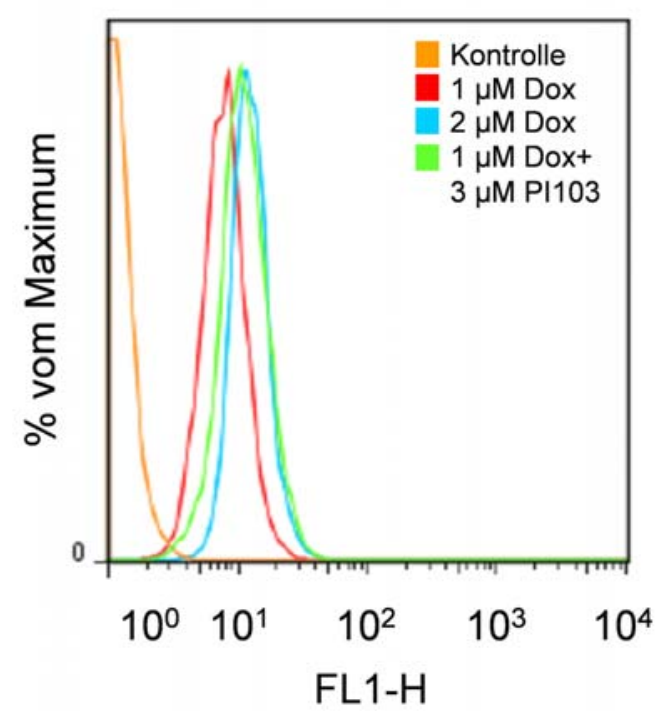

Abbildung 41: Doxorubizin-Akkumulation in RD-Zellen nach Inkubation mit Doxorubizin und/oder PI103. Die Fluoreszenz der RD-Zellen nach Behandlung mit $1 \mu \mathrm{M}$ (rot) oder $2 \mu \mathrm{M}$ Doxorubizin (Dox, blau), mit der Kombination aus $1 \mu \mathrm{M}$ Dox und $3 \mu \mathrm{M}$ PI103 (grün) sowie die Eigenfluoreszenz der Zellen (Kontrolle, orange) wurde im FL1-H Kanal des FACS (BDCalibur) analysiert. Die Fluoreszenzintensitäten sind in einem Histogramm dargestellt und repräsentieren eines von zwei unabhängigen Experimenten, wobei jedes Experiment die Analyse von Duplikaten einschloss.

\subsubsection{Die PI103-induzierte Doxorubizin-Akkumulation scheint nicht für den kooperativen proapoptotischen Effekt verantwortlich zu sein}

Wie soeben gezeigt wurde, führt eine Inkubation mit PI103 zu einer Akkumulation von Doxorubizin. Daher wurde zunächst vermutet, dass diese Akkumulation für den kooperativen proapoptotischen Effekt von Doxorubizin und PI103 verantwortlich sein könnte (siehe Abbildung 23 und Abbildung 24).

Um zu überprüfen, ob der kooperative proapoptotische Effekt von Doxorubizin und PI103 durch die Akkumulation von Doxorubizin in den Zellen verursacht wird, wurden die Zellen mit $1 \mu \mathrm{M}$ Doxorubizin, $3 \mu \mathrm{M}$ PI103, der Kombination beider Medikamente oder mit $2 \mu \mathrm{M}$ Doxorubizin behandelt. Wie gerade beschrieben, führt letztere Konzentration zur gleichen zellulären Doxorubizin-assoziierten Fluoreszenz, wie sie auch durch die Kombination von $1 \mu \mathrm{M}$ Doxorubizin und $3 \mu \mathrm{M}$ PI103 hervorgerufen wird (siehe Abbildung 41). Dann wurde a) die Induktion von DNA-Doppelstrangbrüchen mittels yH2AX-Antikörper, b) die Caspase 3 Aktivität und c) der Anteil 
Annexin $\mathrm{V}$ positiver Zellen analysiert.

Der Anti-yH2AX-Antikörper detektiert die Phosphorylierung der Histonvariante H2AX an Serin 139, welche nach Induktion von DNA-Doppelstrangbrüchen induziert wird. In Abbildung 42 ist zu erkennen, dass sich die Rate von DNA-Doppelstrangbrüchen nach Behandlung der Zellen mit der Kombination von $1 \mu \mathrm{M}$ Doxorubizin und $3 \mu \mathrm{M}$ Pl103 oder nach Behandlung mit $2 \mu \mathrm{M}$ Doxorubizin nicht eindeutig unterscheidet. Dagegen ist das Signal des Antikörpers nach Behandlung mit $1 \mu \mathrm{M}$ Doxorubizin etwas niedriger.

Wie bereits in Abbildung 24 gezeigt wurde, resultiert die Kombinationsbehandlung von Doxorubizin und PI103 in einer starken Zunahme der Caspase 3-Spaltprodukte (siehe Abbildung 42), was auf einen Anstieg der Caspase 3 Aktivität hindeutet. Wie man in Abbildung 42 eindeutig sieht, ist nach Inkubation der Zellen mit $2 \mu \mathrm{M}$ Doxorubizin dagegen kein Anstieg der Caspase 3 Aktivität festzustellen.

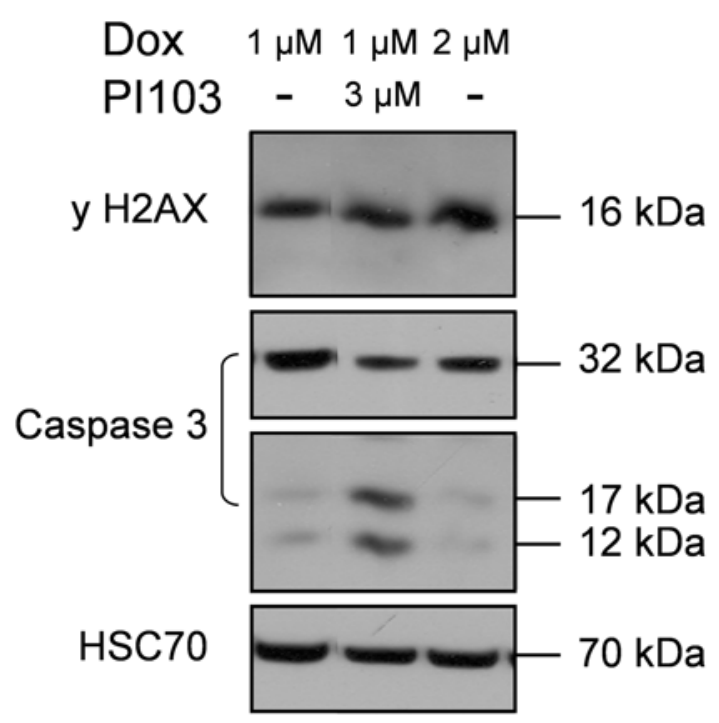

Abbildung 42: Western Blot Analyse zur Untersuchung der Effekte von $2 \mu \mathrm{M}$ Doxorubizin. RDZellen wurden für 24 Stunden mit verschiedenen Konzentrationen von Doxorubizin (Dox) und mit $3 \mu \mathrm{M}$ PI103 behandelt. Analysiert wurden die Induktion von DNA-Doppelstrangbrüchen (mit einem Anti-yH2AX Antikörper), sowie die Aktivität der Caspase 3. Als Ladungskontrolle diente die Detektion des HSC70.

Ähnlich verhält es sich bei der Analyse Annexin V positiver Zellen: Wie in Abbildung 43 dargestellt ist, wird der Prozentsatz Annexin V positiver Zellen durch die Inkubation mit $1 \mu \mathrm{M}$ Doxorubizin und $3 \mu \mathrm{M}$ PI103 stärker als mit $2 \mu \mathrm{M}$ Doxorubizin erhöht. 


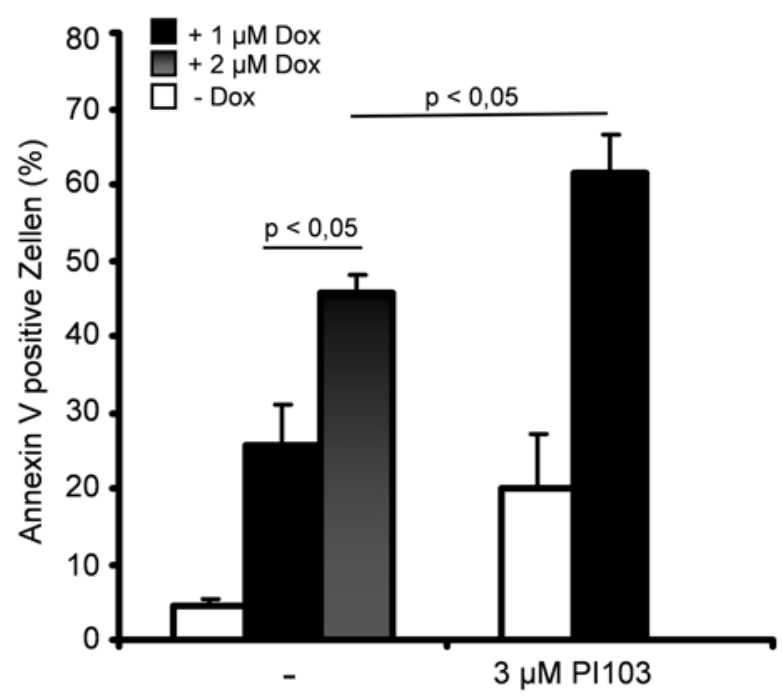

Abbildung 43: Annexin V positive Zellen nach Behandlung mit Doxorubizin und/oder PI103. RD-Zellen wurden für 24 Stunden mit $1 \mu \mathrm{M}$ Doxorubizin (Dox), $3 \mu \mathrm{M}$ PI103, der Kombination der Medikamente sowie $2 \mu \mathrm{M}$ Dox inkubiert. Die Behandlung mit dem Lösungsmittel diente als Kontrolle (jeweils $n=5$ ). Der Mittelwert (+/- SEM) Annexin V positiver Zellen ist als Säulendiagramm dargestellt. Die Durchführung des Experiments erfolgte durch Tiandong Yan.

Diese Daten zeigen, dass die durch $3 \mu \mathrm{M}$ PI103-ausgelöste zelluläre Akkumulation von Doxorubizin zwar vermehrt DNA-Doppelstrangbrüche hervorruft, nicht aber für die erhöhte Apoptoserate verantwortlich sein kann, da $2 \mu \mathrm{M}$ Doxorubizin, welches zur gleichen Doxorubizin-Beladung der Zellen führt wie eine Kombination von $1 \mu \mathrm{M}$ Doxorubizin und $3 \mu \mathrm{M}$ PI103 (siehe Abbildung 41), eine geringere Apoptoserate und Caspase 3 Aktivierung zur Folge hat.

Zusammengefasst bedeuten diese Ergebnisse, dass der kooperative proapoptotische Effekt von Doxorubizin und PI103 nicht durch eine Akkumulation von Doxorubizin ausgelöst wird.

\subsection{Untersuchung der antitumoralen Effekte von Doxorubizin und dem PI3Kinase-Inhibitor GDC-0941 auf RMS-Zellen in vivo}

Die Effektivität einer Kombination von Doxorubizin und PI103 sollte auch in vivo getestet werden. Aufgrund der schlechten Löslichkeit und der rapiden Metabolisierung von PI103 sind in den letzten Jahren PI3Kinase-Inhibitoren entwickelt worden, die eine bessere Pharmakokinetik und Pharmakodynamik aufweisen und oral applizierbar sind. Eines dieser Medikamente ist der PI3KinaseInhibitor GDC-0941. GDC-0941 weist im Vergleich zu PI103 eine bessere Löslichkeit, eine verlangsamte Metabolisierung, und damit auch eine verbesserte Verteilung im 
Gewebe auf. Im Gegensatz zum dualen PI3K/mTOR-Inhibitor PI103, ist GDC-0941 jedoch ein reiner PI3Kinase-Inhibitor [104]. Da die Daten in Kapitel 4.2.2 jedoch zeigen, dass die Sensitivierung von RD-Zellen gegenüber der DoxorubizinBehandlung unabhängig von mTOR sind, wurde dieses Medikament daher für die in vivo-Experimente dieser Arbeit verwendet.

Laut Literaturangaben wird die Applikation von 1,2 mg Doxorubizin/kg jeden 3. Tag über einen Zeitraum von 3 Wochen von SCID-Mäusen gut vertragen [156]. Daher wurde dieses Applikationsschema auch für die in dieser Arbeit durchgeführten in vivo-Studien an Nacktmäusen übernommen. Die Doxorubizin-Lösung wurde dafür frisch mit Kochsalzlösung verdünnt, so dass jedem Tier individuell i. p. 1,2 mg Doxorubizin/kg in einem Volumen von $100 \mu \mathrm{l}$ gespritzt werden konnte. GDC-0941 wurde dagegen täglich per Schlundsonde in einer Konzentration von $75 \mathrm{mg} / \mathrm{kg}$ in $200 \mu \mathrm{l}$ verabreicht. Diese Konzentration war von der Firma Genentech, die dieses Medikament zur Verfügung gestellt hat, für Kombinationsbehandlungen empfohlen worden.

Das Applikationsschema ist in Abbildung 44 dargestellt.

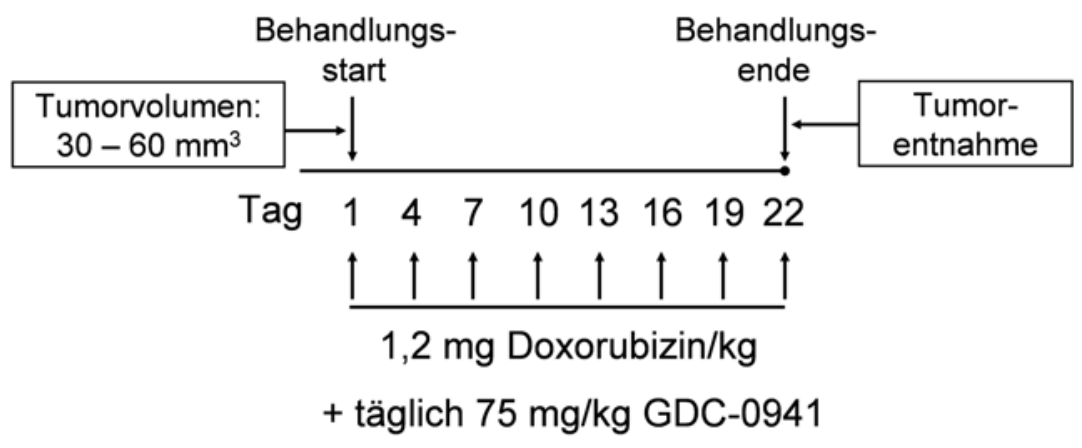

Abbildung 44: Behandlungsschema von Nacktmäusen. Mäusen, denen RD-Zellen transplantiert wurden, wurden jeden 3. Tag für insgesamt $8 \mathrm{mal}$ mit $1,2 \mathrm{mg}$ Doxorubizin $/ \mathrm{kg}$ i. p., und täglich mit $75 \mathrm{mg}$ GDC-0941/kg per Schlundsonde behandelt. Die Medikamente wurden auch kombiniert verabreicht. Kontrollmäuse erhielten anstelle von Doxorubizin Kochsalzlösung, und statt GDC-0941 das Lösungsmittel MCT-Lösung. Das Gewicht der Mäuse wurde einen Tag vor dem Start der Behandlung, sowie während dem Behandlungszeitraum 2mal in der Woche bestimmt.

\subsubsection{Xenotransplantation von RD-Tumorzellen in Nacktmäuse}

Zur Überprüfung der in vivo-Wirksamkeit von Doxorubizin und GDC-0941 sollten Nacktmäuse mit RD-Zellen transplantiert und anschließend mit den Medikamenten behandelt werden.

Die Transplantation von RD-Zellen in Nacktmäuse musste zunächst etabliert werden. 
Anfangs wurden $2 \times 10^{7}$ RD-Zellen in $500 \mu \mathrm{l} \mathrm{PBS}$ subkutan transplantiert (Protokoll: Roland Kappler, LMU München). Gemäß dieses Protokolls sollten die Tumoren nach 10 bis 14 Tagen sichtbar sein. In meinen Händen traten die Tumoren jedoch erst 84 Tage nach Transplantation auf (Daten nicht gezeigt). Zur Beschleunigung des Wachstums der Tumoren wurden die Zellen in Matrigel transplantiert. Matrigel ist eine lösliche Basalmembranmatrix, gewonnen aus dem Engelbreth-Holm-Swarm Tumor (EHS) und bietet den Tumorzellen durch die Vielzahl an enthaltenden Matrixproteinen eine der natürlichen Umgebung des Tumors ähnliche Gewebestruktur. Zur Etablierung der Methode wurden 4 Nacktmäusen je $1 \times 10^{6}$ RD-Zellen in Matrigel in die linke laterale Bauchwand, und je $2 \times 10^{7}$ RD-Zellen in Matrigel in die rechte laterale Bauchwand transplantiert. Alle Tumoren konnten im Zeitraum von Tag 9 und Tag 15 nach Transplantation detektiert werden. Tumoren, die aus $2 \times 10^{7}$ Zellen entstanden, zeigen nach ihrer Detektion teilweise ein rasantes Wachstum, welches bereits nach 4 Wochen das 20fache des Ausgangsvolumens erreicht (Daten nicht gezeigt). Dagegen nahm das Tumorvolumen nach Transplantation von $1 \times 10^{6}$ RD-Zellen in Matrigel nicht ganz so stark zu (etwa um das 3 - 4fache des Ausgangsvolumens; Daten nicht gezeigt). Daher haben wir uns entschieden, für die nachfolgenden Analysen $2 \times 10^{6}$ RD-Zellen zu transplantieren.

\subsubsection{Keine signifikante Verstärkung des antitumoralen Effekts von Doxorubizin durch GDC-0941 auf RD-Xenotransplantate}

Bei Transplantation waren die Nacktmäuse 5 bis 11 Wochen alt. Wie soeben beschrieben, wurde den Nacktmäusen je $2 \times 10^{6}$ RD-Zellen subkutan in sowohl die rechte als auch die linke laterale Bauchwand transplantiert. Die Therapie wurde begonnen, sobald der Tumor eine Größe von $30-60 \mathrm{~mm}^{3}$ erreicht hatte. Insgesamt wurden 10 Mäuse mit den Lösungsmitteln, 10 Mäuse mit 1,2 mg Doxorubizin/kg, 6 Mäuse mit 75 mg GDC-0941/kg und 7 Mäuse mit der Kombination aus beiden Medikamenten für jeweils 3 Wochen gemäß dem gezeigten Schema (siehe Abbildung 44) therapiert. Eine Darstellung der mittleren prozentualen Zunahme des Tumorvolumens unter Medikation ist Abbildung 45 zu entnehmen. 


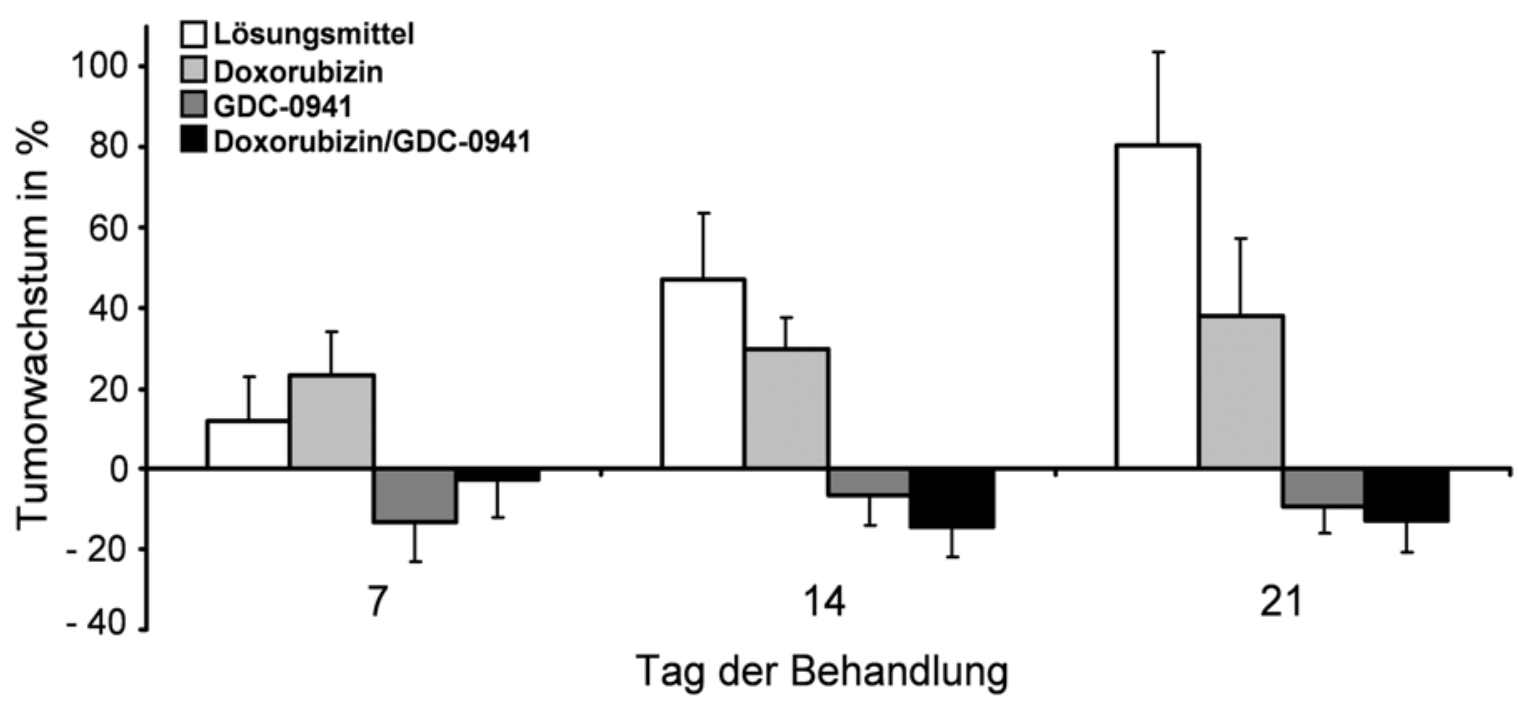

Abbildung 45: Zunahme des Tumorvolumens von RD-Xenotransplantaten nach Therapie mit Doxorubizin, GDC-0941, der Kombination aus Doxorubizin und GDC-0941 oder den Lösungsmitteln. $2 \times 10^{6}$ Zellen wurden subkutan in Nacktmäuse implantiert. Die Mäuse wurden anschließend wie im Text beschrieben für 21 Tage an jedem 3. Tag mit $1,2 \mathrm{mg}$ Doxorubizin/kg, täglich mit $75 \mathrm{mg}$ GDC-0941/kg, der Kombination aus beiden Medikamenten (Doxorubizin/GDC-0941), oder den jeweiligen Lösungsmitteln behandelt. Das Tumorvolumen wurde mittels Messschieber analysiert. Gezeigt ist die mittlere prozentuale Zunahme des Tumorvolumens im Vergleich zum Ausgangswert an den Behandlungstagen 7, 14 und 21. Der Ausgangswert wurde dabei auf $100 \%$ gesetzt. Die Balken zeigen jeweils den Mittelwert (+/- SEM) des dargestellten Tumorwachstums an.

Wie in Abbildung 45 zu erkennen, war ein stetiges Wachstum der Tumoren in der mit Lösungsmittel-behandelten Kohorte festzustellen. Bei Behandlung der Tiere mit Doxorubizin konnte dagegen eine Stagnation des Tumorwachstums über den gesamten Behandlungszeitraum beobachtet werden. Tumoren, die mit GDC-0941 behandelt wurden, wiesen hingegen eine Reduktion der Wachstumsrate auf. Diese Wachstumsrate konnte jedoch durch Kombination mit Doxorubizin nicht weiter signifikant reduziert werden (Tabelle 11). Die Signifikanzen zu den verschiedenen Zeitpunkten sind in Tabelle 11 dargestellt. 
Tabelle 11: Vergleich der Tumorgröße nach Behandlungsbeginn ( $p$-Werte). Die Tumorgrößen pro Kohorte wurden nach Behandlung am Tag 1, 7, 14 und 21 verglichen und die Signifikanzen ( $p$-Wert) nach der Methode von Turkey bestimmt. Dargestellt sind die ermittelten $p$-Werte. Dox, Doxorubizin; Lsgm, Lösungsmittel.

\begin{tabular}{l|l|c|c|c}
\hline $\begin{array}{l}\text { Tag der } \\
\text { Behandlung }\end{array}$ & Behandlung & \multicolumn{1}{l|}{ Lsgm } & \multicolumn{1}{l}{ lox } & GDC-0941 \\
\hline $\mathbf{1}$ & Lsgm & - & 0,0425 & - \\
\hline & GDC-0941 & 0,9464 & 0,3505 & - \\
\hline $\mathbf{7}$ & Dox/GDC-0941 & 0,2177 & 0,9708 & 0,6489 \\
\hline & Lsgm & - & 0,9171 & - \\
\hline & GDC-0941 & 0,2924 & 0,1045 & - \\
\hline $\mathbf{1 4}$ & Dox/GDC-0941 & 0,4221 & 0,1603 & 0,9866 \\
\hline & Lsgm & - & 0,3783 & - \\
\hline & GDC-0941 & 0,0002 & 0,0228 & - \\
\hline $\mathbf{2 1}$ & Dox/GDC-0941 & $<0,0001$ & 0,0011 & 0,9422 \\
\hline & Lsgm & - & 0,0011 & - \\
\hline & GDC-0941 & $<0,0001$ & 0,0053 & - \\
\hline & Dox/GDC-0941 & $<0,0001$ & $<0,0001$ & 0,4799 \\
\hline
\end{tabular}

Die Tumoren wurden dann in Paraffin eingebettet, geschnitten und mittels H\&EFärbung und PAS-Reaktion, welche Polysaccharide, Glykogene, Cellulosen und Glykolipide (und somit auch Matrigel) anfärbt, analysiert. Da mit Hilfe der PASReaktion Blutgefässe sichtbar gemacht werden können, konnte gleichzeitig die Vaskularisierung der Tumoren untersucht werden. Um die Zellkerne sichtbar zu machen, wurden die Schnitte mit Hämalaunlösung gegengefärbt.

Anhand der PAS-Reaktion werden Unterschiede in der Zelldichte der Tumoren deutlich (Abbildung 46). Hierbei kann bei Tumoren aus der Lösungsmittelbehandelten Kohorte die höchste Zelldichte detektiert werden. Bei den Doxorubizinbehandelten Tumoren waren sehr viel weniger Zellen und vermehrt Matrix in dem Tumorgewebe sichtbar. Die Zelldichte der mit GDC-0941- als auch der mit Doxorubizin/GDC-0941-behandelten Tumoren schwankte dagegen sehr stark und lies daher keine eindeutige Aussage zur Zelldichte zu. Deutliche Unterschiede in dem Vaskularisierungsstatus der Tumore zwischen den jeweiligen Kohorten konnten nicht nachgewiesen werden. 


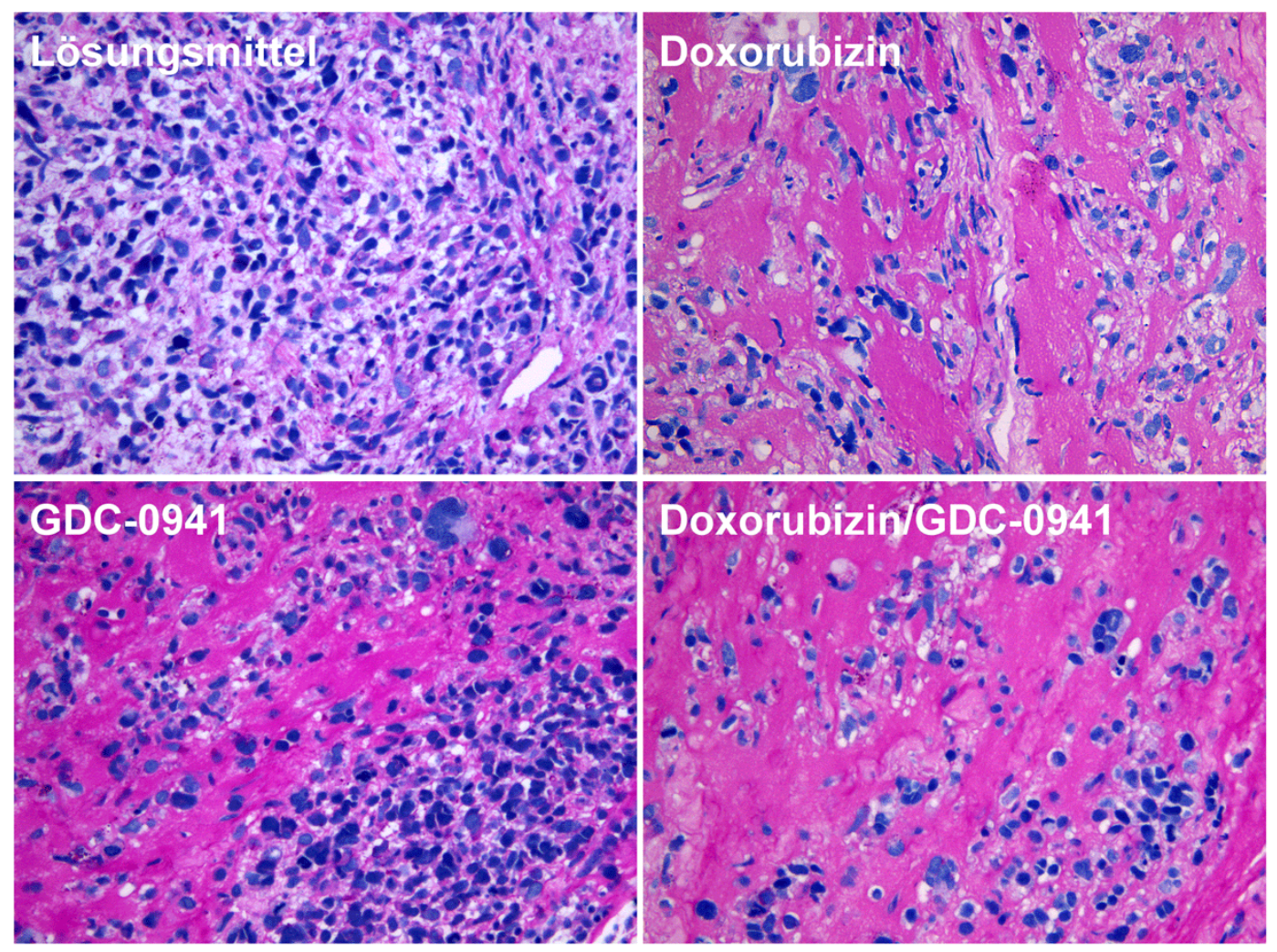

Abbildung 46: Unterschiede in der Gewebestruktur der Tumoren nach der PAS-Reaktion. Dargestellt sind 4 repräsentative Färbungen von insgesamt 6 Tumoren pro Kohorte. Die Fotos wurden mit einer 200fachen Vergrößerung am Mikroskop erstellt.

Zusätzlich wurden der Proliferationsstatus sowie apoptotische Vorgänge untersucht. Der Proliferationsmarker Ki67 wird während der Zellteilung im Zellkern exprimiert. Daher kann eine Ki67-spezifische Antikörperfärbung Aufschluss über die Zellteilung geben. Zur Detektion der Apoptoseinduktion in den Tumorzellen wurde die Aktivität der Caspase 3 mittels eines Antikörpers, der an die p17-Untereinheit der gespaltenen und somit aktiven Caspase 3 bindet, untersucht.

Für die Analyse der Ki67-, sowie der Caspase 3-positiven Zellen wurden Paraffinschnitte von je 6 Tumoren pro Behandlungskohorte angefertigt. Diese wurden mit dem Anti-Ki67 bzw. dem Anti-aktive Caspase 3 Antikörper gefärbt. Pro Tumor wurden 1.000 Zellen mit Hilfe der CellF Software am Mikroskop ausgezählt, und die Prozentzahl der Ki67- bzw. Caspase 3-positiven Zellen bestimmt. Die prozentuale Anzahl an positiven Zellen wurde pro Kohorte gemittelt (siehe Abbildung 47 und Abbildung 48).

Anhand der Auszählung kann im Vergleich zur Lösungsmittelkontrolle eine verminderte Anzahl Ki67 positiver Zellen in den behandelten Tumoren festgestellt werden. Jedoch ist die Abnahme weder nach Doxorubizin-, GDC-0941- noch nach 
Kombinationsbehandlung signifikant (Abbildung 47).

Die Untersuchung von Caspase 3 positiven Zellen zeigt, dass die Anzahl der positiven Zellen schon nach alleiniger Behandlung mit Doxorubizin oder GDC-0941 ansteigt (Abbildung 48). Nach Kombinationsbehandlung zeigt sich jedoch ein Anstieg von Caspase 3 positiven Zellen, der gegenüber der Lösungsmittelkontrolle signifikant ist (Abbildung 48).

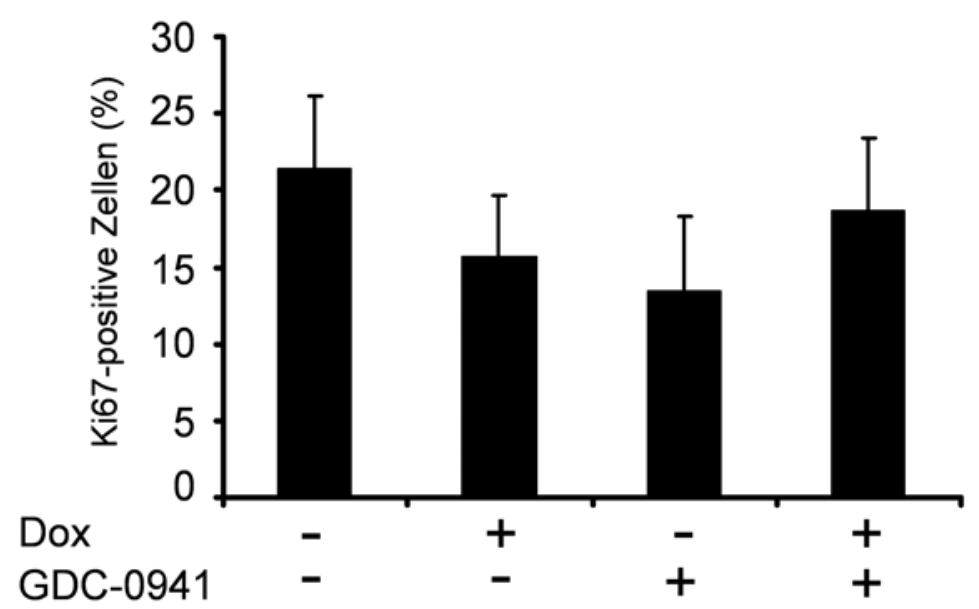

Abbildung 47: Ki67 positive Zellen in den Tumoren der therapierten Tiere in \%. Pro Behandlungskohorte wurden je 1.000 Zellen eines Paraffinschnitts von je 6 Tumoren gezählt und der prozentuale Anteil an Ki67-positiven Zellen pro Tumor bestimmt. Der Wert aller 6 Tumoren wurde gemittelt. Die Abbildung zeigt den Mittelwert des prozentualen Anteils an Ki67-positiven Zellen +/SEM. Dox, Doxorubizin.

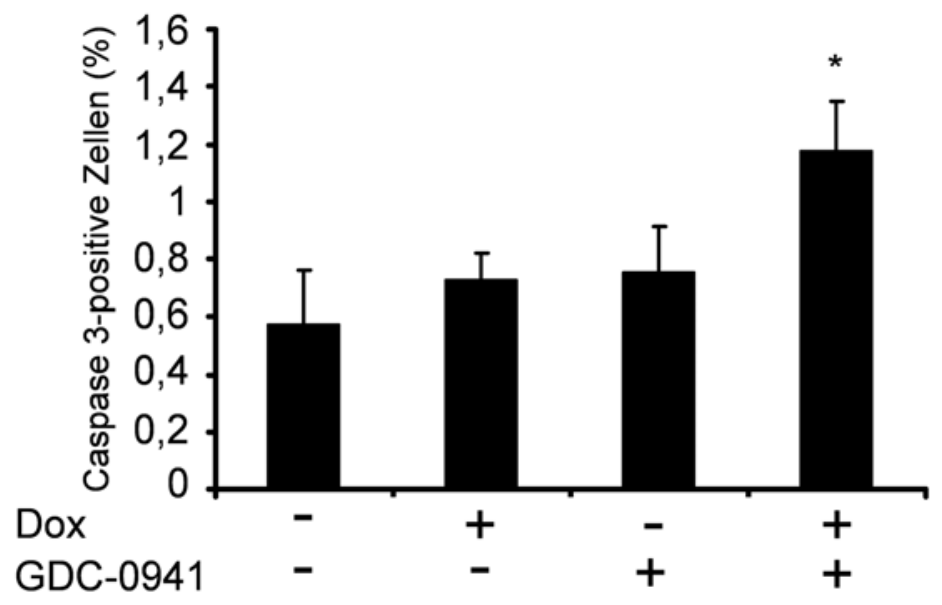

Abbildung 48: Caspase 3 positive Zellen in den Tumoren der behandelten Tiere in \%. Es wurden pro Behandlungskohorte je 1.000 Zellen eines Paraffinschnitts von jeweils 6 Tumoren ermittelt, und der prozentuale Anteil an Caspase 3-positiven Zellen pro Tumor bestimmt. Der Wert von allen 6 Tumoren wurde gemittelt. Die Abbildung zeigt den Mittelwert des prozentualen Anteils von Caspase 3-positiven Zellen +/- SEM. * signifikant $(p<0,05)$ im Vergleich zur Lösungsmittelkontrolle. Dox, Doxorubizin.

Zusammenfassend zeigen die Daten, dass die Behandlung der RD-Xeno- 
transplantate mit Doxorubizin zu einer Stagnation des Tumorwachstums führt. Weiterhin kann das Tumorwachstum mit Hilfe von GDC-0941 reduziert werden. Die Kombination aus Doxorubizin und GDC-0941 hat jedoch keinen Kombinationseffekt und führt zu keiner weiteren signifikanten Hemmung des Tumorwachstums. Weiterhin zeigen die Daten, dass die Hemmung des Tumorwachstums durch Doxorubizin oder durch GDC-0941 mit einer verminderten Zahl proliferierender Zellen einhergeht, was jedoch für keine der Behandlungen signifikant gegenüber der Lösungsmittelkontrolle ist. Dagegen kann für die Kombinationsbehandlung ein signifikanter Anstieg an Caspase 3-positiven Zellen festgestellt werden.

\subsubsection{Vorarbeiten zur Untersuchung der antitumoralen Wirkung von Doxorubizin und GDC-0941 im (B6xBalbc)Ptch ${ }^{\text {neo67/+ }}$-Mausmodell für RMS}

Die Wirksamkeit der Kombinationstherapie soll ebenfalls in Mäusen getestet werden, die endogen RMS entwickeln. Hierfür eignen sich (B6xBalbc)Ptch ${ }^{\text {neo67/t+}}-$ Mäuse.

Das Ansprechen von RMS in (B6xBalbc)Ptch ${ }^{\text {neo67/+ }}$-Mäusen auf Doxorubizin wurde bereits in der Arbeitsgruppe Prof. H. Hahn von I. Ecke analysiert und veröffentlicht [188, 189]. Das Schema, das in Tieren eines gemischten B6xBalbc-Hintergrunds angewendet werden kann, besteht aus der Gabe von $3 \mathrm{mg}$ Doxorubizin $/ \mathrm{kg}$ i. p. am Tag 1, 8, 15 und 29. Dieses Applikationsschema hemmt das RMS-Wachstum von (B6xBalbc)Ptch ${ }^{\text {neo67/+ }}$-Mäusen gegenüber der Lösungsmittelkontrolle [188].

In einem Vorversuch wurde nun die Wirksamkeit von GDC-0941 in RMS von (B6xBalbc)Ptch ${ }^{\text {neo67/+ }}$-Mäusen überprüft. Den Tieren wurde dafür für 5 Wochen täglich 75 mg GDC-0941/kg per Schlundsonde verabreicht. Das Tumorvolumen wurde vor und nach dem Behandlungszeitraum, sowie 3 Wochen nach Abschluss der Therapie mittels VCT erfasst. Insgesamt wurden 5 Tiere behandelt, wobei 2 Mäuse als Kontrolltiere dienten. Die Tumoren der mit Lösungsmittel-behandelten Tiere zeigen, wie erwartet, ein mäßiges, aber stetiges Wachstum (Abbildung 49, \#1p. \#8P). Bei den mit GDC-0941-behandelten Mäusen kann in einem Fall ein stetiges Wachstum des Tumors detektiert werden Abbildung 49; \# 60). Dagegen zeigen 2 Tumoren unter der Behandlung eine Regression auf die Hälfte ihres Anfangsvolumens (Abbildung 49, \#180, \#500). 


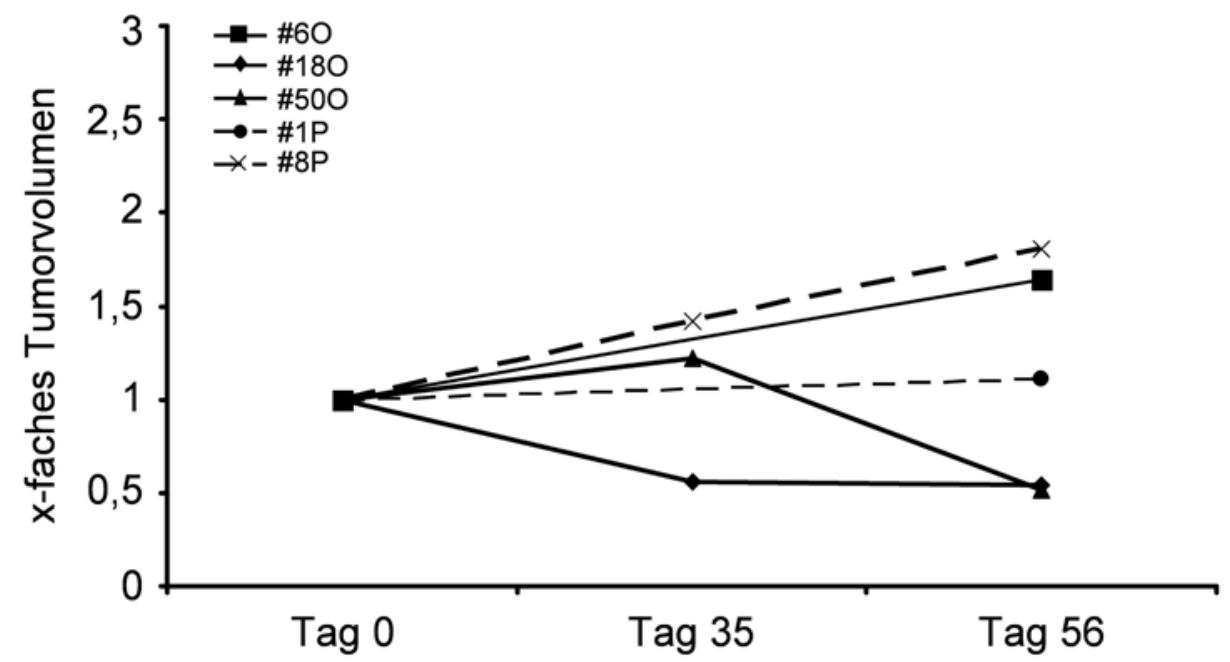

Abbildung 49: Tumorwachstumskurven unter GDC-0941-Behandlung. Tumortragende (B6xBalbc)Ptch ${ }^{\text {neo67/+ }}$-Mäuse wurden für 5 Wochen täglich mit $75 \mathrm{mg}$ GDC-0941/kg behandelt. Das Tumorvolumen wurde mittels VCT analysiert. __ Behandlung mit GDC-0941, _ - Behandlung mit dem Lösungsmittel. Bei 2 Tieren (\#6O, \#1P) konnte das Tumorvolumen an einem von 3 Terminen nicht bestimmt werden.

Es lässt sich somit anhand dieser wenigen Daten festhalten, dass die Applikation von GDC-0941 in 2 von 3 Fällen zu einer Tumorregression führt.

Diese Analysen sollen nun an einer größeren Mauskohorte wiederholt werden. Dabei soll darauf geachtet werden, dass die Tumorvolumina aller Tiere zum Behandlungsbeginn annähernd gleich sind. Zudem sollen die tumortragenden (B6xBalbc)Ptch ${ }^{\text {neo67/t+}}$-Mäuse auch mit der Kombination aus Doxorubizin und GDC-0941 behandelt werden. 


\section{Diskussion}

\subsection{Allgemeine Wirkungen von Doxorubizin in den HT1080-, TP5014- und RD-Zellen}

Es ist bekannt, dass verschiedene Zelllinien unterschiedlich auf Doxorubizin reagieren [190-192]. Die Ursachen dafür sind vielseitig. Auch bei den hier durchgeführten Experimenten fällt zunächst auf, dass die Fibrosarkomzellen deutlich sensitiver auf eine Doxorubizin-Behandlung reagieren, als die RMS-Zelllinie RD. So ist die durch $10 \mathrm{nM}$ Doxorubizin ausgelöste Proliferationshemmung von HT1080Zellen vergleichbar zu einer durch $100 \mathrm{nM}$ Doxorubizin ausgelösten Hemmung von RD-Zellen. Letztere zeigen sich somit resistenter gegenüber einer DoxorubizinBehandlung. Man könnte nun annehmen, dass HT1080-Zellen deshalb sensitiver auf Doxorubizin reagieren, weil sie eine verringerte Expression von dem Multidrug Effluxtransportern MDR1 oder MRP1 oder von beiden Transportern aufzeigen. Tatsächlich kann durch andere Arbeitsgruppen nachgewiesen werden, dass HT1080-Zellen kein MDR1 und MRP1 exprimieren [193, 194]. Auch in unserer Arbeitsgruppe konnte keine Expression von MDR1 und MRP1 auf Proteinebene in den HT1080-Zellen festgestellt werden (Daten nicht gezeigt). Für die geringere Sensitiviät der RD-Zellen gegenüber Doxorubizin spricht nun, dass sie sowohl MDR1 als auch MRP1 exprimieren, und zumindest MRP1 auch auf Proteinebene nachweisbar ist (siehe Kapitel 4.2.4 und [195, 196]).

Auch das TOP2a-Level kann bei erhöhter Resistenz von Zellen gegenüber Doxorubizin eine Rolle spielen, da das Ansprechen von Tumoren auf eine Doxorubizin-Behandlung mit dem TOP2a-Level positiv korreliert ist [61]. Diese Unterschiede wurden in dieser Arbeit jedoch nicht untersucht.

Weiterhin gibt es Studien, die zeigen, dass durch Doxorubizin die AKT-Aktivität erhöht werden kann, und somit eine Resistenz der Tumorzellen gegenüber Doxorubizin ausgelöst wird [197]. Dies scheint mit der Doxorubizin-Dosis zusammenzuhängen. Dabei wird gemutmaßt, dass die Doxorubizin-vermittelte Aktivierung von AKT aus der Heterodimerisierung und der Interaktion der Tyrosinkinasen HER-2 und HER-3 resultiert [197]. Da dieser Effekt jedoch in der 
vorliegenden Arbeit nicht gesehen wurde, kann davon ausgegangen werden, dass die höhere Resistenz der RD-Zellen nicht durch diesen Mechanismus zustande kommt.

\subsection{Keine Erhöhung der antitumoralen Wirkung von Doxorubizin durch 5-Aza oder VPA in HT1080-Zellen}

Wie die Daten zeigen erhöht eine Behandlung mit $5 \mu \mathrm{M} 5-\mathrm{Aza}$, wenn alleine appliziert, die Proliferationsrate der HT1080-Zellen. Dagegen haben zahlreiche andere Arbeitsgruppen einen wachstumsinhibierenden Effekt von 5-Aza gezeigt. So führen $5 \mu \mathrm{M}$ 5-Aza in der Lungenadenokarzinomzelllinie A549 zu einer Proliferationshemmung von 60\% [198]. Auch die Wachstumssrate von Pankreaszellen kann durch 5-Aza um 40 bis 80\% gemindert werden [199], und auch in Fibrosarkomzellen hat 5-Aza $(0,05 \mu \mathrm{g} / \mathrm{ml})$ eine proliferationsinhibierende Wirkung [200]. In der vorliegenden Arbeit zeigt 5-Aza in den HT1080-Zellen außerdem auch nur eine geringe Apoptoseinduktion. Auch dies steht im Gegensatz zu Daten anderer Publikationen. So induziert beispielsweise $1 \mu \mathrm{g} / \mathrm{ml}$ 5-Aza in Fibrosarkomzellen bereits nach einer Inkubationszeit von 2 Stunden eine Apoptoserate von 50\% [200]. Des Weiteren erhöht $1 \mu \mathrm{M}$ 5-Aza die Rate von DNA-Doppelstrangbrüchen in der Kolonkarzinomzelllinie HCT116 auf das 3fache der Lösungsmittelkontrolle, $10 \mu \mathrm{M}$ 5-Aza sogar auf das 7fache [162]. Die Erhöhung der DNA-Doppelstrangbrüche geht dabei mit gesteigerter Apoptoseinduktion in den HTC116 Zellen einher [201]. Der proliferationsinhibierende und apoptoseinduzierende Effekt von 5-Aza ist jedoch abhängig von der Inkubationszeit mit den Zellen. So zeigt $5 \mu \mathrm{M} 5-A z a$ in MCF-7 Zellen nach 2tägiger Inkubation eine Proliferationsinhibierung von 20\%. Diese steigt nach 4 Tagen bereits auf 55\%, und nach 6 Tagen auf mehr als 80\% [202]. Auch in anderen Arbeiten wurden die Zellen zwischen 2 und 6 Tagen mit 5-Aza behandelt [162, 198, 199, 203, 204]. Daher ist es möglich, dass eine verlängerte Inkubationszeit mit 5-Aza in HT1080-Zellen ebenfalls einen signifikanten antiproliferativen, sowie erhöhten proapoptotischen Effekt gezeigt hätte.

Weiterhin konnte in der vorliegenden Arbeit in HT1080-Zellen keine Erhöhung der TOP2a-Expression durch 5-Aza hervorgerufen werden. Der TOP2a-modulierende Effekt von 5-Aza wurde jedoch in $\mathrm{CHO}$ (Chinese Hamster Ovary)-Zellen gezeigt [63]. Möglicherweise beruht dieser Unterschied auf die zelltypspezifische Wirkung von 
5-Aza. Weiterhin ist auch nicht auszuschließen, dass in den HT1080-Zellen durch Einsatz einer höheren Konzentration, oder durch verlängerte Inkubationszeiten mit 5-Aza, eine Modulation der TOP2a-Expression hätte detektiert werden können.

Die Daten zeigen weiterhin, dass 5-Aza weder die antiproliferativen noch die proapoptotischen Effekte von Doxorubizin in HT1080-Zellen steigert. Diese Daten stehen im Gegensatz zu einer Studie, in der Lymphomzellen durch 5-Aza auf die Behandlung von Doxorubizin sensitiviert werden konnten [161]. Auf der anderen Seite kann 5-Aza jedoch auch die Expression von MDR1 induzieren [205], was wiederum eine Resistenz der Zellen gegenüber Doxorubizin auslösen kann, und begründen könnte, weshalb die Kombination von Doxorubizin und 5-Aza zu keiner deutlichen Erhöhung der antitumoralen Wirksamkeit von Doxorubizin in HT1080Zellen führt.

Die antitumorale Aktivität von 5-Aza alleine oder in Kombination mit Doxorubizin scheint somit abhängig von dem behandelten Zelltyp zu sein. Außerdem ist bekannt, dass sich Zellen in Zellkultur verändern können. Es wäre somit weiterhin möglich, dass die HT1080-Zellen eine Modifizierung in ihrem Methylierungsmuster erfahren haben, was in einer veränderten Reaktion auf dieses Medikament resultieren könnte.

VPA induziert, wie auch 5-Aza, unerwarteterweise das Zellwachstum der HT1080Zellen. Interessant ist, dass in einer Arbeit gezeigt wird, dass klinisch relevante VPADosen $(>100 \mu \mathrm{M})$ die Proliferation von Brustkrebszellen hemmen können, wohingegen höhere Konzentrationen von VPA scheinbar den Estrogen-Rezeptor aktivieren und somit den gegenteiligen Effekt hervorrufen [206]. Letzteres kann den wachstumsinduzierenden Effekt von VPA in HT1080-Zellen jedoch nicht erklären, da die Fibrosarkomzellen vermutlich keinen Estrogen-Rezeptor exprimieren [207, 208]. In HT1080-Zellen induziert die alleinige Gabe von VPA jedoch die Aktivierung der Caspasen 3 und 7, was aufgrund der proliferationsinduzierenden Wirkung von VPA sehr widersprüchlich ist. Dieser Effekt konnte jedoch auch in einer Studie an Medulloblastomzelllinien gezeigt werden [209]. So wird in einer der untersuchten Medulloblastomzelllinien (PFSK-Zellen) durch $1 \mathrm{mM}$ VPA die Apoptose, aber auch eine Proliferationsinduktion hervorgerufen [209]. Der genaue Mechanismus, durch den das induziert werden könnte, ist jedoch unbekannt.

Da die klinisch relevante Konzentration von VPA auf $<1 \mathrm{mM}$ angesetzt wird [210], wurde die von mir eingesetzte Dosis von 2 mM VPA möglicherweise zu hoch 
gewählt. Diese Konzentration wurde in der hier präsentierten Studie jedoch deshalb genutzt, da beschrieben wurde, dass hohe VPA-Konzentrationen die TOP2aExpression induzieren [67]. In der vorliegenden Arbeit wird jedoch durch VPA das TOP2a-mRNA-Level reprimiert und das Proteinlevel der TOP2a in HT1080-Zellen nicht beeinflusst. Dieses Ergebnis widerspricht den Daten der gegenwärtigen Literatur. Aufgrund der im TOP2a-Promotor befindlichen HDAC-Bindeelemente [66], müsste VPA eine verstärkte Expression der TOP2a-Transkription induzieren. Dies kann in Glioblastomzelllinien demonstriert werden [67]. Ebenfalls würde man aufgrund der Tatsache, dass VPA das Wachstum der HT1080-Zellen induziert, und die TOP2a-Expression vor allem in proliferierenden Zellen ansteigt [19], eine erhöhte TOP2a-Expression erwarten, welche dann auch in einem erhöhten TOP2aProteinlevel resultiert. Dies war in HT1080-Zellen jedoch nicht der Fall. Und auch in einigen anderen Arbeiten wird ein ähnlicher Effekt wie in den HT1080-Zellen auf das TOP2a-Proteinlevel gezeigt. So ist in Brustkrebszellinien beschrieben, dass durch HDAC-Inhibitoren wie VPA keine Erhöhung des TOP2a-Proteinlevels induziert wird [211]. Und auch in Schilddrüsenkarzinomzellen fehlt die VPA-induzierte TOP2aModulierung sowohl auf RNA-, als auch auf Proteinebene [212].

Weiterhin zeigen die Daten der vorliegenden Arbeit, dass VPA weder die antiproliferative noch die proapoptotische Wirkung von Doxorubizin in HT1080-Zellen erhöht. Im Gegensatz hierzu stehen die Daten der zuvor genannten Studien, in denen gezeigt wird, dass eine Vorbehandlung mit VPA die Sensitiviät von Schilddrüsenkarzinom- und Osteosarkomzellen gegenüber Doxorubizin erhöht [212, 213]. In beiden Arbeiten wurden die Zellen mit $0,5 \mathrm{mM}$ bis $1 \mathrm{mM}$ VPA für 24 oder 48 Stunden behandelt, bevor eine Inkubation mit Doxorubizin für weitere 48 bis 72 Stunden erfolgte. Da auch in diesen Studien im Gegensatz zu der hier vorliegenden Arbeit eine geringere Konzentration von VPA eingesetzt wurde, ist es möglich, dass Modulationen der Inkubationszeit, der VPA-Konzentration oder eine Vorbehandlung möglicherweise auch zu einer Sensitivierung von Sarkomzellen gegenüber Doxorubizin geführt hätten. 


\subsection{Bortezomib sensitiviert HT1080-Zellen gegenüber Doxorubizin- induzierter Proliferationsinhibierung, nicht aber gegenüber der Apoptoseinduktion}

Die antiproliferative und proapoptotische Wirkung von Bortezomib auf Tumorzellen konnte bereits in mehreren Arbeiten gezeigt werden [214-216]. Dabei wird beispielsweise eine zeit- und dosisabhängige Bortezomib-vermittelte Proliferationsinhibierung in Neuroblastomzellen beschrieben [215]. Auch die Bortezomib-induzierte Apoptoseinduktion verhält sich zeit- und dosisabhängig, wie in neuroendokrinen Tumorzellen gezeigt wird [216]. Dieser antiproliferative und proapoptotische Effekt von Bortezomib kann auch in HT1080-Zellen bestätigt werden. Die induzierte Caspase 3 und 7 Aktivität unterliegt allerdings großen Schwankungen. Es ist aber denkbar, dass geringere Dosen präzisere Ergebnisse hervorgebracht hätten. So wird in Lymphoblastoidzellen bereits nach 4- bis 8stündiger Inkubation mit einer Bortezomib-Konzentration von $1 \mu \mathrm{M}$ die Aktivierung der Caspasen 3 und 7 eindeutig induziert [217]. Möglicherweise hätte daher eine verkürzte Bortezomib-Inkubation in HT1080-Zellen exaktere Ergebnisse geliefert.

Hinsichtlich des Effekts von Bortezomib auf die TOP2a-Expression war die Inkubationszeit von 24 Stunden jedoch richtig gewählt. So ist in einer Studie an Myelomzellen gezeigt worden, dass Bortezomib das TOP2a-Proteinlevel nach 24 Stunden maximal erhöht [69]. Tatsächlich führt Bortezomib nach 24stündiger Inkubation auch in HT1080-Zellen zu einem signifikanten Anstieg des TOP2aProteins. Da die TOP2a-Proteine über das Proteasom degradiert werden [218], Bortezomib dessen Funktion jedoch hemmt, ist dieses Ergebnis schlüssig. Im Gegensatz dazu wird jedoch eine drastische Reprimierung der TOP2a-Expression auf transkriptionelller Ebene durch Bortezomib verzeichnet. Da die TOP2a vorwiegend in proliferierenden Zellen exprimiert wird [19, 219], Bortezomib jedoch eine drastische Wachstumshemmung induziert, ist es denkbar, dass die BortezomibBehandlung zwar zur Abnahme der TOP2a-Transkription führt, das TOP2a-Protein jedoch durch Inhibierung des Proteasoms stabiliert.

In HT1080-Zellen verstärkt Bortezomib den Doxorubizin-vermittelten antiproliferativen Effekt. Dieser sensitivierende Effekt gegenüber einer Doxorubizin-Behandlung kann auch in multiplen Myelomzelllinien gezeigt werden. So wird durch gleichzeitige Behandlung der Zellen mit $5 \mathrm{mg} / \mathrm{ml}$ Bortezomib die 20\%ige Proliferationsinhibierung, die durch 40 nM Doxorubizin ausgelöst wird, auf 60\% erhöht [220]. 
In HT1080-Zellen führt Bortezomib ebenfalls zu einer Steigerung der proapoptotischen Wirkung von Doxorubizin. Dieser Effekt ist jedoch nicht signifikant. In einer Studie an multiplen Myelomzellen wird hingegen eine signifikante Bortezomib-vermittelte Sensitivierung gegenüber der proapoptotischen Wirkung von Doxorubizin gezeigt [221]. Ebenso kann der Erfolg dieser Kombinationstherapie in klinischen Studien der Phase I nachgewiesen werden. Dabei zeigen vor allem multiplen Myelome ein Ansprechen auf die Kombination [222, 223]. Die Behandlung mit Doxorubizin und Bortezomib wird daher vorwiegend beim multiplen Myelom eingesetzt und scheint sehr erfolgreich zu sein [224]. Da die kooperativen Effekte von Doxorubizin und Bortezomib teilweise durch Vorbehandlung der Zellen mit einem der beiden Medikamente induziert wurden [221], ist möglich, dass auch in Sarkomzellen ein kooperativer Effekt auf die Apoptose durch Vorbehandlung der Zellen erzielt worden wäre.

\subsection{Pioglitazon sensitiviert HT1080- und TP5014-Zellen gegenüber einer Doxorubizin-induzierten Proliferationshemmung, jedoch nur HT1080-Zellen gegenüber Doxorubizin-induzierter Apoptose}

Alleine appliziert hat Pioglitazon weder einen antiproliferativen noch einen proapoptotischen Effekt auf HT1080-Zellen. Es stellt sich somit die Frage, warum Pioglitazon keine antitumoralen Eigenschaften in Sarkomzellen aufweist, da diese für viele andere Tumorentitäten beschrieben worden ist. Viele Studien belegen, dass PPARy-Liganden in Tumorzellen die Apoptose auslösen, oder zu verminderter Zellproliferation führen. Diese schließen Plattenepithelkarzinom- und Kolonkarzinomzellen sowie Brustkrebszelllinien ein [225-227], die nachweislich den PPARy-Rezeptor exprimieren. Daher ist es denkbar, dass HT1080-Zellen nur geringfügige Expressionslevel dieses Rezeptors aufweisen und nicht auf die alleinige Applikation von Pioglitazon reagieren. Es kann somit eine zelltypspezifische Wirkung von Pioglitazon angenommen werden.

Pioglitazon kooperiert jedoch mit Doxorubizin in dessen antiproliferativer Wirkung sowohl in HT1080- als auch TP5014-Zellen. Ein kooperativer antiproliferativer Effekt einer Kombination von Doxorubizin und Pioglitazon ist bisher noch nicht beschrieben worden. Dagegen ist jedoch bekannt, dass der PPARy-Ligand Rosiglitazon die Doxorubizin-induzierte Proliferationsinhibierung in Prostatakarzinomzellen signifikant 
steigert [228]. Somit scheint Pioglitazon ähnlich wie Rosiglitazon mit Doxorubizin hinsichtlich Proliferationshemmung zu kooperieren.

Pioglitazon zeigt - zumindest in der Fibrosarkomzellinie HT1080 - einen kooperativen Effekt mit Doxorubizin in der Induktion der Apoptose. Die Aktivität der Caspasen 3 und 7 spielt dabei jedoch keine Rolle. Dies lässt auf die Induktion der Caspase-unabhängigen Apoptose durch Pioglitazon schließen. Eine Caspaseunabhängige Apoptose kann auch in hepatozellulären Karzinomzelllinien durch den PPARy-Liganden Troglitazon demonstriert werden [229]. Auch in Ovarialkarzinomzellen wird die Doxorubizin-vermittelte Apoptose durch Kombination mit dem PPARy-Liganden 15d-PGJ2 Caspase-unabhängig erhöht [230]. In letzterer Arbeit wird zusätzlich gezeigt, dass 15d-PGJ2 die MDR1-Expression hemmt. Dies kommt durch die 15d-PGJ2-vermittelte Inhibierung des Transkriptionsfaktors NFkB zustande, der in der Regulation der MDR1-Expression involviert ist [230]. Es ist daher möglich, dass dieser Effekt auch bei der Sensitivierung von HT1080-Zellen eine Rolle spielen könnte.

Entgegen der sensitivierenden Aktivität von Pioglitazon in HT1080-Zellen, wird keine signifikante kooperative proapoptotische Wirkung mit Doxorubizin in der RMSZelllinie TP5014 erzielt. Hierbei könnte möglicherweise ein zelltypspezifischer Effekt des Medikaments ursächlich sein.

Eine sensitivierende Wirkung von PPARy-Liganden gegenüber Etoposid wird beispielsweise in Leukämiezellen beschrieben. Die Sensitivierung der Zellen geht dabei vermutlich mit der Erhöhung der TOP2a-Expression einher [68]. In HT1080Zellen kann ebenfalls eine Induktion der TOP2a-Transkription durch Pioglitazon nachgewiesen werden. Diese Induktion wird jedoch auf Proteinebene nicht bestätigt. Möglicherweise hängt dies mit posttrankriptionellen Modulierungen der TOP2amRNA zusammen, welche die mRNA innerhalb der Zelle vor der Degradierung schützen [231]. Für die mRNA der TOP2a ist eine solche Stabilisierung tatsächlich beschrieben worden [232]. So erhöht die Bindung von Redox-sensitiven Faktoren wie AUF1 (Adenosine or Uridine-rich Element-Binding Factor 1) an die 3'UTR (Untranslatierte Region) der TOP2a-mRNA deren Abbau [232, 233]. Liegt dagegen ein niedriges ROS-Level in der Zelle vor, erhöht sich die TOP2a-mRNA (z. B. während der S-Phase des Zellzykluses) [233]. Da die Generierung von ROS durch PPARy-Liganden wie 15d-PGJ2 beschrieben wird [234], sollte man jedoch 
annehmen, dass die TOP2a-mRNA-Level nach Pioglitazon-Behandlung eher abnehmen als zunehmen. Die beobachtete Induktion der TOP2a-Transkription durch Pioglitazon in HT1080-Zellen führt jedoch nicht zur Erhöhung des TOP2a-Proteins. Hierzu sei anzumerken, dass kürzlich ein Protein beschrieben wurde, welches die Translation der TOP2a-mRNA positiv beeinflusst. Dieses Protein ist HuR, ein RNAbindendes Protein, welches mit der 3'UTR der TOP2a-mRNA interagiert und als Aktivator der Translationsinitiation fungiert [235]. Es könnte daher sein, dass dieses Protein durch Pioglitazon negativ reguliert wird. Hierdurch würde zwar das TOP2amRNA-Level ansteigen, die Translation dagegen gehemmt werden. Auch wäre denkbar, dass die HT1080-Zellen beispielsweise ein mutiertes HuR-Gen aufweisen, und es infolge dessen trotz hohen TOP2a-mRNA-Level zu keiner TOP2a-Translation kommt. Weiterhin kann gemutmaßt werden, dass sich durch Mutationen in der 3'UTR der TOP2a-mRNA die Bindungsstellen für Translationsaktivatoren wie HuR verändern, und folglich in einem verminderten Proteinlevel resultieren [235]. Letztlich ist auch denkbar, dass die Veränderung der TOP2a-Expression nach 24 Stunden zwar bereits auf RNA-Ebene detektierbar ist, das Proteinlevel sich jedoch noch nicht signifikant verändert hat.

\subsection{PI103 sensitiviert HT1080-, TP5014- und RD-Zellen gegenüber den antiproliferativen und proapoptotischen Effekten von Doxorubizin}

Eine alleinige PI103-Behandlung führt in HT1080-, TP5014- und RD-Zellen zur signifikanten Wachstumshemmung. Dies steht im Einklang mit der Literatur, in der für Leukämiezellen durch PI103 eine Proliferationsinhibierung von 50 bis $70 \%$ gezeigt wird [236]. Auch das Zellwachstum von Kaposi-Sarkomzellen wird durch 1 HM PI103 um 70\% [167] und in Chordomzellen um 30\% gemindert [109].

In der vorliegenden Arbeit kann durch alleinige Behandlung mit 3 MM PI103 auch eine Erhöhung der Annexin V positiven RD-Zellen und eine gesteigerte Aktivität der Caspasen 3 und 7 gezeigt werden. Letzterer Effekt wird auch in TP5014-Zellen detektiert. Dass PI103 zur Apoptoseinduktion in Tumorzellen führt, wurde bereits durch mehrere Arbeiten demonstriert. So induziert $1 \mu \mathrm{M}$ PI103 in AML-Zellen eine Apoptoseinduktion von mehr als 30\% und erhöht die Aktivität der Caspase 3 [101]. In einer anderen Studie an promyeloischen Leukämiezellen resultiert die 72stündige Behandlung mit 0,5 $\mu \mathrm{M}$ PI103 in einer Apoptoseinduktion von 60\% [237], 
wohingegen in Kaposi-Sarkomzellen durch eine 6stündige Inkubation mit $10 \mu \mathrm{M}$ PI103 eine Apoptoseinduktion von etwa 30\% induziert wird [167]. Der proapoptotische Effekt von PI103 ist nachvollziehbar, da PI103 die AKT inhibiert, welche eine Vielzahl von Signalen reguliert, die das Zellüberleben und das Wachstum fördern.

Des Weitern wird in der vorliegenden Arbeit gezeigt, dass PI103 keine Auswirkungen auf die TOP2a-Transkription hat, das TOP2a-Proteinlevel jedoch signifikant reduziert. Dies könnte bedeuten, dass die TOP2a-Transkription nicht über den $\mathrm{PI3Kinase/AKT/mTOR-Signalweg} \mathrm{reguliert} \mathrm{wird,} \mathrm{wogegen} \mathrm{der} \mathrm{Signalweg} \mathrm{jedoch} \mathrm{in}$ die Translation dieses Proteins oder in dessen Stabilisierung involviert ist. Eine Modulierung der TOP2a-Expression durch PI103 wurde jedoch eigentlich erwartet. So kommt es durch Inaktivierung von AKT (beispielsweise durch PI103) zur Dephosphorylierung von MDM2 und damit zur Stabilisierung von p53 [84, 167]. Da p53 die Transkription der TOP2a reprimiert [232], sollte dies somit in einer Suppression der TOP2a-Expression resultieren. Wie die Ergebnisse an HT1080Zellen zeigen, wird das TOP2a-Level jedoch durch $1 \mu \mathrm{M}$ PI103 nicht reduziert, was somit gegen diese Hypothese spricht. Möglicherweise wären höhere Dosen an PI103 nötig gewesen um diesen Effekt in HT1080-Zellen zu induzieren. Wie dagegen die durch PI103 hervorgerufene Suppression des TOP2a-Proteinlevels bei normalem TOP2a-mRNA-Level zustande kommt, lässt sich ebenfalls schwer erklären. Da eine aktuelle Arbeit zeigt, dass die Aktivität des Proteasoms durch den PI3Kinase/mTORSignalweg induziert wird [238], würde durch PI103-Behandlung eine Erhöhung des TOP2a-Proteinlevels erwartet werden. Dies ist in HT1080-Zellen jedoch nicht der Fall.

In der vorliegenden Arbeit verstärkt PI103 als einziges der getesteten Substanzen den antiproliferativen und den proapoptotischen Effekt von Doxorubizin, sowohl in den Fibrosarkom- als auch in den Rhabdomyosarkomzellen. Dies geht auch mit einer signifikanten Aktivierung der Caspasen 3 und 7 einher (siehe Kapitel 4.1.1.5 und 4.1.2.2).

Die effektive Wirkweise von PI3Kinase/mTOR-Inhibitoren, Tumorzellen gegenüber Doxorubizin zu sensitivieren, konnten bereits mehrere Arbeitsgruppen zeigen. Insbesondere wird der kooperative Effekt der Kombination von Doxorubizin und PI103 bisher in Glioblastom-, Chordom- und ganz aktuell in Neuroblastomzellen 
nachgewiesen [106-109]. In Glioblastomzellen wird durch Kombination von Doxorubizin und PI103 die Erhöhung von DNA-Doppelstrangbrüchen gezeigt [108]. Dies kann in der vorliegenden Arbeit ebenfalls bestätigt werden (siehe Kapitel 4.2.4.2). Dass die Kombination der beiden Substanzen eine verstärkte Aktivierung der Caspase-abhängigen Apoptose induziert, wird in Neuroblastomzellen demonstriert [106]. Die Aktivierung der Caspasen durch Kombination von Doxorubizin und PI103 kann ebenfalls in der vorliegenden Arbeit gezeigt werden. In Neuroblastomzellen spielen dabei die erhöhte Expression von NOXA und BIM, sowie die Aktivität von BAX und der Verlust des MMP eine wichtige Rolle [106]. Dabei wird durch Doxorubizin und PI103 die Expression von NOXA und BIM erhöht, was in gesteigerter Aktivität von BAX resultiert [106]. Da auch in RD-Zellen eine PI103vermittelte Aktivierung von BAX gezeigt wird (siehe Kapitel 4.2.3.1 und 5.5.3), könnte dies ebenso wie in Neuroblastomzellen über NOXA und BIM induziert werden. Dies wurde in der vorliegenden Arbeit jedoch nicht explizit analysiert und kann daher nur vermutet werden.

Wie bereits in der Einleitung erwähnt (Kapitel 1.2.2.3), wurde 2010 eine Studie veröffentlicht, in der ein kooperativer Effekt von Doxorubizin und dem PI3Kinase/mTOR-Inhibitor NVP-BEZ235 hinsichtlich der Proliferationsinhibierung, jedoch nicht in Hinsicht auf die Apoptoseinduktion in RD-Zellen gezeigt wurde. Durch alleinige Behandlung der Zellen mit NVP-BEZ235 detektierten die Autoren keine Apoptoseinduktion, und übersahen dadurch vermutlich den proapoptotischen Kombinationseffekt von Doxorubizin und NVP-BEZ235 [112].

\subsubsection{Die TOP2a spielt keine Rolle bei der PI103-vermittelten Sensitivierung gegenüber Doxorubizin}

Für Doxorubizin ist bekannt, dass es die Apoptose sowohl über TOP2a-abhängige als auch über TOP2a-unabhängige Mechanismen induziert [3]. So stellen die HTETOP-Zellen ein geeignetes Model zur Analyse der TOP2a-abhängigen bzw. TOP2a-unabhängigen Wirkungen von Doxorubizin dar [148]. In diesen Zellen wird durch Behandlung mit Doxycyclin die TOP2a-Expression reprimiert, ohne die Transkription anderer Gene wesentlich zu beeinflussen [183]. Dass die Doxorubizinvermittelte Apoptose in TOP2a-defizienten HTETOP-Zellen um etwa 50\% zu der in TOP2a-exprimierenden Zellen reduziert ist, ist beschrieben worden [183]. Obwohl sich dieser Effekt auch in der vorliegenden Arbeit andeutet, war er nicht signifikant. 
Dies basiert sehr wahrscheinlich auf der Tatsache, dass in der vorliegenden Arbeit eine $\mathrm{zu}$ hohe Doxorubizin-Konzentration eingesetzt worden ist. Auch ist der Kombinationseffekt von Doxorubizin und PI103 in den HTETOP-Zellen nicht signifikant. Daher gestaltet sich die Interpretation des Einflusses von TOP2a auf den proapoptotischen Kombinationseffekt der beiden Medikamente sehr schwierig. Nichtsdestotrotz kann vermutet werden, dass die TOP2a wahrscheinlich keinen Einfluss auf diesen Kombinationseffekt hat, da sich sonst der Kombinationseffekt in TOP2a-defizienten Zellen sehr viel mehr von demjenigen in TOP2a-exprimierenden Zellen unterscheiden müsste.

Ein weiterer Hinweis darauf, dass die TOP2a wahrscheinlich keine Rolle bei der Sensitivierung gegenüber Doxorubizin spielt, kommt aus dem Experiment, in dem Doxorubizin gegen den spezifischen TOP2a-Inhibitor Etoposid ausgetauscht wurde. Dabei wurde durch alleinige Behandlung mit $5 \mu \mathrm{M}$ Etoposid die Anzahl Annexin V positiver RD-Zellen erhöht, und die Aktivität der Caspasen 3 und 7 signifikant gesteigert. Die Kombination von Etoposid und PI103 zeigt jedoch im Gegensatz zu der Kombination von Doxorubizin und PI103 keinen sensitivierenden Effekt. Auch durch Einsatz höherer Etoposid-Konzentrationen (bis $50 \mu \mathrm{M}$ ) und durch Verlängerung der Inkubation auf 48 Stunden, wird durch PI103 keine Verstärkung der Etoposid-vermittelten Apoptose in RD-Zellen hervorgerufen (Daten nicht gezeigt; Ulrike Graab, Institut für Experimentelle Tumorforschung in der Pädiatrie, Frankfurt). Dies steht im Einklang mit der Arbeit von Martin-Fernandez et al., in der gezeigt wird, dass eine Hemmung der PI3Kinase Kolorektalkarzinomzellen auch bei einer Inkubation für 48 Stunden nicht gegenüber einer Etoposid-Behandlung sensitiviert [239]. Da Etoposid seine antitumoralen Effekte über die TOP2a-Hemmung hervorruft, und da PI103 diese Effekte nicht verstärkt, kann man tatsächlich davon ausgehen, dass der sensitivierende Effekt von PI103 unabhängig von der TOP2a ist. Dies unterstützt die Schlussfolgerungen aus den Experimenten an HTETOP-Zellen, wo zwischen TOP2a-exprimierenden und TOP2a-defizienten HTETOP-Zellen kein signifikanter Unterschied hinsichtlich Apoptoseinduktion durch die Kombinationsbehandlung von Doxorubizin und PI103 detektiert werden konnte.

\subsubsection{Inhibierung von mTOR hat keinen Einfluss auf den kooperativen proapoptotischen Effekt von Doxorubizin und PI103 in RD-Zellen}

Da es in dieser Arbeit vor allem um die Sensitivierung von RMS-Zellen gegenüber 
einer Doxorubizin-Behandlung ging, wurden die anschließenden Analysen zum molekularen Mechanismus ausschließlich an RD-Zellen durchgeführt.

Wie bereits in Kapitel 5.5 erläutert, wurde im Laufe der Untersuchungen eine Studie veröffentlicht, in der die antiproliferativen kooperativen Effekte von Doxorubizin und dem PI3Kinase/mTOR-Inhibitor NVP-BEZ235 in RD-Zellen beschrieben wurden. Aus diesem Grund habe ich mich auf die kooperativen proapoptotischen Effekte der Kombination von Doxorubizin und PI103 konzentriert.

Die Untersuchung, ob die PI103-vermittelte mTOR-Inhibierung zu dem kooperativen Effekt der Kombination aus Doxorubizin und PI103 beiträgt, erfolgte durch Substitution von PI103 durch den reinen mTOR-Inhibitor Everolimus.

Zunächst fällt auf, dass Everolimus zu einer verstärkten Phosphorylierung der AKT in RD-Zellen führt (siehe Kapitel 4.2.2). Dies konnte bereits in mehreren Studien gezeigt werden. Dabei wird dieser Effekt sowohl in Zellkulturexperimenten, als auch an Tumormaterial von Patienten, die mit einem mTOR-Inhibitor behandelt wurden, feststellt [139, 140, 240]. Vermutlich wird die Aktivierung von AKT hierbei durch Induktion von S6K1, einem Zielprotein von mTOR, welches die Proteinsynthese von Proteinen wie IGF-2 reguliert, hervorgerufen [139-141]. Die Überexpression von IGF-2 wiederum führt zur Aktivierung seines Rezeptors IGF-1R, der wiederum die Aktivität der PI3Kinase und damit von AKT stimuliert [139, 142].

Weiterhin führt Everolimus zu einer signifikanten Proliferationsinhibierung in RDZellen. Dies steht im Einklang mit zahlreichen Arbeiten. So inhibiert Everolimus beispielsweise die Proliferationsrate von Hypophysenadenomzellen um mehr als 20\% [171] und das Wachstum von Lungenadenomkarzinomzellen um etwa 40\% [241]. In einer weiteren Studie mit Lungenkarzinomzellen kann durch 6tägige Inkubation mit dem mTOR-Inhibitor eine Proliferationshemmung von 50 bis $70 \%$ gezeigt werden [242]. Diese Wachstumsinhibierung durch Everolimus hängt mit der essentiellen Funktion von mTOR in der Proteinsynthese und dem Zellwachstum zusammen [243].

In RD-Zellen kann in der vorliegenden Arbeit keine Induktion der Apoptose durch Everolimus hervorgerufen werden. Übereinstimmend dazu wird in Blasenkarzinomzellen ebenfalls keine Apoptoseinduktion durch den mTOR-Inhibitor detektiert [244]. 
Weiterhin zeigt Everolimus in den RD-Zellen keinerlei signifikante proapoptotischen kooperative Effekte mit Doxorubizin. Aus diesem Grund kann man den Schluss ziehen, dass mTOR-gesteuerte Vorgänge nicht für den kooperativen antiproliferativen und proapoptotischen Effekt von Doxorubizin und PI103 ausschlaggebend sind. Das Fehlen eines kooperativen antitumoralen Effekts sieht man neben RD-Zellen auch bei Nervenscheiden Tumoren (MPNST Zellen) [245]. Dagegen konnte in Prostatakarzinom-, Leukämie-, Lymphom- und hepatozellulären Karzinomzellen ein kooperativer antitumoraler Effekt von Doxorubizin und Everolimus gezeigt werden [246-249]. Die Ursachen für diese Unterschiede hinsichtlich der kooperativen Effekte werden noch nicht verstanden. Sie stehen jedoch sicherlich mit durch mTOR-regulierte Vorgänge wie beispielsweise IGF-2induzierte Rückkopplung der AKT-Aktivierung (siehe Kapitel 4.2.2) in Verbindung.

\subsubsection{Der kooperative proapoptotische Effekt von Doxorubizin und PI103 korreliert mit der Aktivierung von BAX und der Caspase 3 Aktivierung}

Die alleinige Doxorubizin-Behandlung induziert in RD-Zellen keine Aktivierung von dem proapoptotischen Protein BAX. Dies steht im Gegensatz zu anderen Arbeiten, die eine Aktivierung von BAX durch Doxorubizin zeigen. So aktiviert Doxorubizin BAX in Herzmuskelzellen [250], in Lymphom- und Myelomzellen [251], sowie in Neuroblastomzellen [106]. Wogegen die fehlende BAX-Aktivierung in RD-Zellen eventuell mit einer Überexpression von Bcl-2 zusammenhängen könnte [251]. Dagegen wird durch PI103 eine, wenn auch sehr moderate Aktivierung von BAX in RD-Zellen ausgelöst. Diese geht mit der Inaktivierung von AKT einher. Dieser Einfluss von PI103 auf BAX ist bekannt und wird beispielsweise in Neuroblastom-, Leukämie- und Glioblastomzellen gezeigt [110, 252, 253]. So verändert die Inhibierung von AKT das Verhältnis zwischen antiapoptotischen und proapoptotischen Proteinen, welches dann beispielsweise in die mitochondriale Apoptose (unter Aktivierung von BAX) resultiert. Die Aktivität anderer proapoptotischer AKT-regulierter Proteine wurde in der vorliegenden Arbeit jedoch nicht untersucht. Dennoch kann sehr wahrscheinlich auch in RD-Zellen von diesem Mechanismus ausgegangen werden.

Obwohl PI103 nur zu einer moderaten BAX-Aktivierung führt, kann eine starke 
Aktivierung dieses Proteins nach der Kombinationsbehandlung mit Doxorubizin und PI103 in RD-Zellen detektiert werden (siehe Kapitel 4.2.3.1). Ein solcher Effekt konnte bisher nur in Neuroblastomzellen gezeigt werden [106]. Dabei wird durch Kombination von Doxorubizin und PI103, wie auch in RD-Zellen, eine deutliche Aktivierung von BAX induziert. Im Falle des Neuroblastoms wird die BAX-Aktivierung möglicherweise durch Reduktion des antiapoptotischen $\mathrm{Bcl}-2$ Proteins $\mathrm{Mcl}-1$ ausgelöst. So wird die Expression von Mcl-1 vermutlich durch PI103 gehemmt. Außerdem kommt es zur Aktivierung von BIM und NOXA, was wiederum in einer Aktivierung von BAX resultiert. Die BAX-Aktivierung wiederum korreliert mit der Induktion der mitochondrial-vermittelten Apoptose [106]. Dies konnte auch in anderen Tumorzellen wie beispielsweise AML-Zellen [110] oder Glioblastomzellen nachgewiesen werden. Bei letzteren wird durch die Kombinationsbehandlung der Verlust des MMP und die Aktivierung von Caspasen beschrieben [107]. Da BAX den Verlust des MMP und die daraus resultierende Freisetzung von Cytochrom c aus den Mitochondrien induziert [92], steht der Verlust des MMP und die mitochondrialvermittelte Apoptose direkt im Zusammenhang mit der BAX-Aktivierung.

Die Freisetzung von Cytochrom $\mathrm{c}$ aus den Mitochondrien konnte auch durch die Kombinationsbehandlung von Doxorubizin und PI103 in RD-Zellen gezeigt werden (siehe Kapitel 4.2.3.2). Eine alleinige Doxorubizin- oder PI103-Behandlung zeigt dagegen keinen bzw. nur einen moderaten Effekt auf die Cytochrom c Freisetzung. Ersteres Ergebnis steht im Einklang mit der Studie am Neuroblastom. Obwohl in Neuroblastomzellen sowohl nach alleiniger Doxorubizin- als auch nach PI103Behandlung eine erhöhte Freisetzung von Cytochrom c detektiert werden kann, zeigt sich ein enormer Effekt nach Kombination der Medikamente [106]. Wie bereits beschrieben, spielt hierbei BAX eine wichtige Rolle. Dabei permeabilisiert BAX vermutlich die Mitochondrienmembran, was den Einstrom von $\mathrm{Ca}^{2+}$ in das Zytoplasma zulässt. Hierdurch kommt es zu einem Verlust des Membranpotentials der Mitochondrien, welches zur Freisetzung von Cytochrom c führt [254, 255]. Dieser Mechanismus löst vermutlich auch in RD-Zellen die Cytochrom c Freisetzung und die damit zusammenhängende Caspase 3 Aktivierung aus (siehe Kapitel 4.1.3.2). 


\subsubsection{Die mitochondriale Aktivität von p53 ist vermutlich in den kooperativen proapoptotischen Effekt von Doxorubizin und PI103 involviert}

Die Aktivierung von BAX und die daraus resultierende mitochondrial-vermittelte Apoptose erfolgt nicht nur über die Inhibierung von AKT, sondern kann unter anderem auch durch p53 induziert werden [81, 179]. In der vorliegenden Arbeit wurde daher versucht, die Rolle von p53 bei der Kooperation von Doxorubizin und PI103 in der Apoptoseinduktion ansatzweise zu verstehen.

Es ist bekannt, dass die transkriptionelle Aktivität von p53 zur verstärkten Expression von p21 führt. P21 wiederum ist ein potenter Inhibitor von Cyclin-abhängigen Kinasen und hemmt den Zellzyklus in der $\mathrm{G}_{1}$-Phase [177]. Da Doxorubizin zu einer p53-Akkumulierung [106], zur p53-Stabilisierung und Aktivierung führen kann [28-30], ist es möglich, dass die Sensitivität von Tumorzellen gegenüber Doxorubizin mit einem Anstieg von $p 21$ vergesellschaftet ist.

Wie die in dieser Arbeit erstellten Ergebnisse zeigen, war dies in RD-Zellen jedoch nicht der Fall. Obwohl Doxorubizin die p21-Expression nach 6stündiger Inkubation tatsächlich induziert (was mit der gegenwärtigen Literatur übereinstimmt [178]), nimmt die p21-Expression nach einer verlängerten Inkubation mit Doxorubizin von 12 bis 24 Stunden sehr stark ab.

Auch PI103 hemmt konzentrations- und zeitabhängig die Expression der p21-mRNA in RD-Zellen. Dieser reprimierende Effekt von PI103 auf die p21-Expression ist bekannt [110]. Auch der PI3Kinase/mTOR-Inhibitor LY294002 reduziert das p21-Proteinlevel und bestätigt die Regulation der p21-Expression über den PI3Kinase-Signalweg [256]. Dass PI103 die nach 12 und 24 Stunden durch Doxorubizin-hervorgerufene Hemmung der p21-Expression noch verstärkt, obwohl gerade zu diesem Zeitpunkt der kooperative Effekt beider Medikamente hinsichtlich Apoptoseinduktion (und Proliferationshemmung) beobachtet wird, könnte darauf hinweisen, dass die transkriptionelle Aktivität von p53 bei diesem kooperativen Effekt tatsächlich keine Rolle spielt.

Hierzu ist anzumerken, dass p21 nicht das einzige transkriptionell regulierte Zielprotein von p53 darstellt. Daher hat das Experiment alleine betrachtet wenig Aussagekraft über die gesamte transkriptionelle Aktivität von p53. Außerdem kann p21 je nach Zelltyp und dem zellulärem Kontext gegensätzliche Funktionen (z. B. sowohl proapoptotische als auch antiapoptotische) wahrnehmen [257]. Des Weiteren 
wird die p21-Expression auch durch p53-unabhängige Mechanismen reguliert [257, 258].

Die transkriptionelle Aktivität von p53 ist jedoch noch in einem weiteren Experiment analysiert worden. So wurde versucht, die transkriptionelle Aktivität von p53 mit Hilfe von Pifithrin a (PFTa) zu hemmen [173, 181]. Tatsächlich kann auch in diesem Experiment gezeigt werden, dass die Inhibierung der transkriptionellen Aktivität von p53 den kooperativen proapoptotischen Effekt von Doxorubizin und PI103 nicht beeinflusst. Diese Daten sprechen somit - genauso wie die p21-Expressionsanalysen - gegen eine Involvierung der transkriptionellen Aktivität von p53 in den kooperativen proapoptotischen Effekt von Doxorubizin und PI103.

Im Gegensatz dazu führt eine Inkubation der RD-Zellen mit PFT $\mu$ möglicherweise zu einer Hemmung des kooperativen proapoptotischen Effekts von Doxorubizin und PI103. Da PFT $\mu$ als Inhibitor der mitochondrialen p53-Aktivität beschrieben wird, könnte es daher tatsächlich sein, dass die mitochondriale p53-Aktivität eine Rolle bei dem kooperativen proapoptotischen Effekt von Doxorubizin und PI103 spielt.

Wie schon beschrieben, wird p53 durch den aktiven AKT-Signalweg normalerweise gehemmt [84, 167]. Eine Inaktivierung der AKT durch beispielsweise PI103 könnte daher zur Aktivierung von p53 führen. Bei einer Kombinationsbehandlung von PI103 mit Doxorubizin kommt es zusätzlich zur Akkumulation von p53 [106]. Da die mitochondriale Aktivität von p53 vermutlich eine direkte BAX-Aktivierung induziert [179, 259, 260], wäre es möglich dass p53 in den kooperativen proapoptotischen Effekt von Doxorubizin und PI103 involviert ist.

Zusammenfassend kann man daher die Hypothese aufstellen, dass der kooperative proapoptotische Effekt von Doxorubizin und PI103 die Aktivierung von BAX involviert.

Diese Aktivierung wird durch AKT-Hemmung und wahrscheinlich auch durch Doxorubizin-induzierte Akkumulation von p53 und der mitochondrialen Aktivität von p53 ausgelöst.

\subsubsection{PI103 hemmt die Expression der Effluxtransporter MDR1 und MRP1} Es ist bekannt, dass geringe Level an Multidrug Transportern oder eine hohe Expression der TOP2a Tumorzellen besonders gegenüber einer Behandlung mit 
TOP2a-Inhibitoren sensitivieren [43-46, 59, 60]. Da PI103 die Expression der TOP2a nicht erhöht, die RD-Zellen trotzdem gegenüber Doxorubizin sensitiviert, wurde der Einfluss von PI103 auf die Multidrug Effluxtransporter untersucht. In der Literatur ist beschrieben, dass die Expression und/oder die Aktivität der Effluxtransporter MDR1 und MRP1 durch AKT positiv reguliert wird [79, 80]. Da der PI3Kinase-Signalweg die AKT aktiviert, wurde eine Repression der MDR1- und MRP1-Expression durch Einsatz von PI103 erwartet. Und tatsächlich hemmt PI103 die Expression beider Transporter. Dieses kann zumindest für MRP1 auch auf Proteinebene bestätigt werden. Dagegen konnte das MDR1-Protein in den RD-Zellen nicht nachgewiesen werden. Dies ist vermutlich durch die deutlich verminderte Expression von MDR1 in dieser Zelllinie zu erklären, die durch ein 100fach geringeres Expressionslevel gegenüber der MRP1-Expression in der quantitativen RT-PCR aufgefallen ist. Dieser Expressionsunterschied zwischen MDR1 und MRP1 in RMS-Zellen wurde auch in einer anderen Studie festgestellt [261]. Eventuell hätte das MDR1-Level durch Anreicherung des Proteins mittels Immunpräzipitation nachgewiesen werden können.

Der Mechanismus durch den die MDR1- und MRP1-Expression durch AKT reguliert wird, ist noch nicht aufgeklärt. Es wird jedoch eine Beteiligung von p53 vermutet $[262,263]$. So konnte in der Arbeit von Sullivan et al. gezeigt werden, dass die $M R P 1$-Expression durch wildtypisches p53 gehemmt wird. Ein entsprechendes Motiv im MRP1-Promotor, welches durch p53 gebunden und reguliert werden kann, wurde bisher jedoch nicht identifiziert [264]. Aufgrund der Hemmung von p53 durch die AKT [265], könnte diese positiv mit der MRP1-Expression korreliert sein. Somit könnte vice versa die Hemmung der AKT zur Aktivierung von p53 führen, was wiederum in der Suppression der MRP1-Expression resultiert. Diese Hypothese könnte die PI103induzierte Reduktion der MDR- und MRP1-Expression erklären, was wiederum in einer Doxorubizin-Akkumulation resultieren, und für den kooperativen proapoptotischen Effekt in den RD-Zellen verantwortlich sein könnte.

Die Repression der Transporter in RD-Zellen ist tatsächlich mit einer DoxorubizinAkkumulation vergesellschaftet. Hierbei entspricht die intrazelluläre DoxorubizinKonzentration nach einer Kombinationsbehandlung von $1 \mu \mathrm{M}$ Doxorubizin und $3 \mu \mathrm{M}$ Pl103 derjenigen, die durch eine Behandlung der Zellen mit $2 \mu \mathrm{M}$ Doxorubizin hervorgerufen wird. Die Rate der DNA-Doppelstrangbrüche unterscheidet sich 
jedoch nicht. Das bedeutet, dass lediglich Doxorubizin, nicht aber PI103, für die Induktion von DNA-Doppelstrangbrüchen verantwortlich ist. Dies steht im Gegensatz zu Glioblastomzellen, in denen PI103 die durch Doxorubizin-hervorgerufene DNADoppelstrangbruchrate erhöht. Hierbei soll die DNA-PK eine wichtige Rolle spielen [108].

Die unveränderte Rate an DNA-Doppelstrangbrüchen in der vorliegenden Arbeit steht im Gegensatz zur Apoptoseinduktion. So ist die Zahl Annexin V positiver RDZellen und die Aktivität der Caspase 3 nach Kombination von $1 \mu \mathrm{M}$ Doxorubizin und $3 \mu \mathrm{M}$ PI103 höher als nach einer Behandlung der Zellen mit $2 \mu \mathrm{M}$ Doxorubizin. Dies bedeutet, dass der kooperative proapoptotische Effekt von Doxorubizin und PI103 nicht durch die Akkumulation von Doxorubizin in den Zellen ausgelöst wird.

Weiterhin zeigt dieses Experiment, dass auch die Kooperation von Doxorubizin und PI103 hinsichtlich BAX-Aktivierung und der resultierenden mitochondrial-vermittelten Apoptose nicht durch alleinige Akkumulation von Doxorubizin erklärt werden kann. Vielmehr muss ein anderer Mechanismus involviert sein, wie beispielsweise die Inaktivierung von AKT, was in einer erhöhten Expression und/oder Aktivierung proapoptotischer Proteine resultiert.

\subsubsection{Hypothese über den Wirkmechanismus von Doxorubizin und PI103 in RD-Zellen}

Zusammenfassend resultieren die Ergebnisse dieser Studie in der folgenden Hypothese, die auch in Abbildung 50 schematisch dargestellt ist:

1. PI103 inhibiert den PI3Kinase-Signalweg und hemmt somit die AKT. Dies geht mit einer Suppression der MDR1- und MRP1-Expression einher.

2. Über die Inhibierung von AKT kommt es zur Aktivierung von p53.

3. Durch Doxorubizin werden DNA-Doppelstrangbrüche induziert, die zur weiteren Stabilisierung/Aktivierung von p53 beitragen.

4. Aktiviertes p53 transloziert zu den Mitochondrien und interagiert dort mit BAX um die mitochondrial vermittelte Apoptose zu verstärken.

Die kooperative proapoptotische Wirkung von Doxorubizin und PI103 liegt somit sehr wahrscheinlich in der Fähigkeit der beiden Medikamente die mitochondrial-vermittelte Apoptose über BAX zu induzieren. 


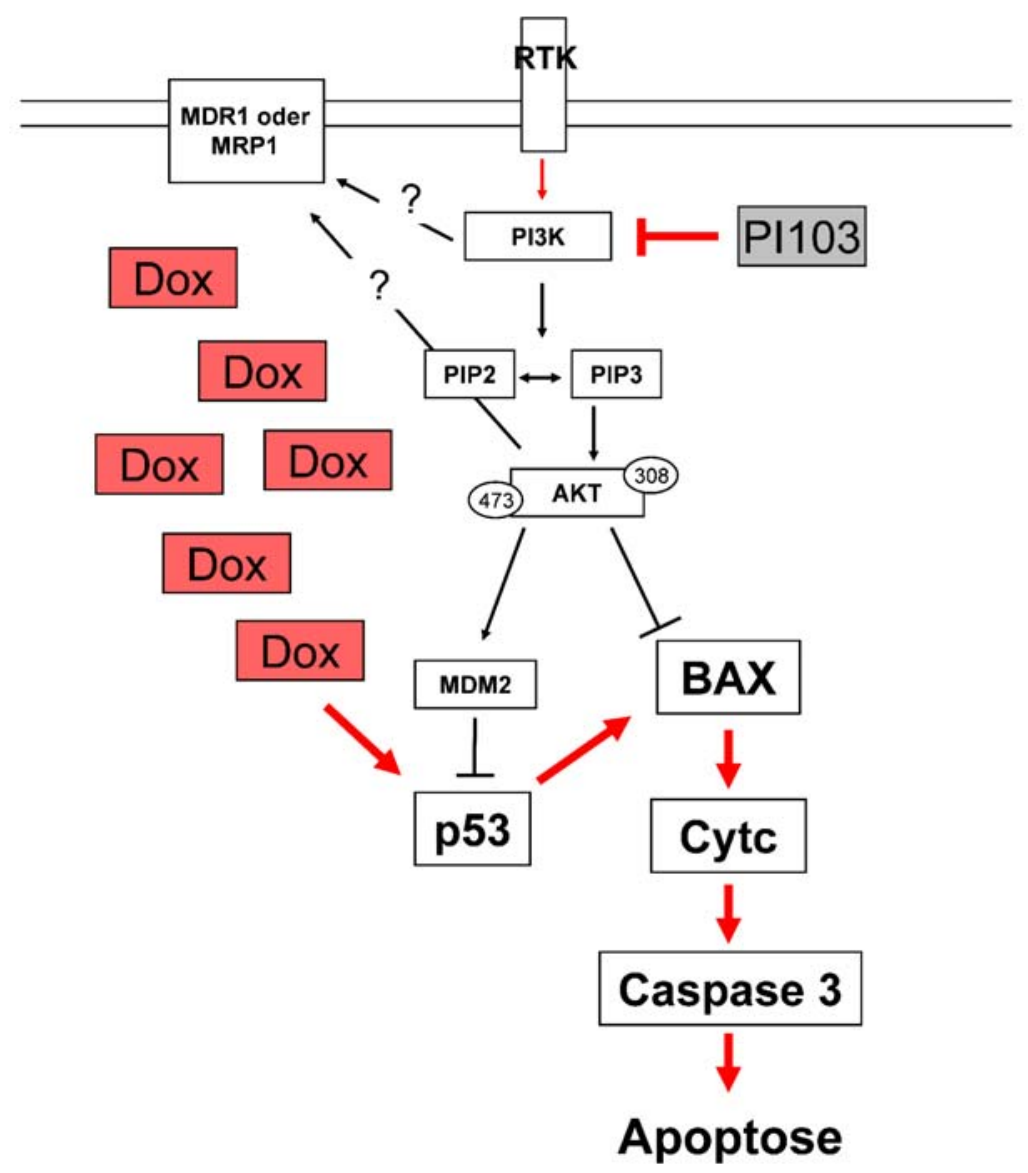

Abbildung 50: Schematische Darstellung der Hypothese des kooperativen Effekts von Doxorubizin und PI103 in RD-Zellen. Für Erläuterungen: siehe Text.

\subsection{Kooperativer proapoptotischer Effekt von Doxorubizin und GDC-0941 in vivo}

Die Kombination von Doxorubizin und dem oral verfügbaren PI3Kinase-Inhibitor GDC-0941 wurde anschließend auch im Tiermodell überprüft. Die verwendeten Konzentrationen der Medikamente wurden von den Tieren gut vertragen. Während des gesamten Applikationszeitraums wurden keine Beeinträchtigungen der Gesundheit behandelter Mäuse festgestellt. Die Gewichtsveränderungen der Tiere verhielten sich in allen Kohorten ähnlich.

Das Schema der Doxorubizin-Applikation (1,2 mg Doxorubizin/kg jeden 3. Tag) wurde zur Behandlung von RD-Xenotransplantaten bereits von Zhang et al. verwendet [156]. Verglichen mit der Arbeit von Zhang und Kollegen sind die RDZellen in der in vivo-Studie der vorliegenden Arbeit sehr viel langsamer gewachsen. Der Unterschied im Tumorwachstum könnte am genetischen Hintergrund der Tiere liegen. So haben Zhang und Kollegen SCID-Mäuse verwendet [156], wogegen die hier dargestellte Studie an Nacktmäusen durchgeführt wurde. Trotz des generell 
langsamen Tumorwachstums zeigten sich am Behandlungsende signifikante Unterschiede zwischen den Kohorten. So unterscheiden sich die Tumorvolumina der Doxorubizin-behandelten Tiere signifikant von denen der Lösungsmittel-behandelten Kohorte. Die mit GDC-0941-behandelten Tumoren stagnierten im Wachstum und waren im Vergleich zu den mit Doxorubizin-behandelten Tumoren signifikant kleiner. Die effektive Wirkweise von GDC-0941 im Mausmodell konnte bereits in mehreren Studien gezeigt werden. So inhibiert GDC-0941 das Wachstum von xenotransplantierten Schilddrüsenkarzinomzellen [266]. Auch auf Brustkrebszellen wirkt das Medikament antitumoral [267]. Dagegen zeigt GDC-0941 auf xenotransplantierte Plattenepithelkarzinomzellen keine Wirkung [268].

In der vorliegenden Arbeit wird nun gezeigt, dass GDC-0941 das Tumorwachstum der RD-Zellen in vivo besser hemmt als Doxorubizin. Hierdurch wird möglicherweise demonstriert, dass Tumorzellen in vitro anders reagieren als in vivo. So wird in Zellkultur durch Behandlung mit dem PI3Kinase/mTOR-Inhibitor PI103 ein signifikanter Effekt auf die Zellproliferation und die Apoptoseinduktion in RD-Zellen registriert. Dieser ist jedoch geringer als derjenige, der durch Doxorubizin ausgelöst wird. Die unterschiedliche Wirkung der Medikamente auf RD-Zellen in den in vivound in vitro-Studien kann durch mehrere Faktoren erklärt werden. Zum einen könnte die Metabolisierung von Doxorubizin durch den Wirtsorganismus eine Rolle spielen. So ist Doxorubizin in Zellkultur für etwa 30 Stunden stabil [159]. In vivo dagegen wird Doxorubizin sehr schnell metabolisiert. In diesem Zusammenhang wurde gezeigt, dass die Plasmakonzentration des Zytostatikums nach der Bolusapplikation von $75 \mathrm{mg}$ Doxorubizin $/ \mathrm{m}^{2}$ innerhalb der ersten Stunde von etwa $5 \mu \mathrm{M}$ auf $0,1 \mu \mathrm{M}$ im Patienten absinkt [159]. Da jedoch Medikamente von Kleintieren schneller metabolisiert werden als vom Menschen [269], kann von einer noch zügigeren Doxorubizin-Metabolisierung im Tiermodell ausgegangen werden. Zum anderen ist unklar, wie viel von dem applizierten Doxorubizin tatsächlich in das Tumorgewebe gelangte. Dabei spielt zum einen die schnelle Metabolisierung des Zytostatikums, aber auch die Gefäßversorgung des Tumors eine Rolle. So wird davon ausgegangen, dass Tumoren, die eine gute Ausbildung von Blutgefäßen aufzeigen eine höhere Wahrscheinlichkeit haben, mit Zytostatika in Verbindung zu treten [270]. Des Weiteren wurde GDC-0941 in der vorliegenden Arbeit in Zellkulturexperimenten nicht ausgetestet. Möglicherweise wäre durch GDC-0941 auch in vitro ein stärkerer antitumoraler Effekt als mit Doxorubizin erzielt worden. All diese Faktoren könnten 
das bessere Ansprechen der Tumoren auf GDC-0941 im Vergleich zu Doxorubizin in vivo, bzw. das bessere Ansprechen der Tumoren auf Doxorubizin im Vergleich zu $\mathrm{PI} 103$ in vitro, erklären.

Im Gegensatz zu den Zellkulturexperimenten hat die Kombination von Doxorubizin und GDC-0941 keinen gesteigerten antitumoralen Effekt im Vergleich zur alleinigen Applikation von GDC-0941. Möglicherweise ist dies tatsächlich in der schnellen Metabolisierung von Doxorubizin begründet. Auf der anderen Seite ist es möglich, dass der durch GDC-0941 hervorgerufene antitumorale Effekt bereits so stark ist, dass ein Kombinationseffekt mit Doxorubizin nicht erkannt werden kann.

Die immunhistochemischen Antikörperfärbungen zeigen jedoch, dass die Anzahl der Caspase 3-positiven Zellen (aktivierte Caspase 3) nach Kombinationsbehandlung mit beiden Medikamenten signifikant gegenüber der Lösungsmittelkontrolle erhöht ist. Diese Erhöhung wird nach Einzelbehandlung mit Doxorubizin oder GDC-0941 nicht gesehen. Dies bedeutet, dass sich zumindest der kombinatorische Effekt auf Caspase 3 Aktivierung, welche in vitro gesehen wurde, auch in vivo zeigt.

Bestimmt wäre es nun interessant, die Aktivität des PI3Kinase/AKT/mTORSignalwegs in den Tumoren weiter zu untersuchen. Hierzu könnte der Aktivierungsstaus von AKT sowie von dem ribosomalen Protein S6 überprüft werden. Anhand dieser Untersuchungen könnte festgestellt werden, ob die Zellen sich eventuell im Organismus verändern, und ob beide Medikamente ihren Wirkungsort erreichen. Ferner könnte im Tumormaterial der Aktivierungsstatus von BAX überprüft werden.

Obwohl aus den in vivo-Experimenten nicht eindeutig hervorgeht, ob GDC-0941 RDZellen tatsächlich gegenüber Doxorubizin sensitiviert, wird aus den Analysen deutlich, dass GDC-0941 ein sehr gutes Medikament zur Behandlung von RMS sein könnte. So sprechen nicht nur transplantierte RD-Zellen auf die Behandlung an, sondern auch endogene RMS von (B6xBalbc)Ptch ${ }^{\text {neo67/+}-M a ̈ u s e n . ~ I n ~ d i e s e m ~ M o d e l l ~ k a n n ~ s o g a r ~ e i n e ~}$ Regression von 2/3 der Tumoren auf die Hälfte ihrer Anfangsvolumina verzeichnet werden. Da diese Daten sehr viel versprechend sind, sollte GDC-0941 unbedingt an einer größeren Kohorte von (B6xBalbc)Ptch ${ }^{\text {neo67/+ }}$-Mäusen analysiert werden. Außerdem muss auch in diesem Modell die Effektivität der Kombination aus Doxorubizin und GDC-0941 untersucht werden. 


\section{Zusammenfassung}

Doxorubizin ist eines der effektivsten Chemotherapeutika und wird bei einer Vielzahl von Tumoren eingesetzt. Obwohl Doxorubizin auch bei der Therapie von Rhabdomyosarkomen Anwendung findet, ist sein Einsatz bei dieser Tumorentität umstritten.

Im Rahmen dieser Arbeit sollte das Ansprechen von Sarkomzellen auf Doxorubizin gesteigert werden. Hierfür wurde Doxorubizin in Kombination mit Medikamenten eingesetzt, die laut Literatur die TOP2a-Expression modulieren können. Getestet wurde zudem der PI3Kinase/mTOR-Inhibitor PI103, da er die antitumorale Wirkung von Doxorubizin in Glio- und Neuroblastomzellen verstärken kann. Anhand von Proliferations- und Apoptosemessungen konnte gezeigt werden, dass Pl103 Rhabdomyosarkomzellen gegenüber Doxorubizin-induzierten antiproliferativen und proapototischen Effekten sensitiviert. Der kooperative proapototische Effekt wurde daraufhin sorgfältiger untersucht. Zunächst scheint dieser Effekt unabhängig von der TOP2a zu sein. Auch spielt die durch PI103 hervorgerufene Hemmung von mTOR eine untergeordnete Rolle. Mittels qRT-PCR-Analysen konnte jedoch gezeigt werden, dass PI103 die Expression der Effluxtransporter MDR1 und MRP1 hemmt. Dies resultiert in einer intrazellulären Akkumulation von Doxorubizin. Diese Akkumulation ist jedoch nicht die alleinige Ursache des kooperativen proapoptotischen Effekts. Vielmehr kooperieren Doxorubizin und PI103 in der Aktivierung des proapoptotischen Proteins BAX, in der Freisetzung von Cytochrom $\mathrm{c}$ aus den Mitochondrien, und in der Aktivierung der Caspase 3. Eine Aktivierung der Caspase 3 kann auch in einem ersten in vivoExperiment an transplantierten Rhabdomyosarkomzellen gezeigt werden. Zusammengefasst zeigen die Daten, dass die durch PI103 hervorgerufene Sensitivierung von Sarkomzellen gegenüber den proapoptotischen Effekten von Doxorubizin über die Komponenten des mitochondrialen Apoptosewegs zustande kommt. 


\section{Literaturverzeichnis}

1. Arcamone, F., Cassinelli, G., Fantini, G., Grein, A., Orezzi, P., Pol, C., und Spalla, C., Adriamycin, 14-hydroxydaunomycin, a new antitumor antibiotic from S. peucetius var. caesius. Biotechnol Bioeng, 1969. 11(6): p. 1101-10.

2. Karukstis, K.K., Thompson, E.H., Whiles, J.A., und Rosenfeld, R.J., Deciphering the fluorescence signature of daunomycin and doxorubicin. Biophys Chem, 1998. 73(3): p. 24963.

3. Minotti, G., Menna, P., Salvatorelli, E., Cairo, G., und Gianni, L., Anthracyclines: molecular advances and pharmacologic developments in antitumor activity and cardiotoxicity. Pharmacol Rev, 2004. 56(2): p. 185-229.

4. Carvalho, C., Santos, R.X., Cardoso, S., Correia, S., Oliveira, P.J., Santos, M.S., und Moreira, P.I., Doxorubicin: the good, the bad and the ugly effect. Curr Med Chem, 2009. 16(25): p. 3267-85.

5. Sciarrino, E., Simonetti, R.G., Le Moli, S., und Pagliaro, L., Adriamycin treatment for hepatocellular carcinoma. Experience with 109 patients. Cancer, 1985. 56(12): p. 2751-5.

6. Borden, E.C., Amato, D.A., Rosenbaum, C., Enterline, H.T., Shiraki, M.J., Creech, R.H., Lerner, H.J., und Carbone, P.P., Randomized comparison of three adriamycin regimens for metastatic soft tissue sarcomas. J Clin Oncol, 1987. 5(6): p. 840-50.

7. Jones, R.B., Holland, J.F., Bhardwaj, S., Norton, L., Wilfinger, C., und Strashun, A., A phase III study of intensive-dose adriamycin for advanced breast cancer. J Clin Oncol, 1987. 5(2): p. $172-7$.

8. McKelvey, E.M., Gottlieb, J.A., Wilson, H.E., Haut, A., Talley, R.W., Stephens, R., Lane, M., Gamble, J.F., Jones, S.E., Grozea, P.N., Gutterman, J., Coltman, C., und Moon, T.E., Hydroxyldaunomycin (Adriamycin) combination chemotherapy in malignant lymphoma. Cancer, 1976. 38(4): p. 1484-93.

9. Palumbo, A., Gay, F., Bringhen, S., Falcone, A., Pescosta, N., Callea, V., Caravita, T., Morabito, F., Magarotto, V., Ruggeri, M., Avonto, I., Musto, P., Cascavilla, N., Bruno, B., und Boccadoro, M., Bortezomib, doxorubicin and dexamethasone in advanced multiple myeloma. Ann Oncol, 2008. 19(6): p. 1160-5.

10. Rabbani, A., Finn, R.M., und Ausio, J., The anthracycline antibiotics: antitumor drugs that alter chromatin structure. Bioessays, 2005. 27(1): p. 50-6.

11. Gewirtz, D.A., A critical evaluation of the mechanisms of action proposed for the antitumor effects of the anthracycline antibiotics adriamycin and daunorubicin. Biochem Pharmacol, 1999. 57(7): p. 727-41.

12. Doroshow, J.H., Anthracycline antibiotic-stimulated superoxide, hydrogen peroxide, and hydroxyl radical production by NADH dehydrogenase. Cancer Res, 1983. 43(10): p. 4543-51.

13. Kappus, H., Oxidative stress in chemical toxicity. Arch Toxicol, 1987. 60(1-3): p. 144-9.

14. Gutierrez, P.L., The role of $N A D(P) H$ oxidoreductase (DT-Diaphorase) in the bioactivation of quinone-containing antitumor agents: a review. Free Radic Biol Med, 2000. 29(3-4): p. 263-75.

15. Champoux, J.J., DNA topoisomerases: structure, function, and mechanism. Annu Rev Biochem, 2001. 70: p. 369-413.

16. Mondal, N. und Parvin, J.D., DNA topoisomerase Ilalpha is required for RNA polymerase II transcription on chromatin templates. Nature, 2001. 413(6854): p. 435-8.

17. Ju, B.G., Lunyak, V.V., Perissi, V., Garcia-Bassets, I., Rose, D.W., Glass, C.K., und Rosenfeld, M.G., A topoisomerase Ilbeta-mediated dsDNA break required for regulated transcription. Science, 2006. 312(5781): p. 1798-802.

18. Lok, C.N., Lang, A.J., Mirski, S.E., und Cole, S.P., Characterization of the human topoisomerase Ilbeta (TOP2B) promoter activity: essential roles of the nuclear factor-Y (NFY)- and specificity protein-1 (Sp1)-binding sites. Biochem J, 2002. 368(Pt 3): p. 741-51.

19. Wang, J.C., Cellular roles of DNA topoisomerases: a molecular perspective. Nat Rev Mol Cell Biol, 2002. 3(6): p. 430-40.

20. Kimura, K., Saijo, M., Ui, M., und Enomoto, T., Growth state- and cell cycle-dependent fluctuation in the expression of two forms of DNA topoisomerase II and possible specific modification of the higher molecular weight form in the M phase. J Biol Chem, 1994. 269(2): $p$. 1173-6.

21. Isaacs, R.J., Davies, S.L., Sandri, M.I., Redwood, C., Wells, N.J., und Hickson, I.D., Physiological regulation of eukaryotic topoisomerase II. Biochim Biophys Acta, 1998. 1400(1- 
3): p. 121-37.

22. Lyu, Y.L. und Wang, J.C., Aberrant lamination in the cerebral cortex of mouse embryos lacking DNA topoisomerase Ilbeta. Proc Natl Acad Sci U S A, 2003. 100(12): p. 7123-8.

23. Azarova, A.M., Lyu, Y.L., Lin, C.P., Tsai, Y.C., Lau, J.Y., Wang, J.C., und Liu, L.F., Roles of DNA topoisomerase II isozymes in chemotherapy and secondary malignancies. Proc Natl Acad Sci U S A, 2007. 104(26): p. 11014-9.

24. Perego, P., Corna, E., De Cesare, M., Gatti, L., Polizzi, D., Pratesi, G., Supino, R., und Zunino, F., Role of apoptosis and apoptosis-related genes in cellular response and antitumor efficacy of anthracyclines. Curr Med Chem, 2001. 8(1): p. 31-7.

25. Hainsworth, J.D. und Greco, F.A., Etoposide: twenty years later. Ann Oncol, 1995. 6(4): p. 325-41.

26. Kersting, G., Tzvetkov, M.V., Huse, K., Kulle, B., Hafner, V., Brockmoller, J., und Wojnowski, L., Topoisomerase II beta expression level correlates with doxorubicin-induced apoptosis in peripheral blood cells. Naunyn Schmiedebergs Arch Pharmacol, 2006. 374(1): p. 21-30.

27. Elmore, L.W., Rehder, C.W., Di, X., McChesney, P.A., Jackson-Cook, C.K., Gewirtz, D.A., und Holt, S.E., Adriamycin-induced senescence in breast tumor cells involves functional p53 and telomere dysfunction. J Biol Chem, 2002. 277(38): p. 35509-15.

28. Oren, M., Regulation of the p53 tumor suppressor protein. J Biol Chem, 1999. 274(51): p. 36031-4.

29. Davis, W., Jr., Ronai, Z., und Tew, K.D., Cellular thiols and reactive oxygen species in druginduced apoptosis. J Pharmacol Exp Ther, 2001. 296(1): p. 1-6.

30. Yeh, P.Y., Chuang, S.E., Yeh, K.H., Song, Y.C., Chang, L.L., und Cheng, A.L., Phosphorylation of p53 on Thr55 by ERK2 is necessary for doxorubicin-induced p53 activation and cell death. Oncogene, 2004. 23(20): p. 3580-8.

31. Steinberg, J.S., Cohen, A.J., Wasserman, A.G., Cohen, P., und Ross, A.M., Acute arrhythmogenicity of doxorubicin administration. Cancer, 1987. 60(6): p. 1213-8.

32. Ferrans, V.J., Clark, J.R., Zhang, J., Yu, Z.X., und Herman, E.H., Pathogenesis and prevention of doxorubicin cardiomyopathy. Tsitologiia, 1997. 39(10): p. 928-37.

33. Simunek, T., Sterba, M., Popelova, O., Adamcova, M., Hrdina, R., und Gersl, V., Anthracycline-induced cardiotoxicity: overview of studies examining the roles of oxidative stress and free cellular iron. Pharmacol Rep, 2009. 61(1): p. 154-71.

34. Lipshultz, S.E., Colan, S.D., Gelber, R.D., Perez-Atayde, A.R., Sallan, S.E., und Sanders, S.P., Late cardiac effects of doxorubicin therapy for acute lymphoblastic leukemia in childhood. N Engl J Med, 1991. 324(12): p. 808-15.

35. Lefrak, E.A., Pitha, J., Rosenheim, S., und Gottlieb, J.A., A clinicopathologic analysis of adriamycin cardiotoxicity. Cancer, 1973. 32(2): p. 302-14.

36. Dean, M., Hamon, Y., und Chimini, G., The human ATP-binding cassette (ABC) transporter superfamily. J Lipid Res, 2001. 42(7): p. 1007-17.

37. Weiss, R.B., The anthracyclines: will we ever find a better doxorubicin? Semin Oncol, 1992. 19(6): p. 670-86.

38. Smith, L., Watson, M.B., O'Kane, S.L., Drew, P.J., Lind, M.J., und Cawkwell, L., The analysis of doxorubicin resistance in human breast cancer cells using antibody microarrays. Mol Cancer Ther, 2006. 5(8): p. 2115-20.

39. Saleh, E.M., El-Awady, R.A., Abdel Alim, M.A., und Abdel Wahab, A.H., Altered expression of proliferation-inducing and proliferation-inhibiting genes might contribute to acquired doxorubicin resistance in breast cancer cells. Cell Biochem Biophys, 2009. 55(2): p. 95-105.

40. Fuchs, J., Wenderoth, M., von Schweinitz, D., Haindl, J., und Leuschner, I., Comparative activity of cisplatin, ifosfamide, doxorubicin, carboplatin, and etoposide in heterotransplanted hepatoblastoma. Cancer, 1998. 83(11): p. 2400-7.

41. Borst, P., Evers, R., Kool, M., und Wijnholds, J., The multidrug resistance protein family. Biochim Biophys Acta, 1999. 1461(2): p. 347-57.

42. Higgins, C.F., ABC transporters: physiology, structure and mechanism--an overview. Res Microbiol, 2001. 152(3-4): p. 205-10.

43. Ueda, K., Clark, D.P., Chen, C.J., Roninson, I.B., Gottesman, M.M., und Pastan, I., The human multidrug resistance (mdr1) gene. cDNA cloning and transcription initiation. J Biol Chem, 1987. 262(2): p. 505-8.

44. Jonsson-Videsater, K., Andersson, G., Bergh, J., und Paul, C., Doxorubicin-resistant, MRP1expressing U-1285 cells are sensitive to idarubicin. Ther Drug Monit, 2003. 25(3): p. 331-9.

45. Park, S.J., Wu, C.H., und Safa, A.R., A P-glycoprotein- and MRP1-independent doxorubicin- 
resistant variant of the MCF-7 breast cancer cell line with defects in caspase-6, -7, -8, -9 and 10 activation pathways. Anticancer Res, 2004. 24(1): p. 123-31.

46. Shen, F., Chu, S., Bence, A.K., Bailey, B., Xue, X., Erickson, P.A., Montrose, M.H., Beck, W.T., und Erickson, L.C., Quantitation of doxorubicin uptake, efflux, and modulation of multidrug resistance (MDR) in MDR human cancer cells. J Pharmacol Exp Ther, 2008. 324(1): p. 95-102.

47. Hortobagyi, G.N., Anthracyclines in the treatment of cancer. An overview. Drugs, 1997. 54 Suppl 4: p. 1-7.

48. Zucchi, R. und Danesi, R., Cardiac toxicity of antineoplastic anthracyclines. Curr Med Chem Anticancer Agents, 2003. 3(2): p. 151-71.

49. Zalupski, M., Metch, B., Balcerzak, S., Fletcher, W.S., Chapman, R., Bonnet, J.D., Weiss, G.R., Ryan, J., Benjamin, R.S., und Baker, L.H., Phase III comparison of doxorubicin and dacarbazine given by bolus versus infusion in patients with soft-tissue sarcomas: a Southwest Oncology Group study. J Natl Cancer Inst, 1991. 83(13): p. 926-32.

50. Liu, L.F., DNA topoisomerase poisons as antitumor drugs. Annu Rev Biochem, 1989. 58: p. 351-75.

51. Nitiss, J.L., Targeting DNA topoisomerase II in cancer chemotherapy. Nat Rev Cancer, 2009. 9(5): p. 338-50.

52. Swain, S.M., Whaley, F.S., Gerber, M.C., Ewer, M.S., Bianchine, J.R., und Gams, R.A., Delayed administration of dexrazoxane provides cardioprotection for patients with advanced breast cancer treated with doxorubicin-containing therapy. J Clin Oncol, 1997. 15(4): p. 133340.

53. Sehested, M., Jensen, P.B., Sorensen, B.S., Holm, B., Friche, E., und Demant, E.J., Antagonistic effect of the cardioprotector (+)-1,2-bis(3,5-dioxopiperazinyl-1-yl)propane (ICRF187) on DNA breaks and cytotoxicity induced by the topoisomerase II directed drugs daunorubicin and etoposide (VP-16). Biochem Pharmacol, 1993. 46(3): p. 389-93.

54. Tebbi, C.K., London, W.B., Friedman, D., Villaluna, D., De Alarcon, P.A., Constine, L.S., Mendenhall, N.P., Sposto, R., Chauvenet, A., und Schwartz, C.L., Dexrazoxane-associated risk for acute myeloid leukemia/myelodysplastic syndrome and other secondary malignancies in pediatric Hodgkin's disease. J Clin Oncol, 2007. 25(5): p. 493-500.

55. Panasci, L., Jean-Claude, B.J., Vasilescu, D., Mustafa, A., Damian, S., Damian, Z., Georges, E., Liu, Z., Batist, G., und Leyland-Jones, B., Sensitization to doxorubicin resistance in breast cancer cell lines by tamoxifen and megestrol acetate. Biochem Pharmacol, 1996. 52(7): p. 1097-102.

56. Wan, X.M., Zheng, F., Zhang, L., Miao, Y.Y., Man, N., und Wen, L.P., Autophagy-mediated chemosensitization by cysteamine in cancer cells. Int J Cancer, 2011. 129(5): p. 1087-95.

57. Schwarzbach, M.H., Eisold, S., Burguete, T., Willeke, F., Klein-Bauernschmitt, P., Schlehofer, J.R., Herfarth, C., Ridder, R., und von Knebel Doeberitz, M., Sensitization of sarcoma cells to doxorubicin treatment by concomitant wild-type adeno-associated virus type 2 (AAV-2) infection. Int J Oncol, 2002. 20(6): p. 1211-8.

58. Schwarzenbach, H., Expression of MDR1/P-glycoprotein, the multidrug resistance protein $M R P$, and the lung-resistance protein LRP in multiple myeloma. Med Oncol, 2002. 19(2): p. 87-104.

59. Davies, S.M., Robson, C.N., Davies, S.L., und Hickson, I.D., Nuclear topoisomerase II levels correlate with the sensitivity of mammalian cells to intercalating agents and epipodophyllotoxins. J Biol Chem, 1988. 263(33): p. 17724-9.

60. Deffie, A.M., Batra, J.K., und Goldenberg, G.J., Direct correlation between DNA topoisomerase II activity and cytotoxicity in adriamycin-sensitive and -resistant P388 leukemia cell lines. Cancer Res, 1989. 49(1): p. 58-62.

61. Burgess, D.J., Doles, J., Zender, L., Xue, W., Ma, B., McCombie, W.R., Hannon, G.J., Lowe, S.W., und Hemann, M.T., Topoisomerase levels determine chemotherapy response in vitro and in vivo. Proc Natl Acad Sci U S A, 2008. 105(26): p. 9053-8.

62. Haaf, T., The effects of 5-azacytidine and 5-azadeoxycytidine on chromosome structure and function: implications for methylation-associated cellular processes. Pharmacol Ther, 1995. 65(1): p. 19-46.

63. Takahashi-Hyodo, S.A., Sakamoto-Hojo, E.T., und Takahashi, C.S., Interaction effects of 5azacytidine with topoisomerase II inhibitors on CHO cells, as detected by cytogenetic analysis. Mutat Res, 1999. 431(1): p. 13-23.

64. Gottlicher, M., Minucci, S., Zhu, P., Kramer, O.H., Schimpf, A., Giavara, S., Sleeman, J.P., Lo 
Coco, F., Nervi, C., Pelicci, P.G., und Heinzel, T., Valproic acid defines a novel class of HDAC inhibitors inducing differentiation of transformed cells. Embo J, 2001. 20(24): p. 6969-78.

65. Minucci, S. und Pelicci, P.G., Histone deacetylase inhibitors and the promise of epigenetic (and more) treatments for cancer. Nat Rev Cancer, 2006. 6(1): p. 38-51.

66. Hochhauser, D., Stanway, C.A., Harris, A.L., und Hickson, I.D., Cloning and characterization of the 5'-flanking region of the human topoisomerase II alpha gene. J Biol Chem, 1992. 267(26): p. 18961-5.

67. Das, C.M., Aguilera, D., Vasquez, H., Prasad, P., Zhang, M., Wolff, J.E., und Gopalakrishnan, V., Valproic acid induces p21 and topoisomerase-II (alpha/beta) expression and synergistically enhances etoposide cytotoxicity in human glioblastoma cell lines. J Neurooncol, 2007. 85(2): p. $159-70$.

68. Kanbe, E., Abe, A., Towatari, M., Kawabe, T., Saito, H., und Emi, N., DR1-like element in human topoisomerase Ilalpha gene involved in enhancement of etoposide-induced apoptosis by PPARgamma ligand. Exp Hematol, 2003. 31(4): p. 300-8.

69. Congdon, L.M., Pourpak, A., Escalante, A.M., Dorr, R.T., und Landowski, T.H., Proteasomal inhibition stabilizes topoisomerase llalpha protein and reverses resistance to the topoisomerase II poison ethonafide (AMP-53, 6-ethoxyazonafide). Biochem Pharmacol, 2008. 75(4): p. 883-90.

70. Courtney, K.D., Corcoran, R.B., und Engelman, J.A., The PI3K pathway as drug target in human cancer. J Clin Oncol, 2010. 28(6): p. 1075-83.

71. Li, J., Yen, C., Liaw, D., Podsypanina, K., Bose, S., Wang, S.I., Puc, J., Miliaresis, C., Rodgers, L., McCombie, R., Bigner, S.H., Giovanella, B.C., Ittmann, M., Tycko, B., Hibshoosh, $\mathrm{H}$., Wigler, M.H., und Parsons, R., PTEN, a putative protein tyrosine phosphatase gene mutated in human brain, breast, and prostate cancer. Science, 1997. 275(5308): p. 1943-7.

72. Samuels, Y., Wang, Z., Bardelli, A., Silliman, N., Ptak, J., Szabo, S., Yan, H., Gazdar, A., Powell, S.M., Riggins, G.J., Willson, J.K., Markowitz, S., Kinzler, K.W., Vogelstein, B., und Velculescu, V.E., High frequency of mutations of the PIK3CA gene in human cancers. Science, 2004. 304(5670): p. 554.

73. Bader, A.G., Kang, S., und Vogt, P.K., Cancer-specific mutations in PIK3CA are oncogenic in vivo. Proc Natl Acad Sci U S A, 2006. 103(5): p. 1475-9.

74. LoPiccolo, J., Blumenthal, G.M., Bernstein, W.B., und Dennis, P.A., Targeting the PIJK/Akt/mTOR pathway: effective combinations and clinical considerations. Drug Resist Updat, 2008. 11(1-2): p. 32-50.

75. Walker, K.S., Deak, M., Paterson, A., Hudson, K., Cohen, P., und Alessi, D.R., Activation of protein kinase $B$ beta and gamma isoforms by insulin in vivo and by 3-phosphoinositidedependent protein kinase-1 in vitro: comparison with protein kinase B alpha. Biochem J, 1998. 331 ( Pt 1): p. 299-308.

76. Balendran, A., Casamayor, A., Deak, M., Paterson, A., Gaffney, P., Currie, R., Downes, C.P., und Alessi, D.R., PDK1 acquires PDK2 activity in the presence of a synthetic peptide derived from the carboxyl terminus of PRK2. Curr Biol, 1999. 9(8): p. 393-404.

77. Hill, M.M., Feng, J., und Hemmings, B.A., Identification of a plasma membrane Raftassociated PKB Ser473 kinase activity that is distinct from ILK and PDK1. Curr Biol, 2002. 12(14): p. 1251-5.

78. Toker, A. und Newton, A.C., Akt/protein kinase $B$ is regulated by autophosphorylation at the hypothetical PDK-2 site. J Biol Chem, 2000. 275(12): p. 8271-4.

79. Liu, F., Liu, S., He, S., Xie, Z., Zu, X., und Jiang, Y., Survivin transcription is associated with P-glycoprotein/MDR1 overexpression in the multidrug resistance of MCF-7 breast cancer cells. Oncol Rep, 2010. 23(5): p. 1469-75.

80. Tazzari, P.L., Cappellini, A., Ricci, F., Evangelisti, C., Papa, V., Grafone, T., Martinelli, G., Conte, R., Cocco, L., McCubrey, J.A., und Martelli, A.M., Multidrug resistance-associated protein 1 expression is under the control of the phosphoinositide 3 kinase/Akt signal transduction network in human acute myelogenous leukemia blasts. Leukemia, 2007. 21(3): p. 427-38.

81. Duronio, V., The life of a cell: apoptosis regulation by the PI3K/PKB pathway. Biochem J, 2008. 415(3): p. 333-44.

82. Markman, B., Dienstmann, R., und Tabernero, J., Targeting the PI3K/Akt/mTOR pathway-beyond rapalogs. Oncotarget, 2010. 1(7): p. 530-43.

83. Haupt, Y., Maya, R., Kazaz, A., und Oren, M., Mdm2 promotes the rapid degradation of p53. Nature, 1997. 387(6630): p. 296-9. 
84. Mayo, L.D. und Donner, D.B., A phosphatidylinositol 3-kinase/Akt pathway promotes translocation of Mdm2 from the cytoplasm to the nucleus. Proc Natl Acad Sci U S A, 2001. 98(20): p. 11598-603.

85. Accili, D. und Arden, K.C., FoxOs at the crossroads of cellular metabolism, differentiation, and transformation. Cell, 2004. 117(4): p. 421-6.

86. Carter, M.E. und Brunet, A., FOXO transcription factors. Curr Biol, 2007. 17(4): p. R113-4.

87. Luo, J., Sobkiw, C.L., Hirshman, M.F., Logsdon, M.N., Li, T.Q., Goodyear, L.J., und Cantley, L.C., Loss of class IA PI3K signaling in muscle leads to impaired muscle growth, insulin response, and hyperlipidemia. Cell Metab, 2006. 3(5): p. 355-66.

88. Yamaguchi, H. und Wang, H.G., The protein kinase PKB/Akt regulates cell survival and apoptosis by inhibiting Bax conformational change. Oncogene, 2001. 20(53): p. 7779-86.

89. Cantley, L.C., The phosphoinositide 3-kinase pathway. Science, 2002. 296(5573): p. 1655-7.

90. Elmore, S., Apoptosis: a review of programmed cell death. Toxicol Pathol, 2007. 35(4): p. 495516.

91. Letai, A., Bassik, M.C., Walensky, L.D., Sorcinelli, M.D., Weiler, S., und Korsmeyer, S.J., Distinct $B H 3$ domains either sensitize or activate mitochondrial apoptosis, serving as prototype cancer therapeutics. Cancer Cell, 2002. 2(3): p. 183-92.

92. Wei, M.C., Zong, W.X., Cheng, E.H., Lindsten, T., Panoutsakopoulou, V., Ross, A.J., Roth, K.A., MacGregor, G.R., Thompson, C.B., und Korsmeyer, S.J., Proapoptotic BAX and BAK: a requisite gateway to mitochondrial dysfunction and death. Science, 2001. 292(5517): p. 72730.

93. Perfettini, J.L., Kroemer, R.T., und Kroemer, G., Fatal liaisons of p53 with Bax and Bak. Nat Cell Biol, 2004. 6(5): p. 386-8.

94. Kroemer, G., Galluzzi, L., und Brenner, C., Mitochondrial membrane permeabilization in cell death. Physiol Rev, 2007. 87(1): p. 99-163.

95. Pradelli, L.A., Beneteau, M., und Ricci, J.E., Mitochondrial control of caspase-dependent and independent cell death. Cell Mol Life Sci, 2010. 67(10): p. 1589-97.

96. Kurokawa, M. und Kornbluth, S., Caspases and kinases in a death grip. Cell, 2009. 138(5): p. 838-54.

97. Han, Z., Hendrickson, E.A., Bremner, T.A., und Wyche, J.H., A sequential two-step mechanism for the production of the mature p17:p12 form of caspase-3 in vitro. J Biol Chem, 1997. 272(20): p. 13432-6.

98. Fuentes-Prior, P. und Salvesen, G.S., The protein structures that shape caspase activity, specificity, activation and inhibition. Biochem J, 2004. 384(Pt 2): p. 201-32.

99. Fan, T.J., Han, L.H., Cong, R.S., und Liang, J., Caspase family proteases and apoptosis. Acta Biochim Biophys Sin (Shanghai), 2005. 37(11): p. 719-27.

100. Motzer, R.J., Escudier, B., Oudard, S., Hutson, T.E., Porta, C., Bracarda, S., Grunwald, V., Thompson, J.A., Figlin, R.A., Hollaender, N., Urbanowitz, G., Berg, W.J., Kay, A., Lebwohl, D., und Ravaud, A., Efficacy of everolimus in advanced renal cell carcinoma: a double-blind, randomised, placebo-controlled phase III trial. Lancet, 2008. 372(9637): p. 449-56.

101. Park, S., Chapuis, N., Bardet, V., Tamburini, J., Gallay, N., Willems, L., Knight, Z.A., Shokat, K.M., Azar, N., Viguie, F., Ifrah, N., Dreyfus, F., Mayeux, P., Lacombe, C., und Bouscary, D., PI-103, a dual inhibitor of Class IA phosphatidylinositide 3-kinase and mTOR, has antileukemic activity in AML. Leukemia, 2008. 22(9): p. 1698-706.

102. Fan, Q.W., Knight, Z.A., Goldenberg, D.D., Yu, W., Mostov, K.E., Stokoe, D., Shokat, K.M., und Weiss, W.A., A dual PI3 kinase/mTOR inhibitor reveals emergent efficacy in glioma. Cancer Cell, 2006. 9(5): p. 341-9.

103. Raynaud, F.I., Eccles, S., Clarke, P.A., Hayes, A., Nutley, B., Alix, S., Henley, A., Di-Stefano, F., Ahmad, Z., Guillard, S., Bjerke, L.M., Kelland, L., Valenti, M., Patterson, L., Gowan, S., de Haven Brandon, A., Hayakawa, M., Kaizawa, H., Koizumi, T., Ohishi, T., Patel, S., Saghir, N., Parker, P., Waterfield, M., und Workman, P., Pharmacologic characterization of a potent inhibitor of class I phosphatidylinositide 3-kinases. Cancer Res, 2007. 67(12): p. 5840-50.

104. Raynaud, F.I., Eccles, S.A., Patel, S., Alix, S., Box, G., Chuckowree, I., Folkes, A., Gowan, S., De Haven Brandon, A., Di Stefano, F., Hayes, A., Henley, A.T., Lensun, L., Pergl-Wilson, G., Robson, A., Saghir, N., Zhyvoloup, A., McDonald, E., Sheldrake, P., Shuttleworth, S., Valenti, M., Wan, N.C., Clarke, P.A., und Workman, P., Biological properties of potent inhibitors of class I phosphatidylinositide 3-kinases: from PI-103 through PI-540, PI-620 to the oral agent GDC-0941. Mol Cancer Ther, 2009. 8(7): p. 1725-38.

105. Moreno Garcia V., R.D.B., K. J. Shah, B. Basu, N. Tunariu, M. Blanco, P. A. Cassier, J. V. 
Pedersen, M. Puglisi, D. Sarker, D. Papadatos-Pastos, A. G. Omlin, A. Biondo, J. A. Ware, H. Koeppen, G. G. Levy, K. E. Mazina, J. S. De Bono, A phase I study evaluating GDC-0941, an oral phosphoinositide-3 kinase (PI3K) inhibitor, in patients with advanced solid tumors or multiple myeloma. 2011 ASCO Annual Meeting 2011. Abstract Number 3021

106. Bender, A., Opel, D., Naumann, I., Kappler, R., Friedman, L., von Schweinitz, D., Debatin, K.M., und Fulda, S., PI3K inhibitors prime neuroblastoma cells for chemotherapy by shifting the balance towards pro-apoptotic Bcl-2 proteins and enhanced mitochondrial apoptosis. Oncogene, 2011. 30(4): p. 494-503.

107. Opel, D., Westhoff, M.A., Bender, A., Braun, V., Debatin, K.M., und Fulda, S., Phosphatidylinositol 3-kinase inhibition broadly sensitizes glioblastoma cells to death receptorand drug-induced apoptosis. Cancer Res, 2008. 68(15): p. 6271-80.

108. Westhoff, M.A., Kandenwein, J.A., Karl, S., Vellanki, S.H., Braun, V., Eramo, A., Antoniadis, G., Debatin, K.M., und Fulda, S., The pyridinylfuranopyrimidine inhibitor, PI-103, chemosensitizes glioblastoma cells for apoptosis by inhibiting DNA repair. Oncogene, 2009. 28(40): p. 3586-96.

109. Schwab, J., Antonescu, C., Boland, P., Healey, J., Rosenberg, A., Nielsen, P., lafrate, J., Delaney, T., Yoon, S., Choy, E., Harmon, D., Raskin, K., Yang, C., Mankin, H., Springfield, D., Hornicek, F., und Duan, Z., Combination of PI3K/mTOR inhibition demonstrates efficacy in human chordoma. Anticancer Res, 2009. 29(6): p. 1867-71.

110. Kojima, K., Shimanuki, M., Shikami, M., Samudio, I.J., Ruvolo, V., Corn, P., Hanaoka, N., Konopleva, M., Andreeff, M., und Nakakuma, H., The dual PI3 kinase/mTOR inhibitor PI-103 prevents p53 induction by Mdm2 inhibition but enhances p53-mediated mitochondrial apoptosis in p53 wild-type AML. Leukemia, 2008. 22(9): p. 1728-36.

111. Wang, Y.A., Johnson, S.K., Brown, B.L., McCarragher, L.M., Al-Sakkaf, K., Royds, J.A., und Dobson, P.R., Enhanced anti-cancer effect of a phosphatidylinositol-3 kinase inhibitor and doxorubicin on human breast epithelial cell lines with different p53 and oestrogen receptor status. Int J Cancer, 2008. 123(7): p. 1536-44.

112. Manara, M.C., Nicoletti, G., Zambelli, D., Ventura, S., Guerzoni, C., Landuzzi, L., Lollini, P.L., Maira, S.M., Garcia-Echeverria, C., Mercuri, M., Picci, P., und Scotlandi, K., NVP-BEZ235 as a new therapeutic option for sarcomas. Clin Cancer Res, 2010. 16(2): p. 530-40.

113. Wexler, L. und LJ, H., Rhabdomyosarkoma and the Undifferentiated Sarcoma. In Principles and Practice of Pediatric Oncology; third edition, edited by Philip A. Pizzo and David G. Poplack. Lippincott-Raven Publishers. Philadelphia, 1997.

114. Dagher, R. und Helman, L., Rhabdomyosarcoma: an overview. Oncologist, 1999. 4(1): p. 3444.

115. Wang, C., Childhood Rhabdomyosarcoma: Recent Advances and Prospective Views. J Dent Res, 2011.

116. Horn, R.C., Jr. und Enterline, H.T., Rhabdomyosarcoma: a clinicopathological study and classification of 39 cases. Cancer, 1958. 11(1): p. 181-99.

117. Merlino, G. und Helman, L.J., Rhabdomyosarcoma--working out the pathways. Oncogene, 1999. 18(38): p. 5340-8.

118. Bridge, J.A., Liu, J., Weibolt, V., Baker, K.S., Perry, D., Kruger, R., Qualman, S., Barr, F., Sorensen, P., Triche, T., und Suijkerbuijk, R., Novel genomic imbalances in embryonal rhabdomyosarcoma revealed by comparative genomic hybridization and fluorescence in situ hybridization: an intergroup rhabdomyosarcoma study. Genes Chromosomes Cancer, 2000. 27(4): p. 337-44.

119. De Giovanni, C., Landuzzi, L., Nicoletti, G., Lollini, P.L., und Nanni, P., Molecular and cellular biology of rhabdomyosarcoma. Future Oncol, 2009. 5(9): p. 1449-75.

120. Breitfeld, P.P. und Meyer, W.H., Rhabdomyosarcoma: new windows of opportunity. Oncologist, 2005. 10(7): p. 518-27.

121. Gottesman, M.M. und Pastan, I., The multidrug transporter, a double-edged sword. J Biol Chem, 1988. 263(25): p. 12163-6.

122. Bonadonna, G., Monfardini, S., De Lena, M., Fossati-Bellani, F., und Beretta, G., Phase I and preliminary phase II evaluation of adriamycin (NSC 123127). Cancer Res, 1970. 30(10): p. 2572-82.

123. O'Bryan, R.M., Luce, J.K., Talley, R.W., Gottlieb, J.A., Baker, L.H., und Bonadonna, G., Phase II evaluation of adriamycin in human neoplasia. Cancer, 1973. 32(1): p. 1-8.

124. Tan, C., Etcubanas, E., Wollner, N., Rosen, G., Gilladoga, A., Showel, J., Murphy, M.L., und Krakoff, I.H., Adriamycin--an antitumor antibiotic in the treatment of neoplastic diseases. 
Cancer, 1973. 32(1): p. 9-17.

125. Bergeron, C., Thiesse, P., Rey, A., Orbach, D., Boutard, P., Thomas, C., Schmitt, C., Scopinaro, M.J., Bernard, F., Stevens, M., und Oberlin, O., Revisiting the role of doxorubicin in the treatment of rhabdomyosarcoma: an up-front window study in newly diagnosed children with high-risk metastatic disease. Eur J Cancer, 2008. 44(3): p. 427-31.

126. Maurer, H.M., Beltangady, M., Gehan, E.A., Crist, W., Hammond, D., Hays, D.M., Heyn, R., Lawrence, W., Newton, W., Ortega, J., und et al., The Intergroup Rhabdomyosarcoma StudyI. A final report. Cancer, 1988. 61(2): p. 209-20.

127. Maurer, H.M., Gehan, E.A., Beltangady, M., Crist, W., Dickman, P.S., Donaldson, S.S., Fryer, C., Hammond, D., Hays, D.M., Herrmann, J., und et al., The Intergroup Rhabdomyosarcoma Study-II. Cancer, 1993. 71(5): p. 1904-22.

128. Crist, W., Gehan, E.A., Ragab, A.H., Dickman, P.S., Donaldson, S.S., Fryer, C., Hammond, D., Hays, D.M., Herrmann, J., Heyn, R., und et al., The Third Intergroup Rhabdomyosarcoma Study. J Clin Oncol, 1995. 13(3): p. 610-30.

129. Ricci, C., Polito, L., Nanni, P., Landuzzi, L., Astolfi, A., Nicoletti, G., Rossi, I., De Giovanni, C., Bolognesi, A., und Lollini, P.L., HER/erbB receptors as therapeutic targets of immunotoxins in human rhabdomyosarcoma cells. J Immunother, 2002. 25(4): p. 314-23.

130. Blandford, M.C., Barr, F.G., Lynch, J.C., Randall, R.L., Qualman, S.J., und Keller, C., Rhabdomyosarcomas utilize developmental, myogenic growth factors for disease advantage: a report from the Children's Oncology Group. Pediatr Blood Cancer, 2006. 46(3): p. 329-38.

131. Taniguchi, E., Nishijo, K., McCleish, A.T., Michalek, J.E., Grayson, M.H., Infante, A.J., Abboud, H.E., Legallo, R.D., Qualman, S.J., Rubin, B.P., und Keller, C., PDGFR-A is a therapeutic target in alveolar rhabdomyosarcoma. Oncogene, 2008. 27(51): p. 6550-60.

132. McDowell, H.P., Meco, D., Riccardi, A., Tanno, B., Berardi, A.C., Raschella, G., Riccardi, R., und Dominici, C., Imatinib mesylate potentiates topotecan antitumor activity in rhabdomyosarcoma preclinical models. Int J Cancer, 2007. 120(5): p. 1141-9.

133. Crose, L.E. und Linardic, C.M., Receptor tyrosine kinases as therapeutic targets in rhabdomyosarcoma. Sarcoma, 2011. 2011: p. 756982.

134. Rees, H., Williamson, D., Papanastasiou, A., Jina, N., Nabarro, S., Shipley, J., und Anderson, J., The MET receptor tyrosine kinase contributes to invasive tumour growth in rhabdomyosarcomas. Growth Factors, 2006. 24(3): p. 197-208.

135. Taulli, R., Scuoppo, C., Bersani, F., Accornero, P., Forni, P.E., Miretti, S., Grinza, A., Allegra, P., Schmitt-Ney, M., Crepaldi, T., und Ponzetto, C., Validation of met as a therapeutic target in alveolar and embryonal rhabdomyosarcoma. Cancer Res, 2006. 66(9): p. 4742-9.

136. Hou, J., Dong, J., Sun, L., Geng, L., Wang, J., Zheng, J., Li, Y., Bridge, J., Hinrichs, S.H., und Ding, S.J., Inhibition of phosphorylated c-Met in rhabdomyosarcoma cell lines by a small molecule inhibitor SU11274. J Transl Med, 2011. 9: p. 64.

137. Petricoin, E.F., 3rd, Espina, V., Araujo, R.P., Midura, B., Yeung, C., Wan, X., Eichler, G.S., Johann, D.J., Jr., Qualman, S., Tsokos, M., Krishnan, K., Helman, L.J., und Liotta, L.A., Phosphoprotein pathway mapping: Akt/mammalian target of rapamycin activation is negatively associated with childhood rhabdomyosarcoma survival. Cancer Res, 2007. 67(7): p. 3431-40.

138. Kappler, R., Calzada-Wack, J., Schnitzbauer, U., Koleva, M., Herwig, A., Piontek, G., Graedler, F., Adamski, J., Heinzmann, U., Schlegel, J., Hemmerlein, B., Quintanilla-Martinez, L., und Hahn, H., Molecular characterization of Patched-associated rhabdomyosarcoma. J Pathol, 2003. 200(3): p. 348-56.

139. O'Reilly, K.E., Rojo, F., She, Q.B., Solit, D., Mills, G.B., Smith, D., Lane, H., Hofmann, F., Hicklin, D.J., Ludwig, D.L., Baselga, J., und Rosen, N., mTOR inhibition induces upstream receptor tyrosine kinase signaling and activates Akt. Cancer Res, 2006. 66(3): p. 1500-8.

140. Wan, X., Harkavy, B., Shen, N., Grohar, P., und Helman, L.J., Rapamycin induces feedback activation of Akt signaling through an IGF-1R-dependent mechanism. Oncogene, 2007. 26(13): p. 1932-40.

141. Carracedo, A., Ma, L., Teruya-Feldstein, J., Rojo, F., Salmena, L., Alimonti, A., Egia, A., Sasaki, A.T., Thomas, G., Kozma, S.C., Papa, A., Nardella, C., Cantley, L.C., Baselga, J., und Pandolfi, P.P., Inhibition of mTORC1 leads to MAPK pathway activation through a PI3Kdependent feedback loop in human cancer. J Clin Invest, 2008. 118(9): p. 3065-74.

142. Dancey, J., mTOR signaling and drug development in cancer. Nat Rev Clin Oncol, 2010. 7(4): p. 209-19.

143. Cen, L., Hsieh, F.C., Lin, H.J., Chen, C.S., Qualman, S.J., und Lin, J., PDK-1/AKT pathway as a novel therapeutic target in rhabdomyosarcoma cells using OSU-03012 compound. $\mathrm{Br} \mathrm{J}$ 
Cancer, 2007. 97(6): p. 785-91.

144. Crosswell H. E. , P.Q., Prince C., De P., Durden D. L., Targeting PI3K in alveolar rhabdomyosarcoma (aRMS). 2006 ASCO Annual Meeting, 2006. Abstract Number 10025.

145. Lieber, M., Smith, B., Szakal, A., Nelson-Rees, W., und Todaro, G., A continuous tumor-cell line from a human lung carcinoma with properties of type II alveolar epithelial cells. Int $\mathrm{J}$ Cancer, 1976. 17(1): p. 62-70.

146. Fogh, J., Wright, W.C., und Loveless, J.D., Absence of HeLa cell contamination in 169 cell lines derived from human tumors. J Natl Cancer Inst, 1977. 58(2): p. 209-14.

147. Rasheed, S., Nelson-Rees, W.A., Toth, E.M., Arnstein, P., und Gardner, M.B., Characterization of a newly derived human sarcoma cell line (HT-1080). Cancer, 1974. 33(4): p. 1027-33.

148. Carpenter, A.J. und Porter, A.C., Construction, characterization, and complementation of a conditional-lethal DNA topoisomerase Ilalpha mutant human cell line. Mol Biol Cell, 2004. 15(12): p. 5700-11.

149. McAllister, R.M., Melnyk, J., Finkelstein, J.Z., Adams, E.C., Jr., und Gardner, M.B., Cultivation in vitro of cells derived from a human rhabdomyosarcoma. Cancer, 1969. 24(3): p. 520-6.

150. Goodrich, L.V., Milenkovic, L., Higgins, K.M., und Scott, M.P., Altered neural cell fates and medulloblastoma in mouse patched mutants. Science, 1997. 277(5329): p. 1109-13.

151. Hahn, H., Wojnowski, L., Zimmer, A.M., Hall, J., Miller, G., und Zimmer, A., Rhabdomyosarcomas and radiation hypersensitivity in a mouse model of Gorlin syndrome. Nature Med, 1998. 4: p. 619-622.

152. Hosoya, K.I., Kim, K.J., und Lee, V.H., Age-dependent expression of P-glycoprotein gp170 in Caco-2 cell monolayers. Pharm Res, 1996. 13(6): p. 885-90.

153. Peyerl, F.W., Dai, S., Murphy, G.A., Crawford, F., White, J., Marrack, P., und Kappler, J.W., Elucidation of some Bax conformational changes through crystallization of an antibody-peptide complex. Cell Death Differ, 2007. 14(3): p. 447-52.

154. Nehls, M., Pfeifer, D., Schorpp, M., Hedrich, H., und Boehm, T., New member of the wingedhelix protein family disrupted in mouse and rat nude mutations. Nature, 1994. 372(6501): p. 103-7.

155. Pantelouris, E.M., Absence of thymus in a mouse mutant. Nature, 1968. 217(5126): p. 370-1.

156. Zhang, L., Yu, D., Hicklin, D.J., Hannay, J.A., Ellis, L.M., und Pollock, R.E., Combined antifetal liver kinase 1 monoclonal antibody and continuous low-dose doxorubicin inhibits angiogenesis and growth of human soft tissue sarcoma xenografts by induction of endothelial cell apoptosis. Cancer Res, 2002. 62(7): p. 2034-42.

157. Greschus, S., Kiessling, F., Lichy, M.P., Moll, J., Mueller, M.M., Savai, R., Rose, F., Ruppert, C., Gunther, A., Luecke, M., Fusenig, N.E., Semmler, W., und Traupe, H., Potential applications of flat-panel volumetric CT in morphologic and functional small animal imaging. Neoplasia, 2005. 7(8): p. 730-40.

158. Dullin, C., Missbach-Guentner, J., Vogel, W.F., Grabbe, E., und Alves, F., Semi-automatic classification of skeletal morphology in genetically altered mice using flat-panel volume computed tomography. PLoS Genet, 2007. 3(7): p. e118.

159. Greene, R.F., Collins, J.M., Jenkins, J.F., Speyer, J.L., und Myers, C.E., Plasma pharmacokinetics of adriamycin and adriamycinol: implications for the design of in vitro experiments and treatment protocols. Cancer Res, 1983. 43(7): p. 3417-21.

160. Speelmans, G., Staffhorst, R.W., de Kruijff, B., und de Wolf, F.A., Transport studies of doxorubicin in model membranes indicate a difference in passive diffusion across and binding at the outer and inner leaflets of the plasma membrane. Biochemistry, 1994. 33(46): p. 137618.

161. Han, Y., Amin, H.M., Frantz, C., Franko, B., Lee, J., Lin, Q., und Lai, R., Restoration of shp1 expression by 5-AZA-2'-deoxycytidine is associated with downregulation of JAK3/STAT3 signaling in ALK-positive anaplastic large cell lymphoma. Leukemia, 2006. 20(9): p. 1602-9.

162. Palii, S.S., Van Emburgh, B.O., Sankpal, U.T., Brown, K.D., und Robertson, K.D., DNA methylation inhibitor 5-Aza-2'-deoxycytidine induces reversible genome-wide DNA damage that is distinctly influenced by DNA methyltransferases 1 and 3B. Mol Cell Biol, 2008. 28(2): $p$. 752-71.

163. Gurvich, N., Tsygankova, O.M., Meinkoth, J.L., und Klein, P.S., Histone deacetylase is a target of valproic acid-mediated cellular differentiation. Cancer Res, 2004. 64(3): p. 1079-86.

164. Mrowka, P., Glodkowska, E., Mlynarczuk-Bialy, I., Bialy, L., Kuckelkorn, U., Nowis, D., Makowski, M., Legat, M., und Golab, J., Pioglitazone, a PPAR-gamma ligand, exerts 
cytostatic/cytotoxic effects against cancer cells, that do not result from inhibition of proteasome. Acta Biochim Pol, 2008. 55(1): p. 75-84.

165. Pigneux, A., Mahon, F.X., Moreau-Gaudry, F., Uhalde, M., de Verneuil, H., Lacombe, F., Reiffers, J., Milpied, N., Praloran, V., und Belloc, F., Proteasome inhibition specifically sensitizes leukemic cells to anthracyclin-induced apoptosis through the accumulation of Bim and Bax pro-apoptotic proteins. Cancer Biol Ther, 2007. 6(4): p. 603-11.

166. Houghton, P.J., Morton, C.L., Kolb, E.A., Lock, R., Carol, H., Reynolds, C.P., Keshelava, N., Maris, J.M., Keir, S.T., Wu, J., und Smith, M.A., Initial testing (stage 1) of the proteasome inhibitor bortezomib by the pediatric preclinical testing program. Pediatr Blood Cancer, 2008. 50(1): p. 37-45.

167. Chaisuparat, R., Hu, J., Jham, B.C., Knight, Z.A., Shokat, K.M., und Montaner, S., Dual inhibition of PI3Kalpha and mTOR as an alternative treatment for Kaposi's sarcoma. Cancer Res, 2008. 68(20): p. 8361-8.

168. Kingma, P.S., Burden, D.A., und Osheroff, N., Binding of etoposide to topoisomerase II in the absence of DNA: decreased affinity as a mechanism of drug resistance. Biochemistry, 1999. 38(12): p. 3457-61.

169. Bender, R.P., Jablonksy, M.J., Shadid, M., Romaine, I., Dunlap, N., Anklin, C., Graves, D.E., und Osheroff, N., Substituents on etoposide that interact with human topoisomerase Ilalpha in the binary enzyme-drug complex: contributions to etoposide binding and activity. Biochemistry, 2008. 47(15): p. 4501-9.

170. Agarwala, S.S. und Case, S., Everolimus (RAD001) in the treatment of advanced renal cell carcinoma: a review. Oncologist, 2010. 15(3): p. 236-45.

171. Zatelli, M.C., Minoia, M., Filieri, C., Tagliati, F., Buratto, M., Ambrosio, M.R., Lapparelli, M., Scanarini, M., und Degli Uberti, E.C., Effect of everolimus on cell viability in nonfunctioning pituitary adenomas. J Clin Endocrinol Metab, 2010. 95(2): p. 968-76.

172. Chipuk, J.E., Maurer, U., Green, D.R., und Schuler, M., Pharmacologic activation of p53 elicits Bax-dependent apoptosis in the absence of transcription. Cancer Cell, 2003. 4(5): p. 371-81.

173. Komarov, P.G., Komarova, E.A., Kondratov, R.V., Christov-Tselkov, K., Coon, J.S., Chernov, M.V., und Gudkov, A.V., A chemical inhibitor of p53 that protects mice from the side effects of cancer therapy. Science, 1999. 285(5434): p. 1733-7.

174. Strom, E., Sathe, S., Komarov, P.G., Chernova, O.B., Pavlovska, I., Shyshynova, I., Bosykh, D.A., Burdelya, L.G., Macklis, R.M., Skaliter, R., Komarova, E.A., und Gudkov, A.V., Smallmolecule inhibitor of p53 binding to mitochondria protects mice from gamma radiation. Nat Chem Biol, 2006. 2(9): p. 474-9.

175. Stahnke, K., Mohr, A., Liu, J., Meyer, L.H., Karawajew, L., und Debatin, K.M., Identification of deficient mitochondrial signaling in apoptosis resistant leukemia cells by flow cytometric analysis of intracellular cytochrome c, caspase-3 and apoptosis. Apoptosis, 2004. 9(4): p. 45765.

176. Saha, M.N., Micallef, J., Qiu, L., und Chang, H., Pharmacological activation of the p53 pathway in haematological malignancies. J Clin Pathol, 2010. 63(3): p. 204-9.

177. Besson, A., Dowdy, S.F., und Roberts, J.M., CDK inhibitors: cell cycle regulators and beyond. Dev Cell, 2008. 14(2): p. 159-69.

178. Ravizza, R., Gariboldi, M.B., Passarelli, L., und Monti, E., Role of the p53/p21 system in the response of human colon carcinoma cells to Doxorubicin. BMC Cancer, 2004. 4: p. 92.

179. Chipuk, J.E., Kuwana, T., Bouchier-Hayes, L., Droin, N.M., Newmeyer, D.D., Schuler, M., und Green, D.R., Direct activation of Bax by p53 mediates mitochondrial membrane permeabilization and apoptosis. Science, 2004. 303(5660): p. 1010-4.

180. Leu, J.I., Dumont, P., Hafey, M., Murphy, M.E., und George, D.L., Mitochondrial p53 activates Bak and causes disruption of a Bak-Mcl1 complex. Nat Cell Biol, 2004. 6(5): p. 443-50.

181. Komarova, E.A., Neznanov, N., Komarov, P.G., Chernov, M.V., Wang, K., und Gudkov, A.V., p53 inhibitor pifithrin alpha can suppress heat shock and glucocorticoid signaling pathways. J Biol Chem, 2003. 278(18): p. 15465-8.

182. Murphy, P.J., Galigniana, M.D., Morishima, Y., Harrell, J.M., Kwok, R.P., Ljungman, M., und Pratt, W.B., Pifithrin-alpha inhibits p53 signaling after interaction of the tumor suppressor protein with hsp90 and its nuclear translocation. J Biol Chem, 2004. 279(29): p. 30195-201.

183. Yan, T., Deng, S., Metzger, A., Godtel-Armbrust, U., Porter, A.C., und Wojnowski, L., Topoisomerase II\{alpha\}-dependent and -independent apoptotic effects of dexrazoxane and doxorubicin. Mol Cancer Ther, 2009. 8(5): p. 1075-85.

184. Mercier, C., Decleves, X., Masseguin, C., Fragner, P., Tardy, M., Roux, F., Gabrion, J., und 
Scherrmann, J.M., P-glycoprotein (ABCB1) but not multidrug resistance-associated protein 1 $(A B C C 1)$ is induced by doxorubicin in primary cultures of rat astrocytes. J Neurochem, 2003. 87(4): p. 820-30.

185. Salomon, J.J. und Ehrhardt, C., Nanoparticles attenuate P-glycoprotein/MDR1 function in A549 human alveolar epithelial cells. Eur J Pharm Biopharm, 2011. 77(3): p. 392-7.

186. Nare, B., Prichard, R.K., und Georges, E., Characterization of rhodamine 123 binding to Pglycoprotein in human multidrug-resistant cells. Mol Pharmacol, 1994. 45(6): p. 1145-52.

187. Porro, A., Haber, M., Diolaiti, D., Iraci, N., Henderson, M., Gherardi, S., Valli, E., Munoz, M.A., Xue, C., Flemming, C., Schwab, M., Wong, J.H., Marshall, G.M., Della Valle, G., Norris, M.D., und Perini, G., Direct and coordinate regulation of ATP-binding cassette transporter genes by Myc factors generates specific transcription signatures that significantly affect the chemoresistance phenotype of cancer cells. J Biol Chem, 2010. 285(25): p. 19532-43.

188. Ecke, I., Rosenberger, A., Obenauer, S., Dullin, C., Aberger, F., Kimmina, S., Schweyer, S., und Hahn, H., Cyclopamine treatment of full-blown Hh/Ptch-associated RMS partially inhibits Hh/Ptch signaling, but not tumor growth. Mol Carcinog, 2008. 47(5): p. 361-72.

189. Wojnowski, L., Kulle, B., Schirmer, M., Schluter, G., Schmidt, A., Rosenberger, A., Vonhof, S., Bickeboller, H., Toliat, M.R., Suk, E.K., Tzvetkov, M., Kruger, A., Seifert, S., Kloess, M., Hahn, H., Loeffler, M., Nurnberg, P., Pfreundschuh, M., Trumper, L., Brockmoller, J., und Hasenfuss, G., $N A D(P) H$ oxidase and multidrug resistance protein genetic polymorphisms are associated with doxorubicin-induced cardiotoxicity. Circulation, 2005. 112(24): p. 3754-62.

190. Conforti, G., Codegoni, A.M., Scanziani, E., Dolfini, E., Dasdia, T., Calza, M., Caniatti, M., und Broggini, M., Different vimentin expression in two clones derived from a human colocarcinoma cell line (LoVo) showing different sensitivity to doxorubicin. Br J Cancer, 1995. 71(3): p. 50511.

191. Serpe, L., Guido, M., Canaparo, R., Muntoni, E., Cavalli, R., Panzanelli, P., Della Pepal, C., Bargoni, A., Mauro, A., Gasco, M.R., Eandi, M., und Zara, G.P., Intracellular accumulation and cytotoxicity of doxorubicin with different pharmaceutical formulations in human cancer cell lines. J Nanosci Nanotechnol, 2006. 6(9-10): p. 3062-9.

192. Poljakova, J., Eckschlager, T., Hrebackova, J., Hrabeta, J., und Stiborova, M., The comparison of cytotoxicity of the anticancer drugs doxorubicin and ellipticine to human neuroblastoma cells. Interdiscip Toxicol, 2008. 1(2): p. 186-9.

193. Slovak, M.L., Mirski, S.E., Cole, S.P., Gerlach, J.H., Yohem, K.H., und Trent, J.M., Tumourigenic multidrug-resistant HT1080 cells do not overexpress receptors for epidermal growth factor. Br J Cancer, 1991. 64(2): p. 296-8.

194. Vanhoefer, U., Cao, S., Harstrick, A., Seeber, S., und Rustum, Y.M., Comparative antitumor efficacy of docetaxel and paclitaxel in nude mice bearing human tumor xenografts that overexpress the multidrug resistance protein (MRP). Ann Oncol, 1997. 8(12): p. 1221-8.

195. Cocker, H.A., Pinkerton, C.R., und Kelland, L.R., Characterization and modulation of drug resistance of human paediatric rhabdomyosarcoma cell lines. Br J Cancer, 2000. 83(3): p. 338-45.

196. Wolf, S.J., Huynh, T., Bryce, N.S., Hambley, T.W., Wakelin, L.P., Stewart, B.W., und Catchpoole, D.R., Intracellular trafficking as a determinant of AS-DACA cytotoxicity in rhabdomyosarcoma cells. BMC Cell Biol, 2011. 12: p. 36.

197. Li, X., Lu, Y., Liang, K., Liu, B., und Fan, Z., Differential responses to doxorubicin-induced phosphorylation and activation of Akt in human breast cancer cells. Breast Cancer Res, 2005. 7(5): p. R589-97.

198. Zhu, W.G., Hileman, T., Ke, Y., Wang, P., Lu, S., Duan, W., Dai, Z., Tong, T., Villalona-Calero, M.A., Plass, C., und Otterson, G.A., 5-aza-2'-deoxycytidine activates the p53/p21Waf1/Cip1 pathway to inhibit cell proliferation. J Biol Chem, 2004. 279(15): p. 15161-6.

199. Missiaglia, E., Donadelli, M., Palmieri, M., Crnogorac-Jurcevic, T., Scarpa, A., und Lemoine, N.R., Growth delay of human pancreatic cancer cells by methylase inhibitor 5-aza-2'deoxycytidine treatment is associated with activation of the interferon signalling pathway. Oncogene, 2005. 24(1): p. 199-211.

200. Momparler, R.L. und Goodman, J., In vitro cytotoxic and biochemical effects of 5-aza-2'deoxycytidine. Cancer Res, 1977. 37(6): p. 1636-9.

201. Schneider-Stock, R., Diab-Assef, M., Rohrbeck, A., Foltzer-Jourdainne, C., Boltze, C., Hartig, R., Schonfeld, P., Roessner, A., und Gali-Muhtasib, H., 5-Aza-cytidine is a potent inhibitor of DNA methyltransferase $3 a$ and induces apoptosis in HCT-116 colon cancer cells via Gadd45and p53-dependent mechanisms. J Pharmacol Exp Ther, 2005. 312(2): p. 525-36. 
202. Ateeq, B., Unterberger, A., Szyf, M., und Rabbani, S.A., Pharmacological inhibition of DNA methylation induces proinvasive and prometastatic genes in vitro and in vivo. Neoplasia, 2008. 10(3): p. 266-78.

203. Balaian, L. und Ball, E.D., Cytotoxic activity of gemtuzumab ozogamicin (Mylotarg) in acute myeloid leukemia correlates with the expression of protein kinase Syk. Leukemia, 2006. 20(12): p. 2093-101.

204. Reu, F.J., Leaman, D.W., Maitra, R.R., Bae, S.I., Cherkassky, L., Fox, M.W., Rempinski, D.R., Beaulieu, N., MacLeod, A.R., und Borden, E.C., Expression of RASSF1A, an epigenetically silenced tumor suppressor, overcomes resistance to apoptosis induction by interferons. Cancer Res, 2006. 66(5): p. 2785-93.

205. Tsang, W.P. und Kwok, T.T., Riboregulator H19 induction of MDR1-associated drug resistance in human hepatocellular carcinoma cells. Oncogene, 2007. 26(33): p. 4877-81.

206. Olsen, C.M., Meussen-Elholm, E.T., Roste, L.S., und Tauboll, E., Antiepileptic drugs inhibit cell growth in the human breast cancer cell line MCF7. Mol Cell Endocrinol, 2004. 213(2): p. 173-9.

207. Gustafsson, J.A., Estrogen receptor beta--a new dimension in estrogen mechanism of action. J Endocrinol, 1999. 163(3): p. 379-83.

208. Munaut, C., Lambert, V., Noel, A., Frankenne, F., Deprez, M., Foidart, J.M., und Rakic, J.M., Presence of oestrogen receptor type beta in human retina. Br J Ophthalmol, 2001. 85(7): $\mathrm{p}$. 877-82.

209. Li, X.N., Shu, Q., Su, J.M., Perlaky, L., Blaney, S.M., und Lau, C.C., Valproic acid induces growth arrest, apoptosis, and senescence in medulloblastomas by increasing histone hyperacetylation and regulating expression of p21Cip1, CDK4, and CMYC. Mol Cancer Ther, 2005. 4(12): p. 1912-22.

210. Loscher, W., Basic pharmacology of valproate: a review after 35 years of clinical use for the treatment of epilepsy. CNS Drugs, 2002. 16(10): p. 669-94.

211. Kim, M.S., Blake, M., Baek, J.H., Kohlhagen, G., Pommier, Y., und Carrier, F., Inhibition of histone deacetylase increases cytotoxicity to anticancer drugs targeting DNA. Cancer Res, 2003. 63(21): p. 7291-300.

212. Catalano, M.G., Fortunati, N., Pugliese, M., Poli, R., Bosco, O., Mastrocola, R., Aragno, M., und Boccuzzi, G., Valproic acid, a histone deacetylase inhibitor, enhances sensitivity to doxorubicin in anaplastic thyroid cancer cells. J Endocrinol, 2006. 191(2): p. 465-72.

213. Wittenburg, L.A., Bisson, L., Rose, B.J., Korch, C., und Thamm, D.H., The histone deacetylase inhibitor valproic acid sensitizes human and canine osteosarcoma to doxorubicin. Cancer Chemother Pharmacol, 2011. 67(1): p. 83-92.

214. Hideshima, T., Richardson, P., Chauhan, D., Palombella, V.J., Elliott, P.J., Adams, J., und Anderson, K.C., The proteasome inhibitor PS-341 inhibits growth, induces apoptosis, and overcomes drug resistance in human multiple myeloma cells. Cancer Res, 2001. 61(7): p. 3071-6.

215. Brignole, C., Marimpietri, D., Pastorino, F., Nico, B., Di Paolo, D., Cioni, M., Piccardi, F., Cilli, M., Pezzolo, A., Corrias, M.V., Pistoia, V., Ribatti, D., Pagnan, G., und Ponzoni, M., Effect of bortezomib on human neuroblastoma cell growth, apoptosis, and angiogenesis. J Natl Cancer Inst, 2006. 98(16): p. 1142-57.

216. Larsson, D.E., Wickstrom, M., Hassan, S., Oberg, K., und Granberg, D., The cytotoxic agents NSC-95397, brefeldin A, bortezomib and sanguinarine induce apoptosis in neuroendocrine tumors in vitro. Anticancer Res, 2010. 30(1): p. 149-56.

217. Zou, P., Kawada, J., Pesnicak, L., und Cohen, J.I., Bortezomib induces apoptosis of EpsteinBarr virus (EBV)-transformed $B$ cells and prolongs survival of mice inoculated with EBVtransformed B cells. J Virol, 2007. 81(18): p. 10029-36.

218. Salmena, L., Lam, V., McPherson, J.P., und Goldenberg, G.J., Role of proteasomal degradation in the cell cycle-dependent regulation of DNA topoisomerase Ilalpha expression. Biochem Pharmacol, 2001. 61(7): p. 795-802.

219. Villman, K., Stahl, E., Liljegren, G., Tidefelt, U., und Karlsson, M.G., Topoisomerase II-alpha expression in different cell cycle phases in fresh human breast carcinomas. Mod Pathol, 2002. 15(5): p. 486-91.

220. Ma, M.H., Yang, H.H., Parker, K., Manyak, S., Friedman, J.M., Altamirano, C., Wu, Z.Q., Borad, M.J., Frantzen, M., Roussos, E., Neeser, J., Mikail, A., Adams, J., Sjak-Shie, N., Vescio, R.A., und Berenson, J.R., The proteasome inhibitor PS-341 markedly enhances sensitivity of multiple myeloma tumor cells to chemotherapeutic agents. Clin Cancer Res, 
2003. 9(3): p. 1136-44.

221. Mitsiades, N., Mitsiades, C.S., Richardson, P.G., Poulaki, V., Tai, Y.T., Chauhan, D., Fanourakis, G., Gu, X., Bailey, C., Joseph, M., Libermann, T.A., Schlossman, R., Munshi, N.C., Hideshima, T., und Anderson, K.C., The proteasome inhibitor PS-341 potentiates sensitivity of multiple myeloma cells to conventional chemotherapeutic agents: therapeutic applications. Blood, 2003. 101(6): p. 2377-80.

222. Orlowski, R.Z., Voorhees, P.M., Garcia, R.A., Hall, M.D., Kudrik, F.J., Allred, T., Johri, A.R., Jones, P.E., Ivanova, A., Van Deventer, H.W., Gabriel, D.A., Shea, T.C., Mitchell, B.S., Adams, J., Esseltine, D.L., Trehu, E.G., Green, M., Lehman, M.J., Natoli, S., Collins, J.M., Lindley, C.M., und Dees, E.C., Phase 1 trial of the proteasome inhibitor bortezomib and pegylated liposomal doxorubicin in patients with advanced hematologic malignancies. Blood, 2005. 105(8): p. 3058-65.

223. Montagut, C., Rovira, A., Mellado, B., Gascon, P., Ross, J.S., und Albanell, J., Preclinical and clinical development of the proteasome inhibitor bortezomib in cancer treatment. Drugs Today (Barc), 2005. 41(5): p. 299-315.

224. Shah, J.J., Orlowski, R.Z., und Thomas, S.K., Role of combination bortezomib and pegylated liposomal doxorubicin in the management of relapsed and/or refractory multiple myeloma. Ther Clin Risk Manag, 2009. 5(1): p. 151-9.

225. Elstner, E., Muller, C., Koshizuka, K., Williamson, E.A., Park, D., Asou, H., Shintaku, P., Said, J.W., Heber, D., und Koeffler, H.P., Ligands for peroxisome proliferator-activated receptorgamma and retinoic acid receptor inhibit growth and induce apoptosis of human breast cancer cells in vitro and in BNX mice. Proc Natl Acad Sci U S A, 1998. 95(15): p. 880611.

226. Sarraf, P., Mueller, E., Jones, D., King, F.J., DeAngelo, D.J., Partridge, J.B., Holden, S.A., Chen, L.B., Singer, S., Fletcher, C., und Spiegelman, B.M., Differentiation and reversal of malignant changes in colon cancer through PPARgamma. Nat Med, 1998. 4(9): p. 1046-52.

227. Hashimoto, Y., Shimada, Y., Itami, A., Ito, T., Kawamura, J., Kawabe, A., Kaganoi, J., Maeda, M., Watanabe, G., und Imamura, M., Growth inhibition through activation of peroxisome proliferator-activated receptor gamma in human oesophageal squamous cell carcinoma. Eur $\mathrm{J}$ Cancer, 2003. 39(15): p. 2239-46.

228. Papageorgiou, E., Pitulis, N., Manoussakis, M., Lembessis, P., und Koutsilieris, M., Rosiglitazone attenuates insulin-like growth factor 1 receptor survival signaling in PC-3 cells. Mol Med, 2008. 14(7-8): p. 403-11.

229. Yoshizawa, K., Cioca, D.P., Kawa, S., Tanaka, E., und Kiyosawa, K., Peroxisome proliferatoractivated receptor gamma ligand troglitazone induces cell cycle arrest and apoptosis of hepatocellular carcinoma cell lines. Cancer, 2002. 95(10): p. 2243-51.

230. de Jong, E., Winkel, P., Poelstra, K., und Prakash, J., Anticancer effects of 15d-prostaglandinJ2 in wild-type and doxorubicin-resistant ovarian cancer cells: novel actions on SIRT1 and HDAC. PLoS One, 2011. 6(9): p. e25192.

231. Eberhardt, W., Doller, A., Akool el, S., und Pfeilschifter, J., Modulation of mRNA stability as a novel therapeutic approach. Pharmacol Ther, 2007. 114(1): p. 56-73.

232. Bakshi, R.P., Galande, S., und Muniyappa, K., Functional and regulatory characteristics of eukaryotic type II DNA topoisomerase. Crit Rev Biochem Mol Biol, 2001. 36(1): p. 1-37.

233. Goswami, P.C., Sheren, J., Albee, L.D., Parsian, A., Sim, J.E., Ridnour, L.A., Higashikubo, R., Gius, D., Hunt, C.R., und Spitz, D.R., Cell cycle-coupled variation in topoisomerase Ilalpha mRNA is regulated by the 3 '-untranslated region. Possible role of redox-sensitive protein binding in mRNA accumulation. J Biol Chem, 2000. 275(49): p. 38384-92.

234. Cho, W.H., Choi, C.H., Park, J.Y., Kang, S.K., und Kim, Y.K., 15-deoxy-(Delta12,14)prostaglandin $\mathrm{J} 2$ (15d-PGJ2) induces cell death through caspase-independent mechanism in A172 human glioma cells. Neurochem Res, 2006. 31(10): p. 1247-54.

235. Srikantan, S., Abdelmohsen, K., Lee, E.K., Tominaga, K., Subaran, S.S., Kuwano, Y., Kulshrestha, R., Panchakshari, R., Kim, H.H., Yang, X., Martindale, J.L., Marasa, B.S., Kim, M.M., Wersto, R.P., Indig, F.E., Chowdhury, D., und Gorospe, M., Translational control of TOP2A influences doxorubicin efficacy. Mol Cell Biol, 2011. 31(18): p. 3790-801.

236. Chiarini, F., Fala, F., Tazzari, P.L., Ricci, F., Astolfi, A., Pession, A., Pagliaro, P., McCubrey, J.A., und Martelli, A.M., Dual inhibition of class IA phosphatidylinositol 3-kinase and mammalian target of rapamycin as a new therapeutic option for T-cell acute lymphoblastic leukemia. Cancer Res, 2009. 69(8): p. 3520-8.

237. Billottet, C., Banerjee, L., Vanhaesebroeck, B., und Khwaja, A., Inhibition of class I 
phosphoinositide 3-kinase activity impairs proliferation and triggers apoptosis in acute promyelocytic leukemia without affecting atra-induced differentiation. Cancer Res, 2009. 69(3): p. 1027-36.

238. Crowe, E., Sell, C., Thomas, J.D., Johannes, G.J., und Torres, C., Activation of proteasome by insulin-like growth factor-I may enhance clearance of oxidized proteins in the brain. Mech Ageing Dev, 2009. 130(11-12): p. 793-800.

239. Martin-Fernandez, C., Bales, J., Hodgkinson, C., Welman, A., Welham, M.J., Dive, C., und Morrow, C.J., Blocking phosphoinositide 3-kinase activity in colorectal cancer cells reduces proliferation but does not increase apoptosis alone or in combination with cytotoxic drugs. Mol Cancer Res, 2009. 7(6): p. 955-65.

240. Ma, B.B., Lui, V.W., Hui, E.P., Lau, C.P., Ho, K., Ng, M.H., Cheng, S.H., Tsao, S.W., und Chan, A.T., The activity of mTOR inhibitor RAD001 (everolimus) in nasopharyngeal carcinoma and cisplatin-resistant cell lines. Invest New Drugs, 2010. 28(4): p. 413-20.

241. Beuvink, I., Boulay, A., Fumagalli, S., Zilbermann, F., Ruetz, S., O'Reilly, T., Natt, F., Hall, J., Lane, H.A., und Thomas, G., The mTOR inhibitor RADO01 sensitizes tumor cells to DNAdamaged induced apoptosis through inhibition of p21 translation. Cell, 2005. 120(6): p. 74759.

242. La Monica, S., Galetti, M., Alfieri, R.R., Cavazzoni, A., Ardizzoni, A., Tiseo, M., Capelletti, M., Goldoni, M., Tagliaferri, S., Mutti, A., Fumarola, C., Bonelli, M., Generali, D., und Petronini, P.G., Everolimus restores gefitinib sensitivity in resistant non-small cell lung cancer cell lines. Biochem Pharmacol, 2009. 78(5): p. 460-8.

243. Wan, X. und Helman, L.J., The biology behind mTOR inhibition in sarcoma. Oncologist, 2007. 12(8): p. 1007-18.

244. Chiong, E., Lee, I.L., Dadbin, A., Sabichi, A.L., Harris, L., Urbauer, D., McConkey, D.J., Dickstein, R.J., Cheng, T., und Grossman, H.B., Effects of mTOR inhibitor everolimus (RAD001) on bladder cancer cells. Clin Cancer Res, 2011. 17(9): p. 2863-73.

245. Johansson, G., Mahller, Y.Y., Collins, M.H., Kim, M.O., Nobukuni, T., Perentesis, J., Cripe, T.P., Lane, H.A., Kozma, S.C., Thomas, G., und Ratner, N., Effective in vivo targeting of the mammalian target of rapamycin pathway in malignant peripheral nerve sheath tumors. Mol Cancer Ther, 2008. 7(5): p. 1237-45.

246. Grunwald, V., DeGraffenried, L., Russel, D., Friedrichs, W.E., Ray, R.B., und Hidalgo, M., Inhibitors of $m T O R$ reverse doxorubicin resistance conferred by PTEN status in prostate cancer cells. Cancer Res, 2002. 62(21): p. 6141-5.

247. Avellino, R., Romano, S., Parasole, R., Bisogni, R., Lamberti, A., Poggi, V., Venuta, S., und Romano, M.F., Rapamycin stimulates apoptosis of childhood acute lymphoblastic leukemia cells. Blood, 2005. 106(4): p. 1400-6.

248. Haritunians, T., Mori, A., O'Kelly, J., Luong, Q.T., Giles, F.J., und Koeffler, H.P., Antiproliferative activity of RADO01 (everolimus) as a single agent and combined with other agents in mantle cell lymphoma. Leukemia, 2007. 21(2): p. 333-9.

249. Piguet, A.C., Semela, D., Keogh, A., Wilkens, L., Stroka, D., Stoupis, C., St-Pierre, M.V., und Dufour, J.F., Inhibition of mTOR in combination with doxorubicin in an experimental model of hepatocellular carcinoma. J Hepatol, 2008. 49(1): p. 78-87.

250. Wang, L., Ma, W., Markovich, R., Lee, W.L., und Wang, P.H., Insulin-like growth factor I modulates induction of apoptotic signaling in H9C2 cardiac muscle cells. Endocrinology, 1998. 139(3): p. 1354-60.

251. Panaretakis, T., Pokrovskaja, K., Shoshan, M.C., und Grander, D., Activation of Bak, Bax, and BH3-only proteins in the apoptotic response to doxorubicin. J Biol Chem, 2002. 277(46): p. 44317-26.

252. Fan, Q.W., Cheng, C., Hackett, C., Feldman, M., Houseman, B.T., Nicolaides, T., HaasKogan, D., James, C.D., Oakes, S.A., Debnath, J., Shokat, K.M., und Weiss, W.A., Akt and autophagy cooperate to promote survival of drug-resistant glioma. Sci Signal, 2010. 3(147): p. ra81.

253. Opel, D., Naumann, I., Schneider, M., Bertele, D., Debatin, K.M., und Fulda, S., Targeting aberrant PI3K/Akt activation by PI103 restores sensitivity to TRAIL-induced apoptosis in neuroblastoma. Clin Cancer Res, 2011. 17(10): p. 3233-47.

254. Green, D.R. und Reed, J.C., Mitochondria and apoptosis. Science, 1998. 281(5381): p. 130912.

255. Mayer, B. und Oberbauer, R., Mitochondrial regulation of apoptosis. News Physiol Sci, 2003. 18: p. 89-94. 
256. Ilyin, G.P., Glaise, D., Gilot, D., Baffet, G., und Guguen-Guillouzo, C., Regulation and role of p21 and p27 cyclin-dependent kinase inhibitors during hepatocyte differentiation and growth. Am J Physiol Gastrointest Liver Physiol, 2003. 285(1): p. G115-27.

257. Liu, S., Bishop, W.R., und Liu, M., Differential effects of cell cycle regulatory protein p21(WAF1/Cip1) on apoptosis and sensitivity to cancer chemotherapy. Drug Resist Updat, 2003. 6(4): p. 183-95.

258. Sato, T., Koseki, T., Yamato, K., Saiki, K., Konishi, K., Yoshikawa, M., Ishikawa, I., und Nishihara, T., p53-independent expression of p21(CIP1/WAF1) in plasmacytic cells during G(2) cell cycle arrest induced by Actinobacillus actinomycetemcomitans cytolethal distending toxin. Infect Immun, 2002. 70(2): p. 528-34.

259. Huang, D.C. und Strasser, A., BH3-Only proteins-essential initiators of apoptotic cell death. Cell, 2000. 103(6): p. 839-42.

260. Schuler, M., Maurer, U., Goldstein, J.C., Breitenbucher, F., Hoffarth, S., Waterhouse, N.J., und Green, D.R., p53 triggers apoptosis in oncogene-expressing fibroblasts by the induction of Noxa and mitochondrial Bax translocation. Cell Death Differ, 2003. 10(4): p. 451-60.

261. Seitz, G., Warmann, S.W., Vokuhl, C.O., Heitmann, H., Treuner, C., Leuschner, I., und Fuchs, J., Effects of standard chemotherapy on tumor growth and regulation of multidrug resistance genes and proteins in childhood rhabdomyosarcoma. Pediatr Surg Int, 2007. 23(5): p. 431-9.

262. Oshika, Y., Nakamura, M., Tokunaga, T., Fukushima, Y., Abe, Y., Ozeki, Y., Yamazaki, H., Tamaoki, N., und Ueyama, Y., Multidrug resistance-associated protein and mutant p53 protein expression in non-small cell lung cancer. Mod Pathol, 1998. 11(11): p. 1059-63.

263. Sullivan, G.F., Amenta, P.S., Villanueva, J.D., Alvarez, C.J., Yang, J.M., und Hait, W.N., The expression of drug resistance gene products during the progression of human prostate cancer. Clin Cancer Res, 1998. 4(6): p. 1393-403.

264. Sullivan, G.F., Yang, J.M., Vassil, A., Yang, J., Bash-Babula, J., und Hait, W.N., Regulation of expression of the multidrug resistance protein MRP1 by p53 in human prostate cancer cells. J Clin Invest, 2000. 105(9): p. 1261-7.

265. Ogawara, Y., Kishishita, S., Obata, T., Isazawa, Y., Suzuki, T., Tanaka, K., Masuyama, N., und Gotoh, Y., Akt enhances Mdm2-mediated ubiquitination and degradation of p53. J Biol Chem, 2002. 277(24): p. 21843-50.

266. Burrows, N., Babur, M., Resch, J., Ridsdale, S., Mejin, M., Rowling, E.J., Brabant, G., und Williams, K.J., GDC-0941 Inhibits Metastatic Characteristics of Thyroid Carcinomas by Targeting both the Phosphoinositide-3 Kinase (PI3K) and Hypoxia-Inducible Factor-1alpha (HIF-1alpha) Pathways. J Clin Endocrinol Metab, 2011. 96(12): p. E1934-43.

267. O'Brien, C., Wallin, J.J., Sampath, D., GuhaThakurta, D., Savage, H., Punnoose, E.A., Guan, J., Berry, L., Prior, W.W., Amler, L.C., Belvin, M., Friedman, L.S., und Lackner, M.R., Predictive biomarkers of sensitivity to the phosphatidylinositol 3' kinase inhibitor GDC-0941 in breast cancer preclinical models. Clin Cancer Res, 2010. 16(14): p. 3670-83.

268. Qayum, N., Im, J., Stratford, M.R., Bernhard, E.J., McKenna, W.G., und Muschel, R.J., Modulation of the tumor microvasculature by phosphoinositide-3 kinase inhibition increases Doxorubicin delivery in vivo. Clin Cancer Res, 2012. 18(1): p. 161-9.

269. Hucker, H.B., Species differences in drug metabolism. Annu Rev Pharmacol, 1970. 10: p. 99118.

270. Primeau, A.J., Rendon, A., Hedley, D., Lilge, L., und Tannock, I.F., The distribution of the anticancer drug Doxorubicin in relation to blood vessels in solid tumors. Clin Cancer Res, 2005. 11(24 Pt 1): p. 8782-8. 
8 Lebenslauf 


\section{Danksagung}

Die vorliegende Arbeit wurde am Institut für Humangenetik (Leitung Herr Prof. Dr. W. Engel) der Universität Göttingen angefertigt.

In erster Linie gilt mein Dank Frau Prof. Dr. H. Hahn für die Bereitstellung des interessanten Themas, für die intensive, wissenschaftliche Betreuung, ihre Diskussionsbereitschaft und ihre Unterstützung meiner Arbeit.

Ganz herzlich möchte ich Herrn Prof. Dr. J. Brockmöller danken, für die Möglichkeit, als Stipendiantin im DFG Gradiertenkolleg 1034 „Die Bedeutung genetischer Polymorphismen in der Onkologie: Von den Grundlagen zur individualisierten Therapie" diese Dissertation anzufertigen. Ebenso bedanke ich mich bei inm und bei Herrn Prof. Dr. D. Kube für die Unterstützung im Rahmen meines Betreuungsausschusses.

Ein großer Dank geht außerdem an Frau Prof. Dr. S. Fulda, die mir die Möglichkeit gab, Analysen in Hinsicht auf die Apoptosesignalkaskade in ihrem Labor durchzuführen. Zusätzlich danke ich ihr für die nette Kooperation mit inrem Labor. In diesem Sinne geht auch ein großer Dank an die Mitglieder der Arbeitsgruppe von Prof. Dr. S. Fulda, insbesondere an Ivonne Naumann und Ulrike Graab.

Des Weiteren danke ich Herrn Prof. Dr. L. Wojnowski für die nette Kooperation mit seinem Labor. Ute Gödtel-Armbrust danke ich für ihre Unterstützung in Western Blot-Fragen und Dr. Tiandong Yan für die freundliche Zusammenarbeit.

Bedanken möchte ich mich bei Herrn Dr. W. Schulz-Schaeffer für die Unterstützung der Interpretation histologischer Färbungen.

Weiterhin möchte ich mich bei Herrn Prof. Dr. J. Wienands für die Kollaboration mit seinem Labor bedanken. An dieser Stelle geht ein großer Dank an Dr. Kai Dittmann und Dr. Michael Engelke, die mich bei meinen FACS-Analysen tatkräftig unterstützt haben, und stets ein offenes Ohr für Fragen hatten.

Ein großer Dank geht an das Team vom VCT und an Frau Dr. S. Kimmina für die problemlose und nette Zusammenarbeit.

Außerdem danke ich dem Team des institutseigenen Tierstalls für ihre tolle Zusammenarbeit, insbesondere Susann Peter, Stefan Wolf und Lea Piontek.

Natürlich geht ein ganz großer Dank an die Mitglieder der Arbeitgruppe von Frau Prof. Dr. H. Hahn: Dr. Anja Uhmann, Dr. Frauke Nitzki, Anke Frommhold, Ina Heß, Simone König, Penelope Pelczar, Marco Becker, Tobias Goldak sowie Benedikt Albert. Herzlich Dank für den regen Austausch, der unermüdlichen Unterstützung, den wissenschaftlichen Diskussionen und der schönen Zeit! Anke, vielen Dank für deine tatkräftige Unterstützung bei den zahlreichen Färbungen! Simone, dir danke ich für deine lebensfrohe Art, mit der du so manchen trüben Gedanken wegwischst, für die netten -nicht nur wissenschaftlichen- Gespräche und für deine aufbauenden, motivierenden Worte zur richtigen Zeit!

Ganz besonders danken möchte ich meinen Eltern und meinen Schwestern, die stets Verständnis für mich hatten und mich immer tatkräftig und seelisch unterstützen! Ein besonderer Dank geht an Thorsten, der immer an meiner Seite gestanden und mich motiviert hat. Vielen Dank für deinen Rückhalt und deine Liebe. 